\title{
Discourses of the Digital Divide
}

\author{
MACS \\ Kevin McSorley
}

Submitted for the degree of Doctor of Philosophy

School of Human Sciences

University of Surrey

January 2006

C Kevin McSorley 2006 


\section{Abstract}

In recent years, closing the digital divide has become a central concern for numerous social actors and institutions, instantiated through a series of policy documents, strategic initiatives, diagnostic instruments, academic analyses and consultation exercises.

This thesis critically analyzes the discursive construction and function of the digital divide within specific discourses. Case studies examined include the UK Social Exclusion Unit, the BT Social Policy Unit, the G8 Digital Opportunity Task Force Initiative, the work of Manuel Castells, and the talk of the 'socially excluded'.

The analysis emphasizes the heterogeneous local articulatory work that 'the digital divide' enables: the renewal of Third Way political discourse, the performance of corporate accountability, the privileging of a 'secular salvation story' of technological globalization, a buttressing of the Network Society thesis. Consistent rules of discursive formation are identified across discourses: the ethical equivalence of a concern with the social and the promotion of the techno-economic, and a teleological conception of causality.

This thesis concludes that the digital divide can be considered as an incomplete and open-ended object of government, a brand of inequality, through which a particular understanding of technosocial formation, exemplified in the idea of connection to an autonomous and inevitable networking logic, is coming to dominate a sense of contemporary ethical possibility, political imagination and the government of conduct.

A discourse analytic approach provides one way of demonstrating the assumptions, seductions and closures of this particular understanding, of recovering a sense of its historical specificity and purposeful construction, and of opening up the digital divide to close critical scrutiny. 


\section{Acknowledgements}

I am indebted to my supervisors Geoff Cooper and Nigel Gilbert for their professional and detailed guidance in the completion of this thesis. I would also like to thank all of my other colleagues in the Department of Sociology at the University of Surrey for the excellent administrative support and sociological imagination they provided. My friends and family deserve particular gratitude for their constant encouragement. I would especially like to thank Teresa McSorley and Sarah Maltby for their thorough and generous support for my work. Finally, I am extremely grateful to all of my participants who gave of their time so willingly. My thanks to all of you.

This thesis was funded via 'The Social-Technical Shaping of Mobile Multimedia Personal Communications (STEMPEC)' project, supported by the ESRC (L487 25 4002), Vodafone, One2One, Orange, BTCellnet and Granada Media Group as part of the Foresight Link Programme, and through the University of Portsmouth School of Social, Historical and Literary Studies Staff Development Fund.

Material from Chapter 4 has previously been published as; McSorley, K. (2002) Performing Corporate Accountability Salford Papers in Social Research: University of Salford. ISBN 0904483398

Material from Chapter 5 has previously been published as: McSorley, K. (2003) 'The Secular Salvation Story of the Digital Divide' Ethics and Information Technology, 5, 75-87 


\section{List of Contents}

1

Introduction

1.1 Developing a Research Question 1

1.2 Rationale of the Thesis 4

$\begin{array}{lll}1.3 & \text { Research Strategy } & 7\end{array}$

1.4 Structure of the Thesis 8

$2 \quad$ Literature Review

$\begin{array}{lll}2.1 & \text { Introduction } & 11\end{array}$

2.2 Discourse Theory and Analysis 12

2.3 Social Exclusion 25

2.4 Technology Studies 33

2.5 The Digital Divide 42

3 UK Government Discourse on The Digital Divide

3.1 Introduction 58

3.2 Technology 61

3.3 Social Exclusion 68

3.4 The Reciprocity of the Social and the Economic 75

$\begin{array}{lll}3.5 & \text { Conclusion } & 79\end{array}$

4 Corporate Discourse on The Digital Divide

4.1 Introduction 84

$4.2 \quad$ Social Reporting $\quad 84$

4.3 'Betterworld' 88

$\begin{array}{lll}4.4 & \text { Constricting the Stakeholder } 90\end{array}$

4.5 Making It Real 95

4.6 Why the Digital Divide? 98

$\begin{array}{lll}4.7 & \text { Mode of Engagement } & 101\end{array}$

4.8 Supplementary Accountability 106

$\begin{array}{lll}4.9 & \text { Conclusion } & 108\end{array}$ 
5.1 Introduction

5.2 Legitimating the DOT Force

5.3 Narrative of the DOT Force

5.4 Secular Salvation Stories

5.5 Conclusion

Academic Analysis of the Digital Divide

6.1 Introduction

6.2 The Information Age

6.3 The Internet Galaxy

6.4 Conclusion

Talking About Technology and Exclusion

7.1 Introduction

180

7.2 Methodological Considerations

184

7.3 Key Themes

189

7.4 Conclusion

Addressing The Digital Divide

8.1 Introduction

221

8.2 'The Digital Divide'

222

8.3 Problematization

228

8.4 The Discursive Construction of Ethos

8.5 The Discursive Construction of Teleology

8.6 Technosocial Implosion

8.7 Summary

8.8 Beyond the Case Study 
$9 \quad$ Conclusion

9.1 Introduction 256

9.2 Summary of Findings 256

9.3 The Discursive Formation of The Information Age 263

9.4 The Ethos of The Information Age 264

9.5 The Teleology of The Information Age 274

9.6 The Digital Divide 277

9.7 Conclusion 288

Coda 290

$\begin{array}{ll}\text { Bibliography } & 295\end{array}$ 


\section{List of Figures}

$\begin{array}{lll}\text { Figure } 3.1 & \text { Text Box } & 67\end{array}$

Figure 3.2 Learning Technology Infrastructure 73

Figure 4.1 Online Debate: Guidelines 92

Figure 4.2 Online Debate: Managing the Consultation 94

Figure 4.3 Divide or Convergence? 99

Figure 4.4 Online Debate: Notes from Your Host 101

Figure 4.5 Online Debate: Interactivity 102

$\begin{array}{lll}\text { Figure 5.1 Membership Structure of DOT Force } & 117\end{array}$

Figure 5.2 Iterations of the DOT Force Report 118

$\begin{array}{lll}\text { Figure 5.3 Cover of DOT Force final report } & 135\end{array}$

Figure 5.4 Protest on Okinawa Beach 135

Figure 5.5 Components of a Development Dynamic 139 


\section{$\square \square$ Chapter 1.}

\section{Introduction}

\subsection{Developing a Research Question}

In this opening section, I discuss the development of my overall research question. This thesis stemmed from a desire to develop a critical understanding of the relationship between technology and inequality, two of my abiding interests and concerns. My preliminary attempt to formulate a research question that could orient my work took the form, 'Does technology exacerbate or alleviate inequality?'. However, several factors led to a reframing of this question, if not the underlying concern.

For one, it was clear to my supervisors that such a general form of question more accurately described the guiding problematic of a research programme rather than the feasible remit of a doctoral thesis. Secondly, my increasing engagement with academic literature, on technology in particular, highlighted the difficulty of ever being able to provide an answer to a question formulated in such terms. Rather it emphasized the importance of offering explanations which attend to, and account for, the heterogeneity of local technological configurations. Indeed, if there were common themes and motifs to this scholarly work, they were of the complicating and disaggregating of abstract universal claims, and that the consequences of the enlisting of technology within social life were complex and often contradictory, rather than amenable to any straightforward evaluation.

However, there was one even more important factor in changing the terms of reference of my research agenda, that became increasingly apparent to me through my own snowballing immersion in general discussion of the 'technology-inequality question'. At this stage of my work, I embraced a form of networked serendipity as an initial research strategy. I spoke to personnel 
from governmental IT task forces, telecommunications corporations and nonprofit organizations concerned with development. I performed searches of academic literature on technology and inequality, and every possible permutation of synonym and neologism. I joined numerous e-mail discussion lists on the topics of technology or inequality, and scanned the media, the UK, international, business, society and technology pages, with an increasingly focussed eye for fragments of news and the form of relevant cultural commentary. I helped out at my local community technology centre, attended the launch event of an 'e-democracy' initiative, and participated in a designers' conference ostensibly on the basis that it had technology and inequality in the title. Indeed, at the height of this initial phase of orientation, I was asked if I was interested in giving expert opinion to a House of Lords select committee on social exclusion and technology in Europe.

As with the evolution of any research agenda, many of these discussions and experiences made more sense in retrospect than they did at the time. What ultimately became clear to me through all this activity was that, beyond academic scholarship, many other interested parties were seeking an answer to the same initial question that I was. Furthermore, it became increasingly evident that accounts directly addressing the question of technology and inequality were rapidly proliferating in many other domains of contemporary society. The figures of the information poor and technological have-nots, the promise of technological opportunity and digital inclusion, had begun to assume increasing salience in the narratives of many social actors and institutions, from government departments, multinational corporations, and global NGOs through to think tanks, marketing agencies and philanthropic organizations. Such themes increasingly informed mass media debate and became the reflexive concern of new media discussion.

Most prominent however was the rapid emergence at the end of the twentieth century of a series of understandings that framed the issue of equality concerns in the context of new digital technology around the figure of 'the digital divide'. The digital divide emerged as a point of reference for an explosion of new academic work which attempted to chart its breadth and 
depth, if not always theorize and analyze its consequences. It was a key term marking the convergence of the concerns of the 'Information Society' and the 'Inclusive Society' discourses. It was heralded as a call to arms by diverse social institutions, from Cisco, to the Soros Foundation, to the United Nations.

To illustrate the prominence of this motif, consider the following two quotes. In April 2000, U.S. President Bill Clinton remarked in discussion with the East Palo Alto community that:

I have been to a lot of these places on my Digital Divide tour - I mean, my New Markets tour - because I see these places as places of opportunity, new markets. This is one of these fortunate times when by doing what is morally right, we actually help keep America's economic expansion churning forward.'

(The White House Office of the Press Secretary, April 17 2000)

On May $17^{\text {th }}$ 2001, World Telecommunications Day, the UN SecretaryGeneral, Kofi Annan, asked that:

'On this day, let us commit ourselves to the task, and let us make a bridge that spans the "digital divide"'

(United Nations Information Service, May 17 2001)

The digital divide thus became a central term in narratives of technology and inequality across numerous domains at the end of the twentieth and beginning of the twenty-first century. It was embedded in a series of academic analyses, policy documents, new media consultations, and diagnostic apparatuses. Bridging the digital divide became a key contemporary concern to be addressed through a profusion of state, corporate and supranational agendas, strategies and initiatives.

In terms of reshaping my own research agenda, the crucial factor was this recognition of the increasing salience of these narratives of technology and inequality, in particular those focussed around the leitmotif of the digital divide, 
as a key contemporary phenomenon. Rather than conceptualizing my research in terms of trying to directly 'solve' some version of the question of the relationship between technology and inequality, or indeed tackle the analogous definitional question of 'What is the digital divide?' (the dominant concern of digital divide scholarship), my research focus became to analyze this phenomenon, to examine the construction, the legitimacy and the effects of these emerging stories of technology and inequality. Indeed, my broad research strategy became to follow 'the digital divide'.

It is this shift from my initial approach, this discursive turn to examine the status, construction and consequences of already existing and increasingly culturally important narratives of technology and inequality, that provides the underpinnings of my research.

\subsection{Rationale of the Thesis}

In this section, I detail the rationale behind deciding upon this particular research focus. There are clearly gains and costs to any research decision, and it useful to try and make the thinking behind these decisions explicit at this stage, to name my research intuitions.

As I have documented above, my immersion in the general discussion of 'technology and inequality' alerted me to the increasing salience of multiple narratives exploring and defining this very relationship, particularly focussing on the figure of the digital divide. There are several reasons why I deem such a phenomenon is worthy of investigation.

In the first place, I consider that it is important not to see such narratives as epiphenomenal to the 'reality' of technology. As I detail in my literature review, any attempt to critically understand technology cannot avoid consideration of the way in which specific forms of explanation frame technology policy, design, practice and hermeneutics in meaningful technoculture, the 'dialectic of ideology and technology' in Gouldner's (1976) terms. 
As Strathern (2002: 311 ) succinctly puts it, 'the hype and rhetoric surrounding ICT is an important part of the technology itself.'

My rationale is thus broadly in line with those sociological accounts that read the category of technology widely, to include the imaginative and interpretative repertoires that frame the understanding and use of technology. To put it another way, I consider my discursive turn not as a remove from my original concern with technology and inequality. Rather it is a reframing of this question that attempts to acknowledge its complexity and current cultural phenomenology.

Secondly, I consider that such narratives and understandings are increasingly central to contemporary practices of government. In many industrialized countries, information and communication technologies are now being seen as a key means through which governments can rethink and address the issue of social exclusion in general. As Selwyn (2002: 1) notes, 'in the UK this perspective has been translated into a multi-billion pound policy agenda aimed at using ICT for socially inclusive purposes'. Barry (2001: 2) relatedly notes a contemporary political preoccupation with the models of social and political order that 'networked' and 'interactive' technology seem to make available: 'We live in a technological society to the extent that specific technologies dominate our sense of the kinds of problems that government and politics must address, and the solutions that we must adopt. A technological society is one which takes technical change to be the model for political invention.' Despite this, and as Mansell (2002: 408) notes, 'there are comparatively few accounts of how those who inhabit the 'meso-level' institutions of policy are constructing prevailing conceptions of the new media and the associated norms for social organization'. If you believe, as I do, that the practices of government should be subject to continual critical scrutiny, then the analysis of such narratives has a clear political, as well as intellectual, rationale. This is particularly the case if, following Barry, we understand an action as political 'to the extent that it opens up the possibility for disagreement' (2002: 270). 
Thirdly, it is my initial feeling that much of the recent academic scholarship that has more explicitly engaged with the question of the relationship between technology and inequality (particularly the burgeoning area of digital divide scholarship, but additionally analyses of the 'Information Society') has done so in ways that have not always adequately reflected upon its categories or assumptions, or indeed upon the ways in which the findings of social scientific analysis may enter reflexively and performatively into the social formations they purport to describe. A discursive approach which takes as its theme narratives of technology and inequality, including social scientific narratives, provides one way of subjecting this intuition, and those assumptions, to more systematic analysis. While not specifically aligned with these traditions of scholarship, it is consistent with a view of the sociological enterprise as a whole as an endeavour or conversation which attempts to reflect critically and systematically upon the assumptions that underpin social scientific practice.

Fourthly, although my analytic attention will focus upon the specific details of the discursive construction of narratives of technology and inequality within particular domains (e.g. corporate discourse, supranational discourse), this focus necessarily affords a window on the wider concerns and assumptions of such discursive domains. In other words, the analysis of how a specific narrative of technology and inequality is discursively constructed within a certain domain additionally addresses the question of why this issue should be of concern in that domain at all, from a potentially alternative perspective to the reasons that are offered face value. As such, an additional rationale for my research focus is to illuminate the sociological understanding of why such narratives of technology and inequality occur in the places that they do.

Finally, as I discuss in the next chapter, I adopt an approach to discourse analysis that treats certain concepts as sensitizing, rather than seek their operationalization onto a particular field of social inquiry. As such, empirical work can be thought of as an opportunity for the articulation and modification of the conceptual resources employed. A final rationale for my research then is the more theoretical concern of developing the conceptual resources of discourse theory through a particular enactment of empirical research. 


\subsection{Research Strategy}

The overall aim of the thesis is to critically interrogate the understandings of technology and inequality that are articulated within specific discursive domains. In particular, I will address the following questions:

- How are specific understandings of technology and inequality constructed and legitimated within these discursive domains?

- What does 'the digital divide' do, both within and across specific discursive domains?

The case studies that I chose to analyze in this thesis are particular discursive events drawn from the domains of UK government discourse, corporate discourse, supranational discourse, academic discourse, and the talk of a group of participants who are recognized in a particular institutional discourse of social exclusion.

In the next chapter I detail my overall understanding of, and approach to, discourse theory and analysis. I detail specific rationales for the choice of each case study in the appropriate chapter. I also set out the boundaries of each discursive event and detail the particular data sources that I analyze within the appropriate chapter.

As such, the thesis can be considered as five distinct case studies of particular narratives of technology and inequality. As Innes (2001: 212) notes, 'the advantages of a case study approach are that it allows for an 'in-depth' treatment of the subject, where a large amount of detail about the practices and processes being studied can be understood in relation to a particular social context'. Case study research thus emphasizes a serious commitment to analyzing the complexity, distinctiveness and embeddedness of a case within a specific social context. As such, Stake (1994: 236) refers to the 'intrinsic case study' where ' this case is of interest .. in all its particularity and ordinariness'. 
Indeed, for Stake the aim of such case study research is purely descriptive, rather than attempting to generalize beyond the bounds of the single case study or develop wider theory. In contrast, Mason (1996: 6) argues that 'I do not think that qualitative researchers should be satisfied with producing explanations which are idiosyncratic or particular to the limited empirical parameters of their study .. Qualitative research should therefore produce explanations which are generalizable in some way, or which have a wider resonance'.

My position in this thesis is that any descriptions and interpretations offered must be grounded in the particularity of the specific discursive event. However, I do not see this as necessarily precluding the attempt to produce explanations which may be generalizable. Indeed, particularism offers a firm grounding for building up generalizations through comparative work (Miller and Slater, 2000: 1).

As such, the multiple case study design that I employ offers a specific opportunity for such comparison. In the final two chapters of the thesis, I engage in this comparative work, drawing upon discourse theory which specifically addresses the problem of how to account for regularities across a multi-sited discourse analysis.

It is worth making one final point at this stage. The research process is an iterative procedure of data collection and analysis. As such, the researcher should be prepared to be surprised by their data, and prepared for further questions and concerns to emerge and guide this ongoing process that were not initially conceptualized as central rationales.

\subsection{Structure of the thesis}

The thesis is divide into nine chapters. A central element of my research strategy is to critically engage with previous literature in order to clarify how my research fits in with, and builds upon, this work. In Chapter 2,1 provide an 
overview of sociological and related work on the four topics of discourse, social exclusion, technology, and the digital divide. The literature review contextualizes the thesis within these traditions of previous academic scholarship, and highlights specific analytic and conceptual resources which are utilized and developed in later chapters.

The following five chapters concentrate on my analyses of specific case studies. In Chapter 3, I provide a detailed critical examination of a policy document produced by the Social Exclusion Unit as a case study in the understanding of technology and inequality within contemporary UK government discourse. The aim of this chapter is to detail the political work that is achieved through the particular articulation of the relationship between technology and inequality in this report.

I examine the work of another 'Social Policy Unit', this time located within the telecommunications corporation BT, in Chapter 4. As a case study in the understanding of technology and inequality within corporate discourse, I pay particular analytic attention to the practices of new media consultation undertaken by the BT Social Policy Unit on the issue of the digital divide. The aim of this chapter is to develop a sociological understanding of the contemporary corporate concern with, and articulation of, the digital divide.

Many similar reports and projects by the private sector and individual nation states fed into the G8's Digital Opportunity Task Force initiative. In Chapter 5 , l examine the organization and the year-long work of the 'DOT Force' initiative as a case study of the understanding of technology and inequality within contemporary supranational discourse. I pay particular analytic attention to any conflicts that occur in this work and their specific processes of resolution. The aim of this chapter is to critically examine the articulation and legitimation of a specific narrative of technology, inequality and the global in this initiative.

In the case studies analyzed in these initial chapters, there is an underlying, if frequently unexplicated, assumption of the increasing importance of the network form of organization and networked processes of social inclusion and 
exclusion. In Chapter 6, I concentrate on the work of Manuel Castells as a key theorist of the 'network society'. In particular, I critically examine the methodological, epistemological and theoretical underpinnings of Castells' analysis of technology and inequality as specifically articulated in his understanding of the digital divide.

The figure of the 'excluded' looms large in Castells' diagnosis, and the goal of 'inclusion' is a prominent concern for the initiatives of earlier chapters. In Chapter 7, I examine a series of focus group discussions with participants who are already recognized in a particular institutional discourse of social exclusion. The aim of this chapter is to analyze the understandings of technology and inequality that are articulated through the talk of this group of participants, and to detail the specific discursive resources and narrative strategies that are drawn upon in these discussions.

In the final two chapters of the thesis, I develop the interpretation of my empirical material, partly through focussing on discursive regularities across my case studies, but additionally through a further engagement with some of the concepts and logics of discourse and related theory. In Chapter 8, I concentrate on UK government, corporate and supranational discourse and pay particular analytic attention to regularities in the discursive construction of ethos, the organization of causal ontology, and the discursive function of 'the digital divide' across these case studies. Following this, I present an argument for conceptualizing these regularities as rules of discursive formation.

I present a summary of the main arguments and findings of my thesis at the beginning of Chapter 9. I finally consider the implications of specific rules of discursive formation for the wider analysis of government in the Information Age. To conclude, and drawing on discussions of the boundary concept and the brand, I return to consider how we might best conceptualize the status of 'the digital divide' in the discursive formation of the Information Age. 


\section{$\square \square$ Chapter 2.}

\section{Literature Review}

\subsection{Introduction}

In this chapter, I am going to discuss sociological and related work on four topics: discourse theory and analysis, social exclusion, technology studies, and finally the digital divide. The overall aim of this thesis is to critically interrogate contemporary discourses of technology and inequality. Each of these four areas of scholarship may be expected to inform this aim in particular ways. Hence the respective reviews of literature in these areas will be tailored to these specific ends, and will highlight specific analytic and conceptual resources which may be drawn upon and developed in the empirical engagements of later chapters.

In the first section, I selectively review several important strands of theoretical and analytic work centring on the concept of discourse, and locate my own approach to discourse analysis by contextualizing it within these traditions of previous academic scholarship.

In the second section, I consider the issue of social exclusion, which has become a focus for academic and political debate on inequality in recent years, and is a central concern in all of the empirical case studies that I later analyze. I review some of these conceptual debates and pay particular attention to work which takes a discursive approach to the issue of social exclusion.

In the third section, I engage with academic work on technology with the specific aim of detailing particular forms of explanation through which the relationship between technological and social change has been understood, e.g. technological determinism. This particular theme of technological and 
social change is again a central concern in all of the discourses of technology and inequality that I later analyze.

Finally, I provide a critical overview of scholarly work on 'the digital divide', examining the significant methodological, epistemological and theoretical trends in the academic discussion of this concept. As detailed in the previous chapter, the digital divide is a key motif in contemporary discourses of technology and inequality, and thus a particular focus of analytic attention in this thesis.

\subsection{Discourse Theory and Analysis}

Theoretical and analytic work centring on the concept of discourse has been one of the key developments in social science over recent decades. Any discussion of this 'discursive turn' must initially acknowledge that the concept of discourse has provoked considerable debate and has been theorized and deployed in many different ways in the contemporary social sciences. The analytic remit of discourse analysis has ranged from a single utterance to the constitution of entire systems of meaning, and the diverse traditions of thinking in which these various conceptions of discourse have emerged have also implied different tasks for discourse analysis.

The theory and analysis of discourse that I am going to concentrate upon is theoretically located in the movement away from the more narrow, technical definitions of discourse evident in positivist research programmes. Its genealogy lies particularly in anti-positivist and anti-essentialist traditions of intellectual inquiry, concerned with developing the insights initially formulated within structuralism and linguistics, and developed in areas such as critical theory, post-Marxism, psychoanalysis and post-structuralism. It has some family resemblance to other hermeneutical modes of inquiry in that the object of research is to attempt to provide novel understandings of discursive phenomena. However, this is attempted through analyzing the way meaning is constructed within incomplete, undecideable discursive structures and located in larger social and historical contexts. These interpretations may 
then provide a basis for the critique and transformation of practices of social meaning.

In order to try and ground the adoption of my particular approach, I intend to provide a selective review of this work here. The aim of this review is to contextualize my approach to discourse analysis within this broad theoretical space, and to identify methodological heuristics and conceptual resources that are consistent with this particular understanding of discourse, and may be deployed and developed in the empirical engagements of later chapters.

Howarth (2000) argues that the theory and analysis of discourse has broadly undergone three significant transformations. The first 'phase' of discourse analysis was primarily concerned with the phenomenon of 'language in use'. This work drew upon theoretical resources such as the analytic philosophy of speech act theory (Austin 1976) as well as insights from Garfinkel's (1967) studies in ethnomethodology. The analytic focus was on the micro level of communicative practices through which individuals both experience their everyday realities and reproduce social order. Such work analyzed in particular the accomplishment and organization of patterned discursive interactions and conversations, emphasizing concepts such as turn-taking (Schegloff and Sacks 1973).

Howarth sees the second 'phase' of discourse analysis as occurring with the extension of the analytic remit and conceptual understanding of discourse beyond dialogue to a wider set of social practices and phenomena, with the key figure in this development being Michel Foucault. In his earlier quasistructuralist or 'archaeological' writings, Foucault $(1969,1972,1973)$ uses the term discourse in a number of different ways:

'Instead of gradually reducing the rather fluctuating meanings of the word 'discourse' I believe I have in fact added to its meanings: treating it as sometimes the general domain of all statements, sometimes as an individualisable group of statements, and sometimes as a regulated practice that accounts for a number of statements' (1972: 80) 
As Mills (2005) notes, while the first definition in this quotation, 'the general domain of statements', refers to discourse in general as all utterances and texts which have some meaning in the real world, the other two definitions are to do with particular discourses. 'An individualisable group of statements' refers to a particular group of utterances and texts which exemplify a specific set of concerns and have a coherence and force in common; for example, a discourse of femininity or a discourse of health. In the third definition, 'a regulated practice that accounts for a number of statements', Foucault's concern moves from the actual utterances and texts that are produced to the rules and structures that underpin their production.

As such, Foucault argues that discourses can be understood as historically specific 'practices that systematically form the objects of which they speak'. (1972: 49). Foucault points to specific rules of discursive formation and practices of enunciation as enabling the production of particular objects, subjects, concepts and strategies. For example, Foucault (1973) argues that the discursive formation of $19^{\text {th }}$ century medicine constituted new objects of knowledge under the clinical 'gaze', involved particular subject positions such as physician and patient, developed the concepts of normal and pathological, and generated particular strategies for the treatment and prevention of diseases.

In this understanding of discourse, 'things' are not referred to in the way that a linguistic referent might designate a particular object, and the extra-discursive nature of the objective world cannot be used to judge the veracity of discourses. Rather, discourses both constitute and generate knowledge about their objects. Hence, Foucault (1972: 47-8) substitutes 'for the enigmatic treasure of "things" anterior to discourse, the regular formation of objects that emerge only in discourse'. In addition, such a discourse is not identifiable with individual 'authors' in the sense that an understanding of discourse as utterance might suggest. Rather the rules or conventions of discourse are not necessarily available to those practitioners enunciating them. As opposed to an emphasis upon the intentionality of the speaker and the influence upon the listener in 'speech acts', where subjects are already 
assumed to be in a position to communicate, Foucault's conception of discourse draws upon the structuralist thesis of language, and symbolic systems in general, as producing subjectivity, positioning human beings as subjects.

One expression of this theoretical movement in discourse theory from speech acts to a more Foucauldian approach, and a concomitant ontological movement from subject to subjectivization, occurs in Judith Butler's work (1990, 1993) and in particular, her distinction of performance from performativity. For Butler, performance presumes a subject, whereas what she terms performativity contests the very notion of the subject. Butler argues that:

'when one starts to think carefully about how discourse might be said to produce a subject, it is clear that one is already talking about a certain figure or trope of production .. at this point it is useful to turn to the notion of performativity, and performative speech acts in particular - understood as those speech acts that bring into being that which they name. This is the moment in which discourse becomes productive in a fairly specific way .. performativity as that aspect of discourse that has the capacity to produce what it names' (1994: 34)

For Butler, female gender is not something that one is, nor is it to be understood in terms of traits that one has. Rather, it is an effect that is produced by way of particular things being done, 'a set of repeated acts within a rigid regulatory frame which congeal over time to produce the appearance of substance, of a "natural" kind of being' (1990: 33). Female gender is something that is accomplished through a repetitive performativity or 'girling', inaugurated by the utterance, 'It's a girl', but constantly reaffirmed by repeatedly performing particular acts in accordance with the cultural norms (themselves historically and socially constructed, and consequently variable) that define 'femininity'. Thus Butler argues that, 'performativity is the vehicle through which ontological effects are established. Performativity is the discursive mode by which ontological effects are installed' (1994: 34). 
A further exploration of the concepts of performativity and repetition is undertaken by Jacques Derrida in 'Signature Event Context' (1997a[1977]) and 'Limited Inc.: abc' (1997b[1977]). I will also be referring here to Gayatri Spivak's (1996) essay, 'Revolutions that as yet have no model', where the author herself is summarising and developing themes from these pieces. Derrida's conception of discourse resists easy summation but he emphasizes a constitutive inability to fix meaning in any final way, and the impossibility of completely closed systems of discourse. In these particular essays, Derrida is concerned to interrogate the limits and implications of the philosophical beliefs that are 'covertly installed' (1997a: 3) in the theoretical language (such as utterance, context and repetition) of Austin's speech act theory, a tradition to which Derrida has indicated his project bears the resemblance of a "'deconstructive" heir' (1997c: 131). Derrida initially points out that the definition of 'ordinary' language that Austin uses depends upon the exclusion of certain speech, such as that spoken by an actor on stage or in soliloquy, as 'parasitic'. For Derrida, such exclusions 'present themselves as strategic or methodological suspensions...fraught with metaphysics and presuppositions' (1997b: 57-58).

Crucial to Derrida's project to develop an alternative understanding of communication is an attempt to deploy an alternative conceptual language to this 'method of metaphysics which, disclosed or undisclosed, inhabits the language of the human sciences' (Spivak 1996: 86). Following on from his earlier introduction of the concepts of trace, differrance and supplementarity (Derrida 1997b), 'Limited Inc.' adds a further piece of vocabulary, the 'graphic of iterability'. The 'graphic of iterability' is Derrida's displacement of the 'logic of repetition' in speech act theory, whereby the possibility of identification is understood by Austin to be based upon pure repetition. Derrida's discussion of the 'graphic of iterability' foregrounds the idea that language presupposes both the repeatability and the alterability of signs, and that there can never be fully formed contexts arresting the production of meaning. 
As Howarth (2000: 41) notes, iterability "implies neither the pure repetition of meaning, which would render the listener insensitive to the differences of particular contexts, nor pure alteration, which would undermine the recognition of the sign in the different situations in which it was articulated". Without both these characteristics, there can be no possibility of communication or identification. The unfolding of the consequences of this revision, 'puts into question both a transcendental idealism that claims that the idea is infinitely repeatable as the same and a speech act theory that bases its conclusions on intentions and contexts that can be defined and transferred within firm outlines' (Spivak 1996: 86). It follows that iterability - repetition and alteration - becomes the condition of possibility of identification, communication and consensus.

The excluded possibilities of, e.g. theatricalising or citing, are thus structurally inherent in every 'intended' speech act: 'Among the many heterogeneous elements that constitute the speech act with traces leading back and forth, the iterable non-self identical intention as well as the 'parasitic' use are structural moments' (Spivak 1996: 87). Derrida thus questions a conception of meaning that depends upon the idea of pure origins, whether in the minds of individual speakers, or in unchanging and universal concepts. Rather, speech acts always presuppose a wider system of language that continues to have effects after the moment of inscription. Further, any investigation of the production of meaning must pay attention to the ways in which specific contexts necessarily transform meaning, and to the fact that there can be no fully closed system of communication.

What might be the implications of these rather abstract ideas for discourse analysis? Spivak acknowledges that the practice of production of theoretical discourse would be significantly altered if it was recognized as irreducibly iterable. However, she also acknowledges the particularity of such production (and hence the difficulty in summarizing it) in stating that, 'it is a mark of the necessity of the 'impurity' of a graphic that such recognition must come through that very conscious intention that the graphic calls into question' (1996: 88). Derrida himself similarly emphasizes the singularity of each of his 
readings, and resists the reduction of deconstructive reading to any formal or general method:

'The incision of deconstruction, which is not a voluntary decision or an absolute beginning, does not take place just anywhere, or in an absolute elsewhere. An incision .. can be made only according to lines of forces and forces of rupture that are localizable in the discourse to be deconstructed.' (Derrida 1981: 82)

Although Derrida cautions against any 'appropriation' of deconstruction then, suggesting that it might be more useful to think of how a system which is 'appropriating' might itself be modified by this movement (1997c: 141), there are clear themes explored in his work which pertain to the practice of discourse analysis. Derrida comments:

'I would say .. of deconstruction, which is above all and from its beginnings .. a practical analysis of what is called the parasite and of the axiomatics upon which interpretation is based. Meaning is founded on these acts, "the exclusion of the parasite", "the will to purity" (1997c: 135).

The Derridean strategy of the 'double reading' of philosophical texts thus aims to rigorously describe and reconstruct the dominant logics and intentions of a text, while simultaneously pointing out how the 'limits' and 'points of closure' that enable its coherence and consistency are themselves undecideable and trouble this precarious unity. More specifically, Howarth (2000: 44) argues that there are several targets that a discourse analysis informed by Derrida's ideas on what makes communication possible, would want to interrogate:

'These include the construction of essentialist logics and forms of thinking; the search for the subjective or objective 'origins' of phenomena or concepts; the positing of absolute historical breaks or 'epistemological ruptures' in traditions of thought .. and the assumption that there are 'fully saturated' or total contexts of meaning.' 
Derridean concepts or graphics such as trace, differance, supplementarity and iterability thus point to the radical incompleteness of meaning as fundamental to the organization of our experience of the world. This underlying principle, and strategies such as 'double reading', interrogating essentialist dichotomies, and locating the 'points of undecideability' in texts, have been crucial resources for rethinking positivist and essentialist approaches to discourse in the work of thinkers such as Laclau and Mouffe (1985), Norval (1996) and Campbell (1999). ${ }^{2}$ Howarth (2000) associates this work with a third phase of discourse analysis, expanding its scope into what he calls discourse theory.

In particular, the approach of discourse theorists such as Ernesto Laclau and Chantal Mouffe (1985), extends the scope of discourse analysis by questioning any a priori separation of different types of social practice and a hierarchy of explanation which would propose an ultimately determining domain, thus rejecting the understanding of ideology in classical Marxist explanation. Rather, through an engagement with the Gramscian notion of hegemony, Laclau and Mouffe argue that no system of practices (e.g. economic, cultural, legal) is autonomous from the effects of others or ultimately determining in the process of production of new collective identities. Instead, seeing all social practices and relations as discursive, they introduce the concept of articulatory practice. I will expand upon some of the key contours of Laclau and Mouffe's approach, which is built upon the related concepts of discourse and articulation.

At its most general, Laclau and Mouffe's theory captures the idea that all objects and actions are only meaningful in a particular system of discourse. Furthermore, and following Derrida's emphasis upon the play of signification which extends indefinitely in the absence of a transcendental signified, Laclau and Mouffe similarly emphasize undecideability and deferral in the construction of meaning. A discourse presupposes the experience of radical incompleteness and the impossibility of symbolization, and meaning is understood as constantly negotiated and constructed: 
'Discourse is the articulated meaning-formation resulting from a construction that starts from a situation of radical incompleteness' (Torfing, 1999: 48)

Howarth and Stavrakakis (2000) give the example of a forest standing in the path of a proposed motorway. It may variously be viewed as an impediment to the road's progress, a site of special interest for naturalists or scientists, or a symbol of the nation's threatened natural heritage. In all cases, the meaning of the forest depends on the particular systems of equivalence and difference that constitute its identity and significance. In discourses of economic modernization, trees may be understood as temporary obstacles to the rapid building of the motorway. In environmentalist discourse, the forest may represent a viable ecosystem or an object of intrinsic worth and beauty. Each of these discourses will have established a system of relations between different objects, practices and 'subject positions', such as eco-warrior, developer, conservationist. In broader social and political terms, 'hegemonic projects' will attempt to weave together different strands of discourse in an attempt to dominate or organize a field of meaning so as to fix the identities of objects, practices and subjects in a particular way.

All objects are thus objects of discourse for Laclau and Mouffe, the discursive is the 'theoretical horizon within which the being of objects is constituted' (Howarth and Stavrakakis 2000: 3). However, Laclau and Mouffe strongly contend the potential criticism that such a position entails a reductionism, in the sense that a certain literal reading of Derrida's 'il n'ya pas de hors-texte' has itself become a slogan imputing a scepticism about the existence of the world. They write:

The fact that every object is constituted as an object of discourse has nothing to do with whether there is a world external to thought, or with the realism/idealism opposition. An earthquake or the falling of a brick is an event that certainly exists .. but whether their specificity as objects is constructed in terms of 'natural phenomena' or 'expressions of the wrath of God', depends upon the structuring of a discursive field. What is denied is not that such objects exist externally to thought, but the rather different assertion that they 
could constitute themselves as objects outside any discursive conditions of emergence' (1985: 108)

Objects can quite clearly have a real existence outside discourse then, but importantly they cannot have extra-discursive meaning in Laclau and Mouffe's approach.

Discourse theory emphasizes the construction of subjects and objects in and through hegemonic practices of articulation, which Laclau and Mouffe define as 'any practice establishing a relation among elements such that their identity is modified as a result of this articulatory practice' (1985: 105). According to Laclau and Mouffe, a discourse is a result of this articulatory practice, this attempt to dominate a field of discursivity, by expanding and tying together signifying chains that partially fix meaning. Although the ultimate contingency of meaning precludes discourses from ever completely imposing order and necessity on a field of meaning, there are privileged discursive points, or nodal points, that sustain the identity of a discourse.

For Žižek (1989: 87-100), nodal points are not necessarily the 'richest' words where all the meaning of a field is condensed but may be 'pure signifiers', "a signifier without the signified" (p99). These points, e.g. God, Country, Party, are characterized by a certain emptiness of content which facilitates their structural role of unifying a discursive terrain, retroactively constructing the identity of floating signifiers by fixing them within a chain of equivalence. Laclau similarly argues that even if the closure of society can never be achieved, the ideal of fullness and closure still functions through empty signifiers. He uses the Hobbesian example of the state of nature as a condition of radical social disorder and disintegration:

In a situation of radical disorder, 'order' is present as that which is absent; it becomes an empty signifier, as the signifier of this absence. In this sense, various political forces can compete in their efforts to represent their particular objectives as those which carry out the filling of that lack. To hegemonize something is exactly to carry out that filling function. (1996: 53) 
Any term that can signify this emptiness or lack in a certain political context plays the same role. Indeed, it is only because of this relation that politics is feasible for Laclau: 'it is because of this tendency of a signifier to evade its strict attachment to a signified while keeping a ghostly relation to it, that politics is possible at all' (1996: 59). Nodal points and pure signifiers are thus understood as key discursive sites that articulatory practice works through. This constitution of relations among discursive elements is further understood in terms of a variety of other concepts, such as social antagonism and dislocation, that Laclau and Mouffe develop to explicate the fundamentally political character of discourses and the identities produced through them.

It is beyond the scope of this review to examine all these concepts in detail, but it is again important to acknowledge the links to Derrida's work in them ${ }^{3}$. For example, Laclau and Mouffe insist that social antagonism occurs because of the impossibility of social agents ever attaining full identity. There is an irreconcilable negativity in social relations where opponents perceive 'blocks' to their respective identities being fulfilled (Griggs and Howarth 2000). Indeed, Howarth and Stavrakakis (2000: 10) suggest that, 'the task of the discourse analyst is to explore the different forms of this impossibility, and the mechanisms by which the blockage of identity is constructed in antagonistic terms by social agents'. Similarly, and drawing on Derrida's conception of the 'constitutive outside', Laclau and Mouffe argue that a particular discourse is established by the exclusion of a discursive exteriority; 'the exclusion of antagonistic force is the sine qua non of hegemonic practices of articulation' (Torfing 1999: 43). This concept of antagonistic force itself follows Derrida's contention that, 'there is never anything called power or force, but only differences of power and of force .. one must start, as Nietzsche did, from difference in order to accede to force and not vice versa' (1997c: 145).

Furthermore, ongoing articulatory practice is theorized by Laclau and Mouffe in terms of the simultaneous working of a 'logic of difference' which creates discursive differences and divisions, and a 'logic of equivalence' which subverts existing discursive differences and divisions. The struggle for political hegemony is understood in terms of various discursive elements being 
constantly combined and divided while prior combinations and separations are constantly being subverted, and this discursive texturing of equivalence and difference is thus a central focus of analytic work.

To conclude this section, I wish to make some further brief comments upon some of the strategies and responsibilities that may follow for the researcher given such a theory of discourse. The overall aim of discourse analysis is to describe, understand, interpret and evaluate carefully constructed objects of investigation (Howarth 2000: 139). For example, Norval (1996) constructs her object of analysis in the following manner:

Rather than trying to penetrate below the surface of apartheid, this subject takes as its object of investigation the discourse of apartheid: the multifarious practices and rituals, verbal and non-verbal, through which a certain sense of reality and understanding of society were constituted and maintained' (Norval, 1996: 2)

As Howarth (2000: 136-37) notes, 'viewing apartheid as a discourse means that she [Norval] does not reduce its specificity to a spurious "objectivity"', for example particular economic interests or racial prejudices. Rather, it enables the analysis of apartheid's changing 'horizons of meaning, conventions and practices, and the .. modes of subjectivization instituted by it' (Norval 1996: 7). Similarly, I have detailed in the previous chapter that my object of investigation is the understanding of technology and inequality, in particular 'the digital divide', that is articulated within certain discursive domains, rather than investigating a relationship between technology and inequality defined a prioiri in specific terms.

In this discussion, I have detailed a series of conceptual and strategic resources (performativity, iterability, double reading, articulation, pure signifier, logics of equivalence and difference) that may initially be considered as 'tools of inquiry' for a discourse analytic toolkit (Gee 2005).

At a broad level, the 'tools of inquiry' that I have detailed here have already guided the particular form of my research questions. In asking 'How are 
specific understandings of technology and inequality constructed and legitimated within these discursive domains?', and 'What, in particular, does 'the digital divide' do?', I am orienting my analytic attention to the constructed, the temporal and the performative dimensions of discourse.

Nonetheless, the researcher should always be prepared that their initial concepts and strategies may be significantly altered, or even discarded, in the course of research in a particular domain. As Gee (2005: 7) notes of discourse analysis in general:

'discourse analysis is not a set of "rules" that can be followed step-by-linear-step to get guaranteed results .. tools and strategies are continually and flexibly adapted to specific issues, problems, and contexts of study .. tools of inquiry .. are meant to be "thinking devices" that guide inquiry in relation to specific sorts of data and specific sorts of issues and questions'.

This is especially so for the discourse theory elaborated above, which fundamentally troubles the philosophical underpinnings of any logic of 'identification'. However, even within the more positivist traditions of discursive psychology, Antaki et al. (2003: 9) draw a related conclusion in arguing that, 'the recognition of features does not constitute analysis .. original analysis should seek to show how established discursive devices are used, in new sets of material, to manage .. interactional business'.

As suggested earlier, the desire for a more programmatic statement of the method of analysis has a fundamental incompatibility with the philosophy of this discursive perspective. As such, rather than attempting here to further directly engage in what positivist styles of research would term the process of 'operationalizing' all the concepts and logics of a particular theory of discourse onto a certain area of social enquiry, I concur with Howarth in seeking:

'the articulation and modification of concepts in each particular enactment of concrete research. The conditions for this conception of conducting research is that the concepts and logics of the theoretical framework must be sufficiently 
'open' and flexible enough to be adapted, deformed and transformed in the process of application' (2000: 139)

Such work will be described in the empirical engagements of later chapters.

\subsection{Social Exclusion}

Research in the social sciences has a long tradition of identifying and examining economic and social inequalities, particularly those associated with the collectivities of class, gender and ethnicity. It is worth stating first off that I concur with numerous theorists (e.g. Henwood et al. 2000) who argue that differences are necessary, but not sufficient, prerequisites for there to be inequality. Differences only confer or are understood as disadvantage in a specific social and political context. For example, differences in employment status may only confer economic disadvantage in certain regimes of welfare and social security. My approach in this review is to concentrate on a dominant discourse of inequality, that of social exclusion, that has emerged in the last thirty years in the particular political context of European social policy.

According to Silver (1994), different 'paradigms' of social exclusion existed in France in the 1970s. The concept of social exclusion was variously understood in terms of a Republican rhetorical tradition that emphasized the importance of establishing solidarity and social cohesion between individual groups and wider society, the strand of existentialism in the French Left where exclusion meant being treated as an object, and the participatory ideology of Catholic social action, to name just some inflections. 'Les exclus' (Lenoir 1974) gradually came to name more and more disadvantaged groups (Paugam 1993), such as 'the ones that economic growth forgot' (Donzelot and Roman 1991) in the recovery following the oil crisis, or the residents of the banlieues, the out-of-town estates and suburbs where unemployment, deprivation and crime were highest. Political responses were numerous and varied in their focus, but often underpinned by an understanding of 'insertion' or integration as the appropriate overall response to exclusion (Martin 1996). Concern with social exclusion has since come to dominate the social policy 
agendas of many Western nations. For its critics, this agenda has displaced a focus on deprivation and goals of poverty reduction and economic equality in many countries' policy-making (Lister 1998).

In the UK, the use of the term social exclusion has been no less varied and was initially highly controversial as it began to be deployed in a political climate in which the existence of poverty was not officially recognized by Conservative politicians. As such, the adoption of the term social exclusion allowed debates about social policy to continue at a European level without offending their sensibilities (Burchardt 2001). In recent years social exclusion has become a focus for academic and political debate, and has ascended to centre stage in British domestic policy. This was officially embodied in the establishment of the Social Exclusion Unit (SEU) by the newly-elected New Labour government in December 1997. According to Tony Blair, this was in many ways "the defining difference between ourselves and the previous government" (The Observer, 23 Nov 97). Peter Mandelson declared just before the launch of the SEU that:

'The biggest challenge we face [is] the growing number of our fellow citizens who lack the means, material and otherwise, to participate in economic, social, cultural and political life in Britain today...[it] is about more than poverty and unemployment. It is about being cut off from what the rest of us regard as normal life. It is called social exclusion, what others call the underclass.' (Mandelson, 1997)

Social exclusion has been conceptualized by the SEU within a deliberately broad and multidimensional framework of understanding:

'Social exclusion is a shorthand term for what can happen when people or areas suffer from a combination of linked problems such as unemployment, poor skills, low incomes, poor housing, high crime environments, bad health and family breakdown. In the past, governments have had policies that tried to deal with each of these problems individually, but there has been little success at tackling the complicated links between them, or preventing them from arising in the first place.' (SEU 2000a) 
The Social Exclusion Unit has no spending budget, but its aim is to co-ordinate the attempt to address social exclusion, developing 'joined-up policies for joined-up problems' (SEU 1998: Foreword), and to make specific policy recommendations to appropriate government departments, with a view to directing existing funding more effectively. To an extent then, its functions are those of the critical scrutiny and reassessment of existing departmental work, audit and accountancy. In its first few years, the SEU focussed on specific issues such as rough sleeping, school truancy and teenage pregnancy, assessed training programmes such as the New Deal and Welfare to Work, and began to formulate a national strategy for neighbourhood renewal involving eighteen areas of concern, ranging from employment to housing, political participation to the use of information and communication technologies (SEU 1998, 2000).

One way of defining social exclusion then is in terms of what the Social Exclusion Unit tackle. I will return to this particular discursive perspective on social exclusion presently, but I wish to first consider some of the other sociological and social policy literature on social exclusion. One summary of the literature concludes as follows:

'Observers in fact only agree on a single point: the impossibility to define the status of the 'excluded' by a single and unique criterion. Reading numerous enquiries and reports on exclusion reveals a profound confusion among experts' (Weinberg and Ruano-Borbalan 1993, translation in Silver 1995: 59)

Clearly, many of the concepts used by social scientists and policy makers exist in stormy definitional waters, and the varied attempts at operationalization are as much political as scientific decisions. Nonetheless, I argue that the contestation alluded to above is of a different degree than, for example, debates about whether to use a $40 \%$ or a $50 \%$ income line for measures of poverty. Ongoing contestation is an essential part of the phenomenology of social exclusion. As Atkinson (1998: 13) notes, 'Social exclusion is a term that has come to be widely used, but whose exact meaning is not always clear. Indeed, it seems to have gained currency in part 
because it has no precise definition and means all things to all people'. Social exclusion has thus operated as a form of linguistic currency which easily converts from university seminar to think-tank to Cabinet, and has been deployed with a certain elasticity of meaning as it moves across the spectrum of academics, advocates and policy-makers.

Within social scientific work, there have been some specific attempts to delimit the meaning of social exclusion, both theoretically and empirically. The more theoretical work of the Centre for the Analysis of Social Exclusion (CASE) based at the London School of Economics, has emphasized an understanding of social exclusion in terms of a lack of participation in wider society, has centrally addressed debates about voluntarism, and has considered whether to best understand social exclusion in terms of state or process. Atkinson (1988: 14) proposes three key features of social exclusion which he terms relativity, agency and dynamics:

relativity: Exclusion is from a particular society, referring to a particular place and time. This demands not just looking at the circumstances of individuals, but also their relationships to others.

agency: An exclusion implies an act, with an agent or agents. If someone or a group is excluded, there is somebody else (an individual, a group of people, an institution or a market) who does the excluding.

dynamics: People are excluded not just because they are currently without a job or income, but because they have little prospects for the future.

Burchardt, Le Grand and Piachaud (1999: 229) relatedly argue that, 'An individual is socially excluded if (a) he or she is geographically resident in a society, (b) he or she cannot participate in the normal activities of citizens in that society, and (c) he or she would like to so participate, but is prevented from doing so by factors beyond his or her control'. CASE have also produced much empirical work, including the analysis of longitudinal cohort data in order to better understand the dynamics of social exclusion. 
One important index which draws upon the theoretical work mentioned above, constitutes social exclusion as a lack of participation over time in five domains 'chosen to represent the spectrum of activities in which it is generally thought to be important for people to participate in Britain in the 1990s' (Burchardt, 2001: 390). These domains are defined as consumption activity (being able to consume at least up to some minimum level the goods and services which are considered normal for the society); production activity (engaging in an economically or socially valued activity, such as paid work, education or training, retirement if over state pension age, or looking after a family); savings activity (accumulating savings, pensions entitlements or owning property); political activity (engaging in some collective activity to improve or protect the social and physical environment); and social activity (engaging in significant social interaction with family or friends, and identifying with a cultural group or community) (Burchardt et al. 1999: 231).

There are two further notable attempts to construct indices to measure social exclusion in the UK. In 1999 the Joseph Rowntree Foundation funded the Millennium Poverty and Social Exclusion Survey of Britain, undertaken by various teams including the Townsend Centre for International Poverty Research. This study built upon the methodology of the previously most significant attempt to assess poverty in Britain, the Breadline Britain survey of 1990 , which sought to establish a consensual view of poverty by initially asking respondents whether they regarded particular resources as necessities (see Gordon and Pantazis (eds.) 1997). The Millennium Survey extended this original methodology and more specifically addressed the issue of participation, both in civic organizations as well as in familial and friendship networks (for a full discussion of the methodology and results of the Millennium Survey, see Pantazis et al. 2004).

Since 1999, the government has also published an annual Opportunity For All survey, drawing on existing routinely collected data sets, such as the British Household Panels Survey and the Family Expenditure Survey to construct a new index of social exclusion. The indicators fall into three main categories: those that focus on incomes; those focusing on wider aspects of welfare such 
as education, housing and health; and those that 'capture factors that affect people during their lives and increase the risk that they experience deprivation at a later point in their lives' such as truancy, school exclusion and teenage pregnancy (DSS 1999: 1). The development of this new index was designed to enable the setting of precise targets to tackle poverty and social exclusion and for trends and progress in addressing this goal to be monitored (DSS 1999).

Recent debate about what social exclusion 'really' is, and what the appropriate policies to tackle social exclusion are, has often taken place through contestation of such indicators (Levitas 2000). A final approach to social exclusion that is worthy of note treats contemporary discourse of social exclusion as the explicit topic of investigation. The aim is to make visible implicit models of causality and the wider political assumptions that underpin particular understandings of social exclusion.

Levitas (2005) undertakes an analysis of the way social exclusion has been employed by New Labour. Her underlying thesis is that the term social exclusion is intrinsically problematic, as indeed are any dichotomous views of society. It serves to obscure the issue of inequalities among the majority, and allows poverty to be seen to co-exist with a view of the attrition of class division in society as a whole. Such an understanding may simply become a defence of the status quo:

It represents the primary significant division in society as one between an included majority and an excluded minority .. Attention is drawn away from the inequalities and differences among the included. Notably, the very rich are discursively absorbed into the included majority, their power and privilege slipping out of focus if not wholly out of sight. At the same time, the poverty and disadvantage of the so-called excluded are discursively placed outside of society. What results is an overly homogeneous and consensual image of society - a rosy view possible because the implicit model is one in which inequality and poverty are pathological and residual, rather than endemic. Exclusion appears as an essentially peripheral problem, existing at the boundary of society, rather than a 
feature of society which characteristically delivers massive inequalities across the board and chronic deprivation for a large minority. The solution implied by a discourse of social exclusion is a minimalist one: a transition across the boundary to become an insider rather than an outsider in a society whose structural inequalities remain largely uninterrogated. (Levitas 2005: 7) ${ }^{4}$

However, Levitas furthermore identifies three principal discourses, with concomitant policy agendas, in which social exclusion is embedded in contemporary British politics, which she names Redistributive Discourse (RED), Social Integrationist Discourse (SID) and Moral Underclass Discourse, (MUD). Their principal focus is on poverty, income and wealth redistribution (RED), the socially integrative function of paid work (SID), and the moral and behavioural delinquency of the excluded (MUD) respectively.

Levitas' analysis shows how the rhetoric and policies of New Labour have negotiated between the different competing discourses, again emphasizing that the term itself facilitates easy slippage between competing discourses, and that this very flexibility is part of the reason for its growth in usage. She highlights how the fundamental rhetorical moves have involved a shift away from understanding social exclusion in terms of RED towards those of MUD and SID, that is from an understanding based around the issue of structural inequality and poverty towards one based around a concern with moral regulation and increasing participation in the labour market. Problems of exclusion are furthermore typically understood in terms of highly specific groups, notably the (male) unemployed. The very rich are not seen as a threat to social cohesion or moral order despite their increasing exclusion.

As such, any discussion of equality and redistribution is discursively limited to the distribution of equal opportunity. Inclusion is furthermore recast principally in terms of paid employment, ignoring the realm of unpaid work, and discursively transformed into an individual obligation requiring active performance: 
'Performative inclusion involves the discursive creation of the self as first and foremost a worker. People - or perhaps embodied worker-selves - are then invited to perform their social inclusion, in paid work if they can get it .. those citizens who have no professional opportunities to perform their inclusion are redirected .. to practice active citizenship.' (Levitas 1998: 158).

This shift towards a social integrationist policy agenda involves a distinctive approach to problems of unemployment and job insecurity, which are understood principally in terms of individual 'employability'. As such, 'rather than insecurity being understood as a structural feature of the economy and the labour market, job security becomes something individuals achieve.' (Levitas 2000: 362)

Levitas' analysis of social exclusion thus takes the discursive construction and deployment of a particular understanding of social disadvantage as a specific site upon which to interrogate contemporary practices of government. Relatedly, Dean's study of pauperism concludes that, 'the event of pauperism .. can be understood as marking a fundamental transformation in modes of governance, and the emergence of a new, liberal style of administration which entailed a reworking of the older systems of police around conceptions of selfand familial responsibility' (1991: 211). Similarly, Himmelfarb argues that the salience of the concepts of 'poverty' and 'unemployment' was brought about not only by earlier economic and social upheavals, but by an accompanying shift in the 'moral imagination' (1984: 19).

I wish to make one final point regarding Levitas' analysis of social exclusion. I have used her work as an exemplary illustration of how a discursive approach to the issue of social exclusion may illuminate contemporary practices of government. However, her particular focus on the political discourse of New Labour does not imply that any analysis with similar aims must necessarily limit itself to this realm of politics. Indeed, as Rose notes, 'the term politics cannot longer be utilized as if its meaning was self-evident .. the idea of the State was, and is, certainly one of the most powerful ways of seeking to codify, manage and articulate - or alternatively contest, overturn and re-articulate - the 
proliferation of practices of authoritative rule throughout our "modern" experience .. but the State is profoundly limiting as a way of rendering intelligible the way we are governed today' (1996: 38).

\title{
2.4 Technology Studies
}

In this section, I provide a selective overview of social scientific work on technology with the specific aim of detailing particular forms of explanation through which the relationship between technological and social change has been understood and narrated, both within academic literature itself and in wider discussions.

The first form of explanation I wish to consider is technological determinism. Grint and Woolgar (1997: 11) argue that:

\begin{abstract}
'at its simplest, technological determinism portrays technology as an exogenous and autonomous development which coerces and determines social and economic organizations and relationships. Technological determinism appears to advance spontaneously and inevitably, in a manner resembling Darwinian survival, in so far as only the most 'appropriate' innovations survive and only those who adapt to such innovations prosper'
\end{abstract}

As an ideal type then, technological determinism is based on three sets of ideas or assumptions (Preston 2001: 111-12). Firstly, that technological development occurs in a distinct realm of technical or scientific activity autonomous from the social or economic spheres. Secondly, that societal development or history is determined by technology, that technological change forces social adaptations that constrain the trajectories of human history. This may be accompanied by the dystopian motif of technology out of control (see Winner 1977), or the utopian claim that social progress is driven by technological progress. Thirdly, that the patterns of technological development, diffusion and use are linear, inevitable and predictable. ${ }^{5}$ 
Technological determinism as a form of explanation occurs in statements that construct the relationship between technology and society in terms of simple cause and "effects". An example of this is the statement that, "the development of the contraceptive pill resulted in the sexual permissiveness of the 1960s and a reduction of family size' (Henwood et al., 2000: 9). Henwood et al. argue that this form of explanation, 'in which technologies emerge as if from nowhere and then proceed to transform the societies into which they are diffused' (2000: 8), is pervasive in contemporary culture.

Preston (2001: 111) similarly argues that, 'technological determinism is probably the most popular and influential model of the technology-society change relationship .. it is the one that most frequently informs popular and journalistic accounts of the effects or impacts of new ICT'. Bauchspies et al. (2006: 80) concur that, 'The media is full of examples of the pervasive myth that technological change is inevitable. Most popular media, business journals and even films represent this myth.' Likewise, Mackenzie and Wajcman (1999: 3) contend that:

'all of our lives are intertwined with technologies .. when this intertwining is discussed in newspapers or other mass media, the dominant account of it can be summed up as 'technological determinism'. Technologies change, either because of scientific advance or following a logic of their own; and they then have effects on society'.

Furthermore, such a form of explanation is considered to explicitly underpin various academic analyses of technological innovation and theories of social change. For example, Bucchi (2004: 77) claims that in the work of the historian Lynn White (1962), 'the introduction of a specific innovation, namely the stirrup, is viewed as the cause of so profound a historical change as feudalism'. Indeed, the notion that technology is the motive force of history has often been associated with Marx's memorable comment in The Poverty of Philosophy (1847) that, "The handmill gives you society with the feudal lord; the steam mill, society with the industrial capitalist". While various authors (e.g. Heilbroner 1974, Mumford 1967, Winner 1977) contend that Marx's work 
embraces a technologically determinist position, Bimber asserts that social and economic forces are more significant than technology for Marx and hence that he is 'portraying technology more as an enabling factor than an original cause, autonomous force or determining agent (Bimber 1990: 345, cited in Grint and Woolgar 1997: 13).

More recently, much theorization of the 'Information Society' (e.g. Toffler 1970, 1980; Negroponte 1995; Kelly 1998) gives analytic priority to the allegedly inherent properties of new information and communications technology (ICT) that are understood to be having a determinant and revolutionary impact upon society (May 2002: 24-28). Webster (1995: 219) contends that 'for those who assert that we are witnessing the emergence of an "information society", high on their list of shared principles is technological determinism'. New ICT is viewed as possessing an independent logic or trajectory of its own which is divorced from any basis in existing socioeconomic or political interests, relations or conflicts. Indeed, as Preston (2001: 112) notes, in Toffler's work such a logic is understood to be not merely neutral but benign:

\footnotetext{
'new ICT represents an autonomous force which eliminates or transcends the 'old' conflicts or interests based on social class or gender cleavages. The result (and message) is that new ICT and other 'third-wave' technologies are to be regarded as nothing less than both the means and ends of social development and the "just society" (e.g. Toffler and Toffler, 1995)'
}

Pinch and Bijker (1989) further argue that even where it is not so explicit, there is often an implicit technological determinism in the historical study of technological innovations, simply due to the asymmetric focus of analysis on successful, rather than failed, technologies. They suggest this implies a linear teleology of technological progress and that, 'the preference for successful innovations seems to lead scholars .. to rely on the manifest success of an artefact as evidence that there is no further explanatory work to be done' (1989: 22). Woolgar (2004: 126-27) similarly notes that 'few scholars now explicitly support the basic theses of raw technological determinism', yet asks 
whether the increasing use of terms like 'affordance' rather than determinism in recent academic research on the Internet may be just a new kind of determinism smuggled in by the back door?'

For many commentators, the problem with the technologically determinist view is that it is theoretically impoverishing in that it leaves no space for considering human choice and intervention in our explanations of technology. Furthermore, it is politically impoverishing in that it absolves those making technological decisions of the responsibility of justifying these choices:

'the view that technology just changes ... promotes a passive attitude to technological change. It focuses our minds on how to adapt to technological change, not on how to shape it. It removes a vital aspect of how we live from the sphere of public discussion, choice, and politics.' (Mackenzie and Wajcman 1999: 5)

Indeed to question the possible consequences of such technological innovation for social structures and economic activity is often regarded as at best having a negative "mindset" and at worst to be labelled a Luddite' (Loader 1998: 6). Technological determinism simply assumes that social actors will or must adapt to it because it is the 'modern' way (Williams 1983: 130).

Henwood et al. (2000: 10) suggest that the related understanding of 'technology as neutral' offers some improvement on the hard determinist position in that, 'at the very least, there are choices about the use of technologies, and if people choose to use them, they have choices about how to do so'. As they note, while this view goes against the claim that technologies have straightforward and consistent social "effects", and intimates a role for the contingent use of technology in shaping social change, it does not problematize the origins of technology. Technologies still emerge autonomously then, but are also seen as morally and politically 'neutral', and thus capable of being used for diverse social purposes. Winner (1977) proposes a related understanding of 'autonomous technology', but stresses 
that politics may be inscribed in technology in such a way that it appears neutral. As Grint and Woolgar (1997: 13) note:

'Its apparent neutrality, according to Winner, then encourages us to adopt somnambulist habits: we are unaware of our real situation; we think we take choices but actually we make responses to a situation preordained by politically impregnated technology - the 'technological imperative'.

Winner (1980: 135) argues that although the intractable properties of certain kinds of technology [e.g. the atom bomb] are strongly, perhaps unavoidably, linked to particular institutionalized patterns of power and authority', it is because most technologies, 'are flexible that their consequences for society must be understood with reference to the social actors able to influence which designs and arrangements are chosen'. Thus technologies are specifically designed, arranged and adopted by certain social groups in such a way that they have particular political consequences, they makes social relations of power durable, and hence "the things we call "technologies" are ways of building order in our world' (p128).

Winner's argument here is exemplary of a large amount of recent scholarly work on technology that explicitly challenges the technologically determinist position (e.g. Heap et al. (eds.) 1995, Mackenzie and Wajcman (eds.) 1999). It should be noted though that there is a certain sense in which a version of technological determinism is kept alive, perhaps most clearly in such edited collections, in order to legitimate a project of calling it into question (see Grint and Woolgar 1997). ${ }^{6}$

The second broad form of explanation that I will consider is the 'social shaping approach' which is 'a generic label for those accounts which suggest that the capacity of the technology is equivalent to the political circumstances of its production' (Grint and Woolgar 1997: 19). The essence of this approach is that technological change is not an autonomous process, but rather the technological innovation process is itself actively shaped by social, cultural and economic factors. Technologies are not separate from, but are 
constituted in a specific socio-economic, institutional and cultural context. The very origins of technologies are thus understood to be part of wider social relationships and processes, and hence technologies are not seen to have fixed 'effects' in themselves.

A further example of this approach is David Noble's study of the development of automated machine tools. Noble (1984: xiii) argues that, 'Because of its very concreteness, people tend to confront technology as an irreducible brute fact, a given, a first cause, rather than as hardened history, frozen fragments of human and social endeavour'. His analysis details a series of strategic technological selections and designs in the history of automation that he argues cannot be explained simply in terms of intrinsic gains in technological efficiency. Noble suggests that the trajectory of this technological development can be best understood as the outcome of social struggle for control over the labour process. Effectively, Noble argues that technological development materially embodies the values and social interests of particular groups and classes in purposive ways.

The variety of work that can be broadly considered to adopt a social shaping perspective has ranged from macro level theorization that emphasizes the systemic determination of technological development via the institutions of the market or the state (e.g. Arthur 1994), through to detailed case studies of individual technologies which emphasize the role of situated cultural factors in their development, such as professional career structures (Kranakis 1997) or the values and visions of amateur communities (Ceruzzi 1996). Ceruzzi's study of the history of computing emphasizes the crucial role that electronic hobbyist groups, with their specific communities of practice, infrastructures of support, DIY values and 'countercultural' politics, played in shaping the development of computing technology away from a trajectory based upon the corporate 'mainframe' model towards an alternative vision of personal technology.

Theorists opposed to technological determinism on the political grounds that it promotes passivity have argued that such groups were, 'pursuing one version 
of the active politics of technology that we are recommending'. (Mackenzie and Wajcman 1999: 17). It is perhaps unsurprising that technology should become a focus for countercultural visions if we accept Woolgar's (2000: 182) description of technology as 'a phenomenon upon which is written the vast array of competing visions of alternative forms of social arrangement'. Indeed, Woolgar (2000: 178) further asserts that 'technology itself is a form of theorizing'.

The social shaping approach in general stresses that technologies are marked by their conditions of design and production, and specific importance is placed upon the values and social interests of particular social groups involved in these processes. However, the notion 'that technologies physically embody political or other values can be as reductionist as technological determinism' (Henwood et al. 2000:12). Further, as Ceruzzi's study demonstrates, and as Fleck (1999) argues, processes of innovation and diffusion may increasingly be best understood, and are practised, as overlapping.

Rather than viewing technologies as the simple embodiment of specific values, an important strand of social shaping thinking known as the Social Construction of Technology (SCOT) approach (Kline and Pinch 1999) stresses the dynamic and contingent process of articulating, if ultimately stabilizing, the meaning of technology. The major theoretical contribution of this approach is the notion of 'interpretative flexibility', whereby the very 'working' of a technology is initially subject to radically different interpretations that are coextensive with different social groups, including its users and nonusers. Rather than any emphasis on the essential features of a technology being designed in, 'the constructivist argument is that the very core of technology, that which constitutes its working, is socially constructed' (Bijker 1994: 281).

Such a view draws on the ideas that users are active and socially situated decoders of technologies and that the consumption process is highly symbolic rather than utilitarian (Preston 2001: 114), and furthermore, that this meaning- 
making is central to the process of creating an artefact. Various case studies have illustrated how different social groups have contested workability. For example, Pinch and Bijker's (1989) study of the trajectory of bicycle design argues that it is best conceptualized not as a linear path, but as a dynamic multi-directional process in which the 'same' technical design comes to mean different things to different groups, e.g. 'sporty' or 'unsafe', 'working' or not. While the interpretative flexibility of technology is emphasized in this approach, the social groups engaged in such interpretation are generally presented as stable entities, whose identities are not themselves reconstituted through these encounters. Feminist scholarship that emphasizes the coconstitution of 'gender and technology in the making' (Cockburn and Ormrod 1993) has been one area where this issue has received more sustained analytic attention.

To summarize then, in contrast to the determinist form of explanation that a technology triumphs because it is technically the best, theorists adopting social shaping and social constructivist forms of explanation have variously explored the ways in which a technology may be considered to have become the 'best' because of the social, political and interpretative processes through which it has been championed.

The discursive construction, legitimation and implications of particular forms of explanation of the relationship between technology and inequality will be a general focus of attention throughout this thesis. To conclude this section, I will draw attention to two more specific issues that I will address in particular chapters.

Firstly, I wish to briefly point to a third form of explanation of the technologysociety relationship in social scientific literature that turns on the motif of the network: 'I would define a good account as one that traces a network' (Latour 2005: 128). Actor Network Theory rejects both the extreme position of technological determinism, with its reification of the object, as well as the fetishization of a certain form of stable agency in some social constructivist approaches that view technology as thoroughly socially determined. Rather, it 
emphasizes the 'deep mutual constitution of humans and artefacts' (Suchman 2000: 4). It is not so much a middle ground between the first two positions as a deferral of any questions of causality in favour of a fundamental overhaul of ontology and a consequent reinscription of notions of agency.

Latour (1993) agues against the modernist epistemology and ontology which slices continuous reality into separate domains; a nature to be observed, a society which is man-made, and further in the postmodern turn, language as an additional autonomous realm. For Latour, this a priori delineation of domains such as nature or society for analytic purposes is fundamentally problematic. As Michael (2000: 21) argues, it is an empirical question as to what has emerged as natural, artificial or social. Disavowing the attempt to understand at which end of the 'nature/society yardstick' the ultimately determining instance might lie, Callon and Latour (1992: 350) stress instead their concern with an orthogonal dimension 'centred on the very activity of shifting out agencies'.

Latour and Callon thus propose the key figure of the network to describe the existence of a hybrid nature, technology and society. A new network emerges from an existing network, tying together both human and non-human actors (or 'actants') through the process of translation and the circulation of 'intermediaries'. ${ }^{7}$ Networks configure ontologies: 'actors are network effects, they take the attributes of the entities which they include' (Law 1999: 5). For Latour, although networks can converge and stabilize by mobilizing allies, 'nothing becomes real to the point of not needing a network to upkeep its existence' (1993: 118). At times the network seems to have the ability to translate all other terms to itself, thus 'an actor network is simultaneously an actor whose activity is networking heterogeneous elements and a network that is able to redefine and transform what it is made of (Callon 1987: 93).

I do not intend to engage in a detailed analysis of this approach here (see Law and Hassard (eds.) 1999). My intention is merely to signal a particular form of explanation that challenges the ontological distinction of the social and the technological and turns on the motif of the network ${ }^{8}$. In Chapter 6, I will 
engage in a detailed analysis of the work of Manuel Castells as a key case study of scholarly work on technology and inequality. Although his work occupies a different theoretical space from that of Latour and Callon, it also turns on the motif of the network as both a particular form of social association (Granovetter 1985, Taylor 2001) and an arrangement of information and communications technology.

Secondly, Henwood et al. (2000: 9) contend that while the simplicity of the technologically determinist model is one principal reason for its endurance, another is that:

'For most people, most of the time, the technologies they use every day are of mysterious origin and design. Most people have no idea from whence the technologies came and equally little idea of how they actually work. People simply adapt themselves to their requirements and hope that they continue to function in the predictable and expected ways promised by those who sold them. It is because technological determinism conforms with a majority of people's experience that it remains the 'common sense' explanation'.

I shall explicitly address this specific claim that technological determinism is the model which makes most sense of people's everyday experiences of technology in Chapter 7.

\subsection{The Digital Divide}

In this section, I provide a historical overview of academic literature on the digital divide, focussing upon the significant methodological, epistemological and theoretical trends in this work.

The naming of 'the digital divide' in the mid 1990s as an object of governmental, corporate and scholarly concern can be traced to a lineage of commercial and social policy work concerned with quantifying differential access to technology according to various demographic criteria. The term 'digital divide' is widely believed to have first come to prominence within a 
notable series of surveys undertaken in the U.S. by a branch of the Department of Commerce, the National Telecommunications and Information Administration (NTIA), throughout the late 1990s and early 2000s, entitled Falling Through The Net I, II, II and IV, (Dept of Commerce 1995, 1998, 1999, 2000) and latterly A Nation Online (Dept of Commerce 2002). ${ }^{9}$ The initial rationale of these quantitative surveys was to measure standard telephony service in the U.S. and the extent to which this sector-specific Universal Service obligation was being met. However, the focus gradually changed over the course of the series from basic telephony to a concern with a digital divide defined and measured in terms of differential access to the Internet, and a concern for 'participation in the digital economy' (Department of Commerce 2000: 2). ${ }^{10}$

Similar surveys and assessments were commissioned and undertaken by governments and corporations in many other developed nations to quantify the demographics of this digital divide within their borders (e.g. Booz, Allen and Hamilton 2000, MORI 1999, National Statistics 2000). Additionally, supranational organizations such as the International Telecommunications Union and the Organization for Economic Co-operation and Development collected and compared measures of teledensity to point to the existence of a digital divide between countries (ITU 1999, OECD 2001, UNESCO 1998).

The same time period witnessed an explosion of commercial activity which aimed to profile the emergent Internet user through the undertaking of additional surveys and the development of more sophisticated techniques of data mining and assessment. The Irish Internet surveying company NUA and the U.S. company CyberAtlas were principal competitors in this market before joining forces to become JupiterResearch in 2003. As well as undertaking their own individually commissioned research, such organizations collate and meta-analyze the results of numerous other datasets with similar concerns. The regular production and dissemination of digital divide trends and statistics is a feature of this work to the present day. 
By the turn of the century then, differential access to the Internet was firmly established as the defining motif of the digital divide, and was being operationalized and quantified through extensive survey work and an array of further technocratic assessment tools. " Van Dijk (2005: 1) describes the situation as follows:

'Around the turn of the century, hundreds of conferences of computer professionals, social scientists, and government policy experts worldwide were dedicated to the issue. It was also put on the agenda of public opinion, political discussion, and mass media attention. Commonly, the digital divide was defined as the gap between those who do and those who do not have access to computers and the Internet. Access first of all meant physical access: having a personal computer and an Internet connection.'

Interpretation of the results of these broad-brush surveys, particularly the NTIA, OECD and ITU datasets, forms the empirical base for much of this early academic discussion of the Digital Divide (e.g. Norris 2000). Stewart (2000) performs a similar exercise to chart The Digital Divide in the UK, undertaking a meta-analysis of surveys and assessments of levels of Internet access, dimensions of Internet use, and attitudes towards use by non-users. These include work conducted by the then National Telecommunications regulator Oftel, the National Statistics Survey of Households, various commercial surveys undertaken by Motorola and Which? Online, as well as by global Internet surveying corporations such as NUA, Fletcher Research and Continental Research.

I do not intend to outline in detail the results of all of these surveys and metaanalyses. This is a huge task which is subject to diminishing returns, and is tangential to my aim in this thesis of examining the discursive contours of the digital divide. Suffice to say that, to a large extent, digital divides in terms of Internet access have been found to exist and to be patterned along the expected lines of differential income, education, employment status, geography, age, gender, and ethnicity. For example, Selwyn (2002: 5) concludes that 'those groups likely to be 'digitally excluded' in terms of access 
to ICT are seen to be remarkably similar to those who can already be characterized as being socially excluded - especially in terms of low income and socioeconomic status'. The flipside of this is that the use of ICTs for socially empowering activities tends to be most prevalent amongst those who are already socially and economically empowered, what Selwyn and Gorard (2002) have referred to as the 'usual suspects' phenomenon. ${ }^{12}$

However, as Van Dijk (2002: 1) asks of such a correlation, 'The result is that the causes and effects of differential access to the new digital technologies are not sufficiently articulated or clarified. Are the digital divides observed simply a by-product of the old social inequalities? Is digital technology intensifying these inequalities in some way or another? Or are new inequalities appearing in the context of a new (information) society?'

DiMaggio et al. (2001: 311) conclude that 'because sociologists have conducted so little research on the digital divide, to chart the dimensions of inequality we rely primarily on studies reporting bivariate statistics', in particular those statistics regarding Internet access. Furthermore, Van Dijk (2002b) has argued that research and analysis based on such resources and descriptive statistics is inadequate for the following four reasons:

[1] They only report the usual, rather shallow, demographics of income, education, age, sex, race and ethnicity ... [2] Lack of longitudinal data prohibits the extrapolation of trends, a necessity for the interpretation of any digital divide ... [3] The multifaceted concept of access is ill-defined. Most often it is limited to material access: the possession of a computer or a network connection ... [4] There is a clear lack of theory. Insufficient attempts of explanation .. by general theories of information inequality in an information society' (2002b: para 2-5)

There is still much work updating demographic differences in Internet access ${ }^{13}$, indeed a continuing discourse organized around the dissemination of such digital divide trends, statistics and meta-analyses by organizations such as the U.S. Benton Foundation via their Digital Divide Network and Internet surveying corporations such as JupiterResearch ${ }^{14}$. However, a 
rejection of this initial narrow conception of the digital divide has become an academic starting point for a renewal of wider theoretical and analytic agendas, less concerned with static statistical snapshots and aggregated findings. Academic discourse on the digital divide has become a site upon which this initially hegemonic understanding, of differences in Internet access between various demographic groups, has been reframed.

\subsubsection{Digital Divide Scholarship in the 2000s}

As I have previously argued, difference can only be understood as disadvantage within a particular context. While earlier scholarship relied upon the general invocation of an information society as the context in which such differences in Internet access would confer disadvantage, authors such as Mueller (2001) stress that the contemporary conditions of the free market will ultimately eliminate the digital divide. Similarly, in 'Declare the War Won', Compaine's (2001) conclusion to The Digital Divide: facing a crisis or creating a myth, he argues that the context of neo-liberal market forces is leading to the rapid diffusion of information technology and the provision of access, even more so than for other services and goods where early adoption is not so pronounced and hence does not induce such a rapid lowering of prices and trickle-down effect (p318-324). ${ }^{15}$

Other authors have argued that the initial consumption-oriented focus on material access to Internet infrastructure and potential economic participation was a severely delimited analysis of what was a far more dynamic and complex social, political and cultural issue. As such, academic work now regularly invokes a considerably more multi-faceted concept of digital divide(s), a 'second level' (Hargittai 2002) digital divide that is 'beyond access' (Carvin 2000, Hellawell 2001) in significant ways, particularly focusing on issues of computer skills or relevant online content. Servon's (2002: 8) analysis stresses both: 'redefining the digital divide, then, requires broadening the concept beyond access to include training and content issues'. Van Dijk and Hacker (2003: 315) similarly regard 'the digital divide as a complex and dynamic phenomenon' and particularly argue for an understanding of access 
as a 'multifaceted concept', covering issues of issues of motivation, skills and opportunities for use as well as the more standard issue of material access.

More central to this new academic work has also been a concern to consider the consequences of the digital divide, particularly whether and how a lack of ICT access, skills or relevant content might lead to social exclusion. The answer to this question was somewhat taken for granted in the earlier statistical work, and certainly one whose dynamics were undertheorized. This common sense assumption is becoming the subject of more explicit critical scrutiny.

For example, Selwyn (2002a) reconsiders the career of the digital divide in terms of the economic, social and cultural capital that individuals and groups utilize and develop at a number of 'stages of the digital divide'; physical provision, 'effective' access, use, meaningful engagement, short-term outcomes and consequences. The consequential domains that he names, production, political, social, consumption and savings activity, draw upon the U.K. Centre for the Analysis of Social Exclusion's (CASE) definition of social exclusion in terms of a lack of participation in said domains (Burchardt et al. 1999). As such, Selwyn sets an agenda for digital divide research within this theorization of social exclusion, where the principal concern is to explore not just the extent, but the meaning of digital inclusion ${ }^{16}$.

Alternatively, Couldry (2002a) emphasizes a domain that is given little analytic attention in the CASE formulation of social inclusion, that of symbolic resources and symbolic production. He argues for a wider analytic agenda for researching the digital divide, mediated citizenship and 'the right to the word' (Melucci 1996: 228), stating that, 'if we want to think seriously about the digital divide in the broadest sense, we should think about the structure of participation (and non-participation) in symbolic production which the media themselves comprise' (p7). The current distribution of symbolic resources and concentration of traditional and new media production may not only be exclusive, but, drawing on Honneth's (1996) theorization of power struggles as involving moral conflicts over self-formation and recognition, Couldry 
argues that it may be that 'we are facing perhaps a "vacuum of recognition": a lack of spaces in which we might recognise each other as potential participants on anything that approximates to politics. If true, then this is both a problem for politics itself and another aspect of symbolic inequality in a world where a few are intensely recognized as agents in public space and the rest live in their shadow' (p8).

Though not explicitly concerned with symbolic production, allied calls for a relocation of digital divide policy into a rights-based discourse are developed by Mansell (2002), drawing on Sen's (1999) discussion of entitlement to 'capabilities'; by Fallis (2004), drawing on Rawls (1971) model of distributive justice to argue that the goal of digital divide policy should be an equitable distribution of knowledge; and by Colby (2001), who proposes a 'new First Amendment' argument for ending the digital divide ( $p 141$ ) based on 'a postmodern network that distributes the productive power of speech' ( $p 123)$. Murdock (2002: 24) similarly argues that 'access to the Internet has become a basic cultural right of $21^{\text {st }}$ century citizenship', while Gandy (2002) argues that the 'real digital divide' lies between models of network activity which view people as consumers or participating citizens.

Two recent books on the digital divide, with an empirical focus on community informatics, further emphasize a shift beyond earlier conceptions. In Technology and Social Inclusion: Rethinking the Digital Divide, Warschauer (2004) draws heavily on the work of Manuel Castells, arguing that 'the Internet .. is in effect becoming the electricity of the informational era' (Castells 2001, cited in Warschauer 2004: 29). Warschauer hence 'takes as a central premise that the ability to access, adapt, and create new knowledge using new information and communication technologies is critical to social inclusion in today's era' (p9). Whilst explicitly arguing that any theoretical framework should emphasize the 'social embeddedness of technology' and 'new institutionalism' (p202-10) rather than determinism or neutralism, he contends that the research agenda should address a 'technology for social inclusion approach' ( $p 213$ ) and that 'the overall policy challenge is not to overcome a 
digital divide but rather to expand access to and use of ICT for promoting social inclusion' (p211).

In Bridging the Digital Divide: Technology, Community and Public Policy, following a preface by Castells, Servon (2002) contends that "IT has instrumented the shift from an industrial age to a network age' (p1). She argues that 'technology can be a tool of inclusion or exclusion' (p232) and specifically points beyond ideas of access and the 'tech-fix' to argue for an agenda in which 'Community Technology Centers (CTCs) are key innovators' in creating "bridging social capital' youth is key .. altering pedagogy and curricula so that they can think and learn in new ways, ways that will serve them well as demands to adapt to new systems increase' (p225).

These analyses thus embody and explore the convergence of the 'information/network society' and 'inclusive society' discourses, which, as I detail in later chapters, have also come together in recent social policy formation on the digital divide (see also Phipps 2000, Selwyn 2002). In these two texts, there is certainly some acknowledgement of the necessity of thinking beyond the issues of access and technological determinism, and a focus instead on people's abilities to make use of technology in meaningful social practices.

However there is also an explicit aim of reorienting policy towards the goal of 'technology for social inclusion', based upon the effective and meaningful integration of technology into communities and institutions, and an empirical emphasis upon positive lessons learned from the study of technology access and training programs, particularly community technology centres. As such, the consequences of technology use, the connection between digital and social inclusion, are still predominantly understood as a promise to be further evaluated or realized, and rarely theorized in detail beyond invoking Castells' particular vision of the Information Age. 
Van Dijk (2005) outlines a more specifically theorized conceptual framework to attempt to understand the causes and consequences of the digital divide, 'based on an explicit theory of inequality in the information and network society'(p2). He draws on Tilly's (1999) relational theorization of inequality whose point of departure is neither the essences of individuals nor of particular social systems, but rather the ties and transactions between people, and in particular, the accretion of durable inequality into institutionalized categories via the distributive mechanism of opportunity hoarding ${ }^{18}$. For Van Dijk, 'special characteristics of information and communication technology' (p15), discussed in terms of the content and the form of contemporary information and communication networks, support this particular mechanism for the reproduction of relative inequality, such that network position and early adoption increasingly confer a strategic advantage for benefiting from further accumulation, mobility and opportunity in contemporary society.

In particular, relevant properties of the content include the information intensity of all activities' (p142), and the fact that information is both a primary and a positional good, essential for self-determination as well as dependent for its value upon the on the extent to which others desire it (p135-39). In terms of the properties of the network form, these include selection, 'continually, actors are assessed for their contribution to the network .. social networks and the network society are competitive by nature' ( $p 148-9)$; variation, "leading to the differentiation of positions within the network .. actors in networks try to vary their contacts, relationships, and information sources to acquire better opportunities of selection for survival .. thus the positions of actors in networks are not equal' ( 1 149-50); and differential mobility and speed, 'because those connected are linked in different ways and intensities, the capacity of people to transcend time and place in networks varies' ( $p 152)$.

Given this context of 'the character of the new media .. and the development of new types of society' (p183), the importance of the digital divide, conceptualized by Van Dijk in terms of pluralistic differences in 'motivational access, material access, skills access, and usage access', is clear: 
'The social consequences of the digital divide are understood as greater or less participation in several fields of society and as matters of social inclusion and exclusion .. not having access to ICTs will substantially diminish the chances of participation in all relevant fields of society' (2005: 177)

I do not intend to discuss Van Dijk's theoretical framework in any more detail here. He himself acknowledges that it is currently being made operational for empirical research and that its elaboration is very much an ongoing agenda, 'a large number of operational definitions of the abstract concepts developed have still to be made .. Data about relationships, ties and networks are very scarce. Most often, I have had to work with demographic data that are recorded in the tradition of methodological individualism .. as proxies to support the argument as far as I can' (p13-14).

The central point I wish to note is that his work on the digital divide relies upon a particular diagnosis of the specificity of the network form for its theoretical context, and network analysis for its methodological orientation. I will pursue these theoretical and analytic themes in the context of a detailed case study of academic discourse on the digital divide, focussing on the work of Manuel Castells, in Chapter 6.

To summarize, the digital divide was predominantly defined and measured in early scholarship in terms of demographic differences in Internet access. Furthermore, the consequential dimensions of such differences were largely undertheorized. Within more recent academic scholarship there has been a general reorientation of discussion of the digital divide, away from the prior dominance of the issue of access and towards the cultural-political concepts of participation, recognition, communicative entitlements, citizenship and particularly inclusion. Recent research agendas have specifically stressed the need to develop more explicitly theorized conceptual frameworks and engage with more sophisticated and subtle empirical methods to advance this work.

However, one significant lacuna throughout all this discussion of what the digital divide is, is that there has been no discursive analysis of what the 
digital divide' does in particular discursive domains. It is to this task that I now turn.

\section{Notes}

${ }^{1}$ This essay was a response to Searle's (1977), 'Reiterating the Differences; a Reply to Derrida', which was itself a response to 'Signature Event Context'.

${ }^{2}$ Cooper (1990) gives one illustration of an attempt to ground a sociological analysis, of organization, in ideas developed from Derrida's conception of discourse. He argues that the dominant mode of understanding 'organization' occurs in a structuralfunctional or systems approach and is 'by way of a fully present unity .. whose main epistemological prop is the asymmetrical frame or boundary' (p182). For Cooper, the statements of the body of work known as 'organization theory' (what he terms the 'organization of organization') are normally regarded as external to the organization, but may instead be thought of as supplementary in the dual Derridean sense:

'As an agent of supplementary production, the text includes itself in the structure it seeks to analyze and understand, thus creating undecideability .. the lack of surety forces theory to invent the means of its own realization' (1990: 197)

Building particularly on Derrida's conception of the play of differrance, embodying difference and deferral, Cooper instead goes on to develop an alternative conception of organization that concentrates on exploring 'intrinsic undecideability which can only be 'organized' or 'systematized' through an external force that is foreign to it' (p182).

3 Laclau (1996:59) considers that deconstruction and hegemony are two essential dimensions of a single theoretico-practical operation central to the recasting of social and political analysis.

4 Indeed, Levitas (1996) considers that the broad character of contemporary political discourse on social exclusion reflects the concerns of Durkheimian sociology. She argues that the model of social process embedded in contemporary political thought, the matrix through which the social world is viewed and which governs the paths of action which appear open to us, is Durkheimian in that its central concern is with how 
social solidarity and cohesion may be maintained under perceived pressures of disintegration.

${ }^{3}$ It is important to recognize that there are a number of different, 'soft' and 'hard', variants of technological determinism identified in the social studies of technology literature (see Jasanoff et al. 1995, Bijker 1995, Heap et al. 1995, Smith and Marx 1994). For example, Bimber (1994) identifies three different strands of technological determinism. In the normative approach, particular technologies are understood to embody specific norms (such as democracy or efficiency) which are automatically promoted through the use of the technology concerned, while other accounts stress the unintended consequences of the use of technology. Bimber contends that, while often included in broad characterizations of technological determinism, norm-centred and unintended consequences approaches are not really fully deterministic, as the use of technology suggests a mediating role for some social determination. Whereas in the nomological approach, 'technological developments occur according to some naturally given logic, which is not culturally or socially determined, and these developments force social adaptation and changes' (1994: 84). For Bimber then, the attribution of technological determinism should strictly be reserved for the nomological approach which sees technology as the sole determinant of social change.

${ }^{6}$ An alternative genealogy of determinist theorizing that is less regularly invoked would include the work of McLuhan, Virilio and Kittler. In particular, Kittler (1999) is concerned with the technologizing, and lately the digitalization, of discourse. He contends that the 'mediality' of discursive practices necessitates an extension of their analysis beyond Foucault's hegemony of written language and furthermore that, following Nietzsche, theoretical and philosophical speculations themselves are determined by the 'commerce' between bodies and media technologies.

${ }^{7}$ (Latour 1993: 124) describes translation as follows:

'Thanks to translation we do not have to begin our analysis with fixed borders and assigned interests. Instead we can follow the way in which actant $B$ attributes a fixed border to actant $A$, the way in which $B$ assigns interests or goals to $A$.. and finally the distribution of responsibility between $A$ and $B$ for their joint action. In a universe of innovations solely defined by the associations and substitutions of actants, and of actants solely defined by the multiplicity of inventions in which they conspire, the 
translation operation becomes the essential principle of composition, of linkage, of recruitment, and of enrolment.'

Callon (1991: 134) defines an intermediary as, 'anything that passes between actors which defines the relationship between them' which can include 'scientific articles, computer software, disciplined human bodies, technical artefacts, instruments, contracts and money'. These intermediaries order and form the medium of the network they describe (Michael 2000: 24).

${ }^{8}$ It should be noted that in his most recent work, Latour (2005: 128-133) proposes a new twist on any literal reading of the term network in suggesting that it should be understood as a 'benchmark of literary quality': 'A network is not what is represented in the text, but what readies the text to take the relay of actors as mediators' (2005: 131).

${ }^{9}$ For example, Servon (2002: 2) states that 'The US Government discovered the Digital Divide in 1995'. For a fuller discussion of claims as to the origin of the term, see Gunkel (2003), Mossberger, Tolbert and Stansbury (2003) and Servon (2002: 24-25).

${ }^{10}$ Falling Through The Net I (FTTN I), subtitled 'A Survey of the 'Have Nots' in Rural and Urban America' was specifically commissioned with a remit to collect data for evaluating the U.S. telecommunications policy of providing 'Universal Service' of standard telephony to households. Simultaneously, it collected data on modem and computer ownership, according to various social stratifications; region, rural/urban/city central, income, 'race/origin', age and educational attainment (Dept of Commerce 1995).

FTTN II, commissioned in 1997 and subtitled 'More Data on the Digital Divide' (Dept of Commerce 1998), had an expanded remit to collect data relevant to the Clinton administration's policy concern with connection to the 'Information Superhighway', and hence updated the original report's figures and additionally obtained figures on e-mail use and Internet use in households, as well as collecting demographic data on the 'household type'. It also introduced 'the Digital Divide' into policy discourse, a term which does not appear in FTTN I. 
FTTN III, subtitled 'Defining the Digital Divide', (Dept of Commerce 1999) repeated the FTTN II analyses and further expanded these to analyze Internet use outside the home, hence collecting individual as well as household data, including demographic data on gender. The next iteration, FTTN IV, subtitled 'Towards Digital Inclusion', (Dept of Commerce 2000) dropped the collection of standard telephony data to concentrate on individual and household Internet access, including for the first time, high-speed internet access (via cable, DSL, ISDN and wireless), as well as adding disability to the previous list of demographic criteria that data were analysed by.

The final report in the series, 'A Nation Online' (Dept of Commerce 2002), discontinues with the FTTN prefix and is thus rhetorically in line with the sudden discontinuation by the Bush administration in 2002 of the funding of Community Technology Centres initiated by the previous administration.

"Access was a central motif in sociological, social policy, and popular discussions of technology in the late 1990s. For example, 'Society on the Line', Dutton's (1999) report on the ESRC Programme on Information and Communication Technologies (PICT) proposes an organizing concept of tele-access, how ICTs shape access to information and other social \& economic resources, as the key to understanding contemporary society. Rifkin (2000) defines the coming epoch as 'The Age of Access', where ownership will become increasingly devalued and outsourced by the 'experience industries' of 'hypercapitalism', in favour of controlling access to experiences of cultural life.

12 This process of accumulation of capital has been previously referred to by Merton (1968) as 'the Matthew Effect', "For to everyone who has, more shall be given" (Matthew 25: 29, New American Bible). As van Dijk (2005: 126) notes, this resonates with the classic knowledge gap hypothesis, a precursor to the digital divide debate: "As the diffusion of mass media information into a social system increases, segments of the population with a higher socio-economic status tend to acquire this information at a faster rate than the lower status segments" (Tichenor et al. 1970).

${ }^{13}$ For example, the UCLA Internet Project, which has produced annual surveys in the U.S. since 2000, and the Oxford Internet Surveys, biannual since 2003, both contribute to the World Internet Project which currently surveys 18 countries worldwide and is sponsored by the likes of AOL, Microsoft, Disney, Sony and Pacific 
Bell. These surveys have attempted to address some of the perceived inadequacies of previous survey work by collecting longitudinal data, standardizing measures across countries, and addressing issues beyond access, such as the quality of Internet use and reasons for non-use. See www.digitalcenter.org, www.oil.ox.ac.uk, www.worldinternetproject.net respectively for details and reports.

14 This can be considered as one element of a wider discourse, centred on the detailed power/knowledge of the Internet user and particularly addressing the imperatives of corporate prediction, that is enabled by the global extension of a surveillant assemblage of identification \& authentication and the development of sophisticated tools of data mining \& modelling (Lyon 1999).

is This market orientation and consumer-led understanding towards technological diffusion was also expressed by the new Chairman of the U.S. Federal Communications Commission, Michael K. Powell, in 2001. According to the New York Times (Labaton, $7^{\text {th }}$ Feb 2001), Powell "said he thought 'digital divide' was a dangerous phrase because it could be used to justify governmental entitlement programs that guaranteed poor people cheaper access to new technology. 'I think there is a Mercedes divide', he said, 'l'd like to have one. I can't afford one." Since the publication of $A$ Nation Online (NTIA 2002), the Bush Administration has cancelled many federal funds which were initiated during the Clinton administration and dedicated to the public development of new media infrastructure and skills, notably the Computer Technology Centres (CTC) program, and the Technology Opportunities Program (TOP). For a fuller discussion of U.S. digital divide policy, see Van Dijk (2005: 192-94). For a critique of the view that access to information technology will reach a socially optimal level as a result of the operation of the free market, see Fallis (2004: 2-3).

16 Academic work in the 1990s whose central concern was the theory and governance of social exclusion paid limited attention to its relationship to technology. For example, in two key theoretical syntheses, Social Exclusion (Byrne 1999) and The Exclusive Society (Young 1999), technology is not given much more than a cursory mention in the context of post-Fordist transformations in production. Similarly, in two recent edited collections on social inclusion (Percy-Smith (ed.) 2000, Askonas and Stewart (eds.) 2000), only one chapter (Sanderson 2000) makes any reference to technology, discussing the regulation of access to utilities. In the more 
empirically grounded approaches to measuring social exclusion by CASE (e.g. Burchardt et al. 1999), there is likewise a lacuna concerning technology, while for the other major attempt to quantify social exclusion via the Millennium Survey on Poverty and Social Exclusion (Gordon et al. 2000), the question concerning technology occurs as one of ownership of domestic technologies such as telephones, televisions, mobiles, PCs.

17 Servon draws on Gittell and Vidal's (1998) distinction between 'bonding' and bridging' social capital 'to distinguish between the kind of social capital that helps people to get by (bonding) and the kind of social capital that helps people to get ahead (bridging)' (2002: 224)

18 Tilly (1999: 91) defines opportunity hoarding as 'when members of a categorically bounded network acquire access to a resource that is valuable, renewable, subject to monopoly, supportive of network activities, and enhanced by the network's modus operandi, network members regularly hoard their access to the resource, creating beliefs and practices that sustain their control' 


\section{$\square \square \square$ Chapter 3.}

\section{UK Government Discourse on The Digital Divide}

\section{$\underline{3.1 \text { Introduction }}$}

One of the dominant themes of political discourse in the UK and other industrialized countries at the end of the twentieth century was a renewed wave of interest in the 'impacts' and promises of technological change, and in particular an emphasis on the importance of information and communications technology for economic development in the 'information age' (Preston 2001). Alongside this renewed concern with technology, political debate in the UK since the 1980s has also been characterized by the increasing centrality of the issue of 'social exclusion' (Levitas 1998). In particular, the formation of the inter-departmental Social Exclusion Unit by the New Labour administration in 1997 officially embodied this emerging concern with developing a 'socially inclusive' policy agenda.

The focus of this chapter is the convergence of these 'information society' and 'inclusive society' discourses in contemporary UK social policy. Information and communications technology has recently become seen as a key means through which the UK government may address the issue of social exclusion. Indeed, this viewpoint has been rapidly instantiated into a multi-billion pound policy agenda, involving the initiation and reorientation of a number of diverse initiatives from various government departments, often branded under the umbrella term of 'UK Online' (Selwyn 2002).

My concern in this chapter is to examine this emerging policy agenda aimed at developing the use of ICTs for socially inclusive purposes. To this end, I will focus upon a key government report that underpins the discursive shaping of this agenda, 'Closing the Digital Divide: information and communication technologies in deprived areas' (Policy Action Team 15, 2000; hereafter 
CtDD). The publication of CtDD was generally received positively by the mass media and specialist IT media as a timely engagement with an important issue. Even opinion pieces which went beyond the straight reportage of its publication, such as Victor Keenan's 'Second Sight' piece in The Guardian 7 Sept 2000, generally accepted many of the terms ('the bare statistics of the digital divide are now fairly well known') and arguments ('knowledge itself becomes the source of competitive advantage') rehearsed in the CtDD report. As yet there has been limited critical analysis of the underpinnings of this policy agenda, within academia or beyond. ${ }^{1}$

My primary objective in analyzing this report is to critically examine the understanding of the relationship between technology and exclusion that is discursively constructed and to consider how this structures the parameters of future policy intervention in this area. In addition, the intention is to critically interrogate the text for the wider framework of assumptions upon which it both relies and which it renews, and to examine their wider political significance.

The understandings of technology and exclusion constructed and legitimated in this report will thus be the focus of some scrutiny in this chapter, but the status and structure of the report requires some initial discussion. The 1998 Social Exclusion Unit report, 'Bringing Britain Together: a national strategy for neighbourhood renewal', recommended that eighteen Policy Action Teams (PATs) be set up to undertake an intensive programme of policy development, focussing on the broad theme of neighbourhood renewal in deprived areas. Each PAT had a specific remit within this overall programme, and 'Closing the Digital Divide' is the final report of PAT15 on Information and Communications Technology. As such, CtDD functions principally as an agenda-setting and promotional document whose broad recommendations inform the Social Exclusion Unit national strategy for neighbourhood renewal, as well as being considered autonomously by individual Departments for translation into specific policies and initiatives. 
The structure of CtDD is as follows:

Foreword (1 page)

Executive Summary (5 pages)

1) Introduction (4 pages)

2) Why are ICTs Important? (11 pages)

3) The current take up of ICTs (4 pages)

4) Current Provision, Barriers and Lessons Learned (25 pages)

5) Black and Ethnic Minority Groups (4 pages)

6) Recommendations (7 pages)

The initial organization of the document, with a quotable Foreword immediately followed by a brief Executive Summary, is thus specifically oriented towards a public relations context, and the management of its reception and dissemination by journalists and other interested parties.

The sequence of the substantive chapters of the report then constructs a straightforward narrative. Chapter Two poses the rhetorical question, 'Why are ICTs Important?' and concludes by constructing a scenario, 'The Vision', which highlights the potential importance of ICTs. Chapter Three then assesses 'The current take up of ICTs'. Chapter Four, 'Current Provision, Barriers and Lessons Learned', is concerned with the transition between current take up of Chapter Three and the vision of Chapter Two, and is organized around the ideas of 'gaps in provision' and 'barriers'. There follows a brief discussion of 'Black and Ethnic Minority Groups' in Chapter Five which concentrates on 'language needs' as a specific barrier in using ICTs. Finally, it is proposed that specific barriers may be 'overcome' through the 'Recommendations' of the concluding chapter. 


\title{
3.2 Technology
}

A key motif in CtDD is that Information and Communication Technologies (ICTs) are represented as autonomously determining a fundamental transformation of society. Typically this transformation is described in the present progressive tense, as an ongoing process of fast-moving and radical change that has begun and will inevitably continue into the future. Change is constructed as radical, unavoidable and technologically determined.

The main supplement to representing ICTs as the responsible agents in this scenario occurs via a bizarre teleology whereby a distinct emerging state of society, most commonly named the Information Age (although various aliases such as the Information Society, the learning society and the knowledge economy are also used in the document) is itself the cause of societal transformation, of its own emergence. Thus the Foreword to CtDD begins:

\begin{abstract}
Information and Communication Technologies (ICTs) and the emerging Information Age are transforming our society. The Information Age is changing how we work, how we learn, how we spend our free time and how we interact with one other. Not since the industrial revolution has new technology had such a fundamental effect on how we live. The old barriers of distance and time are being broken down. ICTs are driving down costs, improving efficiency and creating a climate of innovation, with competitiveness moving from the national to the global level. The new technologies are challenging existing methods of education, and give us the potential for true lifelong learning. As old jobs are becoming obsolete, new jobs are being created. It is a truly exciting time - and the pace of change is phenomenal. (CtDD: Foreword)
\end{abstract}

From the very opening paragraph then, there is a causal and symbolic conflation of ICTs and the Information Age. Throughout the document from here on, it is ICTs themselves, rather than any associated activity, that serve as the symbolic marker of the Information Age. The fact that such terms are interchanged frictionlessly only adds to the lack of clarity of this analysis of a putative societal transformation. 
Fairclough (2000) notes that nominalisations are a favourite rhetorical device of New Labour. In particular, the common use of 'change' as a noun rather than a verb backgrounds detailed questions of agency and causality, of who or what causes such change. Rather, change is understood as an external and inevitable force, as if it possesses social agency itself. As Chilton and Schnaffer (1997) argue, nominalizations assert that the world changes independently and make it easier to avoid contentious issues of blame and responsibility.

In CtDD, it is not simply the term 'change' itself that is nominalized, but ICTs and the Information Age that are represented as autonomous external forces, beyond governmental design or control. The Information Age is not discussed as a complex set of processes and potential outcomes, but is rather represented as a causal entity in other ongoing developments. Its inevitability is rhetorically enhanced by this causal status, but is particularly buttressed by being presented as something beyond us, that affects how we work and transforms our society, yet whose developmental trajectory is not itself open to social shaping.

Fairclough (2000) additionally highlights that the collocation of words alongside the term 'social exclusion' can influence its interpretation as a nominalized state rather than an ongoing process. ${ }^{2}$ In CtDD, 'the Digital Divide' itself is always referred to as something to be closed (as in the title 'Closing the Digital Divide') or to be tackled ('we are determined to tackle the Digital Divide', CtDD: 1). In both formulations, there is a clear nominalization, the Digital Divide is an already existing phenomenon and it is to be tackled, or closed, but not, for example, prevented. Although 'preventing the Digital Divide' would be perfectly sensible grammatically, the discursive emphasis would shift towards the exposition of ongoing processes of polarization, rather than dealing with a particular one-off state.

In the technologically determinist vision of CtDD then, the parameters of policy intervention are immediately restricted to having to cope with the 'realities' of ICTs and the Information Age, in particular the 'climate of innovation, with 
competitiveness moving from the national to the global level' (CtDD: Foreword). As Goodwin and Spittle (2002) note, such a discourse of technological determinism, where governments are understood as unable to change the technologically determined economic ground rules and their responsibility is hence limited to attempting to react to an inevitable situation that they had no hand in creating, has been particularly successful in underpinning the neo-liberal agenda of global telecommunications deregulation.

More generally, Preston (2001: 17) argues that 'the most excited descriptions of the shiny new technologies are almost universally accompanied by fundamentally conservative and strikingly old-fashioned sets of policy prescriptions and political values .. these presumed technological logics are frequently interlaced (explicitly or implicitly) with strong prescriptions to embrace the 'invisible hand' of the market or the benign god of competition'. The rhetorical invocation of an inevitable Information Age then elides the need for a detailed justification of actual policy choices, rather presenting policy 'as if it were directly dictated by matters of fact and deflect[ing] consideration of values, choices and the social, moral and political responsibility for such choices' (Lemke 1995: 58). In a discussion of the policy drive for Electronic Service Delivery (ESD), Hudson (2003: 283-4) argues that:

'Blair's government is being somewhat Janus faced here, for its own plans for the development of ESD demonstrate a clear understanding of the fact that there is nothing automatic about technological change or the direction it takes. Indeed, in attempting to make its services available electronically, it is aware that change in fact needs to be forcefully directed - hence the existence of strict targets, the regular monitoring of departmental progress, tied funds and numerous information age champions'

I wish to consider what support, if any, is mobilized to legitimate the assertion of the Information Age. The only place in CtDD where any external authority is referenced to specifically support this claim occurs in the opening paragraph of the Introduction: 
The rapid spread of information and communication technologies (ICTs) is changing many aspects of modern life. Economic commentators such as Alvin Toffler call this the third, or 'Information' revolution. It is seen as a turning point, a major leap for society equivalent to the Industrial revolution. (CtDD: 7)

The footnotes to this paragraph reference two external texts, The Third Wave (Toffler 1980) and the Performance and Innovation Unit (PIU) report, ecommerce@its best.uk (PIU, 1999). The relevant section in the PIU report is an identically placed introductory paragraph which similarly claims that, 'Leading economic commentators, such as Alvin Toffler, have predicted a third 'revolution' - the information 'revolution' - carrying society forward in another major leap equivalent to the earlier agrarian and industrial advances' (PIU, 1999: 7).

There are several academic versions of the 'Information Society' thesis, and one way of characterizing these analyses is the extent to which they stress continuity or discontinuity from previous societies (Webster 2002). The selection of Toffler as sole intellectual authority, as the summation provided of his work suggests, emphasizes the revolutionary discontinuity of the emerging Information Age from previous societies, a shift to a qualitatively different form of social organization rather than the continuity of established social forces. ${ }^{3}$

This emphasis on discontinuity, discursively replicated throughout the document in statements such as, 'as old jobs are becoming obsolete, and new jobs are being created' (CtDD: Foreword, my italics), is in keeping with the key New Labour theme of 'modernization' (Driver and Martell, 1998) and in particular, the desire to present analyses and policies themselves as innovative, as a rupture with those carried out by previous administrations. Hudson (2003: 281) contends that:

The significance of the notion of an information society to the Third Way should not be underestimated. The discontinuities with the past that it suggests are crucial in framing the Third Way's general standpoint, for it allows New Labour to craft a narrative that presents the abandonment of traditional egalitarian policies 
as a necessary modernization of values; indeed, the only viable form of egalitarianism in the new world order.

Apart from this brief reference to Toffler, the fact that no external support is deemed necessary throughout the document to buttress the specific claim of an Information Age is significant in itself. It suggests and reinforces the taken for granted nature of such a claim, that it can successfully draw upon an understanding of radical, technologically determined social change that is well established within society.

The answer to the following chapter's nominal question, 'Chapter 2, Why are ICTs Important?' has thus already been established as self-evident - because we are in the Information Age. Nonetheless, it is worth highlighting how this assertion of importance is further discursively buttressed within this chapter. The discussion is organized around six key areas 'where ICTs are having, or will have, an impact' (CtDD: 12): Economic Impact, Employment, Education, Health, Modernising Government, and finally Entertainment, Self-Discovery and Creativity. Of the eighteen separate references cited in this overall discussion, twelve refer to other Whitehall publications such as, 'Skills for the Information Age' (DfEE 1999) and, 'Our Information Age: the Government's Vision' (Central Office of Information 1998). ${ }^{4}$

The discussion is thus highly circumscribed, drawing summarily and almost exclusively on other government documents to reach the conclusion that:

The UK government has recognized the impact that ICTs will have at every level of society. (CtDD: 11 my italics)

In spite of the interrogative in the chapter title then, the grammatical mood of the chapter, and indeed the whole report, is distinctly set as imperative. As Woolgar (2002: 8) notes, the 'discourse of the definite' pervades talk of new technology across numerous varied constituencies, from the suppliers and advertisers who emphasize particular beneficial effects to the media experts and consultants who wish to offer certainty in the midst of uncertainty. I argue 
here that this self-referential discursive strategy is one particular source of such confidence in the definitive effects of technology, and the intertextual web of government documents one of the constituencies within which such a discourse takes hold and flourishes. ${ }^{5}$

The transformative and all-pervasive impact of the Information Age/lCTs is the dominant motif in CtDD then. Furthermore, given that such impacts are understood as inevitable and autonomous, they are commonly represented in the dualistic terms of an external threat/opportunity: 'ICTs can pose both threats and opportunities' (CtDD: 66). As Goodwin and Spittle (2002: 235) note, such a discourse 'acts to reduce the complexities surrounding the introduction of new technologies to a choice between a distinct set of binary oppositions'. The reader may be 'seduced by the social simplifications of utopian romance' or less frequently, disturbed by dystopian nightmares (Kling 1994: 168).

Importantly though, the amount of discussion actually given to the threats of the Information Age in CtDD is so negligible in comparison to the discussion of the potential opportunities afforded that such a choice is, to all intents and purposes, non-existent. In fact the only real threat of note identified is that 'we run the risk of leaving behind the people living in our poorest neighbourhoods' (CtDD: Foreword). This is because in these areas, "access to the benefits of the 'Information revolution' is often more difficult because of a lack of awareness, skills or opportunities" (CtDD: 7 ). In other words, the only real threat of the Information Age is not recognizing or having access to such benefits or opportunities.

Following the discussion of the six areas of impact in Chapter 2, the following free-floating text box is presented: 
Although the contents of this text box are attributed to a non-governmental source, the Community Development Foundation, no actual reference is given, nor is there any further information in the chapter about the context in which such aggregated conclusions were reached, which 'people' used which 'ICTs' and so on. As such, these arguments cannot be subject to critical scrutiny. As Miettenen (2002: 31) argues of such text boxes, 'detached from the context of their production and, partly, from the text themselves, they tend to become free standing 'knowledge windows' .. instead of constituting an integral part of the text, they supply examples, illuminate and accompany the main line of argument of documents, giving them face validity by referring to the world of science and research'.

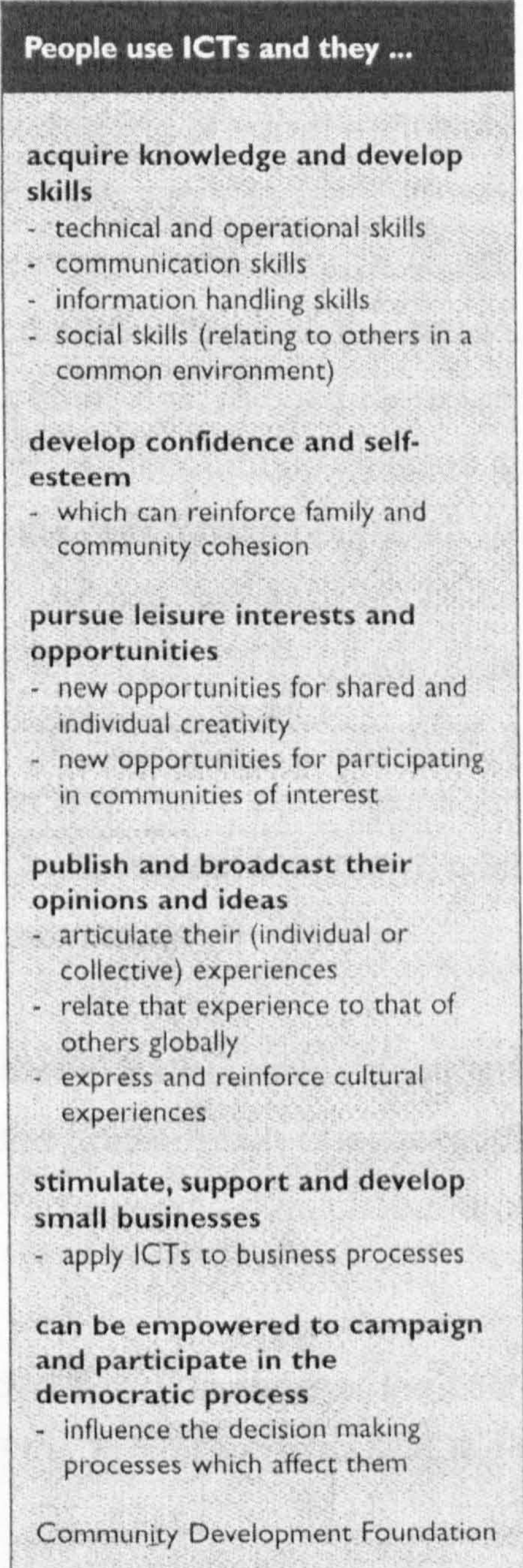

Figure 3.1 Text Box (CtDD: 15)

Such text boxes are a common discursive device in CtDD, particularly used to visually abstract 'good practice' from the singular vignette or anecdotal description. In the case discussed here, the entirely unexplicated nature of the contents, the elimination of all qualifying 'modalities' (Latour and Woolgar 1979) from the claims, and the visual distinctiveness of the 'knowledge window', all lend further discursive support to the overarching assertion of the chapter, the benefits of ICTs. 


\subsection{Social Exclusion}

I will now pay specific attention to the understanding of social exclusion that is articulated within CtDD. CtDD draws on the key Social Exclusion Unit document, 'National Strategy for Neighbourhood Renewal ' (SEU 2000). A thorough examination of this strategy document is beyond the remit of this chapter, but the politically important concept that is developed there, and then taken up within CtDD, is that of the 'deprived neighbourhood' (aliases such as the 'low-income neighbourhood' ( $p 16)$ or the 'poor neighbourhood' ( $p 7)$ are also used in CtDD). ${ }^{6}$ It is important initially to note that such attributions and personifications do not occur in the description of people in CtDD. In contrast to the potentially morally forceful constructions of poor or deprived people, CtDD refers to the less problematic, 'people who live in poor neighbourhoods' (p12) or 'socially excluded adults' (p45). As Goodwin (1995) notes, the concern is not with 'poor people' but with 'poor places'.

Throughout CtDD, the 'deprived neighbourhood' is discursively contrasted with 'the rest of the UK', whether implicitly in the juxtaposition of subsections 2.1. 'Why ICTs in the UK?' with 2.2. 'Why ICTs in deprived neighbourhoods?' or explicitly in statements such as:

Much of the UK is well placed to take advantage .. In some of the poorest neighbourhoods .. access to the benefits of the 'Information revolution' is often more difficult. (CtDD: 7)

As Watt and Jacobs (2000: 18) argue, 'if the emphasis shifts to looking at poor places within an otherwise affluent country, the attention also shifts to what is peculiar to those poor neighbourhoods.' It is not simply the concentration on the 'negative' deprived pole per se that is important to note here, but the discursive contrast that it exists in. The lack of analytic attention to the 'rest of the UK' means that any attempt to understand wider processes of social polarization and inequalities throughout society, a primary reference point for previous centre-left politics, is largely disavowed. To this end, it is also 
important to note that there is no discussion or theorization of technological elites in CtDD.

A presupposition of moral and cultural difference in certain neighbourhoods is clearly signalled in the initial scoping paper for CtDD in stating that the initiative to increase the availability and take up of ICTs for people living in poor neighbourhoods' (CtDD: Annex A, p64) is one that 'requires cultural change on a significant level' (CtDD: Annex $A, p 66){ }^{7}$ Such an understanding of moral and cultural difference is also implicit in the prominence given to reporting the measurement of 'attitudes to ICTs' in CtDD, and the propensity to summarize such attitudinal data in the language of individual psychodynamics:

there is higher resistance to the use of new technologies among people who receive benefits than the general population (CtDD: 24 , my italics)

Indeed, the goal of CtDD is understood as not just discussing these attitudes, but contributing to attitude change through promoting specific arguments:

'The main tasks were seen as:

- Demonstrating that access to ICTs can make a difference and a positive contribution to neighbourhood renewal

- Understanding and proposing solutions to the barriers for individuals and community groups in adopting and exploiting ICTs in their own context, addressing their own interests, at their own pace

- Promoting the argument that the necessary skills are attainable, and not permanently dependent on other factors such as wealth and education

- Understanding the structural barriers preventing access to ICTs and promoting solutions' (CtDD: 8-9)

In Levitas' (1998) terminology, a discursive emphasis upon cultural distinctiveness and attitudinal factors over and above wider structural inequality, exemplified in the ordering of the tasks of CtDD indicated above, draws upon a Moral Underclass Discourse (MUD) of social exclusion rather 
than a Redistributionist Discourse (RED). Indeed, not only does CtDD generally offer minimal discussion of the growing polarization of wealth and income that has been such a marked feature of the UK and throughout the industrialized world in the past two decades, the continuing importance of 'other factors such as wealth and education' as significant 'barriers' is explicitly disavowed in the excerpt above. Rather, discursive prominence is again given to the theme of access to ICTs in isolation from any connection to the broader social relations of contemporary capitalism.

In addition, the understanding of social exclusion developed throughout CtDD draws heavily upon what Levitas (1988) terms a Social Integrationist Discourse (SID) of social exclusion. Here the individual assumes discursive centrality and the emphasis is upon individual responsibility for attaining social inclusion, primarily through achieving job security in paid work.

Thus in Section 2.3 of CtDD, What Can ICTs Do?, there are ostensibly three positive responses given to this question, summarized below, and then discussed in three separate sub-sections:

The Policy Action Team found many positive examples: skill development, entering employment and self-employment; self-development and creativity; and helping communities work. (CtDD: 17)

The first and largest sub-section, Skills Development, Jobs and SelfEmployment most obviously falls into the social integrationist agenda, stressing both the opportunities for those with specific skills in the specialist ICT sector, as well as the overall importance of developing individual ICT skills to improve general 'employability' in the Information Age.

The second response, Self-Development and Creativity initially states that 'ICTs can bring more than just jobs' (CtDD: 19), and describes a particular example of an initiative, the Artimedia project, which demonstrates that 'ICTs can bring out pride and self-respect in very deprived sections of society' (ibid). However, the narrative is one where such goals are not conceived of as ends 
in themselves, but as stepping stones towards a vocational end. Creativity is thus narrowly understood, and the ultimate goal of providing ICTs is that this 'can help people to begin to interact with others and start to develop confidence to move on to other activities'. (ibid, my italics). In the case of Artimedia, this means that they hope to integrate them first into the community, and then to a more commercial basis in the labour market, developing progressional, maintainable skills' (ibid).

Similarly, the third and final response, Helping Communities Work concludes with the broad statement that 'ICTs can stimulate community involvement in a range of activities leading to greater social cohesion, reduced welfare dependency, educational opportunities and economic development' (CtDD: 20). 'The Vision' then is of 'neighbourhoods where awareness and the use of ICTs can lead to greater levels of community involvement, confidence and further development opportunities which can enhance employment, enterprise and personal activities' (CtDD: 21).

In such vague formulations of techno-communitarianism, neighbourhood and community simply function as exchangeable markers of positive moral regulation and social cohesion. ${ }^{8}$ However, ultimately the conjunction of ICTs, community and confidence is understood as a conduit, and however many imprecise invocations of 'other activities' and 'further development opportunities' are made, the important end point is understood as social integration through the individual achievement of job security.

The dominant conception of the individual in CtDD is not, as noted previously, the potentially morally forceful construction of e.g. a poor or deprived person. Rather it is somebody with the potential for transformation, a potential that can be realised if they overcome their difficulties. Crucially, these difficulties are not typically understood as poverty or deprivation per se, but as the personal and attitudinal problems associated with deprivation which could inhibit the securing of paid work: 'the PAT found many examples of people in deprived neighbourhoods who had low self-confidence and low self-esteem due to factors including unemployment, lack of basic skills, language problems, and 
responsibilities for caring' (CtDD: 19, my italics). Individual transformation may then be realised through connection with ICTs:

ICTs are important because they have a key role to play in helping people in deprived neighbourhoods overcome some of the major obstacles they face. (CtDD: 17)

As Barry (2001: 210) notes, the motif of potential has considerable currency in contemporary discourses of the relation between the technological and social:

Today the idea of political revolution is seldom spoken of, except as an historical event. But perhaps more than ever before technology is expected to carry the promise, or the threat, of radical social and political change in the future. Technical change is reckoned to be innovative. By contrast, the social and political realm is thought to be a source of resistance, of inertia. The relation between the two is often represented using the metaphor of potential. Technologies have certain potentials. But in practice all kinds of social, cultural and economic factors prevent this potential being achieved .. Society fails to realise the potential of technology, and therefore to realise its own potential.

Indeed, as detailed earlier, at a macro level the narrative structure of CtDD is similarly one of identifying and overcoming the 'barriers' that prevent the potential of the Information Age from being expressed by current society. Furthermore, as detailed above, a narrative of overcoming personal and attitudinal 'obstacles', such as the fact that 'the target audience lacks awareness of the potential of ICTs and they do not appreciate the benefits they offer' (CtDD: 29), additionally organizes the understanding of individual transformation in CtDD. As such, individual transformation is discursively constructed as a synecdoche for societal transformation in CtDD.

This narrative of individualistic self-discovery through connection with ICTs is continually reinforced in CtDD through the presentation of numerous vignettes and anecdotal descriptions of specific projects that illustrate 'good practice'. For example: 
At the New Start Project in Cardiff, a group of older Muslim women took sewing classes. One afternoon a computer happened to be on a desk in a corner of the room and they tried it out during their break. They found that they could access patterns through the Internet. Interest was generated and three of the women have now developed a network of over 300 women and children. (CtDD: 21, my italics)

Indeed, the story of self-discovery above is rhetorically buttressed through the use of fairytale conventions in its narration. There are forty-three such brief vignettes in CtDD, the majority concentrating on one specific achievement of an ICT project, such as overcoming fear of ICTs (Landport Web, p33) or members' success in gaining employment (TS2K, p36), rather than providing any systematic or consistent assessment of such initiatives. ${ }^{9}$ Furthermore, this narrative of individual transformation is exemplified in the motif of the ICT champion, a figure whose identification, training and accreditation in ICT skills, leadership and entrepreneurship is given particular attention in CtDD's recommendations.

Given that 'new technologies are challenging existing methods of education, and give us the potential for true lifelong learning' (CtDD: 1 ), one of the key vehicles of individual transformation that is emphasized in CtDD is connection to the 'Learning Technology Infrastructure':

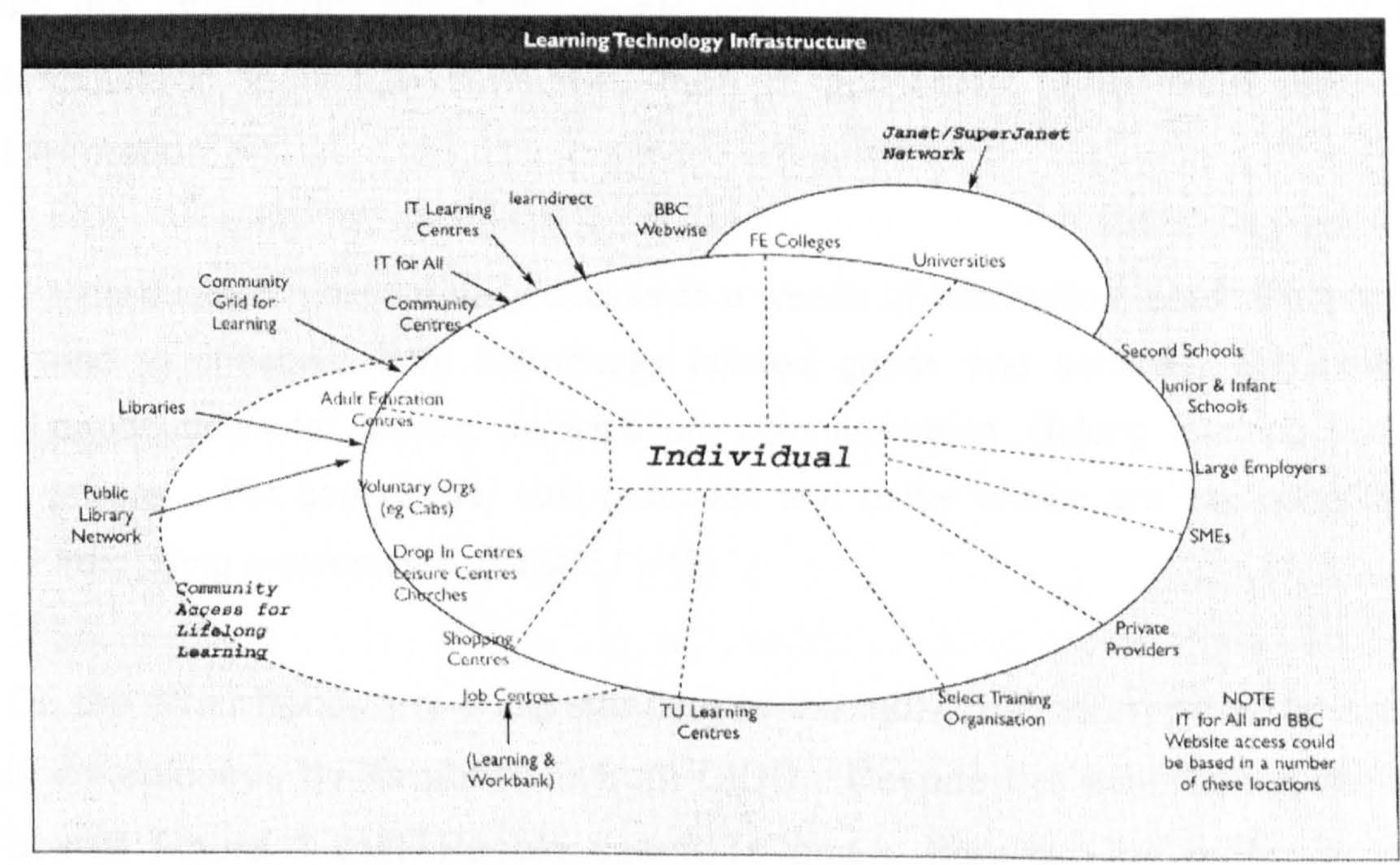

Figure 3.2 Learning Technology Infrastructure (CtDD: 46) 
This theme is visually represented in the only illustration in CtDD, reproduced in Figure 2. While this is undoubtedly a highly confusing graphic, it offers an abstract diagram of inclusion that is centred on the 'Individual', a nebulous figure suspended in a bare web of proliferating choices and potential connections that can be made. Despite this, there is little detail of the learning that such choice will facilitate in CtDD. Indeed, as Selwyn notes:

the emphasis throughout all the current education and training elements of the ICT drive [is] on the use of technology-based lifelong learning for developing workbased, predominantly technological skills, as opposed to the use of technology for general learning .. very little is said about the types of learning that ICT-based education will be used for. (2002: 14)

There are some further opportunities for the individual connecting to ICT that are emphasized in CtDD and worth commenting on. Principal among these, and subordinating any idea of becoming a creative producer of knowledge, is the figure of the individual as an empowered consumer. This transformed consumer is described as potentially taking advantage of the bargain tariffs and prices offered 'as the role of physical intermediaries is supplanted by network intermediaries' ( $p 12)$, as benefiting from the vastly increased choice of lines and titles offered by Internet retailers ( $p 12$ ), and ultimately as able to view 'all the multimedia activities people want' (p32). The key activity for this empowered individual consumer then is accessing rather than producing information:

Individuals can expect easy access to a wealth of information, entertainment, and to cheaper, more individually tailored goods and services, with new opportunities for choice, participation, communication, lifelong learning and leisure .. For consumers, cost reduction and better choice are key benefits from using e-commerce. (CtDD: 11-12)

On the other hand, any understanding of the individual as empowered citizen is conspicuous by its absence from CtDD. Despite the assertion in the text box of Figure 1 that 'People use ICTs and .. they can be empowered to campaign and participate in the democratic process' (CtDD: 15), there is, as 
mentioned, no explication or further analysis of this claim in CtDD. Indeed, the only mention of citizenship in CtDD occurs in an annexed discussion of the 'Modernizing Government' strategy that 'will bring Government services to the citizen, rather than demanding that business and the citizen come to Government' (CtDD: Annex E, p71). Discursive prominence is thus clearly given to the vision of the individual as a potentially transformed consumer, along with a corresponding shift in emphasis from universal service to the increased choice offered by universal access: 'Ultimately the key should be personal choice and equal access for all' (CtDD: 21).

In line with much of the work discussed in the previous chapter, the concept of access (often operationalized simply as differential access to the Internet in the surveys commissioned and referred to) dominates CtDD's overall assessment of 'the digital divide' in the UK in Chapters $3 \& 4$, 'Current Uptake of ICTs' and 'Current Provision, Barriers and Lessons Learned'. Though the available data on deprived neighbourhoods is acknowledged as being limited in scope, the validity of access to ICTs (rather than any more complex measure of the use of ICTs) as the key indicator of difference is not in any doubt.

\subsection{The Reciprocity of the Social and the Economic in the Information Age}

I have argued in the previous sections that CtDD constructs an understanding of technology as an autonomous force determining a radical transformation of both society and economy. The fundamental understanding of the relationship between the social and the economic in the technologically determined Information Age is thus as follows:

To prosper nationally and to compete globally, we need to empower people at the local level to become active participants in society. Social inclusion and economic success are not mutually exclusive - they are mutually reinforcing. (CtDD: Foreword) 
Competitiveness depends on the skills and creativity of the whole workforce. The social arguments for an inclusive information society reinforce the economic ones and vice versa. (CtDD: 2 )

The arguments for social inclusion and for economic development in the Information Age are mutually re-enforcing (sic) (CtDD: 16) ${ }^{10}$

The measures necessary to strengthen national economic competitiveness in the Information Age are thus discursively understood as being equivalent to those for achieving social inclusion. Ensuring that the nation state does not get 'left behind' economically in the Information Age is thus understood as the same as ensuring that people do not get 'left behind' or excluded socially.

I have additionally argued that CtDD draws upon what Levitas (1988) terms a social integrationist discourse of social exclusion, with a particular emphasis upon individual motivational factors. This social integrationist discourse emphasizes the achievement of inclusion via job security as an individual responsibility, rather than understanding insecurity as a structural feature of contemporary capitalism. The individual is furthermore understood as somebody with the potential for transformation through connection with ICTs. There is a discursive highlighting of specific related claims, for example that 'a basic level of ICT literacy is becoming an essential pre-requisite for employment' (CtDD: 58).

These particular claims, such as this necessity for the individual to acquire 'ICT literacy' in order to secure paid work, thus embody the fundamental understanding of the mutual reciprocity of fostering economic enterprise and social justice in the Information Age. This fundamental assertion, and the reconciliatory logic it exemplifies, has been crucial to the construction of the logic and coherence of New Labour's 'Third Way' political programme. Third Way political discourse has attempted to reconcile themes seen as potentially irreconcilable in previous centre-left political discourse, in particular the needs of enterprise and social justice, to cope with the seeming inevitabilities of freemarket globalization. The Third Way agenda is 'shaped by the centre-left's 
values and instincts, applied to a world of rapid change' (Blair 1998: 20), and as Giddens (2000: 23) argues, "modernisation" here means reforming social institutions to meet the demands of a globalising information order. 11

The CtDD report can thus be seen to both fall within this pervasive discursive logic and to be part of its continuing development. The articulation of the relationship between technology and exclusion in the Information Age extends the underlying claim of the mutual reciprocity of enterprise and social justice into a new area of social policy, and in so doing is part of the ongoing rejuvenation of Third Way political discourse.

The recommendations of CtDD emphasize other key themes, such as the benefits of 'partnerships' or 'joined-up' working, and the unambiguous advantages of market forces and entrepreneurship, in order to address the concerns of raising ICT awareness and providing equal access to ICTs:

Our approach is designed to work with the grain of market forces, only seeking to tackle areas where market imperfections or gaps currently occur. It is predicated on the presumption that the following will enable significant progress to be made:

a) improved policy focus on the above aspects

b) the identification, evaluation and dissemination of good practice in the provision of ICT awareness, training and access

c) entrepreneurial management (particularly at the local level) (CtDD: p64)

Here, any residual idea of universal public service has been uncritically subsumed by the language and logic of the market. Future parameters of policy intervention are conceptualized in terms of facilitating 'the grain of market forces'. Moreover, the discursive understanding of gaps in provision as 'market imperfections' suggests that current inequalities in access to ICTS can be ironed out, rather than pointing towards an understanding of market forces as a continuing causal factor in the ongoing differentiation of the quality of online experience. As such, this fits with the overall problematization of the 
nominalized 'Digital Divide' as a one-off state 'to be closed', with little sense of a history or dynamic and continuing presence. The recommendations of CtDD do not address ongoing processes of polarization or consider wider redistributive policies directed towards equality of outcome, rather than equality of access and opportunity. Furthermore, the danger of this static dichotomous conceptualization of access/no access is that, as Selwyn (2002: 10) notes, "by focussing solely on issues of basic access the government are overlooking the quality of that access and, it follows, the quality of access to information and services experienced online'.

Alongside this emphasis on market forces and entrepreneurship, there is a strong focus on the Third Way theme of developing 'partnerships' and a 'joined-up approach' to overcoming barriers throughout CtDD's recommendations. The development of partnerships between local and national government agencies, voluntary and community organizations, and the private sector are specifically encouraged 'to support uptake of ICTs, and to train and employ local people in virtual enterprises' (CtDD: 6).

As Watt and Jacobs (2000) note, this model of distributing stakes in governance has the important strategic function of binding together agencies who might have otherwise potentially antagonistic points of view or conflicting interests, and adopt a more hostile attitude to the strategic model advanced. Moreover, Fairclough (2000) argues that the contemporary development of such joined-up governance, in which diverse agencies increasingly integrate their activities, crucially depends on the role of language to shape the culture of the dispersed agents. To this end, it is worth briefly noting that CtDD itself presents an entirely consensual view. CtDD adopts an authoritative and realist style with no flagging of issues of contention, no reported speech and, beyond headings, no questions presented to the reader. The style is entirely monovocal and declarative then, rather dialogic or interrogative. 


\section{$\underline{3.5 \text { Conclusion }}$}

In this chapter, I have provided a detailed discursive analysis of the report 'Closing the Digital Divide: information and communication technologies in deprived areas' as a case study in the understanding of technology and inequality within UK government. CtDD draws upon two prominent discourses in contemporary politics, that of the 'Information Age' and the 'Inclusive Society'. As Selwyn (2002: 16) notes:

That social exclusion - the current 'buzz theory' of social policy-makers and commentators - has been so readily married to that other 'buzz area' of ICT should be no real cause for surprise. The previous 'technologification' of other policy areas such as education and health has often been used as an apparent 'technical fix' to many pressing policy concerns.

Firstly, $I$ argued that CtDD envisions a technologically determinist vision of radical utopian change in social and economic organization, with an associated policy rationale of helping British society and economy to keep up with the emergence of this inevitable, if ill-defined, 'Information Age'. The new responsibilities of government are thus understood as inexorably framed by technologically determined ground rules. In particular, the narrative structure of CtDD acts as a vehicle for presenting a case for specific action, to identify and overcome the social 'barriers' that might prevent the utopian promise of the Information Age from being realised. At the same time, the direction and shaping of more particular goals beyond such a vague freeing of technological potential is largely absent from CtDD. As Goodwin and Spittle (2002: 246-47) argue:

constructing the debate in a narrow and deterministic manner can only result in a narrowly conceived set of policy solutions which cannot hope to achieve the various social and cultural benefits suggested by the new technologies. Paradoxically, it is this wider ranging set of social and cultural benefits that are driving the debate forward, giving it urgency and becoming part of the political rhetoric that is used to justify policy changes. 
To this end, as Graham (2000: 132) contends, "the "information revolution".. is a mostly obfuscating rhetorical construct'. Furthermore, as Webster (2004: 86) reasons, such a technologically determinist understanding ultimately 'subverts all ambitions to bring about profound social and economic change, since always, but always, there must be acknowledged a decisive, if imprecise, level of technological foundationalism to any dreamed of social system'.

Secondly, I argued that the dominant understanding of social exclusion in CtDD is one which directs moral attention onto the distinctiveness of the 'deprived neighbourhood', and sees the individual attainment of job security as central to the achievement of social inclusion. CtDD thus emphasizes the 'new work ethic' (Holden 1999) that dominates New Labour's social exclusion strategy and overall policy agenda (Levitas 1996, 1998, Byrne 1999). Any broader understandings of social exclusion in terms of structural inequalities and ongoing processes of polarization throughout society, 'the real immiseration of employed workers' (Byrne 1997: 31), domains of social activity beyond production (Burchardt et al. 1999), and redistributive solutions are conspicuously absent from CtDD. As Alibhai-Brown (2000: 249) notes:

Social exclusion experts have shifted the focus from structural problems - some deliberately created to placate the gods of modern capitalism - to a behavioural model where those who are socially excluded carry some of the responsibility for not doing more to belong.

This 'responsibilization' of the individual is furthermore discursively enhanced in CtDD in that the individual in the Information Age is primarily understood as someone with the potential for personal transformation, particularly once certain attitudinal 'barriers' have been overcome, all of which may be realised through connection with ICTs. The utopian figures of the empowered consumer and, in particular, the reconfigured worker armed with new 'employability' skills such as ICT literacy, thus assume prominence in CtDD. The concomitant limits of governmental responsibility are primarily constructed in terms of promoting awareness of, and access to, this potential of ICTs. 
I finally reiterated that the specific account of technology and exclusion constructed in CtDD is discursively buttressed through its drawing upon other particular discourses within the political field, namely those of the 'Information Age' and the 'Inclusive Society'. The CtDD text establishes a chain of discursive equivalences, for example between societal and individual transformation, from which a new articulation of the familiar may be constituted. In particular, I highlighted the continual discursive equivalence constructed in CtDD between the measures understood as necessary to strengthen national economic competitiveness in the Information Age and those for achieving social inclusion:

Making sure everyone has access to the internet will both improve our competitiveness and reduce social exclusion. Policies of enterprise and fairness working together .. We cannot accept a digital divide. For business. Or for individuals. (Blair 2000)

As such, I argued that CtDD embodies the overall vision and discursive logic of New Labour's 'Third Way', a political programme which has attempted to reconcile themes previously seen as antagonistic, e.g. the needs of enterprise and social justice, in centre-left political discourse. I suggest then that the construction of the CtDD text can be understood as a process in which particular political work is done, drawing upon but also, crucially, renewing the wider discourses of the 'Information Age', the 'Inclusive Society' and ultimately the 'Third Way' itself. 


\section{Notes}

'In one notable exception, Hudson (2003: 284) coins the term E-galitarianism 'to encapsulate the fact that notions of an information society and information revolution are increasingly important in framing debates surrounding the welfare state'. Hudson suggests that:

'social policy theorists .. need to pay greater attention to such issues and place an analysis of the idea of an 'information society' alongside analyses of postmodernism, post-industrialism, post-Fordism and globalization. If we do not, the idea that a technologically driven revolution is rendering traditional welfare interventions obsolete will continue to gather pace unchallenged, irrespective of its roots in reality' (2003: 284)

2 In CtDD, the term 'social exclusion' occurs ten times (outside headings and references). Three times it is to be 'tackled', three times there is a need to 'combat' it, twice to 'counter' it, and there is one reference each to the 'experience' and the 'increase' of social exclusion.

${ }^{3}$ Toffler's work emphasizes 'future shock' (Toffler 1970) and radical discontinuity. However, in some respects against this ostensible message and by virtue of its age, it can be argued that it also currently signifies the continuous nature of technorevolutionary prediction. The Third Wave was one of a number of contemporaneous populist titles such as The Mighty Micro, The Micro Revolution and The Silicon Civilisation which heralded an information revolution over 30 years ago.

${ }^{4}$ Of the six others, one is from the Henley Centre for economic forecasting, one a report of the NGO Communities Online, one a HM treasury press release, two websites cited are the Government's National Grid for Learning site and NUA, an internet usage survey site, and one excerpt from The Times quotes Steve Ballmer, the President of Microsoft, as saying that, "the real revolution of the Internet is only just underway" (CtDD: 11).

5 In CtDD, this 'discourse of the definite' pervades not just the diagnosis of the unquestionable and radical transformation of the Information Age, but informs the totalizing ambition to get the whole of the 'UK online'. Thus CtDD's recommendations are absolute, that $100 \%$ of people in deprived neighbourhoods have the capability of online access by 2008 (CtDD: Recommendation 6.5.1 p6). 
${ }^{6}$ The neighbourhood is described as an 'area of a few thousand people' (SEU 2000: 19), the suggested best proxy being the political ward. The key discursive construction of the 'deprived neighbourhood' takes place via a chart contrasting the 'five per cent most deprived wards' with 'the rest of England' (SEU 2000: Figure 1. p19) on percentile measures of lone parentage, unemployment, poor housing, children in low earning households, crime, vandalism and hooliganism, and racial harassment.

7 Similarly, Graham Walker, Assistant Director for Confident People, E-envoy Office, in a speech entitled, 'Defining the Digital Divide' given at a conference for the launch of Citizens Online in May 2000 stated, 'we need to promote cultural change towards a more positive approach to new technologies' (Walker, 2000).

${ }^{8}$ For a discussion of neo-communitarianism with a distinctly technological accent, see Connexity (1997) by Geoff Mulgan, the former director of the think tank DEMOS and special adviser to Tony Blair on social policy issues.

${ }^{9}$ It could be argued however that the very diversity of these vignettes suggests a counter-reading to the notion that there can be any identification and dissemination of 'good practice' beyond the specific local context.

10 This assertion is also repeated in numerous speeches given by Government officials. For example, at the launch of Citizens Online in May 2000, Michael Wills MP, Minister for Learning and Technology, stated that the reason why the digital divide mattered so much was that, 'Firstly it is a matter of social justice .. Secondly it is unacceptable if we want to have a productive and successful economy' Wills 2000)

${ }^{11}$ For further discussion of the Third Way, see Giddens (1998, 2000, (ed.) 2001). A critical interpretation which emphasizes a continuing opposition between the needs of capital and the needs of labour is offered by Fairclough (2000) who argues that Third Way political discourse seeks to achieve rhetorically what it cannot achieve in practice. Emphasizing the constitutive role of social antagonism to the political, Zizek similarly interprets Third Way political discourse as 'an attempt to suspend the destabilizing potential of the political, to disavow and/or regulate it in one way or another' (1998: 992). 


\section{$\square \square$ Chapter 4.}

\section{Corporate Discourse on The Digital Divide}

\subsection{Introduction}

This chapter analyzes the construction and function of the digital divide within contemporary corporate discourse. In recent years, many corporations, particularly large blue chip multinationals, have undertaken initiatives that have been understood as responding to a concern with the digital divide or the issue of 'digital inclusion'. For example, Hewlett Packard launched a number of programs and projects from 2000-2005, such as its Digital Villages and i-communities initiatives, under a broad 'e-inclusion' strategy designed 'to advance social and economic development while accelerating achievement of our long-term business goals' (Hewlett Packard 2004). ${ }^{1}$ Such strategies are themselves typically conceptualized and promoted in terms of demonstrating a commitment to a wider agenda of corporate social responsibility, accountability, or in the example above, 'HP global citizenship'.

This chapter focuses upon a case study of the work of the Social Policy Unit of the telecommunications corporation $\mathrm{BT}^{2}{ }^{2}$ The analysis pays particular analytic attention to a report outlining BT's approach to the Digital Divide, as well as the e-mail and website based consultations on the digital divide that accompany it. The aim is to analyze how the digital divide is understood within this case study of contemporary corporate discourse, and to detail how the issue of the digital divide enables a particular notion of accountability to be played out in practice.

\subsection{Social Reporting}

In this section, I will briefly overview some recent historical developments in corporate reporting and accounting (see Crowther (2000), and Gray, Owens and Adams (1996) for a fuller discussion). Practices of financial accounting, informed by traditional neo-classical economics, have been central to determining what constitutes success in commercial organizations principally in terms of the 
measurement and disclosure of profit (Gray et al. 1996). For Gray (1995: 2), the limitations of traditional economics apply with equal force to conventional accounting:

Both are only interested in property rights exchanged for money; both are informed by a narrow and limited conception of morality and both are motivated by an exceptionally narrow view of efficiency; both ignore the social and environmental consequences of actions to the extent that they are not priced .. accounting excludes all non-priced activities and encourages us to ignore such externalities, and even to consider them in some way as heretical to business orthodoxy

Throughout the $20^{\text {th }}$ century there have been various shifts in the dominant practices of corporate accounting. For example, in the post war period, the emphasis of corporate reports changed from backward to forward looking and inward to outward looking, reflecting the need to attract investment into companies in this period of expansion (Gilmore and Willmott 1992). While current financial results are still contained within corporate reports they are often relegated in importance, and it is future prospects that assume salience, as reports become a mechanism for selfpromotion designed to appeal to a wider range of interests beyond shareholders; investment professionals, financial media, employees, and consumers (Crowther 2000). In the last 30 years, as a general concern with initially environmental issues became more widely respectable, academic and practitioner communities in accounting have become more willing to acknowledge that other issues beyond traditional economic calculations may be relevant to the profession (Gray 1995).

Partly in response to a succession of high-profile campaigns and consumer boycotts pointing to a lack of social responsibility in corporate activity, recent decades have also seen a renewed interest in business ethics and the emergence of a global corporate social responsibility (CSR) movement (see e.g. Bishop 2000, Richter 2001). CSR has been embraced by a growing number of businesses across the world, with increasing membership in business organizations such as the World Business Council for Sustainable Development (Henderson 2001) and involvement in multilateral initiatives such as the UN's Global Compact (Robinson 2004). There has been endorsement for the ideas of CSR within many governments; for example the UK has a Minister for CSR and sees 'CSR as the voluntary actions that business can 
take, over and above compliance with minimum legal requirements, to address both its own competitive interests and the interests of wider society' (DTI 2004: 20). Many corporations now increasingly desire to be seen to be environmentally and socially responsible in an uncertain climate of greater public inquisition, to protect their brand and reputation, and to engage in demonstrations of wider public accountability. As Caulkin (2003) notes, 'companies are hungry for legitimacy. They believe the longterm value of being 'responsible' outweighs the costs'. Henderson (2004: 195) argues that more widely, 'The adoption of CSR by businesses generally is seen as necessary to ensure continuing public support for the private enterprise system as a whole. For modern capitalism to be made acceptable and hence viable, it has to be given "a human face"'.

It is in this general climate that the practices of environmental, and more recently, social accounting have been embraced alongside the legally required reporting of financial accounts. In 1993, 10 percent of the Fortune Global 500 companies produced a separate account of the organization detailing its approach to social, environmental or sustainability issues, whereas by 2002, this figure had risen to 45 percent (KMPG 2002). At face value of course, such social and environmental concerns may not straightforwardly align with the traditional, and legally regulated, concerns of maximizing profit and demonstrating strict financial accountability to company shareholders. The ways in which such varying responsibilities may be discursively configured to stress their compatibility is one particular focus of this case study. Before I detail this, it is important to briefly contextualize this case study within a particular political climate.

\subsubsection{Company Law Review}

In March 1998, the UK Department of Trade and Industry launched the Company Law Review, a fundamental review of the legislature regulating corporate existence. The terms of reference of this review included issues such as the practices of corporate accounting as well as the codification of the legal accountability of company directors in statute. At the time of this case study then, the possibilities of recommendations for expanded disclosure of social and environmental information through mandatory sustainability accounting, or for directors' duties of care being 
extended beyond legal responsibilities to shareholders, for example to include specific duties of care towards communities or the environment, were extant. ${ }^{3}$

BT's position on these issues centred on the concept of 'enlightened shareholder value'. In their '2001 Social and Environmental Report', this is rather confusingly described as follows:

'In BT we fervently believe that creating stakeholder value is the route to creating shareholder value. That maximising employee and customer satisfaction, partnering with suppliers for mutual gain and being accountable for our actions to wider society is as important as making a profit. For they are, in effect, one and the same; because by addressing stakeholder expectations we create shareholder value - enlightened shareholder value'. (BT 2001a: 3)

A full genealogy and discursive analysis of this concept in the work of BT and in the submissions to, and proceedings of, the Company Law Review, is beyond the remit of this chapter. The important point, as illustrated in the excerpt above, is that the concept of 'enlightened shareholder value' implies that there can be an equivalence between wider social responsibility and making a profit. Indeed, a discursive equivalence is constructed between these two duties: 'they are, in effect, one and the same'. As such, this concept does not embody a demand for the separation of these duties of care in statute.

The report of the Company Law Review eventually proposed that as part of the annual corporate report and account, a new Operational and Financial Review (OFR) should address 'material' stakeholder concerns (DTI 2001). BT's position is made much more explicit in their submission to the subsequent 'Operating and Financial Review working group on materiality':

It is in shareholders' best interests for companies to have regard to the interests and concerns of other stakeholders (the "enlightened shareholder value" approach favoured by the Company Law Review), such as employees, customers and the community in which the company operates. However, the OFR should not be written to address these other stakeholder groups specifically. This smacks of the "pluralist" approach rejected by the Company Law Review and which it points out would extend directors' obligations and 
liabilities beyond the shareholders, which is the current position and the one supported by BT. (BT 2003: para.5)

Drawing on the recommendations of the Company Law Review and these further consultations, the 2005 White Paper on Company Law Reform (DTI, 2005) ultimately endorsed this position and proposed to:

'embed in statute the concept of Enlightened Shareholder Value by making clear that directors must promote the success of the company for the benefit of its shareholders, and this can only be achieved by taking due account of both the long-term and shortterm, and wider factors such as employees, effects on the environment, suppliers and customers' (DTI 2005: 5)

Although these regulations were indeed added to the 1985 Companies Act on March 22 2005, mandating companies to produce an OFR with their annual reports from 1 April 2006, the abolition of the OFR was announced by Gordon Brown in a speech to the Confederation of British Industries on 28 November $2005 .{ }^{4}$ To date then, there is no explicit codification of accountability to wider stakeholders in UK company law, and at the time of writing, no requirement even that 'due account' be taken of such groups in achieving the ultimate aim of 'enlightened shareholder value' (see Williams et al. 2004 for a fuller discussion). Indeed, as Day and Klein (1987: 26) note, accountability in general is not a well-defined term, in spite of its deemed significance in democratic states. ${ }^{5}$

\section{3 'Betterworld'}

It is within such a political context that BT offers one contemporary performance of accountability in addressing the issue of the Digital Divide. BT's overall approach to social and environmental accounting centres on an online strategy of 'real-time reporting' and 'consultation' on their 'Betterworld' website, designed to embody the claim that 'better communications help create a better world ' (BT 2001a: 1) :6

If you're looking for BT's Social and Environmental Report, the good news is that you're in it! Welcome to BT's first, all-encompassing, social, environmental, sustainable 
development, corporate social responsibility, triple bottom line report .. The report is essentially the sum total of our internet pages devoted to our social and environmental programmes - plus lots of links to other sites on bt.com and elsewhere .. The internet is the ideal medium for such a report since it illustrates so well how integrated and interrelated all BT's activities are .. And, given the shorter lead times involved and the ease with which information can be updated, this also marks a significant step towards more real-time reporting. .. The concept of triple bottom line reporting has been very influential, but does carry with it a suggestion that there are three separate and distinct, but somehow interrelated, bottom lines - each of equivalent standing. This is not what we have in mind. In our view, in the context of sustainable development, it's impossible to consider the economic dimension in isolation from the social or the environmental. And vice versa. We think that the time has come for organizations to stop compartmentalizing the economic, the social and the environmental, and to find new and innovative ways of reporting their joined-up contributions to a more sustainable society. And that's exactly what we're trying to do here. (BT 2001a: 4, my italics)

The data corpus that I shall reference as my main focus of analysis consists of three interconnected elements of this initiative: ${ }^{7}$

- 'Hot Topic' Report: A report entitled 'The Digital Divide: Better World - Our Commitment to Society' (BT 2001: hereafter DDBW), flagged as a 'Hot Topic' on the BT 'Betterworld' website. A link to download this report was included on the invitation to participate in the e-mail discussion detailed below. ${ }^{8}$

- E-mail Discussion: BT held a two week e-mail discussion around the topic of 'the Digital Divide' from Sept $17^{\text {th }}$ to Sept $30^{\text {th }} 2001$. This was organized as an asynchronous discussion, whereby a single daily e-mail digest, providing a brief summary followed by the full text of all the day's contributions, was posted to all those who had registered for the discussion. Only those who registered to receive the e-mails were allowed to post contributions to the discussion. Registration was available to those who serendipitously encountered notice of the upcoming discussion on the Betterworld website. Additionally, it was solicited from participants on other e-mail discussion lists through a joint invitation sent out by BT and AccountAbility, who moderated the discussion. ${ }^{9}$ 
- Online Debate: A 'live online debate' on the topic of 'the Digital Divide' held from $11 \mathrm{am}-1 \mathrm{pm}$ on October $10^{\text {th }} 2001$, and 'broadcast' on the BT 'Betterworld' website. As above, the debate was advertised online, and promoted via e-mails sent out to existing discussion lists and to those who had registered for the earlier BT digital divide e-mail discussion.

Despite the self-referencing nature of these individual elements, and their links to the 'Betterworld' website, the contours of this corpus do not have an inevitable shape that transcends the analytic encounter. Given the potentially unmanageable number of links and paths such 'new media' may create or nest within, accounting for the circumstances in which routes are made possible and sampling decisions taken, becomes analytically important (Hine 2000). Initially then, the details of my 'route in' to this corpus deserve attention.

\subsection{Constructing the Stakeholder}

'How important do you think the digital divide is?

Do you think BT is doing enough to close the digital divide?

BT is seeking to utilise the power of the Internet to develop its understanding of the digital divide and other social and environmental issues by opening up the debate to all its stakeholders. You are invited to discuss, challenge and influence BT's approach to the digital divide. Senior BT staff as well as experts from outside the company will also take part in the discussion.

The Digital Divide was featured as a hot topic in BT's recent social report. You can read it at www.bt.com/betterworld. The discussion will kick off on September 17th with a twoweek email discussion leading up to a live online debate on October 10th with Patricia Hewitt, Secretary of State for Trade and Industry and Pierre Danon, CEO of BT Retail.

Of course, the very fact that you are reading this email means that you are on the 'right side' of the digital divide. However, we hope that this debate will engage as wide a range of people as possible and ultimately enhance BT's social impact.' 
Any claim to accountability requires someone to be accountable to. On Friday $14^{\text {th }}$ September 2001, I received a 'joint invitation from BT and AccountAbility.. [who] would like you to join us in an open discussion on BT and the Digital Divide'. I was a recipient of this e-mail because of an existing subscription to an e-mail discussion list concerned with the Digital Divide. ${ }^{10}$ The organizing principle for inviting participation and hence conferring stakeholder status was thus one of networking rather than any other form of sampling: 'In terms of contacts, we used our own networks and contacted other organizations and websites with relevant people' (AccountAbility, Jan 2002, personal communication).

The e-mail continues by framing the rationale of this upcoming discussion as one that will, 'utilise the power of the internet...opening up the debate to all its stakeholders'. This introduces the key figure of the stakeholder, whose bounds are immediately presented. By default s/he is configured as someone who is already connected to technological capability, the 'power of the internet'. However, this initial email is not just a presentation of this corporate understanding of who the stakeholder is, its address is a performative construction of stakeholder status.

Because of, 'the very fact that you are reading this email', stakeholder status is not only understood but, in a very literal sense, normatively conferred on those on 'the "right side" of the digital divide'. Such an expression further implies a broad understanding of the technological ordering of morality, whereby those using technology are understood as more virtuous, the digitally correct. This particular construction is formulated as obvious, simple shared knowledge, 'Of course' it is so.

The configuration of the stakeholder is further refined in the process of registration for the online discussion. This involves a detailed presentation of the rules of discussion (Fig. 4.1), which prescribes a particular style of stakeholder engagement that is nonadversarial and strictly delimited in scope, e.g. 'It is important that all participants feel comfortable', 'Send up to 2 messages per day to the debate'. 


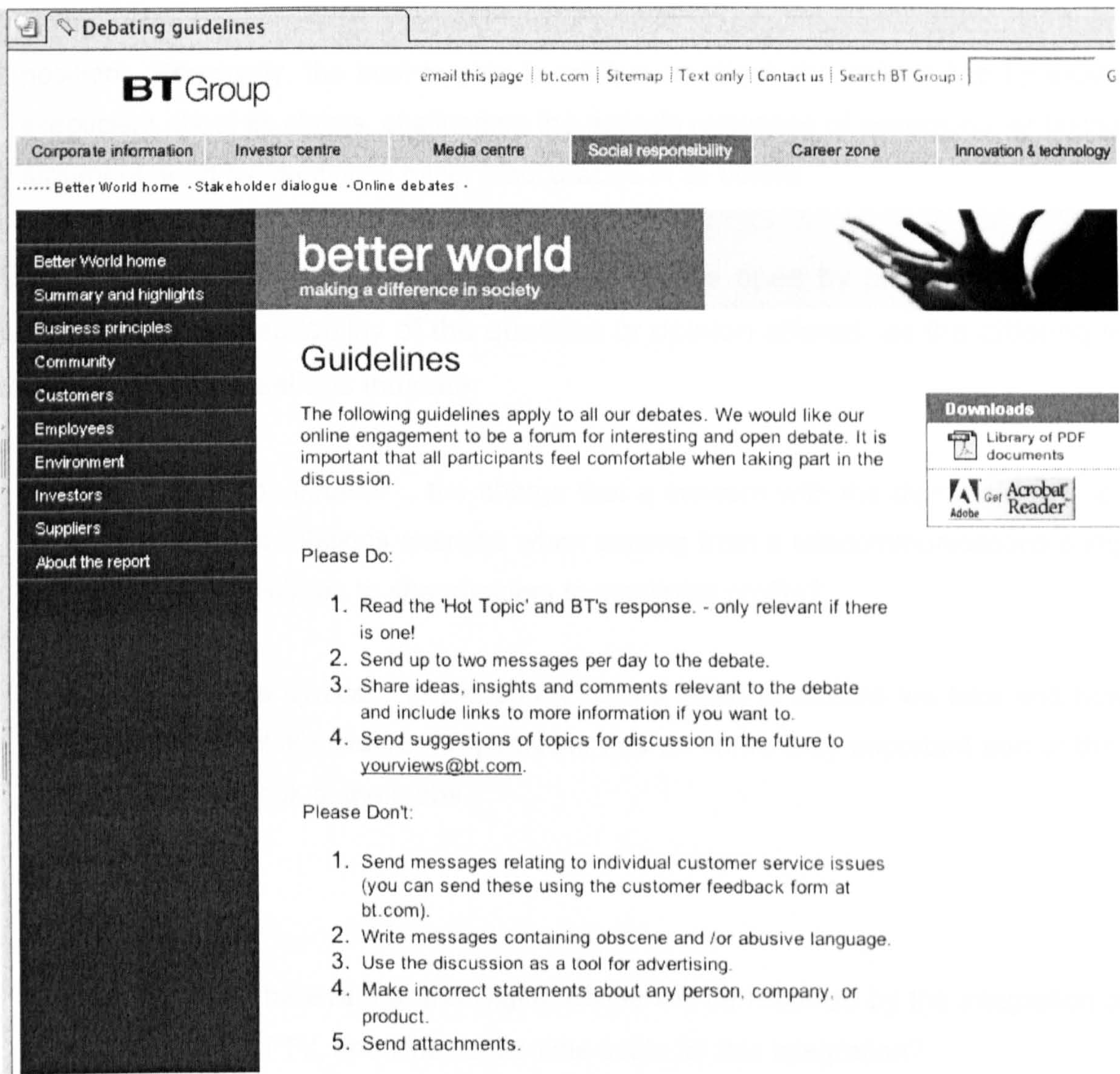

Fig. 4.1 Online Debate: Guidelines

Secondly, the stakeholder engagement is organized in time and space to privilege a particular form of interaction. Contributing participants are requested to enter a single comment or question into an input field on a separate webpage, and to click a button to submit their post. Some minutes later the post appears alongside a reply from the host, spatially aligned as a discrete question and answer (Fig. 4.2). The parameters of this spatial and temporal arrangement thus follow the conventions of the expert panel show, being organized around the self-contained $Q$ and $A$ rather than free ranging discussion or the immediate follow up. As Hutchby (1999: 587) argues in his analysis of radio phone-in shows, the asymmetry of discursive resources available in such an arrangement tends to systematically privilege the host: 
Going second .. represents a more powerful position in argumentative discourse than first position. Principally, the host is able to critique or attack the caller's line by exhibiting skepticism about its claims, challenging the agenda relevance of assertions, or taking the argument apart by identifying minor inaccuracies in its details.

During the online debate then, many of the replies open by providing an evaluative judgement on the suitability of the question or opinion offered, as the differing replies to the following questions indicate:

Q. How would you counter .. the charge that a concern with the digital divide .. is little more than a public relations exercise when coming from a telecommunications company with legal responsibilities to shareholders to maximize profits?'

A. It is easy to be cynical. In the end it comes down to actions we take and how we behave with our stakeholders. In particular it is an immensely important part of the way individuals at BT look at their jobs.

Q. How far do Bt believe that the Digital Divide will be resolved by the integration of the internet and Digital TV, and what is the time scale for this integration?

A. Good question. Our belief is that customers appreciate choice and we are committed to providing as many access channels as work for customers. (Online Debate, my italics)

On the rare occasions when complex or multiple questions are submitted, the content of the submission can threaten to exceed the form. For example, in response to a submission that opens with the question, 'how busy are you for a dialogue?', the response is, "loads of questions coming in! I guess the quick answer is watch this space!' Here the host manages the difficulty via a direct (spatial) reference to the restricted form of the debate (Fig. 4.2). 


\section{Back Forward Stop Refresh Home}

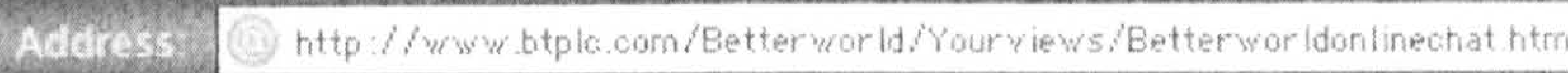

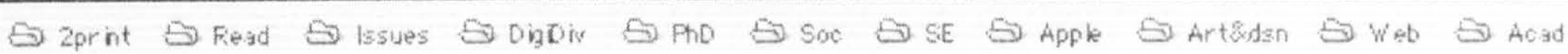

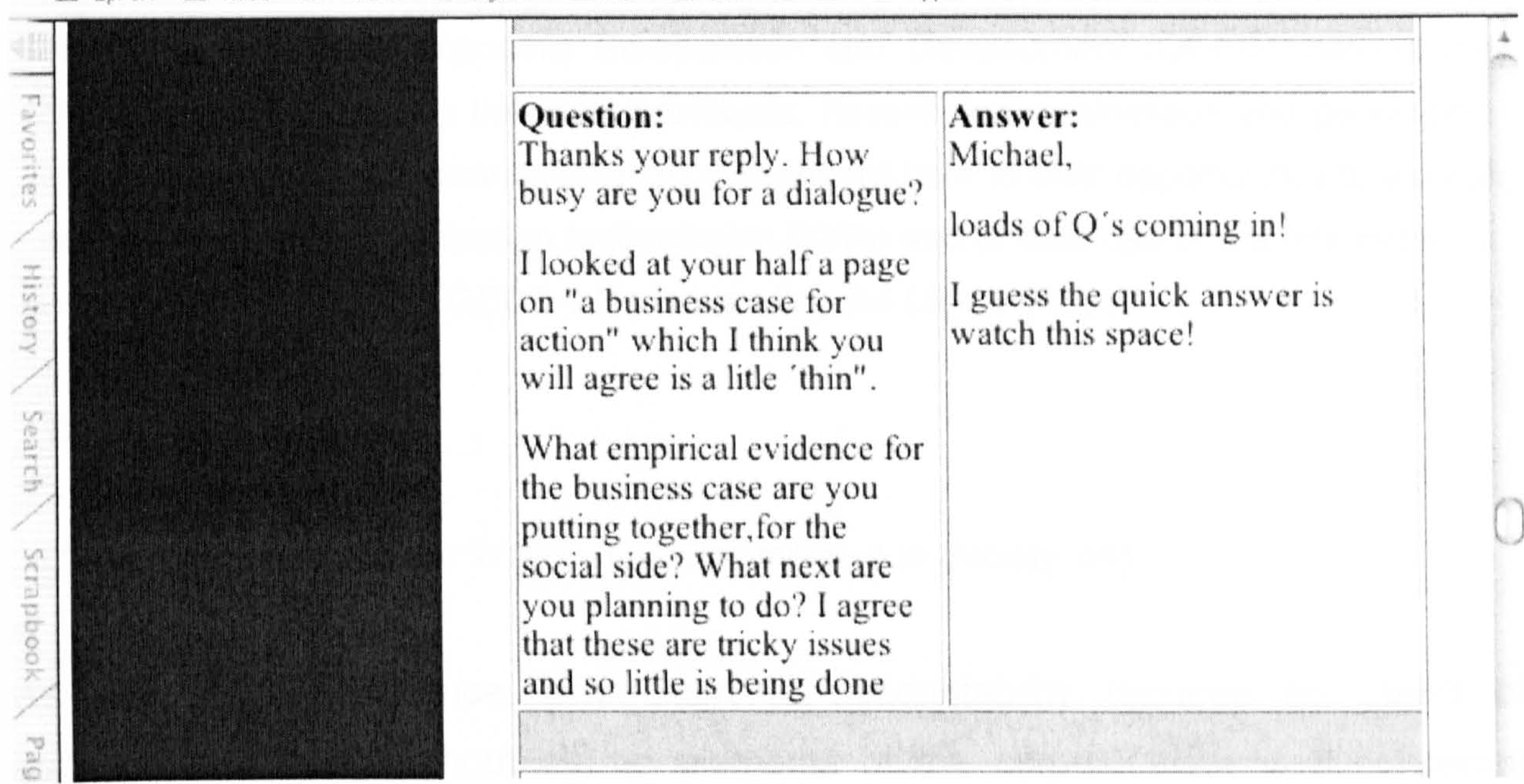

Fig 4.2 Online Debate: Managing the Consultation

Stakeholder engagement is thus managed through all these discursive strategies of the solicitation and filtering of participants, the privileging of a particular style and form of turn-taking, and the evaluation of the content of the submissions. The construction of the dialogic possibilities are carefully orchestrated and constrained, limiting the possibilities of any sustained criticism.

The point I wish to emphasize at this stage is simply that the discursive construction of the stakeholder enables a particular claim of accountability, in that it provides an audience to be accountable to. I shall return to more specific claims about the mode of engagement in due course. 


\subsection{Making it Real}

What is it?

The Organisation for Economic Co-operation and Development (OECD), defines the digital divide as "the gap between individuals, households, businesses and geographic areas at different socio-economic levels with regard both to their opportunities to access information and communication technologies (ICTs) and to their use of the Internet for a wide variety of activities" OECD - Understanding the Digital Divide

The Divide does exist.

(The Digital Divide: Better World - Our Commitment to Society, p4)

As well as an audience, any claim to accountability requires an object of accountability. Throughout all the elements of the corpus, there is a concerted attempt to impose a realist ontology and a naturalist epistemology upon discussion of the 'Digital Divide'. In the invitation to the e-mail discussion detailed in the previous section, the two main questions that frame the upcoming debate are 'How important do you think the digital divide is?' and,' Do you think BT is doing enough to close the digital divide?' - both initially asserting the external reality of the Digital Divide, which exists independently of any opinions, thoughts or beliefs about it.

In the $D D B W$ report, as the quote above illustrates, the initial question posed is, 'What is it?'. This question, together with the answer proffered, precisely citing an earlier OECD definition of the Digital Divide, supports the credibility of the stylistically hard-hitting concluding comment, 'the Divide does exist'. It is not merely a concept or an understanding then but a tangible thing. Subsequent section headings in the report, such as 'Dimensions of the Digital Divide' and 'Unpacking the Digital Divide', are inhabited by a sense of materiality that serves to further buttress its reality.

Establishing and maintaining the Digital Divide within a realist framework means that it becomes an object of accountability and an issue to be 'tackled', with concomitant solutions becoming 'very rear'. 
Everybody wants to make a contribution and by tackling the Digital Divide that becomes very real. Corporate Social Responsibility still has to make good business sense but that doesn't make it any less real. (Online Debate: Pierre Danon, CEO BT Retain)

The term 'Digital Divide' is used liberally throughout the corpus and that such naming is extremely pervasive is also explicable in terms of a corporate culture of branding. Such 'cause branding', e.g., Tesco's association with providing IT equipment for schools, has become 'a core component of corporate reputation and brand personality in recent years' (Cone 2001: 123). More generally, a strategy of

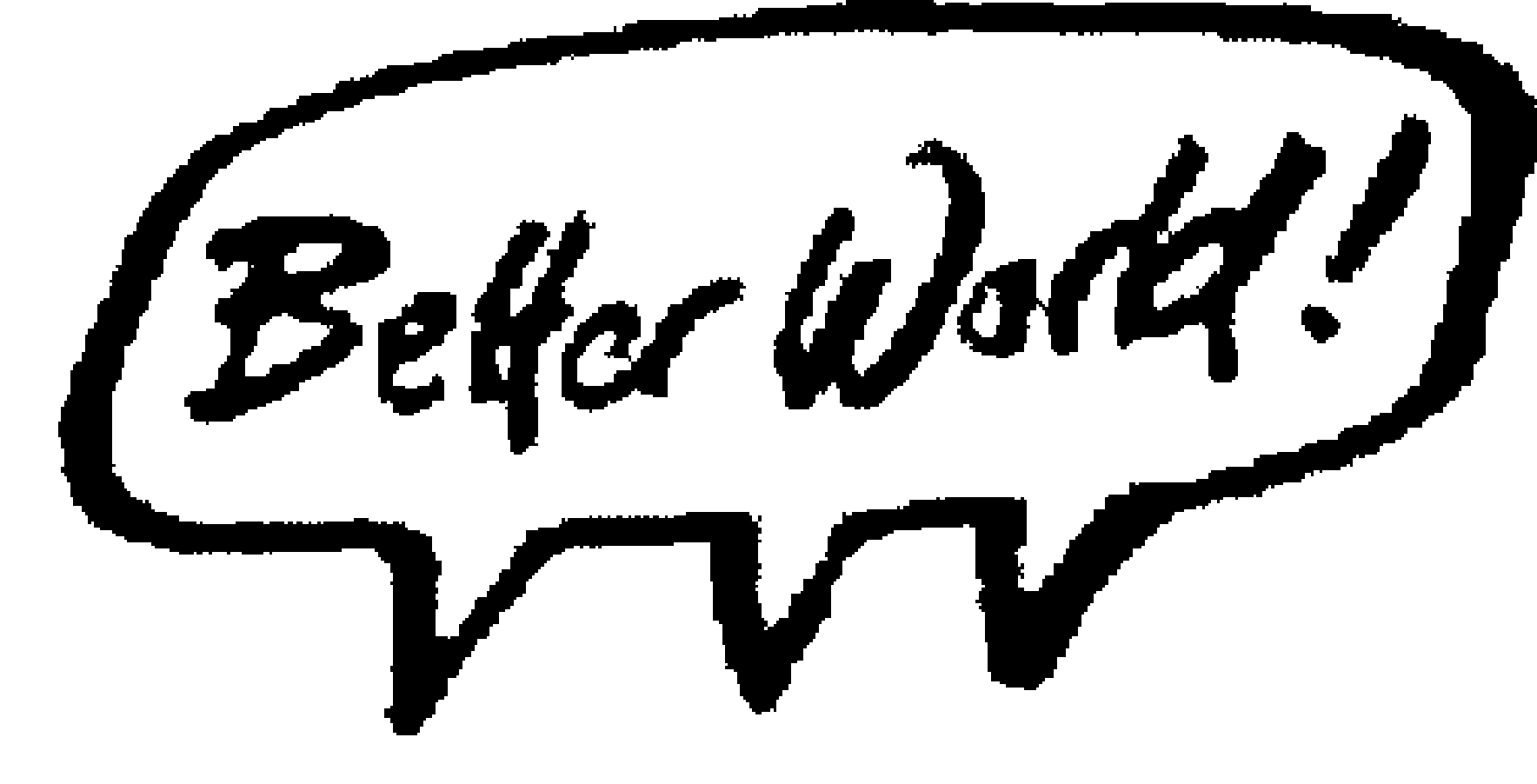
straightforward, aspirational branding extends throughout the corpus. For example, the BT website which hosts the social and environmental report is known as 'Betterworld' and has its own logo (see left).

However, beyond any external public relations context, constructing an object of accountability such as the Digital Divide enables the internal management of organizational identity. BT is a complex organization made up of many separate departments and as such can be opaque, to those within the organization as much as to outsiders. The director of the BT Social Policy Unit understands their work firmly in this dual context of external functionality and the internal 'joining up' of the business:

The openness has enabled us to answer stakeholder questions, from ethical investors, potential customers and other interested constituencies, in a more complete manner [and] It has helped us 'join up' the various social responsibility aspects of BT's business. Disclosure has been a challenge but we found that most parts of BT were happy to publish key indicators and aspects of their performance, and set future objectives. (Online Debate: Adrian Horsford, Director of BT Social Policy)

It is noteworthy that a number of those actually participating in the online debates identify themselves as being from other departments within BT, e.g. Capacity 
Management, Research and Design. During my visits to BT, the role of social responsibility 'issues' was a topic of conversation for members of the company outside the Social Policy Unit:

After spending the morning in the Social Policy Unit, I have a coffee with Margaret, a person of longstanding experience and seniority within the corporation. She herself was intrigued by her own encounter, as my gatekeeper, with the Social Policy Unit this morning. It is only very recently that she came across its existence, and she sees its role as concerned with aspects of internal corporate communications. In Margaret's work in a separate section of the corporation, 'issues' such as the Digital Divide materialize 'via osmosis', and different and ongoing projects are then 'hung on the same peg', so that 'we are all singing from the same song sheet'.

(Field Notes)

Rather than necessarily prompting the initiation of new initiatives then, 'issues' enable organizational identity and a reconfiguring of the logic of the core business:

CSR is of course moving into the core business area more than ever before, and the advent of the Digital Divide as a CSR issue is part of that process. (DDBW: p19)

In the terms of Laclau and Mouffe (1985), the articulation of 'issues' such as 'the Digital Divide' should not merely be viewed as the identification of an external problem to be solved, but function in a large organization as a constitutive enabling of the possibility of any internal politics at all. Hegemonic project realignments, "joining up' and inter-departmental communications are driven via such objective 'issues', providing the organization with the means for 'sensemaking' (Weick 1995) and the ability to renew its identity over time. As Osborne (2004: 15) notes, "Ethical capital is not just about conferring standards of worthy behaviour on business but is about giving companies a sense of themselves, a sense of who they are, a sense of institutional identity and even social purpose. In the process, the very idea of the social is transformed from something external to business to something internal to it, thus even, so to speak, domesticated by it'. 


\subsection{Why the Digital Divide?}

At this point, it is important to consider why the Digital Divide in particular should be constituted as an object of accountability for BT. A response to this question is given in the DDBW report:

Why is BT addressing the Digital Divide? ..

(a) Pressure - Because it has to! BT faces a range of direct pressures that encourage it to take account of aspects of the Digital Divide. BT is rightly sensitive about public reputation .. One particular aspect of this pressure is that it is regulated by OFTEL and has a Universal Service Obligation (USO) to make basic telecommunications services available to all upon reasonable request ..

(b) Strategy - Because it makes long-term business sense. It is clearly in BT's long-term interests to close the Digital Divide as part of its strategy to increase the market in which it operates. .. University of Michigan business guru, C.K. Prahalad, has pointed out the market opportunity in developing countries - four to five billion people that in aggregate have purchasing power; "selling to the poor may be more profitable than selling to you and $m e^{n}$.

(c) Values - BT has a culture of doing the right thing. The Digital Divide has become a key issue of corporate social responsibility particularly for companies involved in IT and telecommunications. BT is well known for its commitment to corporate social responsibility which predates the current interest in the Digital Divide and believes that its public reputation and its performance as a company go hand in hand.

(DDBW: p18)

The important point in this response is that 'addressing the Digital Divide' is understood to concomitantly involve both 'business sense' and 'doing the right thing', further described below as reflecting an already existing reality:

The Digital Divide in its broadest sense has become a critical public policy issue, both reflecting social and economic objectives, and their increasingly inter-twinned relationship .. BT's stance towards the Digital Divide .. is set by its technological competence, and its leadership role as a responsible corporate citizen .. its 
commitment to contributing to address the Digital Divide is .. framed by its underlying business objectives and strategy. (DDBW p.26, my italics)

The discourse of 'corporate citizenship' thus constructs a relation of equivalence between the economic and the social. In Figure 4.3, there is a further figurative performance of this articulation of the social and the economic through the Digital Divide. The Digital Divide is represented in this rather confusing diagram by the central ' $\mathrm{O}$ ' ring, having been 'unpacked' in the adjoining text as involving 'Connectivity, Capability and Content'. Through the Digital Divide then, 'Corporate Social Responsibility' is discursively sutured with 'The New Economy':

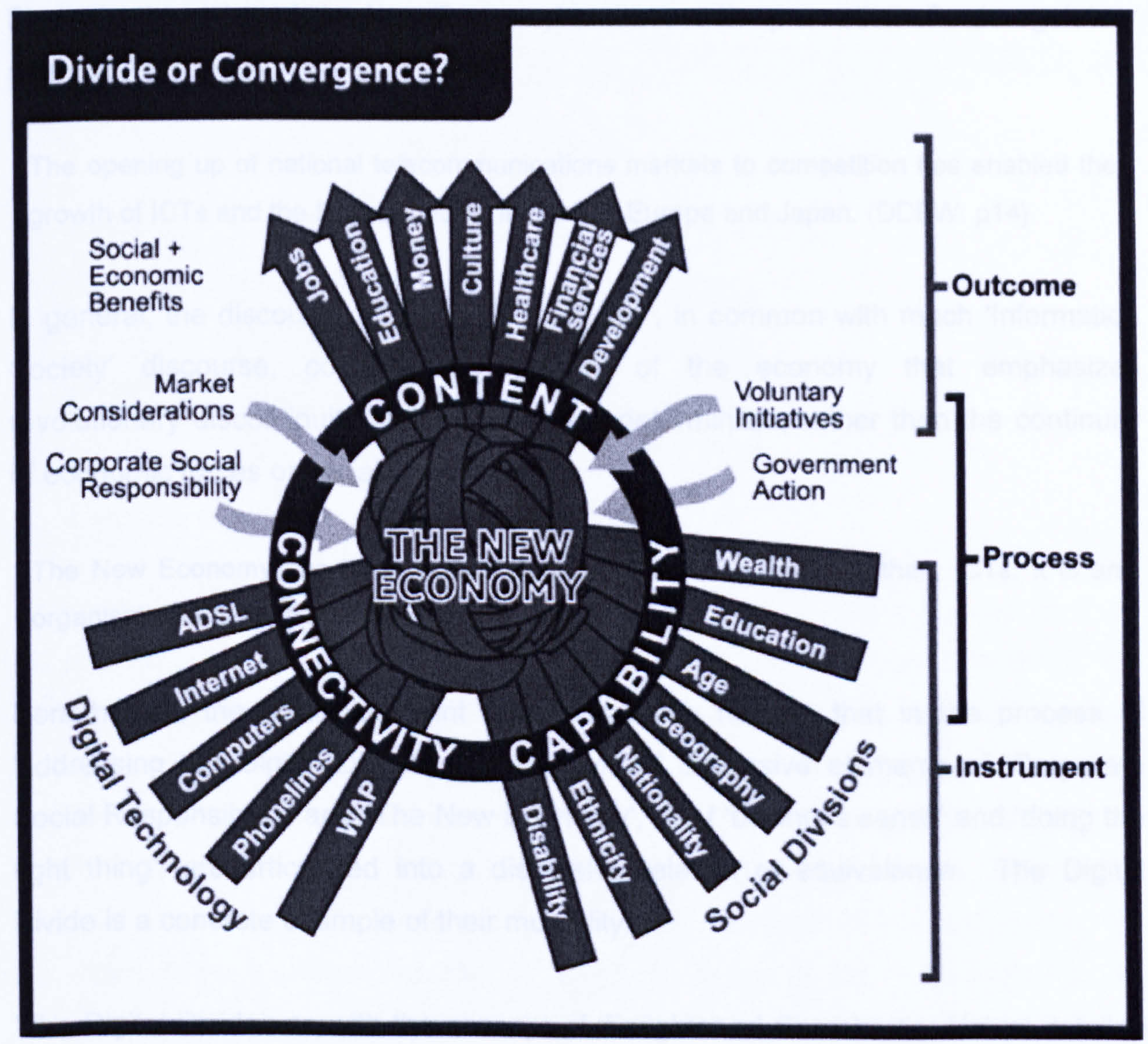

Fig. 4.3 Divide or Convergence? (The Digital Divide: Better World - Our Commitment to Society, p11) 
Individually, discursive projects such as 'Corporate Social Responsibility' and 'the New Economy' dictate important parameters of corporate strategy. For example:

CSR is critical for optimising customer and employee satisfaction .. we estimate that BT's CSR performance accounts for over $25 \%$ of the Image and Reputation driver of customer satisfaction (BT 2001b: 2)

Consequently, CSR is ironically something that corporations such as BT quest for differentiation and seek competitive advantage through. Several places in the corpus mention that BT occupies a top ranking in the Dow Jones Sustainability Index.

Similarly, the vision of 'the New Economy' buttresses the promotion of a deregulatory agenda:

The opening up of national telecommunications markets to competition has enabled the growth of ICTs and the New Economy in the US, Europe and Japan. (DDBW: p14)

In general, the discourse of 'the New Economy', in common with much 'Information Society' discourse, constructs a version of the economy that emphasizes revolutionary discontinuity and technological determinism, rather than the continuity of economic forces or social contingency:

The New Economy has been accelerated by, but is also far more than, ICTs. It is an organisational revolution. (DDBW: p6)

Nonetheless, the particular point I wish to make here is that in the process of 'addressing the Digital Divide', these individual discursive elements of 'Corporate Social Responsibility' and 'The New Economy', or of 'business sense' and 'doing the right thing', are articulated into a discursive relation of equivalence. The Digital Divide is a concrete example of their mutuality.

'The Digital Divide', as with the concept of 'Enlightened Shareholder Value' detailed in Section 4.3, can thus be discursively understood as a vehicle for the wider renewal of a discourse of 'corporate citizenship' based on an equivalence between social and 
economic concerns. ${ }^{11}$ This is exemplified in BT's summary email at the end of the digital divide discussion which introduces the concept of the 'social change business':

While there was broad agreement that the activities of ICT companies are having huge impacts on society, there was a range of opinions on whether companies should actively get involved in the social change business. (E-mail Discussion: BT Summary e-mail, my italics)

\subsection{Mode of Engagement}

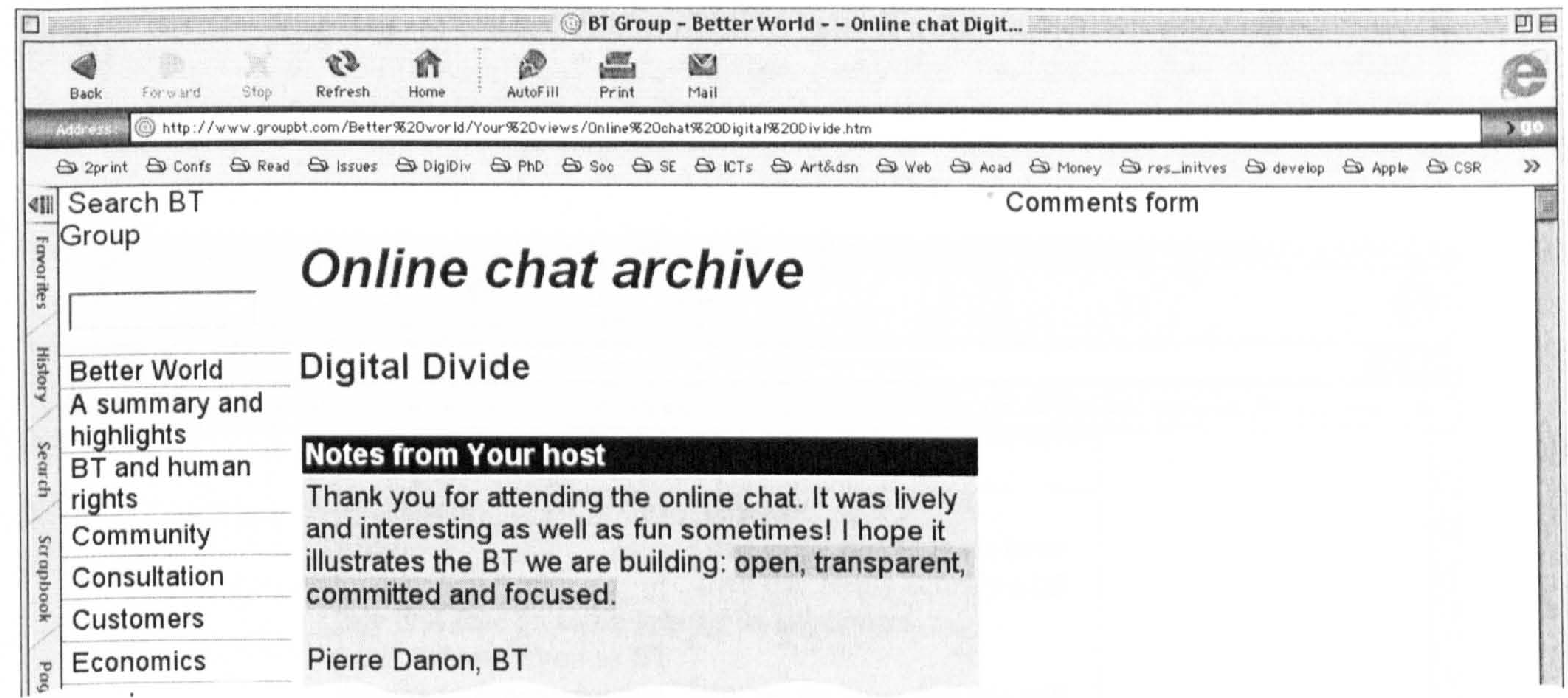

Fig. 4.4 Online Debate: Notes from Your Host

Alongside having an audience to be accountable to and an object of accountability, the claim to accountability is buttressed because of specific qualities claimed for the particular mode of engagement. Virtuous self-descriptions appear regularly throughout the consultations. These occur individually as with the claim for the upcoming 'live online debate' in the introductory e-mail. They also frequently appear together, as in the 'notes from your host' (Fig. 4.4) above: 'open, transparent, committed and focused.' To a significant extent, the qualities that are claimed for the mode of engagement are imbued simply by virtue of the consultations being online, and as such are examples of a simple Utopian 'techno-boosterism' (Barbrook 1996) or 'cyberbole' (Woolgar 2000), equating the technical potential for many-to- 
many communication in the online domain with a necessary reinvigoration of democratic public discussion, operating without restrictions of space or prejudice. ${ }^{12}$

The initial claim that the debate is live, alongside the visual staging of the online discussion, draws upon what Brown and Michael term 'a powerful repertoire of signification on which the authority of both politics and science is based .. it has its roots in the whole spectacle of political parliamentary display on the one hand and experimental display on the other' (2002: 5). Initially then, it is through the technical performance of the consultation as a witnessed public spectacle that claims of accountability may be played out.

\subsubsection{Interactivity}

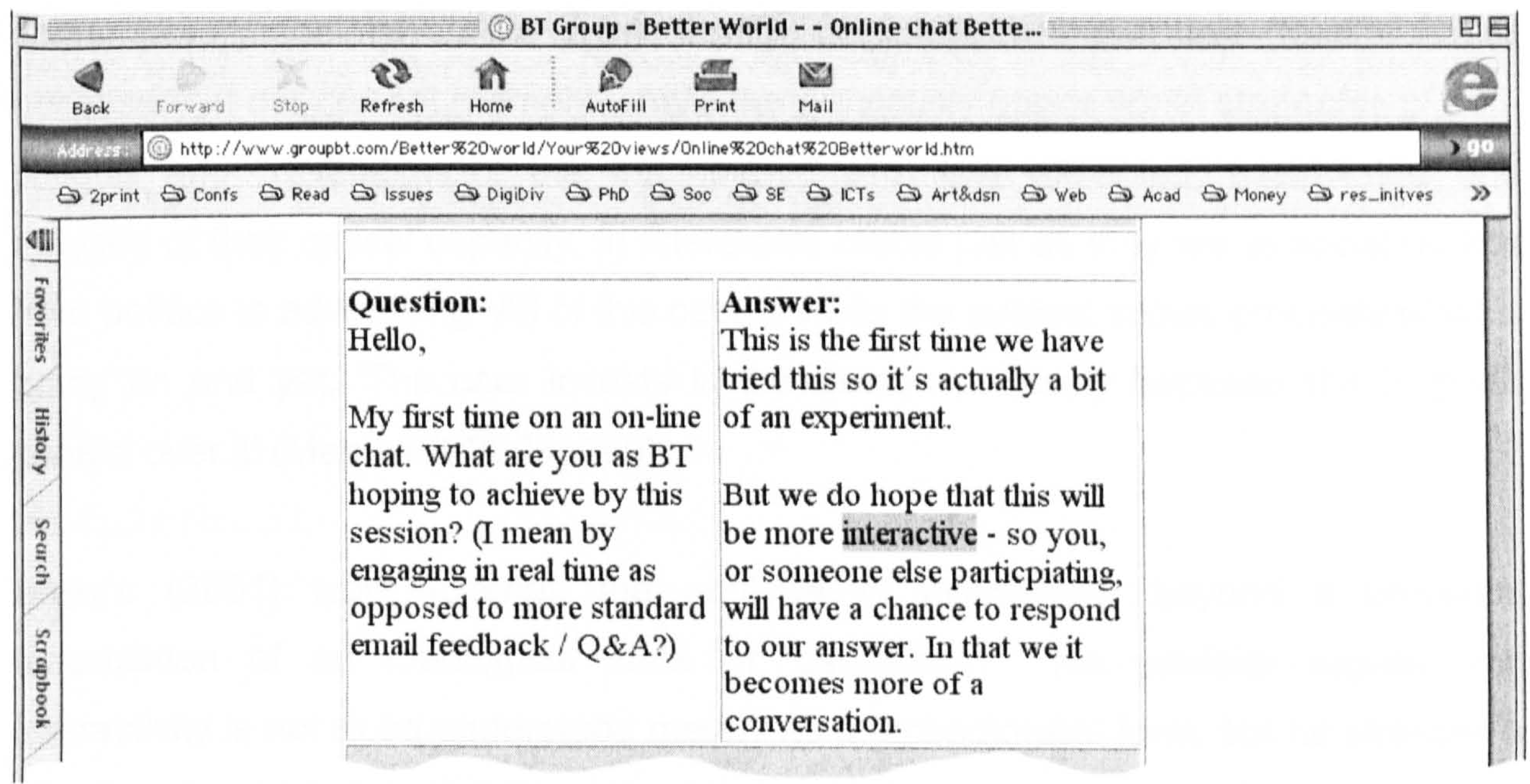

Fig. 4.5 Online Debate: Interactivity

One significant claim made for the mode of engagement is that 'we do hope that this will be more interactive - so you .. will have a chance to respond to our answer .. in that way it becomes more of a conversation' (Pierre Danon, CEO BT Retail, Online Debate: see Figure 4.5 above). This account contains both the valorization of interactivity as a mode of engagement per se, together with a suggestion that the current consultation is an example of this. Indeed, with the invocation of the 
technical in the construction, 'this will be more interactive', the suggestion is that the online discussion is a particularly enhanced instantiation of interactivity.

As Manovich (2001) notes, the concept of interactivity has a long history. He argues for a specific understanding of interactivity in terms of a central ideological relation, one that has assumed particular importance in the era of new media. His argument initially follows a standard line that by having to periodically take an active role and participate in the interactive text in order to complete it, the subject is interpellated into it. This iterability of the new media object also 'assures the users that their choices - and therefore, their underlying thoughts and desires - are unique' (Manovich 2001b: 107). He then takes this a step further, suggesting that the 'oscillation' between the ontological states of interactivity and illusion in our experiences with new media can be understood as a structural feature of contemporary society. Unlike in modernity, complete and seamless illusion is not necessary in our current moment where the previously oppositional strategies of selfcritique and "revelation of the machinery," are now expected, assimilated and emptied of their critical capacity, in interactive media just as they are in social realms from politics to advertising. All of this occurs while the subject knows precisely what is going on and yet, 'The user invests in the illusion precisely because she is given control over it' (Manovich 2001: 209).

Barry's (2001) work extends the analysis of interactivity beyond a universal theorization of an ideological state of 'oscillation'. He similarly argues that interactivity is not to be understood merely as a technological form, but he stresses a situation in which interactivity, as a 'diagram of contemporary social organization' (p31), is instantiated in practice and operates in a local context as 'a dominant model of how objects can be used to produce subjects' ( $p 139)$. In an analysis of 'interactive' science museums, he emphasizes how visitors are not expected to contemplate from a distance nor to engage in critical reflection on the messiness of scientific practice, but 'to have a quite immediate physical and practical connection .. 'interactivity' is intended to direct and enhance the activity and engagement of the visitor [who] becomes herself an artefact of the museum' (p30). As such, drawing on Zizek (1997), Barry argues that interactivity may, 'reduce the space for creative forms of passivity' (p31). 
As I detailed earlier, the form of interactivity instantiated by BT is carefully orchestrated to limit the possibilities of any sustained criticism. The particular claim of interactivity additionally involves an appeal to what Fairclough (2000: 16) terms 'semiotic ordinariness'. Fairclough argues that the reauthorization of contemporary political discourse occurs in part through the appropriation of everyday conversational form. In Fig. 4.5 the appeal is as much blatant as formally staged, simply claiming that the 'interactive' engagement 'becomes more of a conversation'. That such a valorization of conversationalism occurs is unsurprising given that historically, BT's branding has centred on being seen as the 'guardian of communication' and promoting the idea that 'it's good to talk', particularly in order to establish a level of authentic intimacy (Cameron 2000). The promotion of the mode of engagement here as 'interactive' and 'conversational' may thus be seen more widely, beyond the specific performance of accountability, in terms of offering an experience of the meaning of the BT brand. ${ }^{13}$

\subsubsection{Transparency}

Allied to the claims for a live and interactive mode of engagement, a further significant claim made is that the mode of engagement is 'transparent' and 'open'. Alongside accountability, transparency is seen as increasingly important goal for contemporary corporate and political practice in order to assuage potentially damaging mistrust. Zizek (1997) has theorized the motivation to transparency as a cultural logic that operates across many contemporary domains. In a reflection on the contemporary proliferation of 'the making of' films, he argues that, 'in a kind of reversal of the cliché according to which Western ideology dissimulates the production process at the expense of the final product .. the central paradox of postmodernity (and perhaps the most succinct definition) is that the very process of production, the laying-bare of its mechanism, functions as the fetish' ( $p 102)$. Ideology thus paradoxically retains its misrecognising force over subjects through transparency, by exposing its own operations: 'in revealing that ideology is constructed, it effectively says "I have nothing to hide, I possess the real"' ( $p 103)$. 
With reference to discursive micro-management, Potter (1996) similarly argues that where issues of stake are absolutely obvious and salient, transparently acknowledging an element of self-interested motivation may strategically be beneficial. It may be disarming and seemingly honest, and hence actually 'inoculate' against accounts not being taken seriously because of such 'stake accusations' of inevitable self-interest. During visits to BT, which were welcomed under the motif of transparency, an awareness on the part of my interviewees of my status as a sociologist, and hence a potential critical intention, nonetheless prompted a range of responses:

Josephine switches between both a flatteringly complicit open-palmed acknowledgement, e.g. that we both know that 'if we presented it as being in our own interests, it wouldn't look good', as well as numerous stridently naked assertions, which have the content, though not the tone, of confession: e.g. 'the real bottom line comes with making a business case to the board', and, 'we are not going to wire Africa'. The effect of this, both during the interview and in writing up the notes afterwards, is that it is disarmingly difficult to get a critical fix on any position that was presented. It feels like a dizzying reversal in the way that reading an argument such as Baudrillard's, that Las Vegas is so obviously simulated in order to convince us that the rest of America is real, can make you feel. After the interview, Josephine took me on a tour of the Social Policy Unit to meet various people. She had continuously referred to her colleagues as 'from an advocate background' in the interview. Many of the staff had various pages from the Betterworld website showing on their desktop computers as a visible performance of their work. (Field Notes)

A rapidly switching range of discursive strategies were thus displayed in this one encounter, from complicity, through the assertion of further 'bottom lines', to the straightforward working up of a 'counter interest', the advocacy of staff.

Brown and Michael (2002) maintain that, despite its association with the concept of complete visual clarity, transparency is best thought of not as an attainable ideal betrayed in reality by relations of obfuscation, but rather as an always locally constructed practice. They argue that the institutional performance of acts of transparency needs 'to appeal to the audience's sense of belief in the authenticity of disclosure, that facts are real and genuine' (2002: 10). Further, they suggest that: 
openness alone is an insufficiently convincing vehicle with which to persuade audiences of good and honourable intentions. Something more is needed .. the increasing recourse to the 'emotional academy' of political persuasiveness. The shift from authority to authenticity is grounded in a political rhetorical culture that has increasingly come to depend on agnostic demonstrations of personal genuineness. (2002: 7)

In their work on discourses of xenotransplantation, the dominant cultural repertoire that they emphasize is employed to evoke facticity and the authenticity of decisionmaking is that of the performance of pained emotional suffering, particularly in making 'tough choices' which signify that 'all possible perspectives have been accommodated, all that can be borne has been borne' (2002: 7). In this case study, I argue that there is evidence for a similar shift in the epistemological picture from the language of rationalistic authority. However, while this is in part drawn from the naturalistic repertoire of emotions, and the authentic intimacy of conversation referred to earlier, it more widely articulates with a repertoire of religious faith and in particular a performance of commitment, devotional as well as emotional. Such commitment is directly claimed in the 'Notes from Your Host' at the beginning of the online discussion, 'I hope it illustrates the BT we are building: open, transparent, committed and focused, and is referred to regularly in the responses BT provides throughout the discussion: 'we treat it seriously'. 'we do this in good times and bad', 'I share your frustration', 'CSR is the right thing to do because we believe in it'. The authenticity claimed here is for that which is beyond doubt. ${ }^{14}$

\subsection{Supplementary Accountability}

So far I have argued that the issue of (lack of) accountability occupies an increasingly central place in contemporary corporate discourse. The performance of accountability is seen as an increasingly necessary activity, if still a rather unknown proposition. The analysis in this chapter details one such performance and points to a situation in flux, where this process of demonstration and stabilization is being worked through. I have pointed to the contingent discursive practices that configure the parameters of the public in stakeholder subjectivity, construct an object of accountability, and uphold a programmatic self-understanding of engagement via 
new media as live, interactive and transparent. Resources such as the stakeholder, a real issue, interactivity, transparency and commitment are thus enlisted and assembled to partially stabilize this performance of accountability, as an interactive stakeholder consultation on an objective issue.

In many respects opening up this attempted construction to provide points of critique is a perfectly valid sociological reflex, allied to the position of much sociological work which points beyond the understanding of accountability as a thing to be achieved and represented by an artefact such as a report, to argue for a more procedural understanding of the context and social construction of accountability (e.g. Munro and Mouritsen (eds.) 1996). Here records and reports are intermediaries in the accountability process, as well as claimed evidence of it.

However, I wish to finally draw attention to certain moments of ambiguity and undecideability in this particular performance of accountability. The corpus contains several points of internal tension, not least of which is the following technology of non-accountability, the disclaimer, which introduces the DDBW report, and confusingly blurs and separates the accounts of the firm and the individual authors:

This Hot Topic, researched and written by Simon Zadek and Peter Raynard, sets out BT's approach to the Digital Divide. The views represented here are those of the authors, not necessarily those of BT. (DDBW: 3 )

However more importantly, as part of the performance of accountability, there is an explicit request for the audience's ongoing evaluation of the discussion, as in the following example:

we would also like to draw on the guidance of the digital divide audience and will be sending a questionnaire .. this will help to build the indicators that will clarify how to accurately measure the quality of the process.

(Email Discussion: AccountAbility message) 
The particular version of accountability performed thus itself explicitly involves the reflexive acknowledgement that accountability requires working up. There is a recognition that evaluation and quality are ambiguous and contestable concepts requiring ongoing articulation, but this recognition is itself part of the performance of accountability to be evaluated. This undecideable situation is summarized in the following exchange that concluded BT's summary email, sent out at the end of the two-week discussion:

Participants themselves raised a further key issue:

How will this debate be used?

BT is compiling a response to this question which will follow shortly.

(Email Discussion: BT Summary emain) ${ }^{15}$

I argue that such dialogic necessity completes, but also troubles, this particular performance of accountability. In Derrida's (1976: 63) terms, this concomitant closure and vulnerability may be considered as a 'process of supplementarity'. ${ }^{16}$ । suggest that it is important to recognize the centrality of incertitude, undecideability and deferral in the discursive structuring of contemporary accountability, and that corporate, and for that matter sociological, attempts to define it in terms of positive presence, whether artefactual or procedural, only follow one path suggested by its very tissue.

\subsection{Conclusion}

I have argued in this case study that 'the Digital Divide' is discursively understood such that it articulates a chain of equivalence between social and economic concerns, specifically between the projects of 'Corporate Social Responsibility' and 'the New Economy'. As such, it can be considered as both drawing upon and renewing a wider logic of contemporary corporate discourse that emphasizes the equivalence of social and economic concerns through discursive constructions such as 'joined-up' or 'triple bottom line accounting', the 'business case for CSR' and, 
specifically in the political context of the Company Law Review, 'Enlightened Shareholder Value'.

Further, I argued that the 'issue' of 'the Digital Divide' is both meaningful in terms of the management of internal organizational identity and is constructed as a particular object of external accountability. I agued that one ongoing concern for contemporary corporate discourse is that the presentation of the organization as more widely accountable is seen as increasingly necessary but still a rather unknown proposition, although there is some general movement away from inherited understandings of representational financial accountability towards a more dialogic accountability, particularly through the controlled enrolment of the public.

The analysis of the particular performance of accountability in this case study points to a situation in flux, where this process of demonstration is being played out in practice. I argued that the performance of accountability is understood to require having an audience to witness and be accountable to, an object of accountability, and a particular mode of public engagement. I thus pointed to the contingent discursive practices that configure the parameters of the public in stakeholder subjectivity, construct an object of accountability, and uphold a programmatic selfunderstanding of engagement via new media as live, interactive and transparent. Discursive resources such as the stakeholder, the Digital Divide, interactivity, transparency and commitment are constructed and enlisted to partially stabilize this particular performance of accountability, as an interactive stakeholder consultation on an objective issue. I finally highlighted points of undecideability in this particular case study, and suggested that it may be important to pay further attention to such discursive moments in the contemporary phenomenology of accountability. 


\section{Notes:}

'In more detail the rationale is understood as follows:

'By empowering people in developing communities, we enhance our own competitiveness creating innovations we would not have thought of otherwise, discovering talent we never would have found, and spurring revenue growth as we devise new business models to serve emerging markets .. What began as a broad effort to apply technology to closing the digital divide, has become focused largely on using information and communications technology (ICT) to accelerate enterprise and entrepreneurship, and thereby stimulate economic growth' (Hewlett Packard 2004).

${ }^{2}$ This department was previously known as the Corporate Reputation and Social Policy Unit.

${ }^{3}$ Indeed, during the course of the review, an amendment to the 1995 Pensions Act in July 2000 required UK pension funds to disclose in their Statement of Investment Principles 'the extent (if at all) to which social, environmental or ethical considerations are taken into account in the selection, retention and realisation of investments'.

4 Judicial review proceedings were launched against Gordon Brown and Alan Johnson (Secretary of State for Trade and Industry) over this decision in January 2006 (Friends of the Earth 2006).

${ }^{5}$ Mulgan (2000: 555) concurs, arguing that within public administration 'accountability is a complex and chameleon-like term .. A word which a few decades or so ago was used only rarely and with relatively restricted meaning .. now crops up everywhere performing all manner of analytical and rhetorical tasks and carrying most of the major burdens of democratic "governance".

\section{${ }^{6} \mathrm{http}: / / \mathrm{www} \cdot \mathrm{bt} . \mathrm{com} / \mathrm{betterworld/}$}

7 This data is complemented by field notes from visits to BT and discussions with personnel working in the Social Policy Unit and other departments.

${ }^{8}$ As well as the Digital Divide, the 'Hot Topics' for 2001 were 'Masts, Mobile Phones and health', 'BT in India', and 'E-business and the Environment'.

9 According to their website: 'Accountability is an international membership organization committed to enhancing the performance of organizations and to developing the 
competencies of individuals in social and ethical accountability and sustainable development. (www.accountability.org.ukJ, accessed Jan 2004)

${ }^{10}$ The 'Digital Divide Network' discussion list hosted by the Benton Foundation. The Benton Foundation was set up by William Benton, the founder of the advertising agency Benton \& Bowles and publisher of the Encyclopedia Britannica. It is 'a private foundation, an institutional hybrid, bridging the worlds of philanthropy, public policy and community action' whose mission is 'to articulate a public interest vision for the digital age and to demonstrate the value of communications for solving social problems' (http://www.benton.org/accessed Jan 2004).

11 This logic of equivalence between the social and the economic is fortified not just by the particular articulation of 'the Digital Divide' but also by the more general social imaginary of 'best practice' and the 'win-win scenario':

Companies must transparently commit themselves to addressing the Digital Divide within their core business strategies as well as through community investment. Best practice will come when there is a blurring of the lines between the two, thereby creating the win-win scenario. (DDBW: 26-27)

The utopian vision of the 'win-win scenario' is more forceful than BT's previous organizing metaphor of 'balance' between social, environmental and economic concerns ('A Question of Balance', BT 1998). It discursively excludes the possibility that there may be 'tragic conflicts' (Perri 6, 2002) between social and economic concerns, the needs of capital and the needs of society. Indeed, such utopian tropes are salient throughout contemporary discourses of CSR and particularly the organized discursive optimism of 'the New Economy'. As Schiller (2000: 31) notes in his analysis of the New Economy phenomenon, Irrational Exuberance, 'analysts have few worries about being uniformly optimistic; they have concluded that such generalized optimism is simply good for business'.

12 Rhinegold (1993) offers an optimistic defence of the potential of new media for increased participation in democratic consultation. Similarly, O' Baoill (2000) considers online fora as potential installations of the Habermasian 'ideal speech situation'. See Hague and Loader (1999) for a further critical overview of academic debate in this area. 
${ }^{13}$ Klein (2000) argues that much contemporary corporate practice, for example in the construction of palatial, interactive loss-leading stores, can be understood in terms of the reconfiguring of cultural space in order to offer an experience of the animating meaning of the lifestyle brand.

${ }^{14}$ Indeed, in the latest Social and Environmental Report, the Chief Executive's message stresses the value of heart. "I am convinced that being a responsible company through living our values (trustworthy, helpful, inspiring, straightforward and heart) brings us business advantage. (BT 2005: 1)

is In fact, such a response never did follow via e-mail. When accessed in Dec 2003, a 'response to the e-mail debate' had been appended to the website archives of the e-mail debate, which stated that 'One of the key questions raised in this debate has been "how will BT use the debate?" We see engagement not so much as an end in itself, as a means of informing our decisions and keeping up to date with our stakeholders' views.' (http://www.btplc.com/SocietyandenvironmentYYourviews/BTresponsetoDigitalDividedebate.htm)

${ }^{16}$ In Derrida's (1976) reading of the work of Rousseau, beginning from the axiom, 'I can certainly say that I never began to live, until I looked upon myself as a dead man' (p143), he theorizes the supplement as both exterior to and yet completing a supposed self-sufficient presence, it both adds to and takes the place of, 'and each of the two significations becomes discreetly vague in the presence of the other ( $p 145)$. As such, 'the supplement is neither presence nor absence; no ontology can think its operation' (p314). Rather, Derrida's reading suggests an 'indefinite process of supplementarity [which] has always already infiltrated presence' ( $p 163$ ), and hence 'through the sequence of supplements a necessity is announced .. the very sense of the thing they defer' (p157). 


\section{$\square \square$ Chapter 5.}

\section{Supranational Discourse on The Digital Divide}

\section{$\underline{5.1 \text { Introduction }}$}

This chapter analyzes the construction and function of the digital divide within contemporary supranational discourse. In recent years, many international organizations, governmental and non-governmental, have undertaken initiatives, authored reports, and developed policies that have been directly concerned to understand and address the issue of 'the digital divide' beyond a particular national context (e.g. WEF 2001, OECD 2001, Digital Opportunity Initiative 2001). ${ }^{1}$

However, there is little academic work critically analyzing how, and with what consequences, the digital divide is understood within such organizations. In particular, as Mansell (2002: 408) notes, 'there are comparatively few accounts of how those who inhabit the 'meso-level' institutions of policy are constructing prevailing conceptions of the new media and the associated norms for social organization'. She argues, in general terms, that the 'rhetorical form' of intergovernmental digital divide discussions 'emphasizes economic growth and the deployment of pre-figured technologies, over issues of equity, social development and the need for a broader conception of the potential of new media' (2002: 417). Acknowledging that her arguments are based on her own anecdotal experience as a participant in various policy forums, Mansell does not develop the idea of 'rhetorical form' in detail beyond pointing to the economic focus and determinist understandings that individual participants in such forums often seem to bring to them. 
In order to offer a more detailed analysis of what such 'rhetorical form' might mean and do, this chapter undertakes an analysis of one such supranational policy initiative, the year-long activity of the Digital Opportunity Task Force (DOT Force). The DOT Force was initiated at the $2000 \mathrm{G} 8$ summit, where the G8 leaders adopted The Okinawa Charter on the Global Information Society (G8 2000). The charter asserted that 'bridging the digital divide has assumed a critical importance on our respective national agendas' (para 8), and proposed that the DOT Force be set up with a view to 'integrating these efforts into a broad international approach' (para 18) and reporting its findings to the 2001 G8 meeting. The DOT Force thus culminated with the publication of the report 'Digital Opportunities For All: Meeting the Challenge' (DOT Force 2001) at the G8 summit in Genoa one year later.

In selecting the DOT Force as a case study from the plethora of supranational initiatives concerned with the issue of the digital divide, I argue for three main justifications. Firstly, the $\mathbf{G} 8$ is commonly regarded as one of the most important 'global directorates' whose collective decisions have a critical influence on the global agenda and the politics of global governance (Hajnal 1999). Secondly, the setting up and the final report of the DOT Force achieved a saliency within international media coverage far beyond that of any other supranational initiatives on the digital divide. Finally, many of the other supranational initiatives, e.g. the Global Digital Divide Initiative (WEF 2001), fed into the DOT Force process, both via the appointment of key personnel from these projects onto the DOT Force, and through the use of their reports as key consultative and agendasetting documents.

This chapter thus provides a critical discursive analysis of the final report of the DOT Force, together with thick description of the processes by which it was produced. It pays particular analytic attention to the structure of the DOT Force initiative, changes in the various iterations of the final report, and the document trail of associated templates, minutes and documentary submissions ${ }^{2}$. The aim 
is to analyze how the digital divide is understood within this case study of contemporary supranational discourse, and what wider discursive functions this serves. One specific focus will be upon if and how any disagreements between the participants in the DOT Force manifest themselves, and how they are resolved in the processes of production and the narrative of the final DOT Force report.

\subsection{Legitimating the DOT Force}

In order to buttress the credibility of its analysis, the DOT Force final report emphasizes the particular manner in which it attempted to meet its stated objective 'to enhance global understanding and consensus on the challenges and opportunities posed by information and communication technologies, and the role that these technologies can play in fostering sustainable, participatory development' (DOT Force 2001: 21):

'This report is the result of a unique international collaboration. The Digital Opportunity Task Force (DOT Force), created by the G8 Heads of State at their Kyushu-Okinawa Summit in July 2000, brought together forty three teams from government, the private sector, non-profit organizations, and international organizations, representing both developed and developing countries, in a cooperative effort to identify ways in which the digital revolution can benefit all the world's people, especially the poorest and most marginalized groups .. Over several months, through a rich and unprecedented mix of plenary meetings, informal consultations, meetings with stakeholders, and electronic outreach to broader audiences across the world, the DOT Force has examined in depth the challenge of bridging the digital divide.' (DOT Force 2001: 3)

The authority claimed for the analysis is thus predominantly that its organizing principles, of multiple representation, rich consultation and broad 'electronic outreach', are innovative, inclusive, and exemplify the global in their structure: 
A broad, participatory approach to deliberations, securing the views, participation and consensus of a wide range of stakeholders on a global level' (DOT Force 2001: 23)

'The international community in its various guises - governments, private sectors, non-profit sector, international organizations - can and must play a critical role .. The Digital Opportunity Task Force [is] itself structured in a way that affirms the importance of these multidimensional partnerships' (DOT Force 2001: 12)

In this section, I wish to examine these organizing principles in some detail. An extended analysis of the DOT Force process reveals numerous conflicts over its organizational structure and procedures, and their discursive closure in the final report.

The first issue is the claim of multiple representation. The $\mathbf{G} 8$ presidency appointed a DOT Force Secretariat of four people, two from the World Bank and two from the United Nations Development Program (UNDP) who recruited 43 other teams of members to the DOT Force. Further membership was invited in accordance with a principle that Perlas (2000) identifies as 'threefolding', the idea that there are three contending institutional powers - global civil society, government and business - that determine the direction of world development.

This principle was applied for the G8 member states ${ }^{3}$, each of whom had representation on the DOT Force from government, from the private sector, and from a 'non-profit organization' (NPO) ${ }^{4}$. However, beyond the G8 nations, the invitation to eight non-G8 or developing nations to join the DOT Force was extended only to government representation, not private sector or NPO organizations. ${ }^{5}$ In addition to these $\mathbf{3 2}$ groups, representation was recruited from six programmes and agencies directly or indirectly within the UN family of organizations $^{6}$, from three private sector lobbies ${ }^{7}$, and from the European Commission and the Organization for Economic Co-operation and Development (Fig 5.1). 
Secretariat: $2 \times$ World Bank, 2 X UNDP

\begin{tabular}{|c|c|c|c|c|c|}
\hline G8 States & $\begin{array}{l}\text { G8 Private } \\
\text { Sector }\end{array}$ & G8 NPOs & $\begin{array}{l}\text { Developing } \\
\text { States }\end{array}$ & $\begin{array}{l}\text { Multilateral } \\
\text { Agencies }\end{array}$ & $\begin{array}{l}\text { Lobbying } \\
\text { Groups }\end{array}$ \\
\hline Canada & Canada & Canada & Bolivia & UNECOSOC & WEF \\
\hline France & France & France & Brazil & UNCTAD & GIIC \\
\hline Germany & Germany & Germany & Egypt & UNESCO & GBDE \\
\hline Italy & Italy & Italy & India & UNDP & \\
\hline Japan & Japan & Japan & Indonesia & ITU & Other \\
\hline Russia & Russia & Russia & Senegal & World Bank & IGOs \\
\hline UK & UK & UK & South Africa & & \\
\hline US & US & US & Tanzania & & EC \\
\hline
\end{tabular}

Figure 5.1 Membership Structure of DOT Force

As well as organizing the membership of the DOT Force process, the Secretariat was also responsible for developing a framework for the consultation process. The key elements of this were three two-day plenary meetings for the members, held in Tokyo, Cape Town and Siena. After each of the three plenaries, an updated draft of the DOT Force report was put together by the Secretariat and distributed to the members. At each plenary, the members discussed the current draft as well as presenting further documentary submissions. These submissions referred in many cases to consultations within their own member states and networks undertaken in the interim periods. The final report was written by the Secretariat after the Siena plenary and submitted to the Genoa G8 meeting in 2001. 


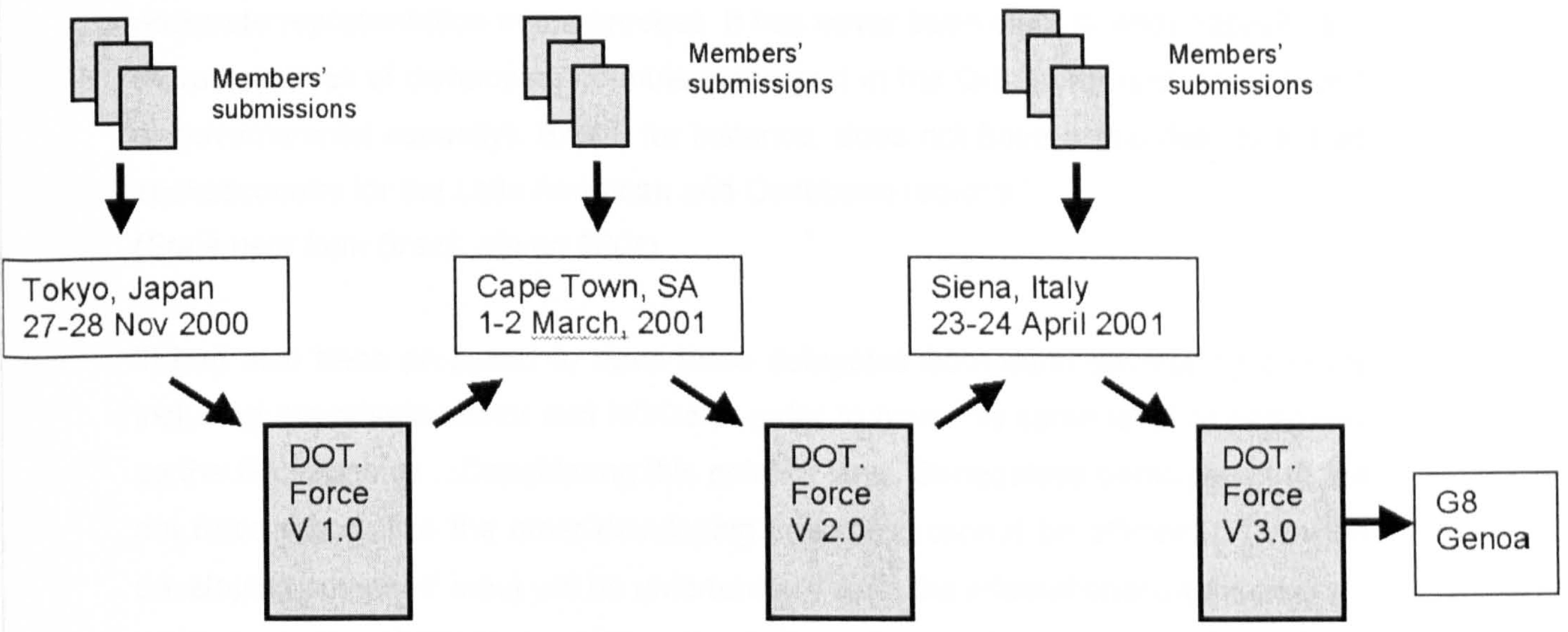

Figure 5.2 Iterations of the DOT Force report

Along with multiple representation, a further fundamental legitimating principle of the DOT Force was that of networking. Members were invited both for their own expertise and for their ability to bring their own networks into the DOT Force process, to organize their own discussions and 'electronic outreach', according to a 'consultation matrix' (Consultation Matrix: DOT Force Secretariat 2000):

'they will bring their own experience and expertise, as well as their contacts and networks to the DOT Force's deliberations ... to take maximum advantage of already existing networks given the short time frame of the DOT Force process' (Consultation Strategy note: DOT Force Secretariat 2000)

There are several points worthy of note at this stage. A fundamental quantitative point is that the disparity in the weightings of the membership privileges the views of the most powerful nations and the private sector over the developing nations. It is clear in the individual submissions of the developing nations to the DOT Force, that their overall under-representation, and enrolment as representatives of global regions, is of key concern: 
'DOT Force represents a challenge for the Developing Countries in terms of their adequate representation in the process. It has never been clear in what capacity the representatives of developing countries take part in the G-8 group (personal, expert or governmental capacity). Brazil, for instance, does not have a mandate to act as spokescountry for the Latin American and Caribbean regions.'

(Statement from Brazil, March 2001)

'It had also been proposed to have three delegates from each developing country including the private sector and NGOs in order to have the same level of delegates as the $\mathrm{G} 8$ countries ...Considering this point of view, Senegalese participation to the dot force report, like the other developing countries, cannot be efficient. Then the developing countries' input will be unfortunately what the international organizations which have the ability to organize consultative missions in these countries - have done instead of the local delegates ... I hope that in the future this kind of experience in international cooperation will be renewed to take into account specific priorities defined by the local populations' representations themselves .. I want to thank all the dot force members to have given us the opportunity to participate and share "success and failed stories" even though this is not obvious sometimes.'

(Statement from Senegal, March 21, 2001)

In addition, the G8 members were able to mobilize many resources for their 'electronic outreach' efforts. For example, the UK members organized a one-day meeting attended by sixty members of the UK development, private sector and government communities and hosted an online discussion before presenting their submission to the Cape Town plenary. By far the most active electronic outreach projects were those undertaken by the Canadian Civil Society Consultation and the e-mail discussion undertaken by the Markle Foundation in the U.S., the Digital Opportunity Working Group, which itself implemented an iterative process of reviewing the Markle Foundation's submission to the DOT Force. In contrast, the submissions of the developing countries emphasize the difficulty in undertaking any extensive consultation because of lack of means and the timescale of the DOT Force process: 
'The extremely fast pace at which the Dot Force group has been progressing is not conducive to adequate developing country representation in the process. More time, discussions and prior knowledge of subject matter are needed so that the developing countries can adequately consult with the representative segments of their respective national societies.' (Statement from Brazil, March 2001)

'the sub-regional representation that is required by the group has not yet been effective because of the lack of means. Indeed, to create dialogue with countries whose rate of internet connectivity is too low, it is necessary to find other ways of communicating, i.e. meetings and consultations.'

(Statement from Senegal, March 21, 2001)

It is clear then that material conditions, constraints of time, finance and resources, underpin any ability to undertake or contribute to a consultation on digital inequality. The concern with the issue of speed resonates with Goldman's (2001) ethnographic findings on social and environmental research carried out for the World Bank. He argues that because such research is rarely a stand-alone project but a pre-condition to a loan process with its own set of temporal imperatives, the most widely used method of research has come to be 'rapid rural appraisal', a highly rationalized means of quickly and cost effectively gathering and analyzing information, with an 'extractive purpose in which outsiders learn about local situations' ( $p 197$ ) whilst inevitably contributing to the subjugation of what he terms 'subaltern knowledges'.

In response to some of the developing countries' criticisms aired at the Cape Town plenary, a further meeting was organized in Pretoria just for the developing countries' representatives. This resulted in a joint submission document from the developing countries (Enhanced Consultations Among DOT Force Developing Countries (ECD), 2001). As clearly stated in the introduction to this submission, the necessity of this meeting was 'that the voices of the developing countries members of DOT Force were not being heard because of their inherent constraints in resources and capabilities, as well as their geographic dispersion, 
they were unable to articulate their needs' (ECD 2001: 1). At this meeting, it also became clear that there was a further issue of concern for the developing countries, the status of the DOT Force beyond the final report:

'Developing countries must be an integral part of DOT Force, and not just be providers of input to it. In order for the DOT Force developing countries to be able to take on active roles beyond the Siena plenary, and to become effective ambassadors of the DOT Force, it will be necessary that they be more integrated within the DOT Force processes, rather than merely providing input to it. At present, nobody knows what will come out of the Siena Plenary. However, the involvement of DOT Force developing countries ends there and all subsequent progress will be determined by the G8 Sherpas and the Genoa Summit. Just as advisors do not identify with their clients' products, the DOT Force developing countries should therefore not be expected to promote this $\mathbf{G} 8$ initiative wherein they have actually only been invited to give inputs.' (ECD 2001: 3)

Such was the feeling that the ECD submission requested a very specific line edit in the draft DOT Force report then current:

'In the BACKGROUND chapter, under the header The DOT Force consultation process has been rooted in the following basic principles, the first bullet should be amended to replace the words "ensure participation of" with the words as underlined

- special efforts have been made to invite inputs from some developing countries' stakeholders who traditionally have limited access to consultations of this sort' (ECD 2001: 11)

Although this change was implemented, the ECD summary that 'the developing countries lack ownership and control of the DOT Force process' (ECD 2001: 5) remains in sharp contrast to the self-legitimating claim ultimately presented in the final DOT Force report that: 
'Participants in the DOT Force have chosen to base their work on a few basic principles: DOT Force members must feel and demonstrate active ownership of the DOT Force process in order for the process to be credible and effective.

(DOT Force 2001: 23)

That this idea was still promoted without acknowledging the radical heterogeneity and conflict in the submissions is only explicable in terms of the shedding of history that the following statement, made on the final page of the Appendix to the DOT Force report, allows:

'All inputs arising from the consultations were considered in the DOT Force's deliberations, but were not automatically incorporated in the conclusions and recommendations of DOT Force's final report.' (DOT Force 2001: 23)

\subsection{Narrative of the DOT Force report}

I will now turn to the more substantive content and form of the DOT Force final report, whilst again referring back to various individual submissions and earlier drafts of the report. As will become clear, the final report adopts an authoritative monovocal style with no reported speech or flagging of ambiguous issues or matters of contention among the submissions.

A brief overview of the structure of the final report is as follows: The 23-page document consists of a summary foreword, three main sections, and an appendix. Part One, 'The Challenge - Digital Opportunities For All, and Part Two, 'Meeting the Challenge Through Concrete and Creative Action', present a certain understanding of global society and an argument for the role of ICTs in development respectively. Part Three, the 'Genoa Plan of Action', consists of nine 'Action Points' 'to achieve sustainable ICT-enabled development, both economic and social' (DOT Force 2001: 14). The appendix charts the genesis of the DOT Force process, and gives details of its membership, meetings, and organizing principles. 


\subsubsection{The Inevitability of Technological Globalization}

Part One of the DOT Force final report, 'The Challenge: Digital Opportunities For All', begins and ends with the following two paragraphs:

'In recent years, major advances in information and communications technologies (ICT) combined with the rapid growth of global networks such as the Internet, have transformed businesses and markets, revolutionized learning and knowledgesharing, generated global information flows, empowered citizens and communities in new ways that redefine governance, and created significant wealth and economic growth in many countries. This "digital revolution" has been made possible by the potent combination of dramatic increases in the power and versatility of technologies, at significantly lower costs with enormous creativity in the applications of these tools and networks in all aspects of the economy and society.' (DOT Force 2001: 6)

'Addressing the issue of the Digital Divide in an open and imaginative fashion could be instrumental in offering an action-oriented vision to all those who, in developed and developing countries, seek to make globalization work for the poor.'

(DOT Force 2001: 9)

These framing paragraphs offer a classic expression of a technologically determinist narrative. In particular, there is an inevitability and irreversibility about the language of revolution and globalization, the need now is to 'make globalization work for the poor'. The main point I wish to make here is not to critique this understanding of globalization, suffice to say that there are a range of social scientific analyses which would contest both the inevitability of current forms of globalization and the determinism of the technological over the cultural, economic, political or ideological (e.g. see Held et al. 2005). Rather, the particular point I wish to argue for, in the material context of the DOT Force process, is that although a technologically determinist understanding of inevitable globalization is expressed in some of the DOT Force submissions, such a 
position is not universally espoused. For example, the Brazilian submission stresses the more nuanced need to 'proceed with great respect for the national cultural specificities ...taking into account the social orientation of Brazil's national Information Society Programme' (Statement from Brazil 2001). Where the DOT Force report does actually make a particular recommendation on local specificities, it is in the context of heritage, a further marker in a discourse of irreversibility:

'Support national and international programs for digitizing and putting public content online, focusing on multilingual applications and local heritage' (DOT Force 2001: 19 my italics)

\subsubsection{The Importance of ICTs to Development}

A difference between countries' ICT capabilities can only be constructed as disadvantage in such a context of an inevitable globalization, a global information society. However, although generative, this is not yet an entirely sufficient precondition for the argument that investment in ICTs is currently necessary for the cause of 'development'. One of the background positions which the DOT Force report defines itself against is the "either/or" understanding of having to make investment choices. This viewpoint, where investment in ICT may be seen to be in competition with direct investment in sanitation, education, healthcare and so on, is attributed to 'decision-makers in some developing countries as well as in the international development community [who] remain skeptical or unaware of the contribution that ICT can make to development' (DOT Force 2001: 8). In contrast, the DOT Force emphasizes that:

'Creating digital opportunities is not something that happens after addressing the "core" development challenges; it is a key component of addressing those challenges in the 21st century.' (DOT Force 2001: 7) 
'There need therefore be no trade-off between investment in ICT and the achievement of development objectives...ICT can help to ignite a virtuous circle of sustainable development.' (DOT Force 2001: 4)

Indeed, a list of the UN's seven international development goals for 2015, including targets for a reduction in the number of people living in poverty, the enrolment of all children in primary school, a reduction in infant and maternal mortality and progress on gender inequality, is supplemented by the argument that 'harnessing the power of information and communication technologies (ICT) can contribute substantially to realizing every one of these goals' (DOT Force 2001: 7).9 As such, one of the aims of any action should be 'stimulating changes in attitudes' (DOT Force 2001: 10) and the Genoa Plan of Action specifically targets such residual skepticism in proposing to 'Enhance the eAwareness of senior policy makers' (DOT Force 2001: 16).

Effectively then the only potentially problematic aspect of ICTs and technological globalization that is mentioned in the final report is the digital divide. As before, it would be entirely possible to point to public and social scientific debates that might question such an understanding of investment choices (e.g. see Lomborg (ed) 2004 on the 'Copenhagen Consensus') or point to other potential 'downsides' of ICTs beyond the digital divide. My position once again is to interrogate such a narrative through the materiality of the submissions to the DOT Force process itself. As before, the position the final report adopts is by no means universally supported in these submissions. For example, although the U.S. submission argues that 'it is imperative to establish at the beginning of the report that ICTs have become an important factor in global economies and should now be a vital ingredient for development' (U.S. Government 2001: 2), the Egyptian submission specifically raised concerns over 'job destruction', while the Brazilian submission argues that:

'Brazil believes there is still insufficient evidence to support the idea that there are no more "either/or" considerations to be made in actions to overcome the social and the 
digital gaps. In many respects - and more so in decisions regarding allocation of scarce resources, the establishment of national priorities and in the burden sharing of costs related to infrastructure, connectivity and regulatory framework - developing countries are still very much faced with "either/or" choices.'

(Statement of Brazil, March 2001)

Of particular interest is a European Commission submission to the DOT Force, a fully referenced review of academic research whose specific purpose was, 'to help address some of the "either/or" arguments that have suggested that the role of ICTs in development is irrelevant to the needs of developing countries. There is an instinctive assumption that countries without advanced telecommunications infrastructures will be left behind. The question is, therefore, can evidence to support this or other assumptions be found in current scientific and economic research?' (EC 2001: 1). The conclusions drawn were far more equivocal than those in the final DOT Force report:

The dynamics of the Divide. The possibility of a growing North-South divide is real. (A lack of access to) Digital technology does not cause this. It adds an extra dimension of access, availability and usability of information to a divide which already has many facets. Research is not very conclusive about the question of whether the growing global importance of ICTs worsens the situation.. There is a lack of linking measurement of ICTs (well underway), monitoring of developments (some initiatives taken), and comparative assessment of impacts (very scarce).'(EC 2001: 15)

Such ambiguous conclusions are simply not represented in the narrative of the DOT Force final report. Moreover, an additional discursive strategy serves to buttress this report against the potentially destabilizing effects of such arguments, to which I now turn. 


\subsubsection{The Need for Speed}

The final DOT Force report is saturated with linguistic proclamations of the virtue of novelty and the necessity of speed. If there were any doubts or calls for steady counsel regarding the appropriateness of the ICT for development agenda, these are rhetorically overwhelmed by the need to react quickly: ${ }^{10}$

'the need for novel forms of partnership and cooperation... in the creation of a multistakeholder "development dynamic". (p3)

'a rapid response to the so-called "digital divide" in accordance with the rapid pace of ICT innovation is essential' (p4)

'ICT must be embraced wholeheartedly by the broad development community at the earliest opportunity.' (p6)

'action should be.. of a "catalytic nature" ...through innovative multi-stakeholder partnerships and path-breaking integrated initiatives.' (p10)

'Development efforts will not realize their full potential if they remain limited to traditional approaches to development and international co-operation. Fresh thinking and attitudes are required from all sides. (p10)

'To make a difference, it is imperative to recognize the dynamic nature of the world of ICT' (p11)

'the complementary interaction between strategic interventions in several key areas .. has the potential to create powerful synergies, resulting in significant multiplier and network effects. These can in turn generate an upward spiral of sustainable social and economic development. (p12) (DOT Force 2001, my italics)

The title of the DOT Force report, Digital Opportunities For All, thus has a specific connotation. Levitas (2005) argues, in her analysis of discourses of social 
exclusion, that a discursive emphasis upon 'opportunity' is concomitant with a lack of analytic attention upon the wider structuring of inequality, and implies a discursive and moral imperative upon the recipients of opportunity to embrace it.

More specifically, the Digital Opportunity is temporal, 'A Historic Moment' as the first subtitle to Part One puts it. It presents a case for immediate action, lest the opportunity be missed. ${ }^{11}$ Hence the focus of the report is not analytical, but 'action-oriented .. if no action is taken at this specific point in time, we might never get another chance' (DOT Force 2001: 9, my italics). As Hudson (2003: 283) argues with reference to the 'Janus-faced' nature of the UK ICT drive, there is a certain paradox at the heart of this vision of a brief window of opportunity in a runaway world, in that highlighting the need for immediate action partly troubles the agency-free understanding of an inevitable and irreversible globalization proposed earlier.

This shift in focus and language from the digital divide to that of 'digital opportunity', and an emphasis upon positive action, is explicitly suggested in one of the submissions:

'We do not believe that a report that focuses on the digital divide rather than the means to create digital opportunity will help spur participation in the DOT Force by governments, private companies and NGOs. We believe that the final report must be more positive and action-oriented than the initial draft.'

(U.S. Government 2001: 1, underlined in original)

It is also instructive to trace the lineage of the trope 'development dynamic' (DOT Force 2001: 3). This objectifying of the adjective dynamic comes from the submission of the Digital Opportunity Initiative, a partnership of Accenture, the Markle Foundation and the UNDP, whose report entitled 'Creating $A$ Development Dynamic' (DOI 2001) centers around a figure of the same name. ${ }^{12}$ By contrast, as I have already indicated, submissions from the developing countries explicitly argued that the pace of the DOT Force process, dictated by 
the timescale of the G8 summits, was counter-productive to their participation and goals. Further, central figurative tropes and concepts from the Enhanced Consultation among Developing Countries, such as 'full-meal' development (ECD 2001: 3) or 'demand-pull and not supply-push' (ECD 2001: 9) fail to appear in the final DOT Force report. ${ }^{13}$

\subsubsection{The Plan of Action: eStrategies and eReadiness}

One of the key areas of controversy in the submissions lies between a dirigiste position, which emphasizes the role of national government in determining the regulatory, taxation and policy environment, and a more neo-liberal, free market approach where pro-competitive regulation, taxation and policy is in place. For example, after the first draft of the DOT Force report was circulated, the following were among the subsequent submissions that argued for, or stated the inevitability of, a predominately free market approach:

'Currently, the report does not emphasize the critical role of the private sector and a pro-competitive policy and regulatory enabling environment .. We believe it should if the DOT Force is to have a meaningful impact .. the report should promote the benefits of competition, liberalization and privatization.'

(U.S. Government 2001: 1-3) ${ }^{14}$

'We believe that the report could have greater focus on the crucial role of private enterprise. In the end, infrastructure has to be built by private companies. In the end, most services will be commercial. Also, local enterprise has shown to be better than government or international organizations in adapting to local demand and creating sustainable development. The role of the private sector is recognized in the report but we believe that greater emphasis is needed, not just on the need for a successful ITC sector but also that this should be in the vital context of a vibrant enterprise economy on the ground.'

(Accenture: Remarks on behalf of Private Sector 2001: 1, italics in original) 
Other submissions expressed reservations about the unfettered promotion of market liberalization and pro-competitive regulation, and emphasized more dirigiste approaches:

'Another important issue is the balance between ownership and control of information infrastructure. Liberalization mostly brings telecommunications owned by a foreign company that never promotes universal access as a main goal but profit instead.' (Submission from Senegal 2001: 3)

We call on the DOT Force, in preparing the draft "Genoa Action Plan" and in its implementation to .. promote policies to ensure the responsible re-investment of domestic telecommunications profits to benefit developing countries, whether that reinvestment comes from the public or the private sector. The insistence by the International Finance Institutions and some governments that government-owned telecom companies be privatised as a matter of ideology denies the role that can be played by a responsible publicly owned telecommunications infrastructure.'

(OECD Trade Union Advisory Committee 2001: 2) ${ }^{15}$

Despite such widely differing opinions in the submissions, the neo-liberal position on competition and regulation dominates entirely in the final DOT Force report:

'A fundamental requirement for reducing the digital divide is for countries to give priority to the development of their communications infrastructure and to provide universal and affordable access to individuals and all geographic areas of their country. A pre-requisite for this is to put in place pro-competitive policies in the communications sector and a regulatory framework that will support such competition.' (DOT Force 2001: 8)

In the final part of the report, the Genoa Plan of Action, such sentiments are translated into specific goals and 'Action Points': 
'Action Point 1. Help Establish and Support Developing Country \& Emerging Economy National eStrategies ..

These estrategies should commit, in particular, to the establishment of an enabling, pro-competitive regulatory and policy framework as well as the associated institutional policy-making and regulatory capacity, including self-regulatory mechanisms; they should also be explicitly linked to the achievement of development goals.' (DOT Force 2001: 14)

The principal resolution of the dirigiste/neo-liberal debate in the submissions then is via the proposal for National eStrategies, which should nonetheless commit to a pro-competitive regulatory and policy environment. Furthermore, it is explicitly stated that, 'Donors should refer to national eStrategies .. when designing approaches and initiatives using ICT for development' (DOT Force 2001: 20).

One particular component of such an eStrategy highlighted in the DOT Force report is that of the eReadiness assessment:

'Countries that express an interest should be supported in the development of such eStrategies which would include, if requested, assistance in performing a preliminary eReadiness assessment.' (DOT Force 2001: Action Point 1)

Over the last decade, a variety of eReadiness diagnostics that measure, amongst other factors, commitment to such a neo-liberal policy and regulatory agenda, have been developed and deployed across practically every country in the world. ${ }^{16}$ A discourse of eReadiness comparison is thus very much in existence. The importance of highlighting eReadiness in the context of the DOT Force then is not simply that the meaning of the digital divide becomes further understood in terms of the practices and standards of such assessment. Embracing eReadiness becomes a quantifiable precondition for the provision of further investment in development. 


\subsection{Secular Salvation Stories}

'The Digital Opportunity Task Force ... calls for an enhanced and coordinated global effort to build digital opportunity for all, to extend the power and promise of the digital revolution to all parts of the globe and all segments of society, to help the poorest help themselves to create richer and fuller lives that express and affirm their own distinctiveness in an increasingly interconnected global village.'

(DOT Force 2000: 12)

'On this day, let us commit ourselves to that task, and let us make a bridge that spans the "digital divide" (Kofi Annan, UN Secretary-General. World Telecommunications Day statement 2001)

Haraway (1997: 41) states that, 'promise is, arguably, the principal social weight of technoscience', and that contemporary technoscientific culture is deeply engaged in producing stories of salvation:

'Containing and fulfilling the whole, (Christian) salvation history is history .. this kind of temporality is utterly alien to the conceptions of classical antiquity .. secular salvation history depends on the power of images and the temporality of ultimate threats and promises to contain the heteroglossia and flux of events. This is the sense of time and representation that I think informs technoscience .. The discourses of genetics and information sciences are especially replete with instances of barely secularized Christian figural realism at work' (Haraway 1997: 10)

In Laclau and Mouffe's (1985) concept of the discursive, there is no literal meaning outside discourse, no route to rationality free of narration, and in the same way, 'nothing comes without its world' (p37). Similarly for Haraway, key figurations and chronotopes ${ }^{17}$ embody such narratives of salvation: 'Contemporary technoscience in the United States is deeply engaged in producing such stories, slightly modified to fit the conventions of secular realism. In that sense the "human genome" regularly functions as a figure in a salvation drama that promises the fulfilment and restoration of human nature' $(1997: 44) .^{18}$ 
The press release for the launch of the UN ICT Task Force in November 2001, an allied global initiative which immediately followed the DOT Force, advertised that:

'Mr. Annan's opening statement will be followed by the launch of the Task Force Website and Portal and the lighting of the IT Globe - a state-of-the-art technology which, through high-resolution satellite and aerial imagery, delivers a streaming, 3D map of the entire world.' (UNICT, 20 Nov 2001)

Through such directed media attention onto this key figure, a splicing of the onthe-fly performance of the global technological surveillant assemblage with cartographic representation, a particular promise is circulated: a state-of-the-art Borgesian fantasy of mapping the whole world, simultaneously figurative and literal, IT (is the) globe. On the cover of the final DOT Force report, there is an allied image, a photograph of two grinning aboriginal children, their bodies covered in ceremonial paint, squatting next to a laptop computer on a dusty plain (Fig. 5.3). For Haraway, the gene and the computer are chronotopes 'bristling with ultimate threats and promises' (1997: 42), and here the laptop promises to conjoin the ancestry of the past with the future of the children. ${ }^{19}$

Replete with such figures and the threat of the Digital Divide, I argue that the narrative that is constructed in the DOT Force can be best understood in terms of the extension and renewal of an action-oriented 'secular salvation story' of globalization. Locally contingent discursive configurations, from the very name of the DOT Force, the goal of raising eAwareness in a public with attitudes but not agency, through to the moral conditions for ascension of eReadiness and embracing 'Digital Opportunity', and the skeptical Thomases, academics and certain decision-makers, who might miss the Historic Moment, are sutured into a tissue of articulations to buttress the resonance and plausibility of the account. The temporality that orders the narrative is one of technologically determined 
inevitability and irreversibility, and an organized discursive positivism regarding the promise of ICT for development saturates the final report.

\section{$\underline{5.5 \text { Conclusion }}$}

I have argued that as a necessary condition of its credibility and moral authority, the DOT Force presents itself as exemplifying the global through an inclusive ethic of representation and an innovative structuring of wide consensus formation. However, an extended analysis of the DOT Force process reveals numerous antagonisms whose resolution in the final report reflects the field of power in which the DOT Force operates.

I suggest that the Digital Divide can be best understood in this particular engagement as an issue through which the various political interests represented in the DOT Force process can normatively reconfigure the conceptual and ethical possibilities it signifies to ultimately renew a dominant, singular 'secular salvation story' of economically and technologically driven globalization. This specific articulation of the Digital Divide instantiates an action-oriented temporality and a transformed moral agenda, from a broad concern with global inequality to a pressing inclusionary imperative to connect with the promise of ICT for development. 


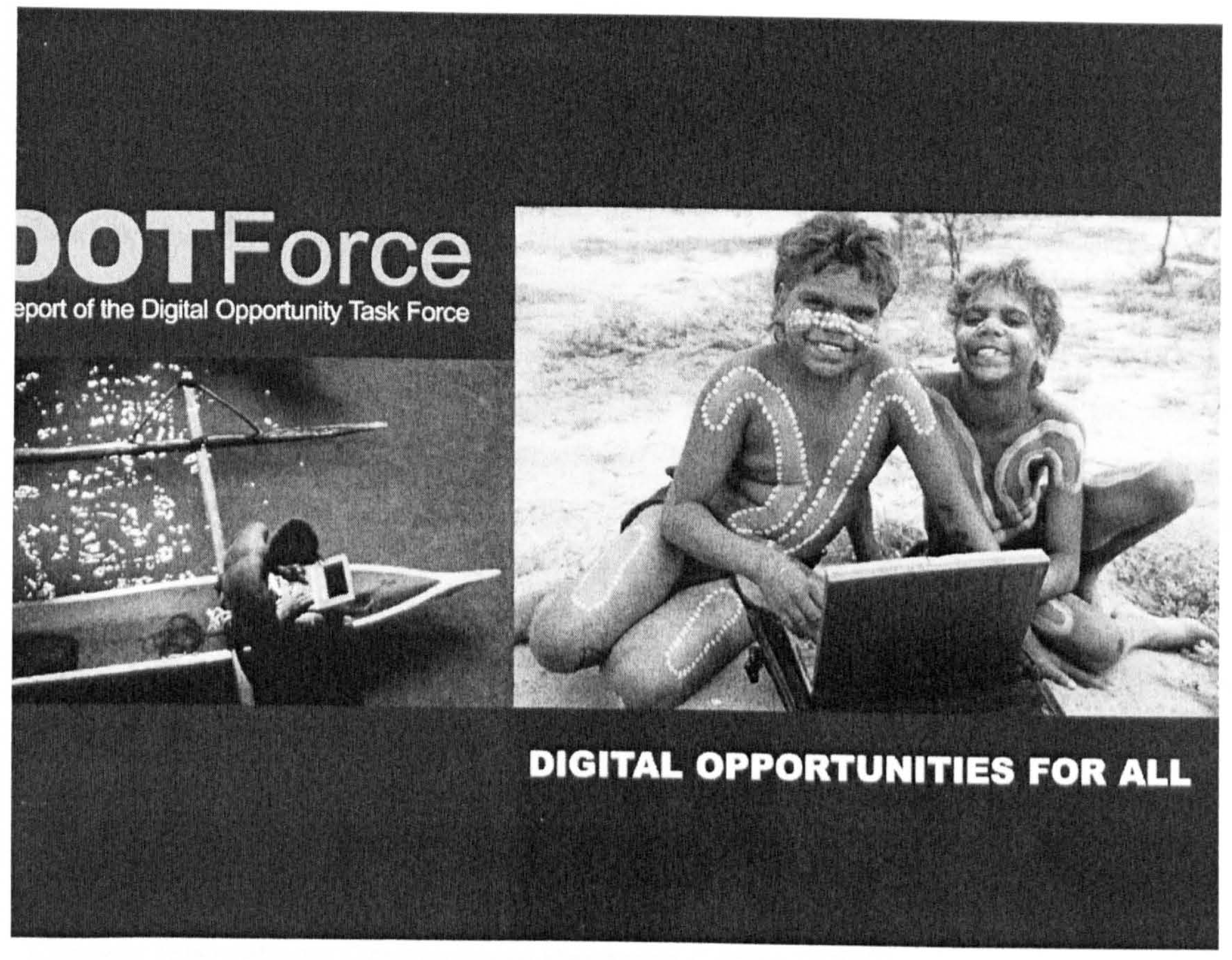

Figure 5.4 Protest on Okinawa beach, July 2000

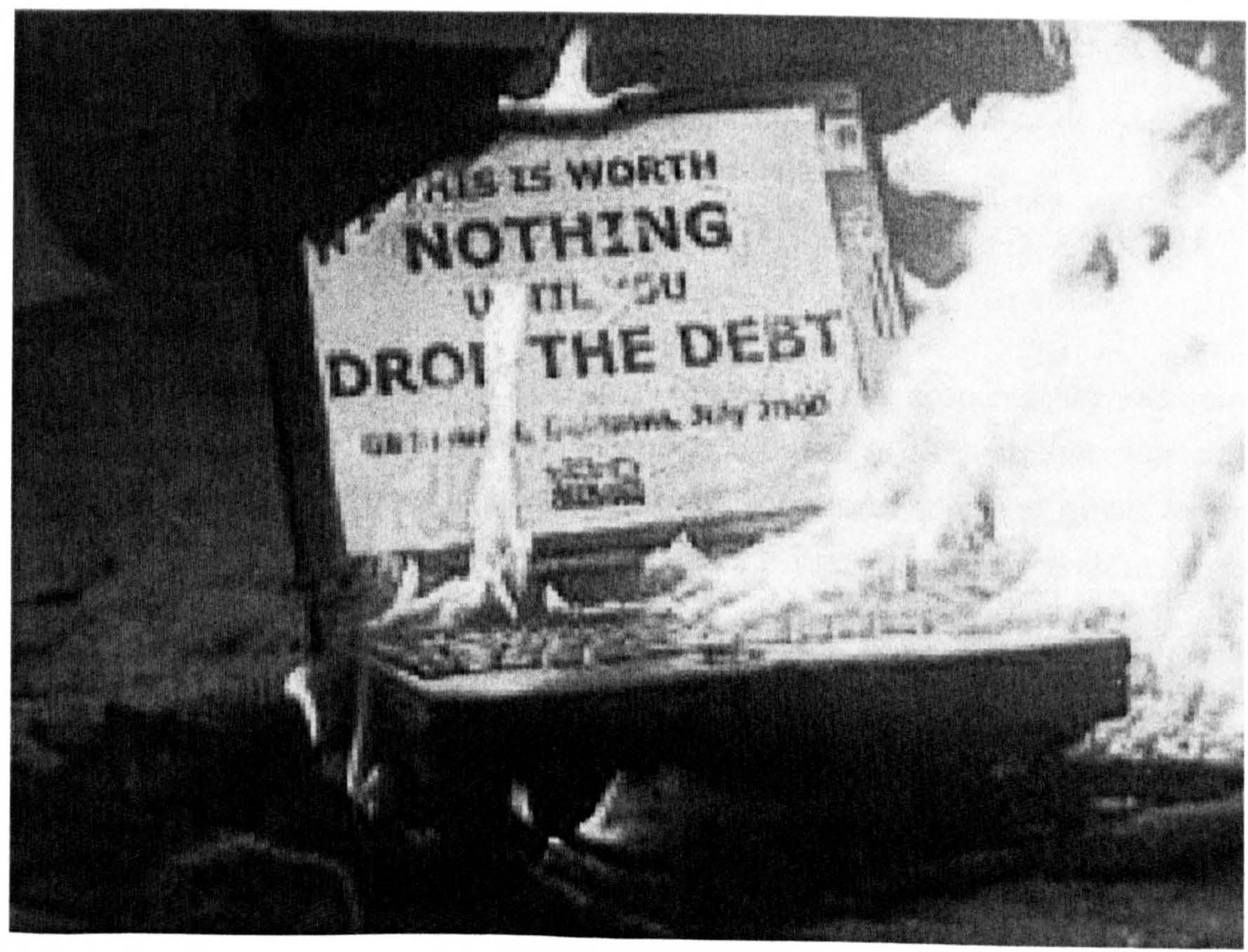




\section{Notes}

${ }^{1}$ The Digital Opportunity Initiative (DOI) is a public private partnership of Accenture, the Markle Foundation and the United Nations Development Programme (UNDP).

2 The strategy documents and individual submissions to the DOT Force referred to in this chapter were accessible throughout the duration of the DOT Force process in the archives of the DOT Force website at http://www.dotforce.org/reports/archive.htm. When last accessed in January 2003, only the final and draft reports remain publicly available.

3 The G8 members are Canada, France, Germany, Italy, Japan, Russia, the United Kingdom and the United States.

${ }^{4}$ The particular NPOs that contributed to the DOT Force were as follows:

Canada: International Development Research Centre (IDRC)

Russia: Russian Union of Internet Providers

France: Veille Européenne et Citoyenne sur les Autoroutes de l'information et le Multimédia (VECAM)

United States: Markle Foundation

United Kingdom: OneWorld International Foundation

Germany. Centre for Development Research, University of Bonn

Italy: Fondazione Eni Enrico Mattei

In recent years, some criticism has been directed at the accountability and remit of NGOs (Bond 2004). For example, Matthews (2004: 274) argues that, 'For all their strengths, NGOs are special interests, albeit not motivated by personal profit .. A society in which the piling up of special interests replaces a single strong voice for the common good is unlikely to fare well'. Sassen (2001: 4) further argues that some NGOs:

'are basically depoliticising the motivations and objectives of NGO activists and more broadly, depoliticizing international political movements .. an elite stratum of NGOs is part of the 
West's hegemonic project, they wind up augmenting the capacities of states, providing the equivalent of welfare services, generally subcontracting "state work"'.

As such, she notes that 'it is clear that simply saying NGOs has become inadequate because we are grouping many different political projects, some related to existing power and others in opposition to it'. (Sassen 2001:5)

In the case of the DOT Force, a common interest across the NPO representation lies in their focus upon technology. For example, the remit of the Canadian IDRC is 'to help developing countries use science and technology to find practical, long-term solutions to the social, economic, and environmental problems they face' (www.idrc.ca accessed December 2005), while the U.S. Markle Foundation's mission statement is that:

Emerging information and communications technologies possess enormous potential to improve people's lives. The Markle Foundation works to realize this potential and to accelerate the use of these technologies to address critical public needs. (http://www.markle.org/ accessed Dec 2005)

5 These were Bolivia, Brazil, Egypt, India, Indonesia, Senegal, South Africa and Tanzania.

${ }^{6}$ These were the United Nations Economic and Social Council (UN_ECOSOC), United Nations Development Programme (UNDP), United Nations Conference on Trade and Development (UNCTAD), United Nations Educational, Scientific and Cultural Organization (UNESCO), World Bank, International Telecommunications Union (ITU). The last three of these are essentially autonomous organizations working with the United Nations via the coordinating machinery of UN-ECOSOC.

${ }^{7}$ These were the World Economic Forum (WEF), the Global Information Infrastructure Commission (GIIC) and the Global Business Dialogue on E-Commerce (GBDE). 
${ }^{8}$ The trope of the 'virtuous circle' is here functionally equivalent to that of the 'win-win situation' in corporate discourse, analyzed in the previous chapter. It discursively excludes the possibility that there may be 'tragic conflicts' (Perri 6, 2002) between development objectives and investment in ICT.

${ }^{9}$ One further way this point is made in earlier drafts of the DOT Force is via the insertion of boxed case studies of 'best practice', widely feted projects such as Grameen Telecom's microcredit loans for mobile phones. These sections do not appear in the final draft. Indeed, the final report is considerably shorter than earlier versions, in line with the suggestion that, 'We believe that the DOT Force report should be re-oriented. It is critical that the DOT Force report be a brief, dynamic, easily digested document geared not only to the G-8 Leaders, but the media and a broad worldwide audience. In our view, the final report should avoid complex charts and academic jargon.' (U.S. Government 2001: 1).

${ }^{10}$ Such a position is also commonly articulated in the wider discourse surrounding the Digital Divide. In an example of the hostility towards lack of speed, Jay Naidoo, chairman of the Development Bank and a member of the UN ICT Advisory Committee, 'called on the private sector to overcome the "paralysis of analysis" on the digital divide and start on concrete projects to overcome it, and profit in the process' ('Naidoo Calls For Digital Divide Courage', ITWeb Johannesburg, May 23, 2001).

11 The DOT Force report also draws upon a wider cultural imperative not to miss the opportunity that is central to discourses of the 'new economy':

'Despite recent turbulence in the so-called "new economy", it is undeniable that the world is in the midst of a set of profound changes that create enormous new opportunities' (DOT Force 2001: 6) 
Figure 3.1 Components of a Development Dynamic

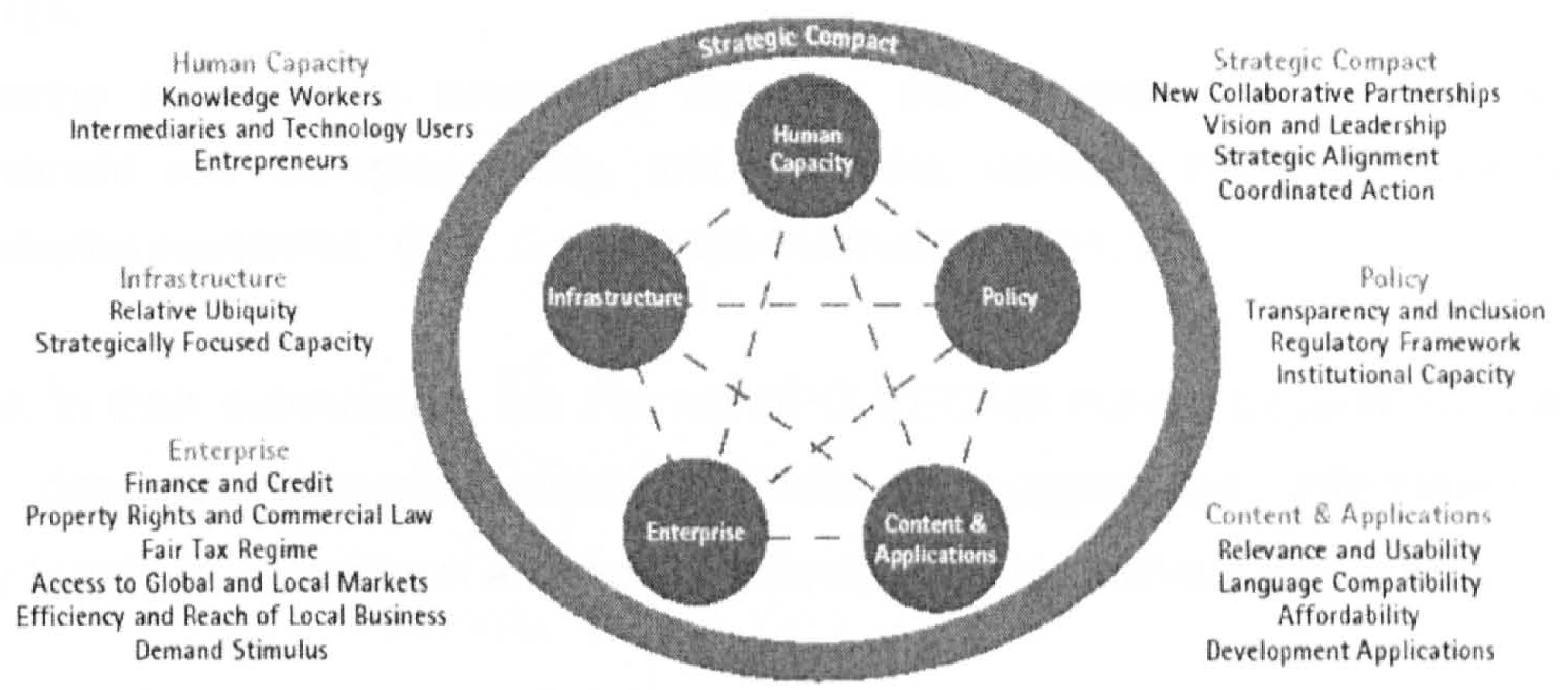

Figure 5.5 Components of a Development Dynamic (DOI 2001: p32)

13 "Participants agreed on the need to adopt what was termed a "full-meal" approach for DOT Force projects. This is opposed to the typical "piece-meal" approach behind numerous unsustainable or incomplete projects, resulting in the project's beneficiaries remaining "hungry" with unfulfilled expectations. Ironically, expectations that are not fulfilled on project completion are sometimes created or amplified by the project itself'. (ECD 2001: Key Outcomes)

${ }^{14}$ In more detail, the U.S. Government submission argues that :

'Within the policy and regulatory reform basket, the U.S. Government particularly supports measures that would facilitate developing countries participating fully in the global economy. Measures that support open trade and the development of a seamless electronic market could include:

- Ensuring that developing countries participate in international fora on trade.

- Supporting such policy objectives as continuing the existing moratorium on the imposition of customs duties on electronic transmissions.

- Helping developing countries eliminate obstacles to free trade over the Internet, especially cross-sectoral barriers in such areas as the telecommunications, transportation, customs, and package delivery sectors. 
- Providing technical assistance to developing countries in targeted trade, policy and regulatory areas.

- Assistance in joining or implementing existing trade agreements such as the WTO GBT and ITA.

- Fostering measures in developing countries that minimize the risks of business investment and entrepreneurship, and, therefore, increase the flow of capital into developing economies.' (U.S. Government Submission 2001: 2)

15 Indeed, in their submission, the French NPO VECAM moves beyond the idea of reinvesting domestic telecommunications profits to suggest an 'Information Society Solidarity Fund', financed from among the following redistributive mechanisms:

'A/ Levying a limited tax (e.g. $0.5 \%$ ) on economic activities related to the information society. The $\mathrm{G} 8$ countries could start by applying this tax themselves, acting as the pioneers before this form of tax spreads to the rest of the world.

B/ Taxing earnings from the attribution of domain names.

$\mathrm{Cl}$ A special tax on the profits that telecommunications companies from the North earn on their subsidiaries in the South.

D/ Following the Italian model, some of the proceeds from the sale of new-generation technology licences (mobile telephony yesterday, local radio loops today, etc.) could be paid in part into the Information Society Solidarity Fund.'

(VECAM submission: 2001)

${ }^{16}$ In February 2005, it was estimated that over 1500 e-readiness assessments have now been conducted across a total of 188 countries, and that only four counties have never been assessed for e-readiness: North Korea, Tuvalu, Monaco and Nauru. (bridges.org 2005: 2). Such assessments vary in their precise definitions of 'e-readiness'.

For example, McConnell International's e-readiness index is intended to measure a country's "capacity to participate in the global digital economy" (McConnell International 2000). As such, 'an "e-ready" country has extensive usage of computers in schools, businesses, government, and homes; affordable reliable access in a competitive market; free trade; skilled workforces and training in schools; a culture of creativity; government- 
business partnerships; transparency and stability in government and an evenly enforced legal system; secure networks and personal privacy; and regulations allowing digital signatures and encryption.' (bridges.org 2002)

Similarly, Harvard University has developed the 'Readiness For The Networked World' diagnostic, which was the basis for the World Economic Forum's report '2002 Global Information Technology Report' (CIDNEF 2002). This defines 'Networked Readiness as the degree to which a community is prepared to participate.. [and] a community's potential to participate in the Networked World in the future' (CIDNEF 2002: 13). As such, a 'Networked-Ready' country 'has the necessary physical infrastructure; integrated ICT use throughout businesses, communities and the government; strong telecommunications competition; independent regulation with a commitment to universal access; and no limits on trade or foreign investment' (bridges.org 2002).

For The Economist Intelligence Unit, which has produced league tables of e-readiness since 2000, 'a country's "e-readiness" is a measure of its e-business environment, a collection of factors that indicate how amenable a market is to Internet-based opportunities.' (EIU 2005).

${ }^{17}$ Haraway follows Bakhtin's (1981) theorization of the chronotope as a rhetorical site through which a particular understanding of temporality (e.g. empty 'adventure time' in the ancient Greek novel) is organized: 'The chronotope is where the knots of narrative are tied and untied .. time becomes, in effect, palpable and visible' (1981: 250). The chronotope can become condensed into particular figurations such as the road which metonymically represent a sense of time and are a means by which we order our sense of ourselves in history and organize cultural interpretative practice.

18 Haraway's (1997) own strategic response to this in her writing is to develop a 'contaminated practice' - 'mixed and differential literacies are required to avoid millenarian closure' (p14) - and to focus on the 'real ambiguity' of things. Her own text is thus an exploration in the material, social and generic conventions of knowledge production, an 'exercise regime and self-help manual for how not to be literal-minded' (p15). 
${ }^{19}$ An alternative, though equally resonant, image was offered by activists on the day that the Okinawa Charter was ratified (Fig 5.4, http://www.summitwatch.org/ accessed July 2000). Protest against the idea that ICT was a priority for development was figuratively ritualised through the burning of a laptop computer on the sands of Okinawa's Nago beach.

In the DOT Force process itself, the spectre of global protest was discussed at the Cape Town plenary through two other conflicting figures, "the so-called "Davos man versus Seattle man" debates' (ECD 2001: 6). At least one submission did not read this as an ultimately tragic conflict:

'The longer term interests of the private sector and the community converge ( 1 think that modern Davos man already recognizes this and is not the same as the stereotype typically painted - though I admit to having an interest here since I am on the Council of the World Economic Forum)' (Vernon Ellis, Accenture: Remarks on behalf of the private sector 2001) 


\section{$\square \square \square$ Chapter 6.}

\section{Academic Analysis of The Digital Divide}

\subsection{Introduction}

In previous chapters, I have analyzed discussions of the digital divide within governmental, corporate and supranational discourse. This chapter deals with the articulation of the digital divide specifically within social scientific discourse.

As I detailed in Chapter 2, from the original Falling Through the Net studies right up to more contemporary scholarly work, a concern with the digital divide has often been discursively concomitant with an underlying, if frequently unexplicated, assumption of the increasing importance of the network form of organization and networked processes of social inclusion and exclusion. Indeed, this understanding has informed all of the case studies I have examined to date in this thesis. For example, in the last chapter, I pointed to the explicit claim that 'significant multiplier and network effects [can] generate an upward spiral of sustainable social and economic development' (DOT Force 2001: 12 my italics).

In this chapter, I will concentrate upon the articulation of the digital divide in the work of Manuel Castells. Castells is a pivotal figure in contemporary social science and his work is an important political script for wider social policy and governance. More importantly, Castells' work forms an appropriate case study as his analysis of the digital divide explicitly develops his Information Age thesis. This is widely recognized as the most sophisticated and explicit narrative of the 'network society' available, and indeed, as I have detailed in Chapter 2, is an important theoretical resource for other recent digital divide scholarship (e.g. Servon 2002, Warschauer 2004). 
The main aim of this chapter then is to analyze the discursive construction and function of digital divide in the work of Manuel Castells. More specifically, I will interrogate the key methodological, epistemological and theoretical underpinnings of Castells' understanding of the digital divide, and consider some of the implications of such a mode of understanding for his own analytic project.

\subsection{The Information Age}

Manuel Castells is principally known for The Information Age trilogy, comprising Volume I: The Network Society (Castells 2000: $2^{\text {nd }}$ edn), Volume II: The Power of Identity (Castells 2004: $2^{\text {nd }}$ edn), and Volume III, End of Millennium (Castells 2000a: $\left.2^{\text {nd }} e d n\right){ }^{1} \quad$ In these and related works, he synthesises an enormous range of detailed empirical work to construct a comprehensive theoretical edifice based around several key explanatory concepts and logics. His work has been widely recognized as one of the most authoritative and agenda-setting narratives of contemporary society, compared favourably with Weber's Economy and Society (Giddens 1996) and even prompting the suggestion that it 'may come to be seen as Das Kapital of our times' (McGuigan 1999: 104). According to Webster (2004a: 133) then 'Castells is the world's leading figure when it comes to delineating the Information Age'.

Of specific interest for my discussion is his analysis of the digital divide. However, in order to proceed to this stage, I need to first discuss some of Castells' more general theoretical claims that specifically underpin this analysis, including the key concept of the network and his understanding of the central social divisions that structure the network society. My reading of Castells will be necessarily focussed then. For a wider discussion of the issues raised in his trilogy, see Webster and Dimitriou (eds.) (2004). 


\subsubsection{The Network Society}

Castells' focus is on the structure and dynamics of the network society, rather than its historical genesis. Nonetheless, it is instructive initially to look at his account of its emergence:

'In my view, it emerged from the historical convergence of three independent processes, from whose interaction emerged the Network Society .. the information technology revolution, constituted as a paradigm in the 1970 s .. the restructuring of capitalism and statism in the 1980s, aimed at superseding their contradictions .. the cultural social movements of the 1960s, and their 1970s aftermath (particularly feminism and ecologism)' (Castells 1997: 7)

As Smart (2000) notes, the independence ascribed to these three processes can be called into question in numerous ways. For example:

'it is the prompting and investing of capital interested in making "the creation of wealth independent (relatively) of the labour time employed on it" (Marx 1973: 706) .. that has contributed powerfully to what has been identified as the information technology revolution.' (Smart 2000: 55)

Of an earlier 'revolution', Lasch (2004: 290) has similarly argued that 'the historical record .. indicates that industrial technology has grown out of concrete struggles for control over production and takes its existing shape not because this is the shape dictated by ethically neutral considerations of technical efficiency but because it concentrates decision making in a managerial and technical elite' (see also Braverman 1974, Noble 1979, Beninger 1986). I am not necessarily proposing here that the information revolution should be identically understood as a continuation of the struggle for control over the labour process, of the further separation of mental and manual labour, but am simply raising an immediate concern about the issue of causality in Castells' thesis to which I shall return. 
For Castells, we are undergoing an epochal transformation to an Information Age, and a new social structure, the Network Society. As Slack (1984: 253, cited in May 2002: 21) notes, the very use of the term 'age' tells us something about what is intended by a specific analysis: 'An age connotes an allpervasive logic, a logic that requires that everything be explained in its own terms .. the information age thus hails all subjects as trapped in its logic'. For Castells then, it is the spread of the network form of organization that is now replacing all other forms of organization, particularly hierarchical forms, and becoming the dominant form of human organization and relationship across the categories of economics, politics and culture. Networks are increasingly connecting people, institutions, countries and regions in ever more flexible, adaptive and fluid ways:

'as an historical trend, dominant functions and processes are increasingly organized around networks. Networks constitute the new social morphology of our societies, and the diffusion of networking logic substantially modifies the operation and outcomes in processes of production, experience, power and culture .. the new information technology paradigm provides the material basis for its pervasive expansion through out the entire social structure. Furthermore, 1 would argue that this networking logic induces a social determination of a higher level than that of the specific social interests expressed through the networks: the power of flows takes precedence over the flows of power .. a society that, therefore, we may properly call the network society, characterized by the preeminence of social morphology over social action' (Vol 1: 500)

\subsubsection{The Network}

The concept of the network is clearly central to Castells' thesis and deserves particular examination. However, as Bromley (1999: 13) notes, given its conceptual centrality to the project as a whole, Castells says remarkably little about the general nature of networks. Van Dijk (1999a: 132) similarly notes 
that Castells does not start with an elaboration of the morphology of networks: 'He takes a historical approach in extensive analysis of current trends and affairs. He demonstrates how formal network structures float to the surface'. The term 'network' is used liberally by Castells in a multitude of contexts. As Smart (2000: 55-56) notes, 'reference is made to networks of trade and investment, production and management; interpersonal, social and communication networks; as well as to interactive network, global network, internet network and network state .. micro-networks, sub-networks, an intermetropolitan network, world medical network, narcotics network, even a network of networks'.

For example, in the field of production, Castells discusses global economic networks which tie suppliers to sellers, monitor and connect dispersed workers, immediately collate detailed feedback on consumption, and so on. Particular emphasis is given here to discussion of the network enterprise (Volume 1 , Chapter 3). For Castells the key unit of production is now not the firm but the business project or the venture ( $\mathrm{Vol}$ 1: 177). Various social actors, firms, segments of firms and individual information workers, organize ad hoc to pool their particular expertise as a network for the duration of a particular project, then splinter apart to recombine in new constellations for the next project.

Castells argues that even transnational corporations themselves are vulnerable to this logic, and are moving from being self-sufficient and vertically integrated to fragmented, amorphous and rapidly recombinant 'horizontal corporations' (Vol 1: 176), where sectoral-level strategic alliances are rapidly made and abandoned. There is a complex mixture of competition and collaboration in the new networked capitalism, and to survive, corporations must devolve power to 'self-programmed, self-directed units based on decentralization, participation and co-ordination' (Vol 1: 178). There is then an empowerment of those people and organizations who are entrepreneurial and effective in terms of networking, 
although it is important to note that any shift in power is fundamentally precarious, 'no nodal domination is systemic' (Castells 2000b: 15).

However, beyond specific discussions of formations such as the network enterprise, there is minimal sustained attempt to discuss the general nature of networks. Indeed, it is not until the conclusion of Volume I that Castells offers a first conceptualization of the network:

'A network is a set of interconnected nodes. A node is the point at which a curve intersects itself. What a node is, concretely speaking, depends on the kind of concrete network of which we speak. They are stock exchange markets, and their ancillary advanced services centres, in the network of global financial flows .. They are cocoa fields and poppy fields, clandestine laboratories, secret landing strips, street gangs, and money-laundering financial institutions in the network of drug traffic .. They are television systems, entertainment studios, computer graphics milieux, news teams, and mobile devices generating, transmitting, and receiving signals in the network of new media.' (Vol 1: 501)

This strange quasi-mathematical formulation rapidly returns to the specific features of multiple examples - the nature of a particular network is defined by its concrete nodes. However, in more general terms, Castells does finally assert that:

'The inclusion/exclusion in networks, and the architecture of relationships between networks, enacted by light-speed-operating information technologies, configure dominant processes and functions in our societies. Networks are open structures, able to expand without limits, integrating new nodes as long as they are able to communicate within the network, namely as long as they share the same communication codes (for example, value or performance goals) .. Networks are appropriate instruments for a capitalist economy based on innovation, globalization, and decentralized concentration; for work, workers and firms based on flexibility and adaptability; for a culture of endless deconstruction and reconstruction; for a polity geared towards the instant processing of new 
values and public moods; and for a social organization aimed at the supersession of space and the annihilation of time .. The convergence of social evolution and information technologies has created a new material basis for the performance of activities throughout the social structure. This material basis, built in networks, earmarks dominant social processes, thus shaping social structure itself' (Vol 1: 501-2)

There is one main point that I wish to draw from this discussion. As Van Dijk (1999a) argues, once the network morphology is deduced by Castells, it is reified and ultimately enters the level of theory as an abstract instrumental determining force. It is 'a new kind of collective - fluid, amoeboid, totally unlike those earlier agencies of the $20^{\text {th }}$ century, the party, the nation-state, the proletariat' (Visvanathan, 2001: 219), but invested with autonomous determinacy nonetheless. This is exemplified in oft-repeated maxims such as 'the power of flows take precedence over the flows of power', and most famously, 'the pre-eminence of social morphology over social action'. For Van Dijk (1999a: 133), what is questionable with this formulation is that, "it will cause much debate among people who think that structures are (re)produced in communicative action... relations do not equal society. Their organic and material properties and their rules and resources should not be eliminated from society to bring it back to its supposed bare essence of relationship.'

In the only other conceptual discussion of the network in his recent work, Castells (2000b) fleetingly raises the possibility of internal social struggle over network design, but does not develop the theme (Castells concentrates on struggles between 'the Net' and the external construction of 'resistance identities' in The Information Age, see later):

'By definition a network has no centre. It works on a binary logic; inclusion/exclusion. All there is in the network is useful and necessary for the existence of the network .. If a node ceases to perform a useful function it is phased out from the network, and the network rearranges itself - as cells do in 
biological processes .. Networks, as social forms, are value-free, or neutral. They can equally kill or kiss: nothing personal. They process the goals they are programmed to perform .. In this sense, the network is an automaton. But, who programmes the network? Who decides the rules that the automation will follow? Social actors, naturally. Thus, there is a social struggle to assign goals to the network. But once the network is programmed, it imposes its logic to all its members.' (Castells, 2000b: 15-16)

However, ultimately the network, or 'the implicit logic of the network society' (Castells 1997: 16), is still seen as the source of imposition and determination here, hence 'the logic of the network is more powerful than the powers in the network' (Vol 1: 208). The logic of the network thus progressively penetrates all spheres of social, economic and cultural life in an autopoietic manner that marginalizes pre-network society forms and underpins all future social action:

All societies in the Information Age are indeed penetrated, with different intensity, by the pervasive logic of the network society, whose dynamic expansion gradually absorbs and subdues pre-existing social forms. (Vol 3: 381)

The logic embedded in this economy, this society, and this culture underlies social action and institutions throughout an interdependent world' (Vol 3: 367)

While hinting at a conceptual elaboration then, Castells' work is elusive as to what the 'logic of the network' might be, its specificity or generality, processes of formation and causal contours, and so on. I shall propose my own interpretation later on, but for now I wish to suggest that there are three principal ways in which Castells addresses this issue in The Information Age.

\subsubsection{Technological Determinism}

The first is that this logic is technologically determined. As the passages already cited make clear, technological determinism is always present in 
Castells' thesis (see also Webster 1997, Smart 2000). Indeed, from the very first page of the Information Age, it is clear that the driver of social change is a 'technological revolution, centred around information technologies, (which) began to reshape, at accelerated pace, the material basis of society' (Vol 1: 1). Hence, 'information networks constitute the backbone of the network society' (Castells 2000b: 17) according to 'the autonomous dynamics of technological discovery and diffusion' (Vol 1: 59).

Castells does occasionally attempt to avoid the charge of technological determinism, for example arguing that 'the dilemma of technological determinism is a false problem, since technology is society, and society cannot be understood or represented without its technological tools (Vol 1: 5). However such disclaimers are rhetorical rather than analytical, and as Webster (2004: 99) notes, 'try as he might to insist that social factors influence the technology, Castells cannot evade the fact that "the new information technology paradigm provides the material basis for (the network's) pervasive expansion throughout the entire social structure"(Vol 1: 500)'. The logic of the network then is technologically determined, a position that is out of step with much current sociological analysis of technological change (Webster 2002: 120), and indeed studies of the design and implementation of actual networks (e.g. Mansell and Silverstone 1996, Barry 2001).

The objection to this claim, that a certain, foundational element of society is aloof from social relations whilst simultaneously of inordinate social consequence is, as Webster (2004: 99) makes clear, that it relegates social analysis, since everything follows after the development of technology'. As Williams (1974: 135) argues, 'new technology is itself the product of a particular social system and will be developed as an apparently autonomous process of innovation only to the extent that we fail to identify and challenge its real agencies'. 
One way in which Castells conceptually asserts the autonomy of the 'information technology paradigm' is by introducing the Touranian concept of a 'mode of development' (e.g. agarian, industrial, informational) as an orthogonal axis through which we can examine change, distinct from a 'mode of production' (e.g. statist, capitalist). The latter Marxist concept refers to a socioeconomic system for the distribution of wealth, in the case of capitalism through a market economy, private property, accumulation through profit and so on: 'The structural principle under which surplus is appropriated and controlled characterizes a mode of production, such as capitalism or statism' (2000b: 8)

However a mode of development refers to the means of producing a given level of wealth, 'the technological arrangements through which humans act upon matter (nature), upon themselves, and upon other humans' (Castells 2000b: 9). As such it is 'defined by the element that is fundamental to fostering productivity in the production process' (Vol 1: 16).

Each mode of development has also a structurally determined performance principle around which technological processes are organized; industrialism is oriented .. towards maximising output; informationalism is oriented towards .. the accumulation of knowledge and higher levels of complexity in information processing. (Nol 1: 17)

In the informational mode of development, according to Castells, the source of wealth is no longer the output of working class labour, as in Marx's labour theory of value, but 'the action of knowledge upon knowledge itself as the real source of productivity' (Vol 1: 17). Notwithstanding the historical coincidence of the independent processes of capitalist restructuring and the IT revolution that allow Castells to propose that we are in a period of 'informational capitalism' (Vol 1: 18), in theory informationalism could exist without capitalism.

Several commentators have questioned this distinction, on conceptual and empirical grounds. For example, Callinicos (2004: 210-11) argues that: 
The technological mode of development apparently gives economic actors motivations independent of those that they derive from their place in capitalist relations of production .. Castells' account of the industrialist and informationalist 'modes of development' suggests that the 'performance principles' that these involve might override or operate independently of capitalist rules of reproduction. But this is not so .. the reason why these changes are undertaken has to do not with abstract considerations related to increasing output or knowledge, but with the more mundane search for higher profits.

Callinicos clearly sees the distinction between mode of development and mode of production as dubious, and the implication that informationalism 'can escape its capitalist carapace' (2004: 211) as untenable. Garnham (2004: 174) similarly argues that 'the informational mode of development is developed for and put at the service of a set of property relations and the goal of accumulation, not vice versa.' Webster (2002: 100) also notes that the 'unresolved tension between the view that capitalism is the most salient feature of the world today and that it is informationalism which is of primary importance runs through the oeuvre of Manuel Castells'.

Castells' position is certainly not consistent throughout his work. For example, he argues that 'profitability and competitiveness are the actual determinants of technological innovation and productivity growth' (Vol 1: 94) and that, 'for the first time in history, the capitalist mode of production shapes social relationships over the entire planet' (Vol 1: 502). However, as I have argued, for the most part he gives analytic priority to the informational mode of development, 'the new information technology paradigm', as exerting a pervasive logic on the transformation of social structure. This determinant logic is identified with distinctive and essential technological properties, 'those features that constitute the heart of the information technology paradigm' (Vol 1: 70), such as openness, recursion, flexibility, adaptability and convergence (Vol 1: 71-76). Castells summarizes this position as follows: 
I propose that what makes this paradigm unique in relation to previous historical developments of information and communication technologies (such as printing, the telegraph, or the non-digital telephone) are, in essence, three major, distinctive features of the technologies at the heart of the system:

- Their self-expanding processing and communicating capacity in terms of volume, complexity and speed

- Their ability to recombine on the basis of digitization and recurrent communication

- Their distributing flexibility through interactive, digitized networking'

(Castells 2004a: 9)

\subsubsection{Out of Control}

A second related theme in Castells' work is that, just as 'the network is an automaton' (2000b: 16), the logic of the network is one of systemic complexity and volatility, ultimately uncontrollable and unknowable. This motif occurs particularly in Castells discussion of the 'New Economy'. Castells argues that today capital is 'realized, invested and accumulated mainly in the sphere of circulation, that is as finance capital' (Vol 1: 502) For Castells then, increasingly, 'the only thing that matters, ultimately, is what this global financial market thinks of you' (Castells 2001b: 26). As Garnham (2004: 174) notes, 'Castells seems to think that capital can induce production (whatever exactly that means) and that value can be created within the autonomous flows of capital on a global network without passing through a process of real production and consumption .. but capital has to invest if value is to be appropriated. In the words of Saskia Sassen (1991) global capitalism has always to come down to earth.' 
Nonetheless, for Castells, it is in this abstract realm of constant informationnetworked financial flows that destinies are determined: 'in the age of networked capitalism the fundamental reality, where money is made and lost, invested and saved, is in the financial sphere' (Vol 1: 503). In addition, 'the development of electronic transactions is transforming the logic of global financial markets in terms of increasing complexity and volatility .. the New Economy is an economy in which valuation is decided in the global financial market through information turbulences, of which traditional economic calculation is only one of the criteria' (Castells 2001b: 26-27). Global financial flows are increasingly volatile and unpredictable then as they are 'affected by, if not constituted as, a hermeneutic spiral of expectations, decisions and events' (Smart 2000: 57, see also Soros 1998, Armitage and Graham 2001).

Moreover, in place of capitalism directed by a ruling, propertied class, Castells is insistent that there is now informational capitalism without an identifiable global capitalist class. Global financial flows are not under such control, rather there is a 'faceless capitalist collective, made up of financial flows operated by electronic networks' (Vol 1: 505). Winners and losers are constantly, unpredictably and precariously incarnated within such an automaton. It is worth pointing out this claim is strongly disputed. For example, Scott (1997) argues that although there may be a partial dissociation between the 'mechanisms of capital reproduction' and the 'mechanisms of class reproduction' in contemporary society, there is little evidence of the decline of a propertied capitalist class (see also Halcli and Webster 2000, Sklair 2001).

Nonetheless, in these discussions, the implicit logic of the network, deduced from an analysis of the 'New Economy', is that it embodies complexity and volatility, and is ultimately uncontrollable and unknowable. Castells' one explicit attempt to define networking logic emphasizes these themes: 
'the networking logic of any system or set of relationships using these new information technologies .. the morphology of the network seems to be well adapted to increasing complexity of interaction and to unpredictable patterns of development arising from the creative powers of such interaction. This topological configuration, the network, can now be materially implemented, in all kinds of processes and organizations, by newly available information technologies. Without them, the networking logic would be too cumbersome to implement. Yet this networking logic is needed to structure the unstructured while preserving flexibility, since the unstructured is the driving force of innovation in human activity' (Vol 1: 70-71) ${ }^{2}$

\subsubsection{The Spirit of Informationalism}

The final way in which Castells suggests what the implicit logic of the network might be, beyond technological or economic determinism, is to propose, following Weber's (1958) classic argument, a 'spirit of informationalism' (Vol 1: 210-215):

'What glues together these networks? .. the networking form of organization must have a cultural dimension of its own .. What is, then, this 'ethical foundation of the network enterprise' this 'spirit of informationalism?' .. There is indeed a common cultural code in the diverse workings of the network enterprise .. a culture of the ephemeral, a culture of each strategic decision, a patchwork of experiences and interests, rather than a charter of rights and obligations. It is a multi-faceted virtual culture .. but it does not stay long .. any attempt at crystallizing this position in the network as a cultural code in a particular time and space sentences the network to obsolescence, since it becomes too rigid for the variable geometry required by informationalism. The "spirit of informationalism" is the culture of "creative destruction" accelerated to the speed of the opto-electronic circuits that process its signals. Schumpter meets Weber in the cyberspace of the network enterprise' (Vol 1: 214-15) 
This is hardly a perspicuous account. It is not clear, for example, whether it is the network itself or its members who are the bearers of the spirit of informationalism', in what sense this ethic can be considered new or foundational, or what the value of accelerated creative destruction might mean. $^{3}$ Webster argues (2002: 104) that this depiction 'evokes an image of those participants in 'cyberspace' who are at ease with information exchanges, are well connected, and are so effectively networked that they may seize the day .. a heady mix of tumultuous change, creativity and personal drive'. Garnham (2004: 176) similarly argues that Castells 'is forced into mysticism to explain the power and actions of his new ruling class - the networkers (who) are the carriers of a 'spirit of informationalism .. it is not clear that new economic forms of organization need - there is certainly no evidence that they have now - a new form of ethical justification'. As Smart (2000: 58-60) notes, Weber recognized that 'this support had long ceased to be necessary for modern capitalism' which had become 'exceptionally emancipated from the importance of such ethical factors' (Weber 1978: 1125, cited in Smart 2000: 58) and furthermore, a 'culture of creative destruction' has long been recognized as a distinguishing feature of capitalist modernity since the mid-nineteenth century (Marx and Engels, 1968). Hence, Smart (2000: 59) argues, following Bauman (1998), that 'rather than ethics, it is aesthetics that is integral to consumer society'.

The main point I wish to make here is that, rather than a technological or economic determination, this intimation of an ethical determination, vague though it is, offers a third understanding of what the implicit logic of the network might be. ${ }^{4}$

\subsubsection{Stratification in The Network Society}

So far I have argued that Castells' thesis of the Network Society, and its axiomatic principle of the pre-eminence of morphology over action, is troubled 
by a fundamental issue of causality. Castells' attempted resolution of this problem rests on the proposal of an 'implicit logic of the network' as central to the causal chain of determination. This logic is undertheorized, but through a detailed reading of Castells' work, I suggest that there are three ways that Castells sketches its contours. While these are not always consistently employed or clearly developed beyond a signalling of affinity, the predominant view reduces this logic to a form of technological determinism. Alternative conceptions of the logic of the network stress the determinacy of (economic) complexity, and the ethical determinism of a 'spirit of informationalism'.

Before I turn to my analysis of Castells' treatment of the Digital Divide, I need to briefly outline Castells' discussion of social divisions in the network society. Castells' central claim is straightforward, he argues that the emergence of the network society is accompanied by profound changes in the major axes of social stratification. Above all, the division and conflict between capital and labour which underpinned politics and identity in the twentieth century, has been fundamentally transformed.

As I have already noted, Castells states that our current age is characterized by an informational capitalism that is systemic yet lacking a guiding, propertied capitalist class. Furthermore, he asserts an informational theory of value over the Marxist labour theory of value. While previously the working class might have been subordinate to the owners of capital, they were also indispensable for the generation of surplus. There was at least a relationship between the two classes, if one characterized by exploitation.

However, there now comes into being something beyond any particular class or group, a 'faceless capitalist collective', embodying diverse 'informational labour' and networking skill, and 'Castells contends that informational labour is that range of jobs which generates change, holds together the new economy, and 
generally does the thinking, conceiving, planning and operationalizing required by informational capitalism' (Webster 2002: 113).

Echoing numerous previous discussions of information workers, variously identified as professionals (Perkin 1989), the cognitariat (Toffler 1990), symbolic analysts (Reich 1991), and knowledge experts (Drucker 1993), Castells identifies the key technologically determined role of 'the networkers .. who set up connections on their initiative .. and navigate the routes of the network enterprise' (Vol 1: 260). In addition, the key skill of the networker is the ability to be 'self-programmable', to train and retrain, to know how to learn, to continually adapt to the flexible world of informational capitalism.

The emergence of the fluid and flexible collective of 'informational labour', that is now both responsible for running capitalism and the prime generator of wealth, announces the decline of the traditional propertied class as well as the working class. Ownership of traditional capital is not sufficient to make headway in the networked world because, without the informational labour to keep pace, it becomes worthless. Moreover, the traditional working class, or 'generic labour' in Castells' terms, is increasingly vulnerable; 'labour loses its collective identity, becomes increasingly individualized in its capacities, in its working conditions and in its interests and projects' (Vol 1: 506). As Webster (2002: 112) summarizes, 'Informational labour acts on generic labour in ways which make it abundantly clear who is most important to society .. by automating generic labour out of existence .. by transferring production to other parts of the world .. by creating a new product towards which generic labour, being fixed and rigid, is incapable of adjusting .. in current parlance, it lacks "flexibility"'.

As I have noted, Castells also argues that just as the logic of networks enables increasingly intensive communications between those in the network, it also progressively excommunicates those who are outside: 
In this condition of structural schizophrenia between function and meaning, patterns of social communication become increasingly under stress. And when communication breaks down, when it does not exist any longer, even in the form of conflictual communication .. social groups and individuals become alienated from each other, and see the other as a stranger, eventually as a threat (Vol 1:3)

Generic labour is in terminal decline, not only as it cannot adapt, but because it is out of the loop, and hence it is increasingly in danger of becoming marginalized to what Castells terms 'the black holes of informational capitalism' (Vol 3: 165) or the 'fourth world'. ${ }^{5}$ For Castells then, an increasing proportion of the world is becoming structurally irrelevant, both as producers and as consumers, from the point of view of a network society where information is the major source of productivity. Millions of people have lost their stable relationship to employment, generic labour has become increasingly disaggregated, class solidarity has gradually dissolved, and more and more people experience their lives as a constant and uncertain struggle for daily survival.

The network society is increasingly polarized into groups who have less communication with and, crucially, less dependency on, each other than in the class stratified $20^{\text {th }}$ century. Rather than stable classes linked by a relationship, even one of exploitation, for Castells the key social division in the network society is between those included in and those excluded from global networks and, for a growing number of people across the globe, there is an increasingly individualized struggle to negotiate this boundary of inclusion/exclusion:

'social exclusion [is] the process by which certain individuals and groups are systematically barred from access to positions that would enable them to an autonomous livelihood within the social standards framed by institutions and values in a given context' ( $\mathrm{Vol}$ 3: 71) 
Finally, as the network(ers) carry the ethical foundation, the common cultural code, of the 'spirit of informationalism', Castells also intimates that the included and the excluded are becoming not just economically, but also morally, distinct. The excluded are 'socially/culturally out of communication with the universe of mainstream society' (Vol 3: 167) and their distinctiveness arises from this insularity, 'the denial of the networking logic through the affirmation of values that cannot be processed in any network, but only obeyed and followed .. cultural communes, that are not necessarily linked to fundamentalism, but which are always centred around their self-contained meaning' (Castells 2000b: 22).

\subsection{The Internet Galaxy}

Castells provides his most comprehensive treatment of the digital divide in a chapter entitled The Digital Divide in a Global Perspective from 'The Internet Galaxy' (Castells 2001). An analysis of this work is the focus of the rest of this chapter. The Digital Divide in a Global Perspective is divided into five sections:
(1) An opening statement (1 page)
(2) Dimensions of the Digital Divide (8 pages)
(3) The New Technological Divide (2 pages)
(4) The Knowledge Gap (2 pages)
(5) The Global Digital Divide (11 pages)

Effectively, there are two separate discussions in this chapter. Sections 2, 3, and 4 discuss the digital divide in the context of education, principally with reference to the United States. Section 5 considers 'the global digital divide' in the context of global development. I will consider each of these discussions separately, as well as commenting on the rhetorical and methodological strategies that Castells employs in his analysis. 
In his opening statement, Castells (2001: 247) claims that:

'The centrality of the Internet in many areas of social, economic, and political activity is tantamount to marginality for those without, or with only limited, access to the Internet, as well as for those unable to use it effectively .. Thus, it is little wonder that the heralding of the Internet's potential comes hand in hand with the denunciation of "the digital divide" .. the differentiation between Internet-haves and have-nots adds a fundamental cleavage to existing sources of inequality .. that appears to increase the gap between the promise of the Information Age and its bleak reality for many people around the world. Yet the apparent simplicity of the issue becomes complicated on further examination. Is it really true that people and countries become excluded because they are disconnected from Internet-based networks? Or rather, is it because of their connection that they become dependent on economies and cultures in which they have little chance of finding their own path of material well-being and cultural identity? Under what conditions and for what purposes does inclusion/exclusion in/from the Internetbased networks translate into better opportunity or greater inequality?

Castells thus initially frames the digital divide as a fundamental cleavage of the Information Age, but additionally suggests we need to be cautious with any simplistic reading of this issue.

\subsubsection{The Digital Divide and Education}

Nonetheless, following this opening statement, the work under the first subheading 'Dimensions of the Digital Divide' consists to a large extent of reproducing descriptive statistics from nationwide surveys of Internet use, principally the four U.S. Department of Commerce Falling Through The Net surveys described earlier (Dept of Commerce 1995, 1998, 1999, 2000). While such a strategy describes the current state of 'the digital divide' and provides the impression of quantitative depth to his analysis, it does little to reframe the focus of debate in the way that he initially alludes to. If anything, it is 
rhetorically complicit with a simple denunciation of the digital divide as differences in Internet access, with an associated technological solution.

As well as reproducing these descriptive statistics, the other main methodological strategy upon which Castells relies in this section is to analyze across these four cross-sectional snapshots to argue for trends-based extrapolations into the future. ${ }^{6}$ Bizarrely, Castells is at pains to explicitly distance himself from this methodological strategy in the Introduction to The Internet Galaxy:

'In the pages that follow you will find no predictions about the future ... I deeply distrust the methodology underlying these predictions. You will not find moral admonitions either - or, for that matter, policy prescriptions or management advice. My purpose here is strictly analytical' (Castells 2001: 4) ${ }^{7}$

Despite such a proclamation, the content is certainly full of trends-informed statements that at the very least do not sit comfortably with contemporary social scientific standards (Fuller 1999), and frequently are more resonant of commercial forecasting, e.g. "With projected penetration rates of $63 \%$ of Americans online by 2003 and over three-quarters around 2005 .. for most people .. access to the Internet is likely to become pervasive, as we see substantial pre-existing divides either disappear or dwindle in just five years' (Castells 2001: 254). ${ }^{8}$

Following this extrapolation from the first four Falling Through The Net studies, the next short section 'The New Technological Divide', concerns the subset of statistics on high-speed internet access, only collected in the final 2000 study (Department of Commerce 2000). After a presentation of the statistics, Castells offers the following speculation:

'The head start that a minority of affluent households is enjoying in the uses and services provided by the Internet may prove a major source of cultural and social 
inequality in the future, as children of the first Internet generation grow up in very different technological environments' (Castells 2001: 257-8)

The next section, The Knowledge Gap, is a two page attempt to flesh out such a scenario, focussing on Internet-based 'new learning':

'Let us go one step further in exploring less obvious dimensions of the digital divide. If there is a consensus about the societal consequences of increased access to information it is that education and life-long learning become essential resources for work achievement and personal development .. Internet-based learning .. changes the kind of education that is required .. the new learning is oriented toward the development of the educational capacity to transform information into knowledge and knowledge into action .. the school system as a whole, both in the US and in the world at large, is, by all accounts, woefully inadequate in the use of this new learning methodology ..

First, there is a substantial cleavage in terms of technology amongst schools. Secondly, Internet access requires better teachers, and yet the quality of the teachers is unevenly distributed among schools. Thirdly, the differential pedagogy of schools contrasts those systems that focus on the intellectual and personal development of the child with those essentially preoccupied with the ability to maintain discipline, warehouse children and process them through their graduation .. overall, upper and middle class schools tend to be more attentive to the opening of the mind than schools in low-income areas. Fourthly, in the absence of adequate training of teachers and pedagogic reform in the schools, families take over much of the responsibility for instructing their children .. in the new technological world ..

The cumulative result of these different layers of inequality translates into vast differences in the effects of Internet use on educational performance .. if these trends were to be confirmed .. the use of the Internet .. could amplify social differences .. This may be the most fundamental dimension of the digital divide emerging at the dawn of the Internet Age.' (Castells 2001: 258-60) 
The importance of this potential scenario is that it offers a context for Castells to move from the earlier reading of the digital divide simply in terms of differences in the current state of Internet access, exemplified in the Dept of Commerce datasets, to proposing a consequential 'dimension' of the digital divide. I do not intend to examine this contextual argument in detail but I wish to make one overall point. The argument is a complex edifice built upon a large number of interconnected, very general, and mainly unsubstantiated claims. If we take Castells' first claim, given the fact that he does not discuss whether there is such 'a consensus about the societal consequences of increased access to information', it simply assumes the air of common sense. Apart from such platitudinous authority, there are only three references to support the entire argument constructed in this section. The sweeping assertion that 'the school system as a whole, both in the US and in the world at large, is, by all accounts, woefully inadequate in the use of this new learning methodology' is backed up only by the 'documented study' (p258) of Bolt and Crawford (2000), which is in fact a tie-in publication from the U.S. PBS television series Digital Divide: Computers and Our Children's Future rather than a serious scholarly analysis. Claims such as 'overall, upper and middle class schools tend to be more attentive to the opening of the mind than schools in low-income areas' are unsupported and, to this reader, rather meaningless. At best, the judgement must be that this contextual argument is highly speculative.

I have not focussed upon this extract simply because I have specific reservations about the particular unreferenced and unexplicated assertions made. Indeed, this section is not stylistically exceptional. ${ }^{9}$ What I additionally wish to exemplify is the more general point about the rhetorical and methodological style that Castells employs in his meta-analysis. To develop his executive summaries, Castells predominantly draws upon survey data and, despite disavowals, locates any trends identified within a future-present discursive space. Given the often broad nature of his conjectures, his work 
draws sparsely on other academic sources for support and, in particular, very rarely engages with more theoretical commentaries and debates. Castells sets out his position on such scholarship at several points in The Internet Galaxy.

The speed and transformation has made it difficult for scholarly research to follow the pace of change with an adequate supply of empirical studies on the whys and wherefores of the Internet-based economy and society... ideology and gossip have permeated the understanding of this fundamental dimension of our lives. Sometimes this has been in the form of futurological prophecies based upon the simple extrapolation of social consequences from the technological wonders emerging .. at other times, it appears as critical dystopia. (Castells 2001: 3 )

Indeed, this standpoint has informed all of Castells' recent work. At the beginning of The Information Age, Castells states that:

This is not a book about books .. it does not intend to discuss existing theories of post-industrialism or the information society .. similarly, I shall not contribute .. to the cottage industry .. around postmodern theory .. I have tried to construct a discourse as autonomous and non-redundant as possible, integrating materials and observations from various sources, without submitting the reader to the painful revisiting of the bibliographic jungle .. where I have lived for the past 12 years. (Vol 1: 25)

Rather, his vision is of an empirically pure engagement, an autonomous confrontation of 'informationalism in itself (Fuller 1999: 165). Such an undertaking will 'form conclusions .. on the basis of convergent trends from several sources, according to a methodology of triangulation with a wellestablished, successful tradition among historians, policemen and investigative reporters' (Vol 1: 27), and will thus be distanced from both prediction and the ideological distortions of theory. As Fuller comments, 'Castells wishes to return to the phenomenon of informationalism without .. wrestling with all the 
ideologues who have mediated the public's understanding of the emergent Information Age' (1999: 165).

I would argue however that no attempt to understand the 'Information Age' can be complete without a consideration of the hermeneutic spirals of theory and belief in meaningful techno-culture, the 'dialectic of ideology and technology' in Gouldner's (1976) terms. Waiting for the 'cyberbole' (Woolgar 2000b) to clear is as much an academic dream as a serious methodological strategy. Indeed, as I have already noted, in another context Castells himself acknowledges the central importance of beliefs, expectations and 'information turbulences' to the workings of the 'new economy'. ${ }^{10}$

\subsubsection{The Global Digital Divide}

Following The Knowledge Gap, Castells' final section in his analysis is The Global Digital Divide. He begins this section by presenting empirical data comparing national levels of Internet access across the world, interpreting these in terms of a passive process of polarization whereby 'key urban centres, globalized activities and highly-educated social groups are being included in Internet-based global networks, while most regions and most people are being switched off' (Castells 2001: 262 my italics). Secondly, he argues that 'coinciding with the explosion of the information technology revolution, the rise of the new economy, and the diffusion of the Internet, the world experienced a substantial increase in income inequality, polarization, poverty and social exclusion' (Castells 2001: 264). Finally, he explicitly connects the two effects:

Naturally, correlation is not causality, so it could well be that all these social and environmental problems are independent of the process of globalization and Internet-led economic development. It could be, but it's not. It can be argued instead that, under the current social and institutional conditions prevailing in our world, the new techno-economic system seems to induce uneven development, simultaneously increasing wealth and poverty, 
productivity and social exclusion, with its effects being differentially distributed in various areas of the world and in various social groups. And because the Internet is at the heart of the new socio-technical pattern of organization, this process of global uneven development is perhaps the most dramatic expression of the digital divide.' (Castells 2001: 265)

There then follows a summary of the thesis presented in The Information Age, condensed into 8 progressively numbered sections whose (rhetorical form and) content further elaborates Castells' argument of causal connection. This forms the theoretical context for Castells to move from a reading of the global digital divide in terms of national differences in the current state of network density, exemplified in the comparison of various national datasets on Internet access, to proposing a consequential morphogenetic 'expression' of the global digital divide as a fundamental source of uneven development.

My point here is not to argue that, as articulated, these phenomena, the global digital divide and global uneven development, are unconnected. Rather, it again focuses on what enables Castells to make such a direct imputation of causal relations. In the terms of the classic critique of arguing from correlation, it focuses on the 'third term' underpinning both the first and second. To this end, I shall concentrate on the first paragraph in the summary of the network society thesis presented:

(1) The extreme social unevenness in the development process is linked to the networking logic and global reach of the new economy. If everything and everyone that can be a source of value can be easily connected, and as soon as he/she/it cease to be valuable, can be equally easily disconnected, then the global production system is composed simultaneously of highly valuable and productive people and places, and by those who are not so. (Castells 2001: 265-66 my italics)

As in The Information Age then, key to the causal chain of determination described here is Castells' elusive theoretical kernel, 'the implicit logic of the 
network', 'the pre-eminence of social morphology over social action'. Crucially however, I argue that what this description of if-then causality obscures through its primary emphasis on hypothetical social morphology ('if everyone .. can be easily connected'), is that actual network activity (then the global production system is composed of.. valuable and productive people and places) depends upon purposive and particular connection. Furthermore, such connection depends upon a meaningful understanding of the possibility that 'everyone can be connected', a concept of the network and ultimately its specific and purposive instantiation.

As 1 argued earlier, 'networking logic', understood ultimately and variously in terms of a technological, economic or ethical determination, assumes an inevitability in Castells' Information Age thesis, as an abstract determining force with an autopoietic telos. The link between state and process, morphology and action, is glossed via the a priori assertion of the pre-eminence of one over the other. Here, the particular causal chain of determination between 'everyone can be connected' and 'everyone connects' is similarly elided as the inevitable expression of networking logic. Recalling McLuhan (1964) then, Castells titles the opening to The Internet Galaxy as 'The Network is the Message' (Castells 2001: Opening).

\subsubsection{Networking Logic as Social Activity}

In my alternative reading, the network is a message and 'networking logic' is social activity, the performance and material instantiation of this message. I thus argue against Castells' proposal of networking logic as an abstract determining force. Rather 'networking logic' testifies to the specific translations of the concept of the network in relevant domains. These include 'transformations in the problematics of rule' (Rose 1996: 47) in advanced liberal democracies, where the concept of the network is a way of rendering reality thinkable such that it is amenable to new forms of political programming (see e.g. Perri 6, 2002). For 
Barry (2001: 87), 'Networks do not so much reflect social, political and technological reality; they provide a diagram on the basis of which reality might be refashioned and reimagined: they are models of the political future'.

The network itself then is not merely an empirical deduction. The network, or rather the idea of network morphology, is a model of institutional and organizational change that is materially developed and instantiated through white papers and political activity, regulatory policy, corporate strategy, Information Society and Network Society initiatives, academic conferences and symposia, and ultimately infrastructural assembly, interface design and the structuring of databases. ${ }^{11}$ For Castells the network is an empirical deduction that then enters the level of theory as the abstract determining force of networking logic. In my reading, networking logic is a social activity, the particular material instantiation of the concept of the network. ${ }^{12}$

Such a reading has many implications, of which I wish to mention two. Firstly, such a double hermeneutic complicates a methodological belief in constative analysis based upon pure empirical knowledge available to the detached observer. Castells mentions that 'the February 1997 Davos meeting titled the general programme of its annual meeting 'Building the Network Society' (Castells 2001b: 148). However, despite his position as a highly esteemed government advisor, he is mostly strangely silent on the theoretical and political implications of his own 'scanning of our world' (Vol 3: 383). As my analysis in earlier chapters has documented, the work of Bell and Toffler in particular has been widely used in the legitimation of various initiatives and policy agendas, and suggests a situation in which the findings of social scientific analysis and interpretations of the present may enter reflexively, and with considerable importance, into the social formations they purport to describe. I concur with Lyon (2000: 67) who argues that, "Castells is writing of an information age, in which surely any serious sociology is implicated in ways that go beyond mere detached observation'. 
Secondly, Castells' view of the determination of networking logic implies a powerlessness to contest this logic from within. For Castells, the key vector of contemporary struggle occurs via the construction of 'resistance identities', necessarily external to this pervasive networking logic:

In the Information Age, the prevailing logic of dominant, global networks is so pervasive and so penetrating that the only way out of their domination appears to be out of these networks and to reconstruct meaning on the basis of an entirely distinct set of values and beliefs ( $\mathrm{Nol} 3: 382$ )

With the unpacking of networking logic as a social activity, meaningful political resistance can be reconfigured from Castells' 'resistance identities' to focus on the possibility of internal contestation. ${ }^{13}$ Mansell and Silverstone (1996) analyze one set of conflicts absent from Castells' focus, the internal conflict over the design of networks. Van Dijk (1999a) further points to social struggles over the use of networks, in which 'social actors take positions inside networks, communicating at centres, nodes and terminals, and are engaged in daily struggles over the construction and use of these networks, in the roles of managers and employees, producers and consumers or governors and citizens' ( $p 135$ ). Both these examples point to the importance for power of an awareness of interdependence and the specific topography of networks, the knowledge of network connectedness and position. This may no longer be a class consciousness of hierarchical relations of production as a prerequisite for political action, but neither does it assume the externality of resistance and deny the possibility of meaningful resistance within the network. 


\subsection{Conclusion: The Digital Divide in the work of Manuel Castells}

Castells sums up his analysis of The Global Digital Divide as follows:

'Development without the Internet would be the equivalent of industrialization without electricity in the industrial era .. This is why the often-heard statement concerning the need to start with the "real problems of the third world" .. reveals a profound misunderstanding of the current issues in development .. The Internetbased economy and information system, proceeding at Internet speed, has locked in the developmental trajectories .. And once the option is taken to be part of the global networks, the Internet-based logic of production, competition and management is a prerequisite for prosperity, freedom and autonomy. But it can also be a recipe for crisis and marginalization...this is not the consequence of the Information Age per se, but of the digital divide. That is, the divide created between those .. that have the material and cultural conditions to operate in the digital world, and those who cannot, or cannot adapt to the speed of change. Under such conditions, the networking logic of the Internet-based global system scans the planet for opportunities, and links up what it needs for its programmed goals.'

(Castells 2001: 268-270)

There are two crucial points I wish to make about Castells' understanding of the digital divide. Firstly, just as the context for his earlier discussion of the digital divide as consequential was that of the necessity of 'new learning', the context in which the global digital divide may be understood as consequential inequality is that of the Information Age, and specifically networking logic as the associated and inevitable developmental trajectory.

The second point is that the pre-eminence of morphology over action, the theoretical kernel of concept of networking logic, can also be unpacked specifically with relation to Castells' particular articulations of the digital divide. I have shown how, in the structure of Castells' arguments about both education 
and development, through his empirical and rhetorical strategies, there is a slippage between two concepts of the digital divide, one strictly morphological, the other more consequential and active.

Castells' articulation of the significance of the digital divide thus fundamentally depends upon the problematic master concept of networking logic, at the same time as discursively renewing its core theoretical underpinnings.

As 1 argued in the previous section with reference to the concept of the network, what Castells similarly glosses here is the way in which the concept of 'the digital divide' itself becomes central to the process of change. I have detailed in previous chapters various case studies in which the digital divide has become a focus for debate and governance. The very idea of the digital divide has been contingently and materially instantiated through numerous policy documents, new media consultations, technocratic assessments, symposia \& conferences, programmes and initiatives, and so on.

As I have documented, a key contemporary endeavour, at state, corporate and supranational level, is that of 'bridging the digital divide', constructing and promoting specific imperatives to connect and network. But this social project is not a path that is determined by an assessment of a state of digital division, or inevitable 'once the option is taken to be part of the global networks' (Castells 2001: 270). Whether and how that option is taken depends upon the articulation, and most importantly the meaningful interpretation by relevant social actors, of those seductive and thoroughly permeated ideas of the network and their position within it, the 'digital divide' itself. 
Castells concludes with a customary denunciation of the digital divide:

The new model of development requires leap-frogging over the planetary digital divide. It calls for an Internet-based economy, powered by learning and knowledge-generation capacity, able to operate within the global networks of value, and supported by legitimate, efficient political institutions. It is in the shared interest of humankind that such a model emerges while there is still time. (Castells 2001: 271) ${ }^{14}$

While it may well be in the shared interests of humankind that a 'new model of development' emerges, it is difficult to see how the vision outlined here offers any real alternative to the current structures of the Information Age or indeed any real intimation of a socially determined course of action. Indeed, as Castells (2001: 271) notes, this model 'depends on the ability of countries and social actors to adapt to Internet speed in the process of change'. In a discussion of Castells' analysis of cultural change, in terms of the emergence of a new informationnetwork based 'culture of real virtuality', Calhoun similarly highlights a sense of inevitability: 'the issue of real virtuality is not that it produces a new culture, but that it facilitates a new acceptance of one limited reality, the idea that deep alternatives are impossible. This kind of closure is always one of the most basic supports of existing power relations' (2000: 47).

I argue that the key closure in Castells' work is the a priori pre-eminence of morphology over social action. This is why his discourse is troubled by causality and dependent for its telos upon seductive, normative ontology, particularly the master concept of an abstract, determinant and inevitable networking logic. Castells' understanding of bipolar stratification in the network society and in particular his articulation of the dichotomous digital divide fundamentally relies upon this problematic master concept whilst simultaneously discursively renewing its core theoretical underpinnings. 
For Castells, because the 'network .. works on a binary logic: inclusion/exclusion' (2000b: 15), ultimately:

'there is little chance of social change within a network, or network of networks. Understanding by social change, the transformation of the programme of the network, to assign to the network a new goal, following a different set of values or beliefs' (2000b: 22).

However, I argue that it is not the inside/outside privileging of an abstract networking logic that marginalizes the relevance of social struggles within networks. Rather it is Castells' discourse that neglects to consider networking logic as a social activity and potentially the subject of internal contestation, elides the possibility of purposively constructing a different system, and ultimately has political implications that mitigate against imagining a new model for development beyond the inescapable structures of his Information Age.

\section{Notes}

${ }^{1}$ All page numbers given refer to the second editions of The Information Age, and are hereafter cited as Vol 1, Vol 2, Vol 3.

2 Castells' argument ( $\mathrm{Ool}$ 1: 74-76) is clearly influenced by 'chaos theory' and the associated idea of 'complexity' (e.g. Waldrop 1992). For example, of Kelly's (1995: 25-7) assertion that 'The symbol of science for the next century is the dynamical Net .. Whereas the Atom represents clean simplicity, the Net channels the messy power of complexity .. The only organization capable of nonprejudiced growth, or unguided learning is a network.. A network swarm is all edges and therefore open ended any way you come at it. No other arrangement .. can contain true diversity working as a whole', Castells (Vol 1: 70, fn87) remarks that 'the basic message is an interesting one: the convergence between the evolutionary topology of living matter, the openended nature of an increasingly complex society, and the interactive logic of new information technologies'. 
${ }^{3}$ Castells' description of the spirit of informationalism in terms of a common cultural code has potential resonances which remain undeveloped. In 'Code and other laws of cyberspace', Lessig (1999) argues that, contra its foundational mythology, the Internet is not only governable, but that the range of available online behaviours is becoming increasingly constrained through regulatory software code: 'Code is the technology of inscription for the roles, relations and activities that are the grammar of online social life'. For Lessig, (corporate) codewriters are the new lawmakers, zoning and personalizing cyberspace according to values of 'identification, authentication, authorization, integrity and non-repudiation'. Castells' unexplicated use of the term code suggests a residual technological determinism in its understanding, rather than a consideration of code as a broad socially shaped text (see also Suchman 1994). For other analyses of the concept of code in social theory, see Baudrillard (1997), Deleuze (1985), Douglas (1998).

4 The analysis of the 'spirit of informationalism' has since been developed by the Finnish sociologist Pekka Himanen in The Hacker Ethic and the Spirit of the Information Age (2001), which includes an epilogue by Castells. Himanen defines the hacker ethic in terms a commitment to individual flexibility and freedom in organizing work, a dedication to creativity for its own sake, and hence a passionate relationship to work where play is central to job satisfaction. Himanen identifies the figure of the hacker as the embodiment of this ethic, a person not answerable to their employers or necessarily directly to capital, but instead motivated by the esteem of those others with the capacity and talent to network.

5 'The fourth world comprises large areas of the globe, such as much of sub-Saharan Africa, and impoverished rural areas of Asia and Latin America. But it is also present in virtually every country, and every city .. It is formed of American inner-city ghettos, Spanish enclaves of mass youth unemployment, French banlieues warehousing North Africans, Japanese Yoseba quarters, and Asian mega-cities' shanty towns' (Vol 3: 168) 
${ }^{6}$ The Falling Through The Net studies are not longitudinal data on the same subjects. Indeed, the number of participants significantly increases in the later studies.

${ }^{7}$ Such an empirical vision is reiterated throughout The Internet Galaxy. For example, in a passage that is also notable for the lack of analytical symmetry proposed, Castells argues that:

I have never known how to predict the future. What I do know is that the only serious way to think about the future is to have a clear idea, empirically grounded, of our present and of our past .. In other words, the way to understand the potential relationship between the Internet and the media world is to reflect on the few success stories of their integration. (Castells 2001: 195)

${ }^{8}$ Sardar (1999: 27) notes that 'in a very subtle way, predictions and forecasts silence debate and discussion. They present technology as an autonomous and desirable force and project the future as unavoidable .. We are locked in a linear trajectory that has actually foreclosed the future .. There is no such thing as the future; there are many, many futures. And our concern should be with what the future ought to be, what we want it to be.'

${ }^{9}$ It may be argued that The Internet Galaxy falls within a more populist scientific genre in which the expectations of full referencing are less stringent. Nonetheless, the book was conceived from a series of scholarly lectures, the 2000 Clarendon Lectures in Management at Oxford University, and such a style sits awkwardly with Castells' numerous claims to serious scholarship over prediction.

${ }^{10}$ As an example, consider Castells' analysis in The Internet Galaxy of the collapse of the dot.com 'bubble', a phenomenon whose explanation elsewhere has been inextricably linked with the role of ideology and belief in creating hyperbolic and unsustainable stock valuations (see e.g. Schiller 2000 on 'irrational exuberance', Cassidy 2002 on 'the greater fool theory', Frank 2002 on 'market populism'). Castells' own analysis (2001: 105-108) argues against this hyperbolic over-inflating of valuations. Rather he concentrates on other 'information turbulences' such as 
transactions where 'customers were nervous about giving away their information online', the 'anticipated end of the PC era', a decline in the rate of growth of IT spending by companies following the 'need (or belief in the need) to update their aging systems following Y2K', and political instability in Japan and the U.S. over 'the soap opera of the contested presidential election' (p106-107). My point is not to query the particulars of his analysis. Even if you accept his view, it is still utterly dependent upon the crucial importance of ideology and belief. In his concluding remarks on this phenomenon, Castells (2001: 108) attempts a rhetorical move to disassociate the 'real' and 'instinct' from the ideological.

It is a well-known fact that some prominent academic economists never believed in the existence of a new economy .. and kept pounding away at the inevitability of the bursting of the bubble, until they were gratified with the realization of their self-fulfilling prophecy .. Echoed by traditional leaders of traditional companies, a number of academic economists played a substantial role in diminishing expectations of the harvest of innovation in the information economy .. It is probably to the credit of Alan Greenspan that markets still believed in what they were seeing through the screen of mainstream economic analysis. Greenspan kept defending the reality of the new economy .. partly because he instinctively perceived that only an underlying productivity surge could explain .. the behaviour of an economy whose pulse he was feeling in real time. As soon as signs of a downturn appeared in the stock market, many conventional economists and veterans of the old economy, with a sigh of relief, seized the opportunity to push for a return to business as usual. (Castells 2001: 108 my italics)

However, even in this version, which disavows the role of overinflated hype, 'negative' ideological beliefs have an essential role in the historical real of the collapse, or collapse of the 'real'. As Armitage and Graham (2001: 114-115) argue, '[one of] the .. most distinguishing differences between hypercapitalism and its previous forms is the speed at which processes of circulation and self-valorization occur.'

${ }^{11}$ In a passage in which he explicitly puts the denial of his futurological shroud on hold, Castells argues that: 
The maturing of the informational economy .. will be made visible by changes in statistical accounting, when twentieth-century categories and procedures, already manifestly inadequate, will be replaced by new concepts able to measure the new economy. There is no question that the twenty-first century will witness the rise of an extraordinarily productive system by historical standards. (Vol 3: 385 , my italics)

Here, following his inversion of Marx's eleventh thesis on Feuerbach ('In the twentieth century philosophers have tried to change the world. In the twenty-first, it is time for them to interpret it differently', Vol 3: 390), he alludes to the need for conceptual change to be able to adequately measure the 'new economy'. However, 1 argue that the articulation of these conceptual resources, often centred on the figure of the network (for example, through the diagnostic indices of 'Networked Readiness' (CIDNEF 2002, see Chapter 5) or the revival of Social Network Analysis in U.S business schools), is not simply a case of enabling the more accurate measurement of the new economy. Rather such activity is itself part of the creation and definition of the 'new economy'.

12 In the language of Actor-Network Theory, one might be tempted to say that the idea of the network itself becomes a social actant, a participant in active debates.

13 In Chapter 31 argued, following Levitas (2001), that an allied theoretical move is similarly ruled out of court by the discourse of dichotomous social exclusion which focuses analytic and moral attention on the excluded, and rhetorically constructs a homogenous and unproblematic included.

14 This passage has a resonance with the currently popular idea of 'leapfrog technologies' (for example, the development of mobile technology infrastructure where no landlines exist). The Institute for Prospective Technological Studies report for the DOT.Force initiative (IPT 2001) concluded that there is at present, little evidence for the success of this as a developmental strategy. 


\section{$\square \square$ Chapter 7.}

\section{Talking About Technology and Exclusion}

\subsection{Introduction}

In previous chapters I have detailed the ways in which various social actors and institutions have articulated the relationship between technology and inequality, particularly through the motif of the digital divide and narratives of digital opportunity and inclusion. I have further highlighted some of the consequences of this articulatory practice: the legitimation of particular parameters of policy intervention, the performance of accountability, the renewal of a narrative of technological globalization, a buttressing of the imagineering of a network society.

The main aim of this chapter is to analyze the understandings of technology and inequality that are constructed in the talk of a specific group of participants in the discursive context of a focus group. In order to communicate meaningfully with others, individuals must draw upon publicly available narrative themes and resources when articulating their own positions. As Schofield Clark et al. (2004: 532) note:

None of us can construct completely idiosyncratic narratives .. but must choose which public narratives we will draw upon from a 'repertoire' of narratives which are afforded legitimacy or delegitimated, depending on their relation to existing institutions or structures of power.

In particular then, I aim to examine what specific discursive resources, narrative strategies and frameworks of meaning are drawn upon in these discussions, how 
these are articulated and for what purpose. As I detail below, a specific aim is to interrogate the claim that technological determinism is the 'common sense explanation' that structures the routine experience and understanding of technology.

\subsubsection{Technological Determinism as Common Sense}

As I detailed in Chapter 2, technologically determinist narratives have often been considered to be pervasive in popular and journalistic accounts of technology (Bauschpies et al. 2006, Preston 2001, Mackenzie and Wajcman 1999). Moreover, in the introduction to Technology and In/equality, a text which marks one of the most concerted recent social scientific attempts to directly consider the relationship of technology and inequality, Henwood et al. (2000: 9) contend that:

Thinking about the relationships between technology and society in terms of effects has been 'common sense' for so long that it has not needed a label. But its critics have termed it technological determinism. This approach is usually associated with the notion that technological progress represents social progress .. a technological breakthrough is claimed to have important social consequences .. the simplicity of this model is a principal reason for its endurance. But it is also the model which makes most sense of many people's experiences. For most people, most of the time, the technologies they use every day are of mysterious origin and design. Most people have no idea from whence the technologies came and equally little idea of how they actually work. People simply adapt themselves to their requirements and hope that they continue to function in the predictable and expected ways promised by those who sold them. It is because technological determinism conforms with a majority of people's experience that it remains the 'common sense' explanation.

There are numerous reasons to be sceptical of this claim that technological determinism is 'the model which makes most sense of many people's experiences' and hence underpins 'common sense explanation'. The general terms that this claim is couched in make it difficult to critique, and it also conflates 
several potentially distinct ideas under the heading of technological determinism: the autonomous, predictable, coercive and socially progressive nature of technological development. ${ }^{1}$

Furthermore, in the past decade, 'everyday life' has become a more explicit focus for technology and internet studies (Lie and Sorensen 1996, Bakardjieva and Smith 2001) and such work troubles the aggregation and the content of such a claim. Rather than focusing on sites of production, practices of design and workrelated use of technologies, this research has concentrated upon the mundane settings and everyday situated practices in which technologies are negotiated, appropriated and lived by 'ordinary' people. Such work has pointed to the active nature of consumption (Silverstone and Hirsch 1992), the 'interpretative flexibility' of technologies (Bijker and Law 1994), and the possibilities for unanticipated symbolic meanings and material uses of technology that people exercise in their everyday lives (McGrail 2002). Scholarly work has also recently begun to explore the 'non-use' of technology (Selwyn et al. 2005). For example, in categorizing non-users into resistors, rejectors, excluded and expelled, Wyatt et al. (2002) suggest that some non-use of the internet might be an agential choice that does not necessarily imply disadvantage.

The broad idea that 'adaptation' structures everyday experience and understanding of technology is increasingly subject to question then. Moreover, whilst it may be that in some circumstances, people 'adapt themselves' to the situated 'requirements' of a technology, for potentially diverse reasons, it does not necessarily follow that they understand technological development as autonomous, or wider social change as fundamentally determined by technological progress. There may be a relationship between endorsing elements of a broad 'technologically determinist' worldview or vision, and enlisting and interpreting technologies within specific biographical projects in particular ways, but this is an empirical question. 
At the very least, I suggest that it may be more useful to think of technological determinism as a broad interpretative repertoire, consisting of numerous interconnected elements, which may be variously drawn upon and emphasized in everyday explanations of technology for specific reasons.

Further, the claim that technological determinism is a dominant interpretative repertoire may potentially be at odds with the suggestion that the hegemonic 'first language' that structures and limits the way in which people are able to speak of their experiences is that of individualism (Bellah et al. 1985), of personal initiative, choice and self-reliance. There has been much scholarly work documenting the increasing contemporary salience of discourses of individualism in the articulation of the political (Eliasoph, 1998), the intimate and interpersonal (Bauman 2003, Hochschild 2003), the emotional (Sennett 1998, Elliott and Lemert 2006) and so on. For example, in Avoiding Politics, Eliasoph (1998) identifies the myriad ways in which US citizens are discouraged from talking in a 'public-spirited' way, that is 'politically' in the broadest sense, outside the most private arenas of their lives. However, there has been little work looking at how such a discourse of individualism may inform the articulation of the technological. Indeed, as Hutchby (2001) notes, there is little academic work in general looking at how people talk about the category of technology.

Within the overall remit of this chapter, to analyze what specific discursive resources and strategies are drawn upon in discussions of technology and inequality, a more specific aim then is to interrogate the claim that technological determinism is the dominant interpretative repertoire that structures the routine experience and understanding of technology. 


\subsection{Methodological Considerations}

One of the most important methodological issues was deciding who to talk to. In part, I was motivated by a seemingly straightforward ethical concern to listen to and represent the voices of 'the excluded'. This seemed particularly important given that the figure of the 'excluded' and the goal of 'inclusion' have particular salience in the discourses that I have analyzed in previous chapters. Moreover, in my analysis of these discourses, 1 argued that an ethic of inclusive representation is commonly alluded to as a specific legitimation of the understandings presented, while in reality such representation is often conspicuously absent. For example, in the engagement with those on 'the right side of the digital divide' in corporate discourse, or in the concomitant appeal to and disregard of developing nations' concerns in the production of supranational discourse, there is a systematic elision of the voices of the less powerful.

Such an ethical concern implies a need to define and operationalize the excluded' in accordance with some specific demographic or conceptual criteria, such that a process of purposively sampling and recruiting particular participants can take place. As I argued in my review of the social exclusion literature, any such process involves the researcher's own scientific and political construction of their object of study, which needs to be acknowledged.

The participants I spoke to were all tenants from a housing scheme that has a specific remit of helping excluded young people in London. The scheme was known to me through an acquaintance who was employed as a social worker there. Tenants are not entitled to a place on the housing scheme through selfreferral. They are all referred via various referral agencies (principally social services, probation services and asylum services) and for various reasons (principally domestic problems, recently leaving young offender institutions or prison, and having sought asylum). 
It can be argued that by talking to these participants, my own sampling implicitly constructs them as representative of the essential, and previously neglected, category of the 'excluded'. Indeed, my recruitment letter, drafted in consultation with a project keyworker to make sure it was in line with the housing scheme's 'ethos', reinforces this understanding to some extent by presenting the upcoming focus groups as a chance for the tenants to 'have your say' as someone who 'frequently may feel that you are not being listened to'. However, it is important to note that my participants were already recognized in a certain discourse of social exclusion through the institutional arrangements of the principal referral agencies. One of my analytic concerns was to explore the experiential meaning of the discursive processes of categorization to which these participants were already subject. I hence view my decision to recruit participants in a manner partially complicit with a reification of the excluded as strategically crucial to reflexively open up such processes to interrogation.

The second point I wish to discuss is my decision to talk to my participants in the context of focus groups. As I detail below, this was a relaxed discursive space in which the participants could discuss their biographical experiences and understandings of technology explicitly and at some length, and hence was highly appropriate to the particular analytic aim of examining what discursive resources and narrative strategies are drawn upon in the construction of such accounts. Nonetheless, as Eliasoph (1998: 244) notes, we always need to consider people's 'beliefs about what it is right to say' and wrong to say in specific social situations. Certainly the licence of the focus group situation may differ markedly from the constraints on speech and reflection that operate in other contexts, including those where the actual negotiation of technology in everyday life is typically encountered. Indeed, as noted above, this particular discursive space was specifically presented as a chance for the participants to 'have your say'. 
It is ultimately an empirical question that I cannot address here as to how the accounts articulated by the participants in this particular research setting would relate to more mundane talk about technology in other social settings, or indeed to particular technological decisions and actions, and to what degree they encompass specific rationalizations and retrospective adjustments. However, they should not be thought of in terms of their relation to some attainable ideal 'truth'. Indeed, as Bourdieu (1999: 63) notes, the very act of reflecting out of the flow of everyday life carries its own distortions, it does not yield simple research 'truths'.

All accounts are constructed and made meaningful then within a certain social situation with particular performative demands, and may be usefully considered in terms of the 'co-production of knowledge' (Callon 1999). In my analysis I will thus attempt to be sensitive to the specific performative dimensions of these accounts, what they enable the speaker to do in a specific discursive context involving myself and all the other participants, rather than treat them as constative and attempt to assess their fit to some other reality. Notwithstanding, I do not intend to address how specific accounts may be performative in the sense of interactional micro-management, for example in terms of managing conversational turn-taking.

\subsubsection{Focus Group Details}

At this point, some further detail of my participants, the focus groups, and the context in which they took place is necessary. The housing scheme provides low cost accommodation and utility provision to the tenants in houses of 8-12 people. Each house has one social worker assigned who organizes house meetings to deal with any problems that arise in the course of communal living. Additionally, each individual tenant has an individual keyworker who liaises with other social, counselling, training and occupational services and agencies as necessary. The keyworker may provide the tenant with support, advice and assistance in 
developing a programme of work, education or training, filling out forms and claiming benefits, and dealing with health and personal issues.

The overall aim of the scheme is to enable those referred to eventually be in a position where they are able to secure their own independent accommodation and support themselves through their own means. As such, tenants generally stay in the scheme for between 6 months and 2 years. My informal contact with the tenants, keyworkers and managers of the scheme suggested that it is highly successful and well respected in the field. However, at the time of my focus groups, changes in the funding structure of the scheme meant that it was being asked to provide more evidence-based assessment of the quality of service provided. Within this context, my involvement as an independent researcher was welcomed. Indeed, it was audited in a report to the funding agencies as an example of good practice in widening the involvement of tenants in external activities.

The focus groups were both a serious but also a relaxed social space. There were many determinants of this situation. As mentioned, the recruitment letter was framed very much in the terms of the ethos of the housing scheme, which encouraged honest and open communication. The physical environment in which the focus groups took place was a kitchen/living room for the tenants' own use on the occasions when they needed to come and see their keyworker in the scheme's main building. As well as comfy seating and magazines, the room contained a fridge, microwave and hot and cold drinks. I brought fruit and sandwiches along for the focus groups additionally.

On my gatekeeper's suggestion, I reinforced at the beginning of the focus groups the scheme's ethos that there should be respect for everybody's contributions when in the building, and this carried through to a considerable extent. Despite the fact that debate was lively and disagreement was frequent, there was no dismissal of other's points of view, and on occasion, apologies for swearing in my 
presence. Though there was unsurprisingly a range of participation from the loquacious to the more considered, all the participants were articulate and appeared genuinely interested, and none could be considered taciturn.

Five focus groups were conducted with the number of participants in each ranging from five to eight. Of the total of thirty one participants, fourteen were male and seventeen female. The participants were of various national and ethnic backgrounds: five white British, twenty three black British, and three refugees from African states. The age of the participants ranged from eighteen to twenty six with the majority being in their early twenties. All of the participants were of low income and socieconomic status. Three of the females were single parents. The majority were undertaking elements of part-time employment, further education and training, often organized through the New Deal for Young People or the New Deal for Lone Parents. All of the participants were receiving either Jobseekers allowance or income support.

In the following discussion, all of the participants' names are changed, as are the names of identifiable geographic locations and social institutions such as colleges and places of employment. As noted, I do not intend to specifically address the issue of conversational micro-management. As such, the level of transcription provided reflects this orientation to the data and imposes certain conventions of dramaturgical conversationalism that do not attempt to represent specific features of the mundane interactional situation, in particular temporally concurrent and overlapping speech. 


\subsection{Key Themes}

\subsubsection{Form and Function}

Initially it is important to point out that some of the accounts that the participants construct may be considered to be broadly technologically determinist in so much as they emphasize the immutability, the pre-ordained functionality and the material form of 'technology':

Celia: then again like a phone, you could have a landline, that's technology because that's you know wires and stuff that are connected to it.

(Focus group 1)

In the following excerpt where the discussion concerns what to do when artefacts break down, the participants draw upon the theme of specialist knowledge as central to the demarcation and meaning of technology:

Paul: you normally get in contact with like the supplier of the goods like, whether it be Canon, whether it be a computer firm or something, get in contact with the manufacturer and see what see what can be resolved.

Kevin: so do you ever try it yourself?

Paul: no because it messes up your warranty or whatever doesn't it? If you tamper with it yourself.

(Focus group 1)

Indeed, where an alternative tactic is mooted, it is in terms that make clear that this is an idiosyncratic rather than a reputable strategy:

Andrea: l'd take it apart and put it back together, I'm notorious, I do things like that (Focus group 3: my italics)

In the following excerpt, an ostensibly determinist view, that technology has preordained functions, is expressed: 
Del: everyone's gonna look to buy it, the next phone again, but there's no point really, all those acts and all them new ones you can flip it and the touch-sensitive, all that stuff

Ade: because the purpose of the phone really is not how it looks, it's what it can do for you anyway, that's what it's supposed to be

(Focus group 1)

Nonetheless, the expression of utilitarian functionalism, it's what it can do for you, that is mobilized in this context operates in order to undercut an alternative narrative that the purpose of technology is fashion and style. As such, it is important to note that what is in some respects a technologically determinist position concerning the functional essence of a technology is actually used locally in order to contest the everyday experience of the aesthetic dimension of a technology.

\subsubsection{Epoch and Life}

Arguably a more direct expression of a technologically determinist worldview lies in the assertion of epochal change, such that society is technologically transformed to a qualitatively new form of social organization. The initiatives analyzed in previous chapters were replete with such understandings, crystallized in naming such change as 'the digital revolution' and the resultant era 'the Information Age'. As many commentators have argued, such terms may be inadequate descriptors of social change. For example, Hakken (1999: 25) criticizes the notion of a 'computer revolution' for its binary quality, that a revolution either has or hasn't taken place, which blocks the disciplined examination and discussion of incremental social change. May goes further in arguing that such language is not merely (inadequately) descriptive but prescriptive and that, "postindustrial analyses which claim the information society is emerging have themselves contributed to the appearance of this new sociological 'reality'" (2002: 8). As such, Webster (2002) prefers to talk of 'informatization' as a process that emphasizes the continuities of established 
social forces rather than the revolutionary and epochal shift implied by advocates of the information society.

In the current discussions, the term 'information society' or its analogues had negligible currency. For that matter, neither did the phrase 'digital divide'. Rather change was principally discussed through the discursive trope of life, an articulation of the societal and the experiential. In the following excerpt, Laura discusses her understandings of the unavoidable technological dimension of this life now.

Laura: You have to have, not know everything, but you have to know about computers to get along in life basically, in this life now, so I don't personally know that much about computers or go on internet or anything like that but I need to know, cos you need to do whatever you have to do in life. (Focus group 1: my italics)

In the next excerpt, at first glance Bernard's statement may seem to give a clearer endorsement to the idea of an epochal shift to a qualitatively new form of social organization, 'modern society':

Andrea: its something its just been stuck in our head that we need it, we need to do this to get this far, if you want to be this in life then you're gonna have to learn this, and if you don't want to learn it then what's the point of wanting to be that

Bernard: like keeping up innit, not being left behind, no one wants to know someone who doesn't know what modern society is

(Focus group 3: : my italics)

Bernard's statement asserts the exclusionary consequences for the individual of not keeping up. Nonetheless, it does not simply endorse the term 'modern society' as a descriptor of change per se. Rather it brackets its ontological status and points to processes of social epistemology and social exclusion in its 
determination. In the following excerpt, while Del initially expresses a view that that's the way the world is, he also contests the inevitability of this situation.

Del: yeah I mean obviously there's a smooth with a rough, there's a smooth and a rough with everything, I mean obviously people dependent on technology, that's the way the world is these days, but I don't think it has to be that way. That thing of the passport, that's a prime example, why should everything be on one, that one card is your whole, your DNA, your blood type, everything is on that one card.

(Focus group 1: my italics)

Del's statement contains several related discursive motifs. The first is the idea of technological dependence. The second draws on popular understandings of technology as both threat and opportunity, that the technological moment is a double-edged sword, a concomitant utopia and dystopia, a smooth with a rough. This dualism of threat/opportunity is well established within society as a way of understanding technological change (see e.g. Shields, 1996, Jordan 1999). Indeed, as I have discussed in previous chapters, it additionally structures the narrative of policies and initiatives and hence 'acts to reduce the complexities surrounding the introduction of new technologies to a choice between a distinct set of binary oppositions' (Goodwin and Spittle, 2002: 533). It is also a well established motif within academic literature and critical social theory that emphasizes the irrationality of the overly rational and technocratic.

The mobilization of such motifs here prefaces the questioning of inevitability, that things don't have to be the way that they are, and hence potentially contests the limits of technological determinism as the hegemonic interpretative repertoire for the understanding of technology. I shall return to further understandings of what might then determine why things are the way that they are in due course, but for now I wish to further discuss the idea of technology as radically double-edged. 


\subsubsection{Dystopia and Utopia}

Phil: it's a bit of both innit

Celia: it's a two way thing

Paul: it's good and its bad

Ade: it might work to your disadvantage and it might work to your advantage

(Focus group 1)

As in the above co-constructed exchange, an understanding of technology as double-edged was a prominent theme which structured much of the discussion in the focus groups. Some of the principal dystopian concerns that were discussed related to issues of health, surveillance, privacy and security, constructed as prominent issues of risk in the mass media. In the following conversation, security is the issue in question:

Paul: yeah cos if you buy your phone as a default yeah, as a default your PIN number is 1210 right. Now anybody that goes to a phone box and calls up your phone, and your phone's not on reception, will automatically go to answer machine. Now when the answer machine comes on, if you press hash it'll say please enter your PIN, and if this person has not changed their PIN you press 1210 and you're into their voicemail, listening to their messages, going through changing things. you can do whatever you want. Laura: is that only on a OnezOne?

Paul: on One2One but on another network, it'll be another number, it'll be another PIN but it'll be a general PIN.

Phil: for the company.

Paul: so you can always access things like that.

Kevin: are there lots of these kind of little tricks?

Phil: yeah.

Del: there are because people find them out.

(Focus group 1) 
Here an acceptance of the pre-given mode of operation, codified by the universal default settings, is specifically understood as a practice which enables the playing of tricks around issues of security. Furthermore such tricks are by no means seen as epiphenomenal, you can always access things like that. Rather they are understood as a systematic and inevitable outcome, central to the meaning of technology. ${ }^{2}$ The theme is further elaborated in the following discussions:

Ade: they sometimes offer, the companies offer like software in form of encryption to prevent that but in most cases there are ways that you can go round the encryption.

Celia: you can override the security, any technology that's been invented for security you can override the security there's a way it can be done Ade: you can go through a firewall, it's very easy if you know how to do it, it's easy to do.

Del: because it's only technology .. cos it's man made, technology is man made.

Ade: though the software is there to prevent it, the encryption sometimes it's not so strong.

Paul: there's always gonna be a fault.

Celia: there's always gonna be a way.

Ade: it depends on the encryption you have anyway.

Del: they'll always be people who run scams and stuff like that anyway.

(Focus group 1: my italics)

Francine: technology can be a good and a bad thing depending on the individual that's using it, cos you can go on the internet and go and make a bomb, learn how to make a bomb, d'you know what l'm saying

Bernard: yeah, technology is always made to be broken really innit, cos man himself will always be able, cos he made it innit, man or woman whatever, so he will always be able to override it, there's always some key to get through

(Focus group 3: my italics) 
The understanding that is stressed here is that the sole predictable feature of that which is only technology is that, paradoxically, it is frail and indeterminate, always open to reconfiguration. At the very least, this troubles the idea that the dominant interpretative repertoire for the understanding of technology is one of straightforward technological determinism. The predictable indeterminacy of technology may lead to further discursive 'explanation', for example in terms of the purposive action of particular social groups, a point to which I shall return presently.

It is worth pointing to the fact here that the accounts articulated were rarely bound to discussions of experience located categorically in the present moment. The excerpt below follows a discussion of electronic tagging:

Paul: you know they even want to put chips in people, they want to put chips in people so you'll get scanned.

Del: and I'm sure it'll get worse, l'm sure you know, as time goes on, it'll get worse, if you walk out, you know you'll get a shock or something.

Celia: they do it with cats and dogs already, in the neck, so you don't need a collar no more. If it gets lost, the vet can scan your cat and know what's up with your cat, that the cat's wrong. It's true, it's actually happened, people have implanted chips in their cats' necks and they don't wear tags. The vet, some of them have this thing, where they just scan the cat to find out where the chip is.

Steven: you sure it's not the magnet for the cat flap?

Phil: it's in case they get stolen or lost or something, so you can find out where the cat lives.

Celia: register your cat to your address, if you forget to register it.. (shrugs)

Steven: can you remote control it?

(Focus group 1) 
Here the participants shift temporal registers, blending together that which is discursively marked as extrapolation, as time goes on, with discussion of contemporary practices of implantation and scanning. Constructing such a complex future-present discursive space contains its own contingent failure, if you forget to register it. This is rhetorically resolved via a further technological moment, the prefigured dystopian motif of physical punishment at a distance, whose temporality, can you remote control it? is neither clearly present nor future but best described as open to discussion. This final comment is further an example of how the use of a humourous register may rhetorically enable speakers to create a discursive space in which to explore multiple interpretations and voice imaginative ideas about technology and the future that may not be possible in more serious discourse (Moore 2002).

Finally in this section, I wish to point to how the participants' narratives are often directly informed by the more utopian accounts about technological futures that are told by the 'professional producers of stories about technology' (Knights et al. 2002). However, this is not necessarily in terms of a straightforward endorsement. Rather, the promissory nature of such accounts may be discursively reconfigured to articulate more specific local desires.

Van Lente argues that 'when technological futures find a ready ear, as they often do, the necessity of developing technology may become so pressing that technologists, in a sense, are victims of their own promises' (2000: 60). McGrail (2002) similarly discusses the reasons why residential CCTV schemes may arouse much debate but little clear resistance, whereby residents 'keep the whole issue of electronic surveillance on the boil' (p135) but never reject the technology fully and outright. He argues that:

'By constantly reminding commissioning authorities of their interests in the new technology, they aim to attain a new sense of freedom and thus self-respect .. the promise of the technology can often turn out to be empty .. At the same time, the 
onus or burden of proof as to the effectiveness of electronic surveillance remains on systems commissioners to prove the social value of CCTV in real terms'.

(McGrail 2002: 135-36, italics in original).

In the following excerpt, it is a more general technological vision that is being discussed:

Del: everyone that is here has obviously had some sort of, like, default in their background, yeah. Like for someone like me, yeah, when I was having problems in my home, yeah, I never used to go to school, back in the day. I never used to go to school, and that sort of affected my exam results and my qualifications. And then again, the way the government see it is, we're gonna put all this stuff here for the people that want to learn it. Then you think about this, that there's only two or three or maybe, no l'd say about five, yeah, five people that go through all like a system, that go through school, college, university, and they go and do this and do that. It's only aimed at those sort of people. People like me yeah, well why can't I learn computers as well?

(Focus group 1:)

Here, Del contrasts his understanding of government policy with what he regards as a reality that betrays its universal and voluntaristic promise. It is hence through discursive appropriation of this meritocratic narrative of technology and inequality that those who seek recognition of their desires, whether to learn or the indexical desire for self-respect, may articulate them, without necessarily endorsing the terms of such a utopian vision. 


\subsubsection{Consumption and Identity}

In contrast to an interpretative repertoire of technological determinism, a prominent way in which the participants articulated their understandings of technology was that, as in the previous example, technology was discursively associated with particular social groups. Indeed, the attributes of such groups were partially understood in terms of such an association.

Discussion often focussed around the consumption of personal technologies, and as such followed a perceived logic of market segmentation based around age, gender, finance and lifestyle, or their combination in the rhetorical construction of groups such as 'businessmen'. In the following excerpts, Davina clearly identifies those with financial capital, and particularly young people with few other financial commitments, as social groupings whom specific technologies are designed for and marketed at.

Davina: people with money is what technology is for, people that can afford cos technology is not cheap. It's expensive and I think a lot of the things that are designed these days are, some of them you can see are, aimed at young people, and some of them are aimed at the more older people like, er, I don't know, well computers and stuff's aimed for everybody, but a lot of businessmen, they have certain things that I mean, I've never seen before, they leave the mobile phones and CD players and stuff for the young people. (Focus group 2)

Davina: it does, it shows what kind of person you are, basic people would have a microwave that looked like that (points to microwave in room). Me personally, I wouldn't have that cos that's just not me, yeah.

Haydn: it's a bit old fashioned.

Davina: yeah, it's a bit old fashioned but some people don't mind, as long as it works.

Haydn: you want a digital one, innit. 
Davina: yeah, or the stainless steel or something, the stylish kind of you know.

Kevin: even for a microwave you

Davina: yeah even down to a microwave, that might be just me Davina Williams, as a young person right now. Maybe as I get older, I wont look at it like that, but right now I haven't got any children, I haven't got anything else to spend my money on, apart from paying rent and buying little things that are going to make me happy you know. It does show who you are I think, definitely.

(Focus group 2)

In this narrative, identity is in part constructed through the consumption, display and recognition of a hierarchy of technologies, it shows what kind of person you are. Technologies are understood as an arena for the production of meaning boundaries between groups are constructed in terms of technology consumption, basic people have stylistically old fashioned technology. In such a narrative, the meaning of technology is explicitly understood as determined via its relation to, and distinction from, other elements in a fluid symbolic code, whose parameters may be variously culturally shared and contested, some people don't mind as long as it works. Davina locates her own identity in relation to the consumption of specific technologies. However, while certain stylish technologies, even down to a microwave, are important for her temporal identity as a young person right now, for other technologies with different cultural and age-specific associations, an alternative to style is articulated:

Davina: when I was younger, I used to be excited by it, when I was in my teens, id be like 'oh gosh, new phone, new this, new that' but now like it doesn't faze me.

Michelle: I think with me now the most important thing is, I think I think to myself, is it relevant? Is it something I need, you know. If I thought I had no use of it, I could make do, just cope with you know, say like it's my computer, or just what I have. 
Haydn: sometimes you can feel cheated, innit, cos you buy something and they say, 'this is the best ever', and like two weeks down the line they're bringing out a new one.

Michelle: Playstation2, Playstation 5, 6, 7. ..

Davina: that's why its better to get classic stuff other than stuff that is just in fashion, classic quality you know, not so much style but you know the classic, something that doesn't go out of fashion you know.

(Focus group 2)

No longer 'fazed' by the consistently transitory novelty of technologies such as phones, a position she associates with her teenage self, Davina now describes classic quality as the key to an identity which is not completely subject to the vagaries of fashion, a position beyond or at least not so much style.

For other participants, there is an even more marked ambivalence expressed to claims of technological advancement, a sense of feeling cheated by the routine hyperbole of marketing and increasingly rapid usurpation of technology, Playstation 2, Playstation 5, 6, 7. Such numerical codification of technological development is simultaneously a marker of precession and preordained obsolescence. Technological innovation is discursively understood as progress only in so much as it is occurs with a concurrent narrative of the archaic. In the following excerpt, the logic of technological miniaturisation is being discussed:

Anneisha: I'm sure when they made that big phone they knew they could have made that phone really small at the start but they just had to keep getting smaller and smaller, you spend so much more money

Sherene: if they just made one small phone they wouldn't make any money would they, so they have to do it

Anneisha: certain models and get them and get them

(Focus group 4) 
This conspiratorial understanding is clearly non-technologically determinist in emphasizing the ultimate determination of economic profit. Despite such expressed disavowal of the incessant logic of marketing in this instance, an attendant narrative that the social categorization of status is dependent on technology ownership meant that such a position was by no means universally or unproblematically held:

Joseph: cos phones keep coming at ya, and if you don't, you might not want to buy a phone yeah, but after everyone gets it, you feel left out if you don't buy one

Sherene: no I think that's for kids, I think its for mainly like the younger generation because now I just, I'm not into that anymore like Joseph: true sometimes

Anneisaha: but would you have a face-off, would you like, it'd be ok, be confident that's your phone?

(Focus group 4$)^{3}$

In this exchange, the understanding articulated is one in which ownership of personal technology is potentially a source of status anxiety and hence it is discursively meaningful to raise it as an issue of individual confidence. In the following excerpt Paul further articulates a hierarchy of technologies as providing the discursive basis for a stark, gendered, categorization of social status:

Leford: if you're using a new phone, now people can think, yeah, you've got money or something cos you've got a new phone, you get me Del: or you're trendy or whatever, you know what I mean

Paul: you get a lot of people get categorized anyway, but when you've got something that's new or a new technology, you're categorized even more. Yeah this guy's got money, look at that, he's got that new BMW compact, blah blah blah, with the new technology and the heated seats, $\mathrm{rr}$ rr rr rr rr. You're put into categories, as to what technology you've got, what you're wearing, what you're doing, it's all to do with categories, and that's how 
technologies operate. You get the Lowest Girl, LG, that'll be like the lower grade DVD player, then you get the Sony DVD player with this that and the other, it's all to do with categories they're trying to put you into.

Del: they're trying to make you live in that certain lifestyle.

Kevin: they actually call them LG.

Paul: yeah, they're called LG from the DVD player

(Focus group 1) ${ }^{4}$

Social classification then is one of the defining themes that structures the participants' understandings of technology. Such classificatory schemes appropriate corporate logics of marketing, segmentation and personalization, are built up through talk, and are sources of contestation and change. Individuals attempt to discursively position themselves and to construct contingent and credible narratives of personal identity through the acceptance, rejection and interpretation of such structured symbolic codes.

\subsubsection{Social Interests and Individual Empowerment}

As well as technology being discursively associated with social groups oriented around specific constellations of age, lifestyle and financial capital, distinct understandings were also articulated about which social groups' interests were promoted through technology. One particular rhetorical invocation structures much of this discussion - there is very profuse use of the third person 'they' throughout the focus groups. Although at times it is reasonably clear from the context to infer the referent, in many cases 'they' simply functions as a generalized Other to oppose personal or group identity:

Del: I also think that it's sort of like a system that they put you into Celia: basically what they've done is they've created the need for computers.

Ade: it's just a vision that they're pushing, and it's whatever they say runs 
Del: it's just whatever they want to do, they will do, and that's just it, they want to push computers, everyone must be computer literate, then you have to be.

Paul: there's always somebody one step ahead of somebody else ...there's probably a government to the government anyway, d'you know what I mean. (Focus group 1: my italics)

While participants often stressed powerful institutional interests such as corporations and the government, other interests were also seen as being promoted through technology and in particular, through the resources that culturally organize the interpretation of a technology. This theme is developed in the following discussion:

Celia: it's like there should be two forms of manuals basically. You have manuals that are full of jargon, full of technology term.

Paul: for the people that are up on that.

Celia: for the people that are up on their vocabulary and their language, then there should be what we call layman's.

Paul: simplified.

Celia: layman's terms, straight up, to the point. You can't find a manual like that. You find a manual to use a phone, I don't open that, I put it down and I work my way through it myself because otherwise you go through this language, you end up somewhere else, and it doesn't, you feel like it doesn't apply to you so you don't bother with it.

Kevin: so the jargon's for someone else?

Celia: the jargon is for the people who made the phone themselves because they understand the language innit.

Del: not for people like us, for people who've got to strive through life and do this and do that.

(Focus group 1) 
Here, the professional rhetoric and narratives, jargon and manuals, that culturally organize the interpretation of a technology or 'configure the user' (Woolgar 1991), are understood as reinforcing the interests of those with specific technical knowledge and cultural capital, the 'techno-elites' in Jordan's (1999) terms. Hence in this particular discursive context, such resources are seen as disempowering, not for people like us, and as such, you feel like it doesn't apply to you so you don't bother with it. In the following excerpt, Marta expresses a complex, though differing, understanding of her ability to deal with the same technology:

Marta: I don't know, it's like a way of motivating myself to show me that Marta you're capable, you know, you're a very confident person, it's like pushing my way ahead. It's like, I don't know, some people don't seem to realise that the phone is like the first big step to actually communication with people.

(Focus group 2: my italics)

Lyon (2002: 32) argues that, 'time and space are so deeply organized by artificial means to connect presence and absence that it is more appropriate to think of technology as activity and environment than "tool". Certainly Marta's statement offers a striking example of how particular technologies of communication may be understood as the environment in which life is lived, as communicative and social possibility itself.

However, the realization of such sociality, of communication, is nonetheless framed and understood within a discourse of individualism which stresses self motivation, the cultural privileging of confidence and its specific historical association with technical competence. Furthermore for Marta this is an individual achievement which some people don't seem to realise. In the following excerpt, individualism is again a salient motif: 
Andrea: I do have interests, don't get me wrong, I do have interest with some technology but I just don't let it get to me so much, cos the way I see it, there's me, one in this world, and without all of this stuff, it takes me to operate it, so I don't let it get above me

(Focus group 3)

Here a discourse of individualism similarly frames the way in which Andrea talks of her own relationship to technology. However, unlike Marta, her understanding of individual agency stresses not technological competence, but rather selfreliance in the face of potential technological demands.

In the above examples, there are clearly heterogeneous positions expressed. Marta locates a sense of agency in technological capability, Andrea rather in the ability to not let it get above me. Celia articulates an understanding between these two positions in arguing that I work my way through it myself because otherwise you go through this language, you end up somewhere else - by implication, not where she desires to be.

I suggest that if anything consistently underpins this continuum of positions, it is not an emphasis upon a deterministic adaptation to technological imperatives, but rather an emphasis upon values of self reliance and initiative. These values assume complex resonances and dissonances with the perceived values and interests of particular social groups that are variously understood to be promoted through technology, and as such construct a heterogeneous discursive space.

Overall, $I$ argue that in these accounts and those in the previous section, technology is understood in terms of social classification and the social interests it embodies. The participants' own personal trajectories and biographical projects are negotiated within these narrative structures and framed by an underlying discourse of individualism, rather than understood in terms of a hegemonic interpretative repertoire of technological determinism. 


\subsubsection{Job Seeking}

Central to many of the biographical projects articulated was the requirement to find work. As discussed in Chapter 3, UK government policy on social exclusion emphasizes the importance of technological skills for contemporary employability, and this theme is extremely salient and rarely contested in the participants' accounts:

Celia: the first thing on most application forms, or when you go to college, they ask you 'are you computer literate?'

(Focus group 1)

Andrea: the more words you can type on the computer in an amount of seconds is the more money you can get

(Focus group 2)

Anneisha: most jobs, like, you need to have the basic knowledge of computer, like lots of people do IT course just to get a little, have to know something about them

Joseph; not when you're a cleaner though

Sherene: but most general people have. They, if it's their own business and stuff, they have to enter the

Joseph: true, true

Sherene; accounts or whatever on the computer so everyone has to know the

Joseph: that's what l'm saying, you have to know a little bit but you don't have to know everything

(Focus group 4)

These accounts are thus broadly resonant with the dominant governmental narrative of technology and inequality, that computer literacy is a key conduit for social inclusion via paid work. However, in the following extended extract, there 
is a further orthogonal dimension to this relationship articulated, that of the technologically mediated micro-management of job choice:

Del: at the job centre they got new computer thing now innit.

Paul: touchscreen.

Del: yeah them touchscreens and that, but another thing is yeah, 1 just think it's a bit discriminating yeah, people that goes into job centres, because no matter what your background is, that don't stop you from being intelligent or not, you know what l'm saying, and I reckon that you should have the chance to do what you want. When you go to the touch screen you don't see no business job, you just see labour porter, you know them type of jobs, like you don't see I want to go work in an office, you know what I mean, or here's an apprenticeship to be managing director or whatever, you don't see nothing like that.

Kevin: so before you get there, what they've brought up on the screen.

Del: yeah it's like, when you get there, you got the touch screen and you say what sort of jobs you want, so you press it and, retail, all it is like is working in shops and labour on site, be a porter or a cleaner.

Phil: it's limited.

Del: it's very limited.

Kevin: and who does the pressing, is this you or

Del: it's like the government isn't it, like job centre plus.

Kevin: but physically, who presses that screen?

Del: no, you do it yourself.

Paul: but there's only limited options.

Del: what I mean is, when you go into your options, there's only limited stuff, and it's like, you get lumbered with 'people that need to go to the job centre', get lumbered with those jobs.

Kevin: right ok, just thinking again about the actual technology, the physical thing if you like, when you're sitting there, like, who uses it, who can see it?

Celia: you see they've got a screen and a lot of them don't like you to see what is on the screen. 
Phil: yeah, that's what l'm saying.

Paul: turn it round.

Kevin: right, and what do they say when you say can you turn it round to me?

Celia: they've got a security thing that they put in, it's like a card for each keyboard, and when they move away from the desk, they take it out so you can't see it.

Kevin: oh right.

Celia: and I told them I want to see the screen, I'm entitled to see what is on the screen, and if I didn't say that she says, 'well you know actually we're not supposed to show you it, it's actually employment service personnel'. Yeah, but it's my information on your screen.

(Focus group 1)

In stressing that you should have the chance to do what you want, Del initially echoes the social integrationist discourse of social exclusion (Levitas 2001) where the emphasis is upon equality of opportunity and individual choice in finding paid work. However, when discussing the specific lived situation of the job centre interview, his account additionally highlights the contradictory issue of constraint. In particular, the accentuation of the technological and symbolic motif of 'options' discursively conjoins these two narrative strategies, when you go into your options, there's only limited stuff. 'Options' are understood to embody categorization and constraint as much as the instantiation of choice, you get lumbered with 'people that need to go to the job centre' jobs.

In this extract then, life trajectories are described being played out through a particular technological environment in which the ideas of individual choice and responsibility, seen as central to the negotiation of the complexities of a fragmented contemporary job market, are embodied in a particular diagram of client interactivity. However, the understandings articulated by the participants additionally highlight the enduring experience of constraint in their options, as 
well as the micro-management of information through the spatial control of information architecture.

Celia's account of her interjection and contestation of this information micromanagement is distinctive in that it draws on a public discourse of information rights and entitlements. Such a theme is notable in that it is largely absent from the majority of the focus group discussions.

Eliasoph (1998: 235) argues that 'not only are dominated people powerless, they lack the power to name their own powerlessness'. In his study of single mothers' experiences of welfare surveillance in the U.S., Gilliom (2001) similarly argues that the appeal to notions of rights is strikingly rare: 'Neither the language nor the actions of these women reflect the sort of rights consciousness or tactical uses of law identified in other studies of people who have grievances' (p70). He argues that the conditions which seem to push his participants away from the language of rights include 'that they live in a context defined by understandable confusion and ignorance about basic regulations, by fear of the welfare agency and its enforcement of those regulations, and by profound need for the support that the welfare system provides .. the result is that, although they live under an almost totalizing system of laws, they are unable to use other, more emancipatory elements of that same legal system to give voice to their frustrations' (p71-72).

\subsubsection{Dependence}

I wish now to consider a highly prominent motif that has already occurred in previous accounts analyzed in this chapter, but has not been explicitly addressed. This motif is that of dependence on technology. In the following extract, the participants are discussing losing a mobile phone:

Celia: I know I'm dependent on my phone. I had to go and get the money and go and get another phone because I need it, I didn't need it before like I didn't need a microwave, but I need it now 
Kevin: so you got

Celia: you get dependent on them

Del: yeah, they suck you in man

Celia: it starts off through choice but later on it becomes a necessity, you have no choice because you adapt your life to it

(Focus group 1)

Here the participants ultimately stress a sense of technological determinism rather than individualism, you have no choice because you adapt your life to it. Nonetheless, there is a distinct unease about the development of such a scenario. The temporal structure of the narrative is that of the morality tale, it starts off through choice but later on it becomes a necessity, and the language of being sucked in and becoming dependent highlights this marked sense of ambivalence about individual choice becoming need. In the following extract, a similar resonance is made explicit:

Andrea: I think human in general, human beings do not need technology to live their life but they have made it as if it was a drug so that you do need it there. It's like when you stick some one out, if you was to stick someone out in the

Francine: wilderness

Hayley. bush

Andrea: wilderness with nothing and just food, and like old fashioned way, no lighting, no nothing, none of that like to keep you warm, if you had to do everything the old way, I think you'd be able to survive because it's within the human, it's within the human nature to survive, but humans have made it to see that they can only live with technology. Like if my kettle ain't working, I will feel no way to pick up a pan and boil it downstairs

(Focus group 3)

Andrea's account emphasizes the danger of technological dependence by contrasting it with an idea of natural humanity as a particularly rugged form of 
individualism, although she acknowledges that this narrative is somewhat nostalgic in her closing comment that the mundane realities of boiling a pan of water would not be attractive. More typically, the discussion of technological dependence was articulated in terms of a double-bind, as a necessity but one that is additionally a threat to a coherent sense of individualism and the intrinsic value of self-reliance:

Laura: yeah my chip got blocked once and I was like, oh damn mad, everything was in there, I needed it and especially when you've got kids, you need a phone so I was, for like emergencies and for people to contact you and whatever, you need it. It's not like you want it anymore, you have to have it.

(Focus group 1)

In his analysis of the media and modernity, and with particular reference to the vast resources of symbolic content increasingly made available through new media, Thompson (2001: 215-5) details the double bind of mediated dependency': ${ }^{6}$

'The more the process of self-formation is enriched by mediated symbolic forms, the more the self becomes dependent on media systems which lie beyond its control. In this respect reflexivity and dependency are not necessarily opposed to one another. A deepening of the reflexive organization of the self can go hand in hand with a growing dependence on the systems which provide the symbolic materials for selfformation'

As Thompson (2001: 215) notes, 'the paradox of reflexivity and dependency - or in Beck's terms individualization and institutionalization - is a pervasive feature of modern social life; it is by no means restricted to the domain of the media'. In the following accounts, the participants discursively explore the limits of their negotiation of technological dependence: 
(1) Andrea: I would say you have to get on with it but if there was something that came in modern technology and I disagreed with it, I would stand my ground and I would not let it come anywhere near me. See, the chip in my hand, if the government said no, pure, people go missing, so they want to know everyone's exact location so there must be a chip put in their hand or their forehead, and it's the mark of the beast, I disagree with that because I been raised in religion, religion matters, basically that is what matters. Like I'm not gonna go further into that but that's something I would stand my ground on.

(Focus group 3)

(2) Bernard: it depends on you, how far you use technology, you know what I mean, how far you allow it to exploit you or how you exploit it

Francine: $\mathrm{mm}$, cos you can be like, fact is, if you know that technology's getting the better of us yeah, you can use it to your advantage. But at the same time it might make you seem like you're a hypocrite. But you can use it and be like, well I'm gonna be one step ahead and I'm gonna use this and that, so l'm gonna have to go this path and use technology. I'm gonna have to use it in here to get me a certain amount of research otherwise I'm gonna have to travel all the way to America and go and read a book, you get me. So there's certain things that do help you with being a certain way, you get me

(Focus group 3)

In the first extract, although initially arguing that dependence on technology in modern life is something that you have to get on with, Andrea then describes a hypothetical scenario where the assertion of wider religious values would ultimately take priority over the acceptance of a socio-technical imperative.

In the second extract, Francine discursively negotiates the double-bind of technological dependence in a more complex manner. The position she describes recognizes the value of technological knowledge and the necessity of acknowledging dependence. However, the key value that she asserts is trying to 
stay one step ahead despite a certain acceptance of technological pathdependence. In her understanding, individual agency can only be reasserted within these parameters and, unlike Andrea, the structural threat of hypocrisy is less important to her biographical project than the risk of potential powerlessness.

Overall I argue that, in all these discussions, the occurrence of the motif of dependence marks a point of antagonism between a hegemonic discourse of individualism and an interpretative repertoire of technological determinism. ${ }^{7}$ There is a marked ambivalence to a simple understanding of technology making a complicated world easier to live in. As such, the discursive resolution of this conflict rarely emphasizes an unproblematic deterministic adaptation to technological imperatives. Rather, the discursive reconfiguration and reassertion of heterogeneous values is continually and variously negotiated by the participants in these discussions.

\subsection{Conclusion}

The discussions analyzed in this chapter were heterogeneous, multifaceted and at, at times, contradictory. Initially it is important to note that there was some broad discursive recognition that technological change was a salient theme in the participants' lives that had to be negotiated. However, such change was rarely articulated in terms of epochal shifts in their sociocultural environment, nor in the utopian terms of the potential of technology to widely propagate social, political and civic empowerment, both themes that are prominent in the various policies and initiatives that I have analyzed in previous chapters.

Rather the participants articulated an understanding of technology as radically double-edged, routinely emphasizing dystopian motifs of risk and the threat to values such as privacy. In particular, this narrative of technology was frequently organized, at a personal level, around the motif of the double-bind of 
technological dependence, and the concomitant threat to a coherent sense of self-reliance. In addition, there was some discursive appropriation of the more promissory narratives of technological futures through which the participants sought recognition of their desires without necessarily endorsing the terms of these utopian visions.

The discussions further highlighted the theme of social determinism in the production of technology and the development of socio-technical imperatives. The particular social groups and institutions mentioned were various and regularly described through reference to an abstract they or the system, but notably included the government, corporations and those with technological capital. There was thus a discursive emphasis upon the continuities of established social powers and constraints over and above an autonomous shift to a qualitatively new form of social organization, and a consequent questioning of the inevitability of such arrangements.

The consumption and display of technology was understood as an important symbolic resource for processes of social classification and meaningful identity construction. However, an understanding of technological development as economically underpinned by corporate logics of marketing and lifestyle segmentation led to much discursive contestation. Individuals attempted to discursively position themselves, to construct contingent and credible narratives of status and personal identity, through the acceptance, rejection and appropriation of such perceived logics.

The participants' perception of contemporary labour as inexorably technological led to an endorsement of the belief that the development of technological capital, in particular the educational attainment of computer literacy, was a primary route to secure the paid work that might enable them to get by in their lives. Nonetheless, such a belief was articulated within a more complex narrative in 
which the enduring experience of constraints upon voluntarism in this particular domain of their lives was salient.

Taken as a whole, there were radically heterogeneous views expressed as to whether technology might facilitate individual empowerment. The participants' own diverse life trajectories and biographical projects were discursively articulated by variously appropriating elements of both technologically and socially determinist narratives. However, I suggest that if anything consistently underpinned the continuum of positions expressed and negotiated, it was not an emphasis upon deterministic adaptation to social or technological imperatives, but rather a discourse of individualism.

Individual values of self-determination and self-reliance assumed complex resonances and dissonances with perceived socio-technical imperatives and with the values and interests of particular social groups that were variously understood to be promoted through technology. As such, the understandings articulated constructed a heterogeneous discursive space through which such values were negotiated, reconfigured and reasserted.

Discursive positions ranged from those which located a sense of personal agency in the ability to avoid any deterministic adaptation, through to those which located such agency in the ability to adapt to and work with such perceived imperatives. In particular, I pointed to the articulation of a 'techno-individualist' position that acknowledged the potential of technology to propagate individual empowerment whilst locating agency in the ability to stay one step ahead of potential determinism, dependence and exploitation.

Clearly this analysis offers little support to Henwood et al's (2000:9) contention that technological determinism: 
is the model which makes most sense of many people's experiences .. It is because technological determinism conforms with a majority of people's experience that it remains the 'common sense' explanation.

Although this was not an issue that was examined in specific detail, I would additionally suggest that the current analysis offers limited support for disaggregating this claim along the lines that endorsing elements of a technologically determinist worldview may map in a straightforward way onto a continuum of technological use, for example as a form of post-hoc rationalization. In the current discussions, narratives of technological use and non-use alike were similarly structured around motifs of dependence and negotiations of ambivalence. However, it is clearly an empirical question that I cannot address here as to how the understandings articulated in these discussions might correspond with the beliefs of the 'techno-elites' (Jordan 1999) or those with higher socioeconomic status.

Woolgar (2004) details the ethnocentricity and lack of imagination in much public discussion of new electronic technologies in Britain in the 1990s, typically organized around the speculative presentation of 'future scenarios' populated by homogeneous consumers and novel 'gizmos' - 'key applications to meet the pressing needs of twenty-first century British society these were notl' ( $p 139$ ). However, he recounts one memorable occasion when Richard Sykes, a former industrialist, offered an alternative vision:

The key characteristic of the British network society of 2015, he predicted, was one where the major and most striking change would be the attitude of the population at large to new technologies. They would by that time be entirely unimpressed by the overblown cyberbole associated with new technologies. They would resist the mad rush to invest (literally and metaphorically) in the views propagated by the collusion of government, supply-side industries, and the media. Instead, they would be .. poised to undertake a cool and considered appraisal of the claims being presented to 
them .. such that any commentator failing to deploy a critical analytic skepticism would simply not be taken seriously. (Woolgar 2004: 139-140)

For Woolgar such a vision embodies 'what I suggest are some unique features of a growing British scepticism to the new technologies. The specific feature of the British network society is that it reflects the inclination towards counter-intuition and analytic scepticism on the part of a growing number of its observers and analysts' (p140). ${ }^{8}$

I suggest that this broad inclination is not only to be found in the observers and analysts of the 'network society', but is articulated far wider throughout its constituencies, particularly by those who speak from the lived experience of disadvantage. In the narratives that I have detailed in this chapter, properties of technology and elements of technological change were understood in ways that were heterogeneous, complex, contradictory and not always easily communicated. While this may be a potential disadvantage for political rhetoric or corporate imagineering, these particular interpretations are meaningfully enlisted into specific biographical and discursive projects through which their authors may strive to construct a sense of self-respect.

\section{Notes}

1 As I detailed in Chapter 2, there are many different understandings of technological
determinism expressed in the Science and Technology Studies literature. In one sense
then the idea of technological determinism has functioned as a shibboleth against which
the enterprise of STS can assume a common critical stance (Grint and Woolgar 1997).

2 Demonstrating knowledge of such tricks and scams can be understood as a particular performance of (sub)cultural capital, directed both to the other participants and to myself. 
In the specific context of these focus groups, this performance was enabled by the discursive construction of my own status as not being 'streetwise':

Bernard: the fact is that we know how the scams work because we know how the street is

(Focus group 3: my italics)

Celia: like people dropping ACs

Kevin: dropping?

Celia: ACs. Cimme your card and I'll blah blah blah blah

Leford: he don't know what it is, easy now, he don't know what $A C$ is so you have to explain

Kevin: I don't know that term

Celia: basically what it is, is someone can go to any internet shop or whatever and do a transfer from another account into your account

(Focus group 1)

${ }^{3}$ A 'face-off' is where two mobile phone owners place their phones in front of them for direct comparison.

${ }^{4}$ LG is a US business group with concerns in Chemicals \& Energy, Electronics \& Telecommunications, and Financial Services, principally known in the UK for retailing cheap consumer electronics through high-street chainstores.

5 It is important to note that technological dependence is particularly salient in the previous accounts at moments of technological or infrastructural breakdown, a kettle not working, losing a mobile phone, a chip becoming blocked.

6 Jordan (2002) develops a related analysis of 'the technopower spiral' to describe the structuring of dependence in cyberspace. He argues that, "What can be called the technopower spiral is constituted out of three moments: information overload, mastering overload with a tool, and the recurrence of information overload' (p125). In his view, what is fundamental to the patterns of technopower is that: 
Information overload is addressed with new technologies .. they impose some new moment of technology between user and information. This is always a moment in which technopower is articulated because some technological tool, appearing as a thing yet operating according to values, is the means of controlling information overload .. new tools nearly always make cyberspace easier to use .. however, the very success of any such tool means the production of more information because the tool makes gaining information more efficient and there is always more information waiting out there .. This, in turn, means that the ability to act in cyberspace is constantly elaborated by those who have technological expertise. The digital elite can now be defined as those controlling the expertise to manage and create the virtual possibilities that others rely on (Jordan, 2002:125-126).

${ }^{7}$ A related but less pejorative discursive motif than that of dependence was that of the seduction of convenience, as elaborated in the following discussions:

Ade: Computers, if you are doing research or something, maybe you have a project or something, it's much easier and quicker to get the information off the net because you can access so many different databases, make so many searches.

Kevin: so it speeds up, it's kind of labour saving

Laura: it depends on the problems you've got. If they're personal problems then technology can't help you. I mean, if it's work-related then yeah it can, but that's why it's there, that's why they make it make it more convenient. If it's personal stuff, computer can't help you out

(Focus group 1)

Andrea: if mankind from centuries ago could live without it, what are we doing living with it? Just to make life easier, and how easy are we gonna make life? So all you have to do is wake up and push a button and go back to sleep

(Focus group 3)

These accounts of the technological structuring of convenience are discursively organized in an analogous manner to those of dependence, stressing both temporal and spatial benefits as well as a misalignment with personal values or natural humanity.

8 Although as Woolgar notes of the 'strikingly counter-intuitive results' of the Virtual Society? program, such results were viewed as more or less commonsensical in some 
quarters, and hence 'to the extent that we are willing to accept that such insights are counter-intuitive, we might legitimately inquire: what then has happened to our intuitions?' (2004: 137). (The Virtual Society? program was 'a major program of empirical research examining the social implications of Internet technologies in a wide range of application areas across the UK' (Woolgar 2004: 137). For further details, see unw.virtual-society.org.uk or Woolgar (ed.) (2002), particularly the introductory chapter, 'Five Rules of Virtuality'.) 


\section{$\square \square$ Chapter 8.}

\section{Addressing The Digital Divide}

\subsection{Introduction}

In previous chapters I have detailed and interrogated the local articulation of the digital divide within UK government, corporate and supranational discourse. The aims of this chapter are twofold.

Firstly, I wish to develop the interpretation of this empirical material, partly through paying particular analytic attention to the regularities across these case studies, but additionally through a further engagement with some of the concepts and logics of discourse theory and analysis. My analytic attention in this chapter will thus focus on the discursive function of 'the digital divide', the discursive construction of ethos, and the discursive organization of causal ontology, and in particular I will draw upon Zizek's theorization of the 'pure signifier' and Foucault's work on problematization.

Secondly, I wish to use this empirical grounding as an opportunity to explore and develop this theoretical framework itself. In other words, rather than attempting to directly operationalize the concepts and logics of particular theories of discourse onto a certain area of social enquiry, I will treat them as sensitizing concepts and concur with Howarth in seeking 'the articulation and modification of concepts in each particular enactment of concrete research: (2000: 139). As such, this chapter will weave together empirical analysis with more theoretical reflections, rather than try to strictly separate the two.

Finally, I wish to emphasize that, for the sake of clarity, the analysis in this chapter is intended to set up various arguments whose implications will be more fully developed in my concluding chapter. 


\section{2 'The Digital Divide'}

I will begin by considering the discursive function of 'the digital divide' in more detail. First of all, I will briefly reiterate some of the conclusions I drew in my individual case studies.

In Chapter 3 on UK government discourse, the particular construction 'the digital divide' only appears twice in the key document analyzed, once in the document title 'Closing the Digital Divide' and once in the Foreword - 'we are determined to tackle the 'digital divide' and prevent a new gulf emerging between the information-rich and the information-poor. We want everyone to be able to reap the benefits of living in an e-nation'. (PAT 15, 2000: Foreword)

Hence in this case study, the discursive status of 'the digital divide' is purely titular. Additionally, on both of these occasions, 'the digital divide' is specifically nominalized as something to be 'closed' or 'tackled'. It is named as a problem then, but is itself not defined in any meaningful sense.

In Chapter 4 on corporate discourse, as well as being the title of the BT report 'Digital Divide: Better World - Our Commitment to Society' (BT 2001, hereafter DDBW), the term 'the digital divide' is used much more frequently throughout the corpus. I argued that the DDBW report begins by suggesting a certain incertitude as to its meaning - indeed the first two occurrences of the term in the introductory paragraph refer to the 'so-called Digital Divide'. Following this is a section entitled, 'What is it?':

What is It?

The Organisation for Economic Co-operation and Development (OECD), defines the digital divide as "the gap between individuals, households, businesses and geographic areas at different socio-economic levels with regard both to their opportunities to access information and communication technologies (ICTs) and to their use of the Internet for a wide variety of activities". OECD - Understanding the Digital Divide. 
I argued that the discursive function of this citation, itself a wide-ranging description, is specifically to support the credibility of the hard-hitting concluding comment, 'the Divide does exist'. The instantiation of a realist ontology, exemplified in this discursive moment but buttressed throughout the corpus, functions to construct 'the Digital Divide' as an object of accountability.

However, after this initial broad designatory moment that establishes 'the Digital Divide' within a realist framework, there is minimal further direct definitional elucidation of the term beyond rather self-referential generality. For example:

"The Digital Divide is where new information and communication technologies ('the digital') meet existing socio-economic inequalities ('the divide')." (DDBW: 6)

Instead, the dominant discursive construction in the rest of the document is one which understands 'the Digital Divide' simply as something to be addressed. ${ }^{1}$ Moreover the remit of this address is extremely flexible:

"There are a myriad of initiatives attempting to address the Digital Divide, and it would be both impossible and pointless to try and list them all." (DDBW: 13)

In this case study then I argued for understanding the discursive use of 'the Digital Divide' in terms of its internal function, as an umbrella term under which ongoing initiatives within the organization can be realigned, as well as its external function in the presentation of the organization as accountable. However, the definitional contours of this particular object are simply that it is real and capable of being flexibly addressed.

In Chapter 5 on supranational discourse, the term 'the digital divide' does not actually appear in the name of the DOT Force document, whose titular motif is 'digital opportunity'. The first mention of the phrase however is in the opening paragraph of the foreword: "The "digital divide" is threatening to exacerbate the existing social and economic inequalities between countries and 
communities, so the potential costs of inaction are greater than ever before.' Nevertheless, after this discursive adumbration, this initial signification of a vague foreboding, $I$ argued that the governing discursive occurrence of 'the digital divide' is, as in the previous case studies, simply as something to be addressed or equivalent (bridged, tackled). ${ }^{2}$

In UK government, corporate and supranational discourse then, 'the Digital Divide' is clearly a privileged discursive point, named before any shape is given to it. However, I also want to emphasize the fact that after this initial and precise nominalization, that strategically posits a certain substantiality, 'the digital divide' is an extremely nebulous concept in all of these case studies.

\subsection{1 'The Digital Divide' as Nodal Point}

Laclau and Mouffe (1985) contend that the practice of articulation, of establishing equivalences and differences among discursive elements such that their meaning is modified, occurs in relation to privileged discursive points that they term nodal points. Given that their analytic framework insists on the flow of differences and the impossibility of fixing ultimate meanings, they emphasize that any fixation of meaning is always partial:

"Any discourse is constituted as an attempt to dominate the field of discursivity, to arrest the flow of differences, to construct a centre. We will call the privileged discursive points of this partial fixation, nodal points."

(Laclau and Mouffe, 1985: 112)

Here I want first of all to stress that 'the digital divide' can be conceptualized, in Laclau and Mouffe's terms, as a nodal point in each case study. It could be argued that 'the digital divide' is self-evidently a privileged discursive point in the UK government and corporate case studies, given that it names the key documents which delimit the field of discursivity in each case. Articulatory practice in each of these case studies ultimately occurs under the titular sign of 'the digital divide'. However, let me additionally reconsider a statement from 
the supranational case study that is exemplary in terms of the way 'the digital divide' functions discursively in the body of the case studies, simply as something to be addressed:

'Addressing the issue of the Digital Divide in an open and imaginative fashion could be instrumental in offering an action-oriented vision to all those who, in developed and developing countries, seek to make globalization work for the poor.' (DOT Force 2001: 9)

Here, through 'addressing the issue of the digital divide', the discursive element 'globalization' is, in Laclau and Mouffe's terms, articulated or partially fixed in a chain of equivalence with, 'working for the poor', and its local discursive identity is modified as such. 'The digital divide' then names the privileged discursive point where this partial fixation takes place. In Laclau and Mouffe's terms, it is a nodal point.

\subsubsection{The Pure Signifier}

I will return to this example, but at this point I need to consider an argument proposed by Slavoj Zizek that qualifies the theorization of nodal points.

Zizek (1989: 87-131) intervenes in the dispute between descriptivists and antidescriptivists around the question of how names refer to objects. According to descriptivists such as Searle, each name refers to an immanent cluster of descriptive features and hence to those objects in the world displaying those features. For the anti-descriptivists such as Saul Kripke, a name can and does continue to refer to an object even if all the descriptive features of the object at the time of its 'primal baptism' have disappeared - the reference is guaranteed by the causal chain of communication that leads to the primal linking of word to object. Zizek suggests that such an answer denies the 'radical contingency of naming, the fact that naming itself retroactively constitutes its reference' (p95). He argues instead that: 
What is overlooked, at least in the standard version of anti-descriptivism, is that this guaranteeing of the identity of an object in all counterfactual situations through a change in all of its descriptive features - is the retroactive effect of naming itself: it is the name itself, the signifier, which supports the identity of the object' (Zizek 1989: 94-95) .. In the last resort, the only way to define 'democracy' is to say that it contains all political movements and organizations which legitimize, designate themselves as 'democratic'; the only way to define Marxism is to say that this term designates all movements and theories which legitimize themselves through reference to Marx, and so on. In other words, the only possible definition of an object in its identity is that this is the object which is always designated by the same signifier' (Zizek 1989: 98)

As such, Zizek further qualifies the theorization of a nodal point, or what he terms, following Lacan, a point de caption (quilting point), as follows:

'If we maintain that the point de caption is a 'nodal point', a kind of knot of meanings, this does not imply that it is simply the 'richest' word, the word in which is condensed all the richness of meaning of the field it 'quilts': the point de caption is rather the word which, as a word, on the level of the signifier itself, unifies a given field, constitutes its identity: it is, so to speak the word to which 'things' themselves refer to recognize themselves in their unity' (Zizek 1989:95) .. 'the point de caption .. which totalizes an ideology by bringing to a halt the metonymic sliding of its signified, is not a point of supreme destiny of Meaning, a kind of Guarantee which, by being itself excepted from the differential interplay of elements, would serve as a stable and fixed point of reference .. In itself it is nothing but a 'pure difference': its role is purely structural, its nature purely performative - its signification coincides with its own act of enunciation: in short, it is a "signifier without the signified"' (Zizek 1989: 99)

Zizek follows Laclau then in arguing that nodal points sustain the identity of a discourse by constructing a knot of meanings, 'quilting' the discursive field, and emphasizes that this does not occur with reference to any essential descriptive feature of the nodal point. It is simply the naming of the nodal point that facilitates the purely structural role of unifying a discursive terrain, constructing the identity of elements by articulating them within a chain of equivalence. ${ }^{3}$ The assignation of meaning should not be considered as a 
direct effect of the dense meaning of the privileged nodal point itself. Rather, as an ideal type, the nodal point is a pure signifier that articulation works through. ${ }^{4}$ Butler offers one interpretation of Zizek's position as follows:

A set of fears and anxieties emerges, a name is retroactively and arbitrarily attached to those fears and anxieties: suddenly, that bundle of fears and anxieties becomes a single thing, and that thing comes to function as a cause or ground of whatever is disturbing. What first appeared as a disorganized field of social anxiety is transformed by a certain performative operation into an ordered universe with an identifiable cause. (Butler 2000: 26)

\subsection{3 'The Digital Divide' as Pure Signifier}

Let me consider the statement from the supranational case study again:

'Addressing the issue of the Digital Divide in an open and imaginative fashion could be instrumental in offering an action-oriented vision to all those who, in developed and developing countries, seek to make globalization work for the poor.' (DOT Force 2001: 9)

What I want to emphasize here is that the articulation of 'globalization' with 'working for the poor' occurs through the nodal point, the signifier of 'the digital divide', not because 'the digital divide' refers to a fixed signified which itself confers meaning on 'globalization'. Following Zizek then, I additionally argue then that 'the digital divide' in this paradigmatic example functions as a particular type of nodal point - as a pure signifier.

At this point, one might raise a certain objection to this definition. 'Addressing the digital divide' does always signify at least a vague threat, that needs to be addressed. Additionally, 'the digital divide' at least always signifies a conjunction of the technological and the social, if at the broadest level of syntactic signification. The definition from the corporate case study in Chapter 4 is exemplary in this regard: 
"The Digital Divide is where new information and communication technologies ('the digital') meet existing socio-economic inequalities ('the divide')." (DDBW: 6)

Nonetheless beyond these very imprecise connotations of a threat and a meeting of the social and technological, it is without any lucid signified. In each case study then, 'the Digital Divide' is named before any shape is given, and remains a nebulous construction through which various local articulatory practices occur. Certainly the construction of what 'addressing the digital divide' involves becomes relatively clear in each case study, but never what 'the digital divide' is, beyond that which is named as 'the digital divide'. I maintain then that although 'the digital divide' is not unreservedly 'a signifier without a signified', it can still be best conceptualized in terms of a pure signifier in each of my case studies.

\subsection{Problematization}

I will now consider some of the other regularities across my case studies. I have already argued that a consistent and central position developed in UK government, corporate and supranational discourse is that 'the digital divide' names a problem, indeed it is denounced as a 'real' problem. This naming inaugurates a commitment to its solution, the expressed raison d'etre of these case studies is to develop solutions to tackle or 'bridge' this problem, despite the fact that it is never really clear what 'the digital divide' is, only what 'addressing the digital divide' involves. At this point I wish to consider Foucault's work on problematization (Foucault 1984, 1984a, 1984b, 2001).

Foucault first discusses problematization in the Introduction to The History of Sexuality Vol II, where he is concerned with "how, why and in what forms is sexuality constituted as a moral domain' (1984: 10), arguing that, 'the proper task of a history of thought .. [is] to define the conditions in which human beings 'problematize' what they are, what they do and the world in which they live' (1984: 10). He clarifies this conception of problematization as follows: 
'The work of a history of thought would be to rediscover .. the general form of problematization that .. has made possible the transformation of the difficulties and obstacles of a practice into a general problem for which one proposes diverse practical solutions. It is problematization that responds to these difficulties, but by doing something quite other than expressing them or manifesting them: in connection with them it develops the conditions in which possible responses can be given; it defines the elements that will constitute what the different solutions attempt to respond to. The development of a given into a question, this transformation of a group of obstacles and difficulties into problems to which the diverse solutions will attempt to produce a response, this is what constitutes the point of problematization and the specific work of thought' (Foucault 1984a: 389)

In other words, problematization refers to the way something becomes transformed and posed as a problem in the first place. More generally problematization is that which makes it possible to think in terms of problems, solutions and values at all, a discursive ordering of ethos. ${ }^{5}$ It is not simply the expression of manifest difficulties, but their transformation into a moral space. 6

Foucault (1984b: 49) argues that, 'the study of modes of problematization .. is thus the way to analyze questions of general import in their historically unique form'. According to Foucault, analytic attention is to be focussed upon how something comes to constructed or thrown forward as an issue or a problem at a specific point in history: 'The question I raise is this one: How and why were very different things in the world gathered together, characterized, analyzed, and treated as, for example, "mental illness"? What are the elements which are relevant for a given "problematization"?' (Foucault 2001: 171). As such, and rather than accepting 'the digital divide' face value as a problem, I suggest that it is useful to consider it similarly in terms of the naming of a certain field of problematization.

It is important to note that, although Foucault's emphasis in his discussions is on the concomitant discursive construction of problems and solutions through problematization, the 'transformation of a group of obstacles and difficulties 
into problems to which the diverse solutions will attempt to produce a response' (1984a: 389), he does stress the reality of the underlying difficulties which become problematized:

'When I say that I am studying the 'problematization' of madness, crime, or sexuality, it is not a way of denying the reality of such phenomena. On the contrary, I have tried to show that it was precisely some real existent in the world which was the target of social regulation at a given moment. .. For I think there is a relation between the thing which is problematized and the process of problematization. The problematization is an 'answer' to a concrete situation which is real' (Foucault 2001: 171-172).

In this formulation, the difficulties which provoke problematization are understood as a 'real existent'. On the other hand, Zizek's (1989) particular conception of 'the real' or Laclau's concept of dislocation, to which I now turn, both emphasize relative extradiscursivity in their understandings of the particular discursive elements that might provoke such discursive management.

\subsubsection{Dislocation}

I will consider here Laclau's (1990: 39-59) theorization of dislocation as an account of the disruption of a particular discursive order. For Laclau, discourses are fundamentally undecideable, and dislocations are particular events which reveal their contingency. If the emergence of these events cannot be symbolised or integrated within the particular discourse in question, they function to destabilize that discourse. For example, Torfing argues that 'the concurrence of inflation and unemployment in the early 1970s dislocated the Keynesian orthodoxy which claimed that 'stagflation' would never occur' (1999: 301). ${ }^{7}$ Laclau's conceptualization of dislocation thus refers to particular events that are unrepresentable and hence disrupt discursive unity.

Now, while Laclau's discussion of dislocation concentrates on particular, unrepresentable events, $I$ argue that in the discourses under discussion here 
it is not simply the inability to discursively recognize or integrate a particular event or state that threatens discursive unity. Rather it is the lack of a particular social state that potentially troubles the integrity of the respective discourse. Indeed, it is the lack of a utopian social state that assumes a potentially dislocatory function.

I will argue that, in order to avoid potential dislocation, such dystopian lacks are not manifestly represented in these discourses. Rather they are discursively managed in a particular way, through the problematization of 'the digital divide'. Furthermore, I will argue that this management involves two discursive procedures. Firstly, it involves the discursive construction of a particular ethos. Secondly, it involves a particular discursive construction of causality. It is through this double movement that such dystopian lacks are not directly represented but invoked and problematized. At the moment of course these claims must be held in suspense, but I will try to establish that they are reasonable in the rest of this chapter.

\subsection{The Discursive Construction of Ethos}

The first of these procedures that I want to highlight is the construction of a particular ethos through the problematization of 'the digital divide', such that two values, a concern with the social and the promotion of the technoeconomic, are discursively understood as equivalent, indeed indivisible. I will summarize some of my key findings from earlier chapters to exemplify this claim.

In Chapter 3 on UK government discourse, I highlighted how ICTs were understood to be radically transforming the economy. Furthermore, 1 emphasized how the relationship between the social and the technoeconomic in the Information Age was understood in terms of the key 'Third Way' motif of the mutual reciprocity of fostering enterprise and addressing social justice. The measures necessary to strengthen national economic competitiveness in the Information Age were discursively understood as being equivalent to those for achieving social inclusion. 
In Chapter 4 on contemporary corporate discourse, I highlighted the discursive structuring of an analogous relation of equivalence between the social and the techno-economic realms. In this case, tackling the digital divide was discursively understood as simultaneously demonstrating corporate social responsibility as well as advancing the techno-economic project of the New Economy.

Finally, in Chapter 5 on supranational discourse, I argued that the account of the digital divide constructed in the DOT Force process sutured an ethical concern with global inequality into a 'secular salvation story' of an economically neo-liberal and technologically driven globalization.

In all of these case studies then, I have previously highlighted a broad underlying issue that potentially troubles the integrity of the respective discourses. In the case of UK government discourse, this potential dislocation is a lack of social inclusion. Contemporary corporate discourse is troubled by a lack of social responsibility. In the case of supranational discourse, the potential dislocation is a lack of global equality. Further, I have argued that in each case study, 'addressing the digital divide' discursively constructs a relation of equivalence between this broad underlying concern (social inclusion, social responsibility, global equality) and a concomitant endorsement of the techno-economic (enterprise, the New Economy, globalization).

Crucially, it is important to emphasize that this underlying concern is not 'the digital divide' itself. As I have detailed earlier in this chapter, in each case study it is never clear what 'the digital divide' actually is, only what 'addressing' it involves. Although nominally a 'real' problem, I have argued that the digital divide is best thought of as naming a field of problematization. Furthermore as Foucault (1984a: 389) argues, "It is problematization that responds to .. difficulties, but by doing something quite other than expressing them or manifesting them: in connection with them it develops the conditions 
in which possible responses can be given". Problematization can thus be understood as the organization of discursive ethos.

Across all these case studies, I argue that the equivalence of a concem with the social and the promotion of the techno-economic describes the conditions in which possible responses to the underlying issue can be given. The problematization of 'the digital divide' constructs a moral space where these two values are discursively understood as equivalent. Indeed, a separation of the social and the techno-economic is itself an antagonistic position against which their equivalence is discursively contrasted.

For example, in UK government discourse, the 'Third Way' motif of the mutual reciprocity of fostering economic enterprise and addressing social justice is discursively contrasted with a perception of traditional political discourses as emphasizing either social or economic concerns but not both together. Similarly, the discourse of 'corporate citizenship', which articulates a concomitant concern with the new economy and corporate social responsibility is discursively contrasted with a discourse of 'corporate regulation', in which the concerns of social equality are seen as not able to be met by the market.

I will return to this discussion in the next chapter. However, it is important to note at this stage, and I will clarify this further, that this is not an argument that these case studies propose crude technological fixes for specific social problems. Rather, I am simply emphasizing here that the dominant discursive ethos in all these case studies is that of the equivalence of two values, a concern with the social and the promotion of the techno-economic.

\subsection{The Discursive Construction of Teleology}

Now, crucially, I additionally argue that in my case studies there is a discursive relation of equivalence constructed not just between the social and the techno-economic, but also between state and process. The second 
discursive procedure that I want to highlight then is the discursive organization of a specific, teleological, form of causality.

To illustrate, I will consider two statements from my case studies, one from the corporate and one from the supranational domains:

'ICTS need to be part of solutions that meet social and economic needs by leveraging the potential created by the emerging New Economy' (DDBW: 17)

'Addressing the issue of the Digital Divide in an open and imaginative fashion could be instrumental in offering an action-oriented vision to all those who, in developed and developing countries, seek to make globalization work for the poor.' (DOT Force 2001: 9)

In the first statement, the underlying concern of 'social needs not being met' is not directly recognized on its own, because of its potential threat to discursive coherence. Rather, the discursive management of this dystopian lack is such that it occurs concomitantly with the process of leveraging the potential created by the emerging New Economy'. Moreover, this particular discursive management only actually refers to the sutured lack, to a utopian state which can be represented - leveraging the New Economy can meet social needs. Additionally, the particular techno-economic process is discursively justified as a 'solution'.

Similarly in the second statement, the underlying concern of 'the poor' is not discursively recognized on its own, but only along with the process of 'globalization'. As before, the particular discursive management only actually refers to the utopian state, globalization can work for the poor, and the particular techno-economic process is discursively justified as an 'actionoriented vision'.

In both these examples then, I argue that a particular process is discursively justified through reference to a telos or utopian state with which it is problematized. Now in the previous section, I analyzed these statements 
principally in terms of the construction of ethos, the discursive equivalence of two values, a concern with the social and the promotion of the technoeconomic. Here I am not specifically focussing on this ethical dimension of the problematization, but rather the discursive construction of causality.

I argue that the understanding of causality is strictly delimited in these statements. For example, a broader consideration of the responsibility of a particular process for the propagation of a state, (e.g. the responsibility of 'leveraging the new economy' for 'social needs not being met', or the responsibility of 'globalization' for 'the poor'), is discursively ruled out in these statements. Rather, the causal contours of these statements are such that the propagation of a particular process is discursively buttressed through reference to a particular telos or utopian state. The seeming inevitability of the particular process is thus discursively enhanced.

I argue then that the current examples discursively organize a specific, teleological, form of causality, through the discursive enfolding of utopian state and process. To clarify, a classic example of teleological explanation is the vitalist 'doctrine of design', whereby a process such as the evolution of a species is understood in terms of its current state. The process as such is endowed with purposive meaning, justified in terms of inevitably expressing this immanent state.

\subsubsection{Teleological Peformativity}

It will be helpful for later discussion to propose a specific name for this discursive organization of teleology. As already discussed, Foucault's concept of 'problematization' refers more explicitly to the discursive construction of ethos rather than causal ontology. One candidate term is suggested by the Foucauldian scholar and theorist of gender Judith Butler, who defines the term performativity as follows: 'What I'm trying to do is think about performativity as that aspect of discourse that has the capacity to produce what it names .. this kind of production actually always happens through a certain kind of repetition and recitation .. performativity is the vehicle 
through which ontological effects are established. Performativity is the discursive mode by which ontological effects are installed.' (Butler 1994: 34, my italics). Butler's understanding of performativity thus encompasses the discursive organization of causal ontology. However, her broad definition of performativity refers to more than just the installation of a sense of discursive causality.

I propose to use the term implosion to denote the discursive organization of specifically teleological performativity, through the ontological enfolding of utopian state and process. Of course, the term implosion itself has a particular, heterogeneous history in social theory. ${ }^{8}$ As such, it should be noted that I am only endorsing the general sense of this term as used by thinkers such as McLuhan, Baudrillard and Virilio, rather than locating my analysis within any one of these particular traditions of theoretical work. For example, Baudrillard refers to implosion generally as 'the absorption of one pole into another, the short circuit between poles of every differential system of meaning, the effacement of terms and distinct oppositions' (1983: 102-103). More importantly, my strategy here is to conceptualize, define and analyze implosion as a specific discursive movement, rather than as a contemporary media logic.

\subsubsection{Indeterminacy of State and Process}

At this stage, I wish to consider a potential critique of my argument so far regarding implosion as a specific discursive enfolding of state and process. This is that we might want to be cautious about identifying any individual discursive element simply as a state or process. As an example, take the particular discursive element 'globalization' in the statement below and my earlier identification of this as a process.

'Addressing the issue of the Digital Divide in an open and imaginative fashion could be instrumental in offering an action-oriented vision to all those who, in developed and developing countries, seek to make globalization work for the poor.' (DOT Force 2001: 9) 
This might be thought questionable because the status of 'globalization' as process beyond this local discursive context, this instance of parole in Saussure's terms, is ultimately ambiguous. Within a different local discursive context, this element could refer to a particular state. At the level of langue then, as a disarticulated element, 'globalization' is polysemic, it is indeterminate as state or process.

I subscribe to this potential critique, but I would not concede that it invalidates the analysis or conceptualization of implosion. Rather, it points to important directions in which to seek the development and elucidation of the concept. Firstly, describing implosion in terms of an ontological enfolding of state and process does not imply the permanent identification of the individual elements as state or process beyond the context of their implosion. In order for the above scenario to be posed as potential critique, an operation of contextual rearticulation was necessary, considering 'globalization' in another local discursive context. Implosion always takes place within a specific discursive context, and thus its analysis needs to be faithful to that context. In this particular example, the preceding sentence stabilizes the interpretation of 'globalization' as process:

'the members of DOT Force call on the support and continued commitment of the leaders of the G-8 to initiate a broad range of local, regional and international initiatives to foster a development-supportive process of globalization. Addressing the issue of the Digital Divide in an open and imaginative fashion could be instrumental in offering an action-oriented vision to all those who, in developed and developing countries, seek to make globalization work for the poor. (DOT Force 2001: 9)

While at the level of langue then, individual discursive elements may be indeterminate qua state or process, the particularities of the local discursive context will, in most cases, determine to what extent the articulation of two elements may be considered one simply of equivalence between two states or between two processes, and to what extent it involves an ontological enfolding of state and process, which we can additionally term implosion. 
There may be occasions when the local discursive context underdetermines the status of a discursive element qua state or process. For example, consider the paradigmatic statement from UK government discourse below:

'The arguments for social inclusion and for economic development in the Information Age are mutually re-enforcing (sic)' (PAT 15, 2000: 18)

Now, it is again possible to argue that this statement follows the same logic as those previously discussed - a utopian state of 'social inclusion' is discursively concurrent with the process of 'economic development'. However, the local discursive context, the preceding and following paragraphs, does not explicitly discuss social inclusion in further detail in this case. Hence, there is no discursive privileging of one particular interpretation of 'social inclusion', as the state or process of being included. I shall return to discuss the centrality of such ontologically ambiguous terms in contemporary political discourse in the next chapter.

\subsubsection{Wider Implosion}

There is one final point that I wish to make at this stage. This is that while implosion may be analytically clearest in the example of a distinct discursive statement as considered in Section 8.4, teleological performativity is not limited to such discrete discursive forms in these case studies. I argue that the construction of teleology also takes place through a dense tissue of other discursive devices at many levels, from the macro level of narrative structures, through the meso level of individual statements already analyzed, right down to the micro level of particular rhetorical tropes, diagrams, metaphors and figurations. To support this claim of teleological performativity beyond the level of the discrete discursive statement, I wish to briefly reiterate some of my findings from earlier chapters in the light of the preceding discussion.

Turning to the macro level of narrative construction first, I wish to highlight the allegorical structure of supranational discourse that I detailed in Chapter 5. I 
argued here that the sense of discursive teleology in the DOT.Force final report can be understood in terms of generic Christian narrative, as a secular salvation story (Haraway 1997) which stresses the immanent promise of technological globalization. A similar teleological narrative structures UK government discourse, analyzed in Chapter 3 . Here I detailed a narrative of inevitable societal and self-transformation in the future-present Information Age. The 'state' of the Information Age is itself understood as the cause of societal transformation, of its own emergence, exemplified in the opening declaration that ' $\mathrm{C} T$ S and the emerging Information Age are transforming our society' (PAT 15 2000: Foreword). ${ }^{9}$

I also argue that the discursive enfolding of state and process is further buttressed at the micro level of specific rhetorical tropes. For example, in Chapter 5 on supranational discourse, the title of a figure in one of the submissions to the DOT Force, the development dynamic, becomes a central figuration in the final report. In its intimation of teleology, there is a functional equivalence between this and prominent figurations and tropes in the other case studies (e.g. the virtuous circle in Chapter 3 on UK government discourse, the win-win scenario in Chapter 4 on corporate discourse, network effects across all the case studies).

I argue then that implosion or teleological performativity does not take place only at the exemplary level of the discrete discursive statement, but throughout the discursive tissue of all of my case studies. This is not to say that each of the case studies exhibits all of the discursive constructions discussed. However, each clearly includes some, and within each case study their cumulative effect is to overdetermine and naturalize the overall sense of discursive teleology.

\subsection{Technosocial Implosion}

So far I have identified two key discursive operations: the instantiation of discursive ethos through the problematization of the social with the technoeconomic; and the privileging of a particular teleology, via the implosion of 
utopian state and process, which mitigates against alternative causal ontologies. For the sake of analysis, my discussion to date has treated these two discursive operations separately.

Indeed, it is clearly possible to envisage situations where these discursive operations would play out separately - a problematization of the social with the techno-economic which does not additionally involve an enfolding of state and process, but simply the discursive equivalence of social and technoeconomic states for example. Or the discursive implosion of state and process within only one domain, the social or the techno-economic.

However the two discursive movements are clearly contemporaneous in each of the case studies discussed here. This is exemplified where the two discursive movements occur in the same discrete statement, as illustrated in Section 8.4. Here, a utopian social state functions as the telos which legitimates the inevitability of a particular techno-economic process. It would be inadequate to characterize such discursive construction only in terms of an implosive form or the ethical content of the problematization.

As such, for clarity I shall describe this concomitant construction of discursive ethos and teleology as technosocial implosion. Technosocial implosion takes place where teleological performativity, the discursive enfolding of utopian state and process, occurs simultaneously with the problematization of the social with the techno-economic.

\subsection{Summary}

At this point I wish to briefly reiterate my main findings in this chapter. I have identified and discussed four key points within each of my case studies.

Firstly, I argued that in each case study 'the digital divide' effectively functions as a pure signifier through which various local articulations occur. Named and denounced as a 'real' problem to be tackled or 'addressed', it is nonetheless never clear what 'the digital divide' is, beyond the name of a discursive field of 
problematization which conjoins the techno-economic (digital) and the social (divide).

This brings me to my second main point. In 'addressing the digital divide', each case study constructs relations of equivalence between the social and the techno-economic, specifically the mutual reciprocity of a concern with the social and the promotion of the techno-economic. The dominant discursive ethos in all these case studies is that of the equivalence of these two values. I additionally pointed to a dystopian lack as the underlying dislocatory anxiety that is never manifestly represented in these case studies but provokes discursive management via this mode of problematization.

Thirdly, I highlighted the discursive organization of causal ontology in my case studies. In addressing the digital divide, various processes buttress their legitimacy through discursive enfolding with separate utopian states. I used the term implosion to describe this discursive enfolding of utopian state and process, which instantiates and privileges a specific discursive teleology and mitigates against alternative causal ontologies.

Finally, I identified technosocial implosion as the concomitant discursive organization of ethos and teleology. I argued that this occurs where teleological performativity, the discursive enfolding of utopian state and process, is discursively concurrent with a problematization of the social with the techno-economic. In technosocial implosion, a utopian social state functions as the telos which legitimates the inevitability of a particular technoeconomic process.

I will explore the implications of these findings further in the next chapter. In order to do this, I wish to consider how we might best conceptualize the regularity of these findings across the case studies. This chapter will thus finish by addressing this issue, beginning with a reconsideration of the delimitation and status of these case studies. 


\subsection{Beyond the Case Study}

In each of my previous chapters I focussed my analytic attention upon a particular case study. Each case study contained what may be termed particular 'discursive events': a white paper in UK government discourse, an online debate in corporate discourse, a final report in supranational discourse, and so on.

Now, within the relevant chapters I set out how I delimited each case study. The boundaries of these case studies were set both strategically in relation to specific research aims, as well as through responding to opportunities that came from locating myself within this emerging discursive field of 'discussion of the digital divide', the affordances of quasi-ethnographic immersion to put it another way.

For example in chapter 3 on corporate discourse, I detailed my encounter with the discursive event of the BT online debate via an email invitation that I received as a member of another discussion list, the Digital Divide Network. In chapter 4 on supranational discourse, I detailed a specific strategic decision to examine the submissions to the DOT Force as part of this case study as 1 was concerned to analyze how any disagreements in these sources might be resolved in the processes of production and the narrative of the final report.

The key point I wish to emphasize here is that the contours of such case studies and moreover the particular discursive events themselves are, certainly to some extent, an analytic construction. They do not have an inevitable shape that transcends the individual analytic encounter. The 'case study' or 'discursive event' is partly a concept that the researcher projects onto the field of discursivity in order to create a framework for study. Of course an analytic encounter may have some fidelity with other encounters, particular formations of readership for example, that themselves construct similar boundaries. In such a case the delimitation of the discursive event in particular may appear more 'self-evident'. I will return to this discussion of privileged formations of readership shortly 
For now though I simply wish to shift my earlier analytic focus slightly, from a particular concern with the way that articulatory practice is locally organized within a bounded discursive event, to highlighting how elements of such articulatory practice also necessarily point beyond the bounds of the discursive event.

The main argument I wish to make then is very straightforward: that we can describe numerous relations beyond (and indeed certain relations between) the individual discursive events that I concentrated upon in previous chapters, These discursive events do not then have to be necessarily conceptualized as existing entirely independently, as completely ex nihilo discussions of the digital divide. ${ }^{10}$ It is not incommensurable with this earlier strategic analytic outlook to now highlight an anamorphic view of how such discursive events also exist within a force field of relationships, a wider field of discursivity, that extends beyond and through them.

\subsubsection{Relations of Production}

There are a number of relationships that traverse the discursive event that $I$ wish to point to. For the sake of this discussion I will classify them as relations of production and relations of readership. As an example of relations of production, I will highlight citation, the act of directly citing and referencing elements of other texts, datasets, declarations and so on. These elements are the building blocks for various local articulatory practices within a specific discursive event.

I have previously described the citational networks that are assembled within particular discursive events in some detail. For example, in chapter 3 on UK government discourse, I pointed to how the 'Closing the Digital Divide' report directly cites other government white papers on the deprived neighbourhood, the work of Alvin Toffler, and so on, in order to buttress specific understandings of social exclusion and technology. 
Similarly, in chapter 4 on corporate discourse, the BT betterworld website which hosted the online debate provides hyperlinks to the websites of related initiatives, the Falling Through the Net studies, a Business Week special on the digital divide. The key BT report on the digital divide also references the work of Manuel Castells, the Universal Declaration of Human Rights and so on.

In chapter 5 on supranational discourse, I pointed out that there are ultimately no explicit citations or mention of particular documentary submissions in the unreferenced DOT Force final report, in accordance with the generic conventions of the authoritative Communiqué which largely effaces its processes of production. Nonetheless, I paid particular analytic attention to the material relationships which underpinned the process of this report's production. These included the structured enrollment of personnel according to the principles of multiple representation and networking capability, and the coordination of plenary and ancillary meetings alongside further 'electronic outreach'. I detailed this material assemblage and analyzed its textual echo, embodied in a heterogeneous collection of documentary submissions, minutes and versions of the final report. The final report is ultimately the refraction of this far wider textual environment through a field of power codified in the secretariat's 'consultation matrix'. ${ }^{11}$

I am not going to reiterate my analysis of what local discursive claims are buttressed by the articulation of particular citational networks here. The key point I wish to make is simply that while from one point of view, citation evidently occurs 'within' the discursive event, citation also clearly points to the construction of the discursive event within a wider field of discursivity.

\subsubsection{Relations of Readership}

Citation indicates a direction for further readership in the wider field of discursivity. I additionally wish to draw attention to those discursive practices which point in the opposite direction, which mean that such a wider field of discursivity effectively becomes a discrete discursive event for its readers. In 
other words, $I$ intend to highlight those discursive practices, or aspects of textuality, that organize the reader's enrolment into, and interpretation, of the wider field of discursivity in specifically delimited ways. Such practices are akin to Foucault's $(1977,1981)$ theorization of the 'author function', or Couldry's (2000) discussion of how a 'reading formation' structures the experience of a wider textual environment into the phenomenal form of a 'text', a unified and attributable whole. Here I will refer to such discursive practices as organizing relations of readership.

In Chapter 3 on UK government discourse, I pointed in particular to the generic conventions of governmental white papers; ministerial forewords, executive summaries, bullet-pointed arguments, and briefing documents; that construct relations of readership specifically in terms of press mediation.

In Chapter 4 on corporate discourse, I pointed to various practices of enrolment, such as the invitation e-mail to the online debate that I received from BT. In the case of this online debate, relations of readership and production overlap in a very specific way, and I detailed the rules and spatiotemporal practices of engagement that manage this 'interactivity'. I also pointed to the disclaimer as privileging the reading of particular sections of the digital divide report and online debate as non-attributable to BT.

In chapter 5 on supranational discourse, I pointed to the monovocal style and in particular the unreferenced nature of the final report as privileging a form of readership that does not engage with the particular submissions to the DOT Force process.

Again, I am not going to reiterate these analyses in detail. Earlier, I pointed to how 'discursive events' can be considered to take place within a network of relationships that traverse them and, in the case of citational relations of production in particular, point beyond the discursive event to a wider field of discursivity. In the light of these traversals then, such events need not necessarily be conceptualized as completely autonomous. That they typically are is best explained in terms of how the various discursive practices detailed 
above construct particular relations of readership. These structure the experience of this potentially wider textual environment and privilege its interpretation in terms of a unified and authored discursive event. I do, however, wish to develop one further related point, which complicates matters slightly.

As mentioned, in chapter 5 on supranational discourse, the final DOT Force report elides any mention of the radical heterogeneity present in the submissions. However, the existence of these underlying relations of production is not entirely effaced. Indeed, they are regularly referred to as an innovative consultative process designed to 'enhance' and 'secure' consensus. This tension between design and actual outcome is ultimately discursively resolved through the statement that, 'All inputs arising from the consultations were considered in the DOT Force's deliberations, but were not automatically incorporated in the conclusions and recommendations of DOT Force's final report.' (DOT Force 2001: 23 )

Certain relations of production then, such as those pointing to wide consultation, may be discursively highlighted in order to enhance the reading of a discursive event as credible and morally authoritative. In practice, as above, this highlighting may only be a nominal invocation rather than anything substantive. My point is that, whatever the reality, this representation of a diverse community of interests involved in the production process provides the discursive event with an added sense of credibility.

Such a motif also occurs in Chapter 3 on UK government discourse with reference to 'joined-up' policy, and in Chapter 4 on corporate discourse in referring to the involvement of the 'stakeholder' public into deliberations. I suggest that the invocation of some degree of wider input into the process of production and authorship in all these discursive events implies that they are not to be received exclusively as the products or confines of one particular discursive domain with a specific mode of understanding, whether that be governmental, corporate or supranational. Rather, it additionally privileges their reception as part of a wider contemporary discourse of hybrid 
governance and policymaking, where reality is represented as governable according to the success of understanding and mobilizing connections.

Selwyn (2002a: 2) suggests that, 'the notion of the digital divide has been furiously promoted by an unusual alliance of academics, IT industry executives, politicians and social welfare organizations'. What I am arguing here is that what is additionally promoted in such cases is the idea of the 'unusual alliance' itself, the representation of coalition, regardless of any actual alliances, or for that matter antagonisms, that underpin it.

\subsubsection{Discursive Renewal}

Let me return to the issue of how we might best conceptualize the regularity of my findings across my case studies. In previous chapters I have chosen to locate much of my explanatory work in terms of the wider discourses that are renewed through the discursive events that I have identified.

This type of analysis was closely allied to Laclau and Mouffe's (1985) framework. To briefly reiterate, in Laclau and Mouffe's theory, discourse itself refers to the ordering of a field of discursivity made up of indeterminate elements. Through articulatory practice, principally the expansion of signifying chains to construct relations of equivalence and difference, the meaning of such elements becomes partially fixed into discursive moments. Torfing (1999: 99) summarizes their position as, 'The discursive moments are dispersed but the ordering effects of the relations of difference and equivalence, the workings of different kinds of overdetermination, and the nodal points are factors that give rise to a certain regularity which can be signified as a "totality".

Laclau and Mouffe thus conceptualize individual discourses as relational and mutually exclusive entities, contingent yet bounded wholes, whose identities depend upon their differentiation from other discourses. By definition, discourses compete with each other to articulate indeterminate elements and 
order a field of meaning, and hegemonic struggle occurs at the boundary between discourses.

Accordingly, in Chapter 3 I argued that the 'Closing the Digital Divide' report can be understood in terms of the extension and renewal of 'Third Way' discourse, where the concerns of social justice and economic enterprise are seen as equivalent. Competing political discourses which see the needs of social justice and economic enterprise in potential conflict are necessarily delegitimated.

In Chapter 4 on corporate discourse, I pointed to the renewal of a specific discourse of 'corporate citizenship', which articulates a concomitant concern with the new economy and corporate social responsibility. This is positively contrasted with a discourse of 'corporate regulation', in which the concerns of social equality are seen as not able to be met by the market.

Similarly, I argued in Chapter 5 that the discursive construction of the nation state as having to react to an inevitable globalization, rather than shape it, buttresses a neo-liberal rather than a competing dirigiste discourse.

So far this is all relatively straightforward. However, it is not clear within such an explanatory framework of mutually exclusive and competing discourses where, if anywhere, we may be able to conceptualize the regularities that I have identified across my case studies, across different discursive events and the particular discourses they renew. ${ }^{12}$

\subsubsection{Rules of Discursive Formation}

I wish to turn then to another discussion of discursive delimitation. Foucault (1972) has theoretically addressed the problem of how to account for the relative unity of discourses across a multi-sited discourse analysis. He initially suggests four possible answers for finding a principle of unity, in that all the statements refer to the same object, in the style of statements that are 
deployed to produce meaning, in the constancy of concepts, or in terms of a general theme or theoretical strategy. He rejects each of these individual possibilities as insufficient. For example, there may often be little agreement on what the objects of a discourse are, but that does not mean that we do not consider it as being unified (e.g. sociology is generally considered a relatively unified discipline despite modest agreement on what its objects are, Lopez 2003: 9). Foucault argues instead that we should look at how all these possibilities are configured together, their regularity of dispersion:

Whenever one can describe, between a number of statements, such a system of dispersion, whenever, between objects, types of statement, concepts, or thematic choices, one can define a regularity (an order, correlations, positions and functioning, transformations), we will say, for the sake of convenience, that we are dealing with a discursive formation ...the conditions to which the elements of this division are subjected we shall call the rules of formation. The rules of formation are conditions of existence (but also of coexistence, maintenance, modification, and disappearance) in a given discursive division.' (Foucault 1972: 41, my italics)

For Foucault, neither of these four possibilities alone can account for discursive unity, but we should rather understand unity in terms of their combination, what he terms a 'discursive formation'. Foucault goes on to propose various rules of discursive formation, although I would stress that the term 'rules' is slightly misleading in that it suggests a generative mechanism. The rules which Foucault (1972) discusses in The Archaeology of Knowledge come into play in the very existence of such a discursive formation. ${ }^{13}$ They can be more simply termed as empirically inductive descriptions of a system of dispersion of discursive statements. I do not intend to pursue in detail the particular rules that Foucault proposes here. Indeed, Foucault himself never deployed his panoply of rules, archaeology's 'bizarre machinery' (Foucault 1972: 135), to conduct new empirical research. Rather I simply wish to emphasize the idea that the coherence of a 'discursive formation' may be given in terms of its rules of formation. 
As should be clear from the previous chapters, it is the case that there is no stable object that can be identified as 'the digital divide' across my diverse case studies, nor any conceptual consistency in the different states and processes that are discussed in each. However, despite these various and dispersed moments, in this chapter I have identified certain clear regularities across these case studies, notably the consistent problematization of the social with the techno-economic, the consistent implosion of state and process, and indeed their simultaneous technosocial implosion. Further these discursive practices consistently occur under the pure signifier of 'the Digital Divide'.

Such regularities across the case studies are clearly not, in Laclau and Mouffe's terms, direct relations of equivalence, which occur via articulatory practice and the expansion of signifying chains. Rather they can be best conceptualized in terms of structural equivalence or homology. Or in Foucault's terms, these regularities (the problematization of the social with the techno-economic, implosion, technosocial implosion, the pure signifier) can be considered as the rules of formation which describe a certain system of dispersion of statements. Following Foucault then, and similarly for the sake of convenience, I wish to propose that across my case studies, we are dealing with a 'discursive formation' whose conditions of existence are such rules.

It should be stressed that the proposal of a discursive formation must guard against the dangers of reification and its taking on of causal determination. It would be analytically circular to now argue that all that happens in my case studies is an effect of a particular discursive formation. Following Foucault, I am not saying that these particular rules of formation can now be considered as generating the discursive moments in individual discursive events. I am simply saying that the proposal of a discursive formation offers a clearer way to organize the discussion of such regularities. ${ }^{14}$ I will undertake this discussion in the next chapter. 


\section{Notes}

1 Of the sixty occurrences of the term 'the Digital Divide' in the DDBW document, twenty four are of the form 'addressing the Digital Divide' or 'addressing the issue of the Digital Divide'. The next most numerous construction is 'concern with/about the Digital Divide' which occurs three times. The only other constructions to appear more than once are 'Close the Digital Divide' and 'Dimensions of the Digital Divide' which occur twice.

2 Of the thirteen occurrences of the term 'the Digital Divide' in the DOT Force final report, three are of the form 'addressing the Digital Divide' and three 'bridging the digital divide'. No other construction appears more than once.

${ }^{3}$ Laclau summarizes Zizek's position as follows:

Like myself Zizek sides with the anti-descriptivists. But he also introduces a variant into the argument which is of crucial importance .. If the unity of the object is the retroactive effect of naming itself, then naming is not just the nominalistic game of attributing an empty name to a preconstituted subject. It is the discursive construction of the object itself. The consequences of this argument for a theory of hegemony or politics are easy to see .. If the process of naming of objects amounts to the very act of their constitution, then their descriptive features will be fundamentally unstable and open to all kinds of hegemonic articulations. The essentially performative character of naming is the precondition for all hegemony and politics (Laclau, Preface in Zizek, 1989:xiv).

${ }^{4}$ I use the term pure signifier rather than empty signifier as used by Torfing (1999) in his discussion of Zizek. Laclau (1996: 36-47) also discusses the empty signifier, but offers a very particular definition, 'the precise theoretical possibility of something which points, from within the process of signification, to the discursive presence of its own limits' (1996: 36), which I do not follow here.

${ }^{5}$ Callon, Law and Rip (1986: xvii) propose a specific definition of problematization as 'a form of translation that posits an equivalence between two problems that require those who wish to solve one to accept a proposed solution to the other'.

6 This theorization of problematization coincides with Foucault's general project to 'see if it would be possible to describe the history of thought, as distinct from the 
history of ideas' (Foucault 1984a:388). Thought is understood by Foucault as distinct from ideas because of this ethical orientation:

'The history of thought is the analysis of the way an unproblematic field of experience .. becomes a problem, raises discussion and debate, incites new reactions, and induces a crisis in the previously silent behavior, habits, practices, and institutions. The history of thought, understood in this way, is the history of the way people begin to take care of something, of the way they became anxious about this or that.'

Problematizing Parrhesia (Foucault 2001: 74)

As such, a focus on problematization carries with it an intrinsically ethical connotation as, 'it seeks to show that dominant discursive constructions are contingent and political, rather than necessary, and that different ways of conceiving of the connections .. need to be cultivated' (Howarth 2000: 135).

7 Laclau (1990: 39-59) further argues that societies are undergoing a proliferation and an accelerated tempo of dislocatory experiences as capitalist relations extend into new spheres of social life through processes of commodification, bureaucratization, rationalization and globalization, shattering existing identities.

${ }^{8}$ The following is a brief discussion of the motif of implosion in the work of McLuhan, Baudrillard and Virilio. For all these thinkers, implosion involves loss, whether of space, time, meaning or the social. McLuhan defines implosion as the "pulling out of spaces \{and time\} between components" (cited in Genosko 1999: 94), advanced by revolutions in the speed of telecommunications which are reconfiguring "all operations, all information, all associations" (ibid.):

"The stepping-up of speed from the mechanical to the instant electric form reverses explosion into implosion. In our present electric age the imploding or contracting energies of our world now clash with the old expansionist and traditional patterns of organization" (McLuhan, Understanding Media, 1964: 47)

More specifically, Baudrillard (1983: 96) discusses the implosion of meaning in the media'. The collapse of the medium and the real into hypersimulation, "reduplicating simulation and exterminating it according to its own logic' (p47), ultimately means the 'impossibility of mediation' ( $p 103$ ). Relatedly, Baudrillard controversially argues that 
the implosion of 'the social' in the media marks its death as anything other than an empty alibi of media institutions and academic disciplines, notably sociology, that advance its simulation. The mass (society) created by media technologies is ultimately an implosive, reabsorbent form that refuses socialization. Hence, simulating McLuhan's celebrated dictum, Baudrillard claims that "Mass(age) is the messagen (1983: 44).

The dialectic between speed and disappearance is central to Virilio's discussion of implosion. In his essay, 'The Last Vehicle' (1989), Virilio argues that the speed of the collapse of space and time paradoxically heralds the victory of sedentariness and inertia over movement and change. Exercise machines, flight simulators and the like reveal 'the last vehicle' as static rather than dynamic. The automotive and the audiovisual implode with the constant, near instantaneous presence of places and moments brought about by the information and telecommunications technology revolution. As speed supplants place, so chronopolitics displaces geopolitics, and Virilio theorizes a loss of time for political decision-making, the present ultimately collapsing into an automated instantaneousness of decision as the implosive .. reduces reaction time, and the time for political decision, to nothing .. the implosive .. inaugurates the war of time" (1986: 138-39).

It should be noted that in the work of the three theorists mentioned, there is little sustained empirical analysis to clarify what might underpin this logic of implosion, beyond a recurring reference to revolutions in the speed of information processing. Additionally there is little suggestion as to the further discrimination of the concept. 1 argue that implosion itself takes on a heavy explanatory weight in such discussions, in part as a deliberate strategy to develop a conceptual language and style that is somewhat dislocated from modern forms of explanation and representation and which can in this way attempt to come to terms with the assumed speeding-up of historical processes. While a potentially suggestive concept then, it is never adequately developed beyond a fairly abstract level of theorization.

9 In corporate discourse, there is a similar degree of ontological ambiguity and a connotation of a teleological process of emergence in the discursive construction, 'the emerging New Economy' (DDBW: 17). 
${ }^{10}$ Latour (1996: para 22) argues that 'The idea of a mediation or event enables [us] to retain the only two characteristics of action which are useful -i.e. the emergence of novelty together with the impossibility of ex nihilio creation'

11 In the context of highlighting material relationships between my case studies it is worth pointing to the fact that personnel from both the UK government and BT worked on the DOT Force initiative.

12 Philips and Jorgensen (2002: 55-57) argue that it is unclear in Laclau and Mouffe's writings as to whether the field of discursivity refers to any meaning whatsoever outside a specific discourse, or if it more narrowly refers only to potentially competing discourses and fragments of meaning. They ask if football, for instance, should belong to the field of discursivity of Western medicine, or whether this should be reserved to cover only potentially competing discourses such as alternative medicine. Suggesting not, they reformulate Chouliaraki and Fairclough's (1999: 73) conception of an order of discourse (note that this concept bears little resemblance to the analysis Foucault (1981) offers in his inaugural lecture to the College de France, The Order of Discourse) as 'a potentially conflictual configuration of discourses within a given social field' to mediate between the concepts of discourse and the field of discursivity. Order of discourse effectively refers then to a discursive domain consisting of more than one competing discourse. In my analysis of corporate discourse in Chapter 3, 'corporate citizenship' and 'corporate regulation' would be competing discourses in the 'order of corporate discourse'. Philips and Jorgensen (2002: 56) argue that:

'The relationship between a discourse and its exterior can now be formulated using three concepts. 'Discourse' continues to be the term for the structuring of a particular domain in moments. A discourse is always structured by the exclusion of other possible meanings and the term for this general exterior is the 'field of discursivity'. But now 'order of discourse' denotes two or more discourses, each of which strives to establish itself in the same domain ... The concepts of 'antagonism' and 'hegemony' will, in this construction, belong to the level of 'order of discourse'; 'antagonism' is open conflict between the different discourses in a particular order of discourse, and hegemony is the dissolution of conflict through a displacement of the boundaries between the discourses' 
I concur with their argument that there is some conflation between the conception of rival discourses and the field of discursivity in Laclau and Mouffe's work, and that they undertheorize the relationship between different discourses and processes of discursive change. As such, the concept of an 'order of discourse' does allow some clarification, some conception of 'scale' within a field of discursivity.

Nonetheless, it is important to point out that the topography of this formulation is essentially still one-dimensional. Discourses are still conceptualized as competing and separate, except at their boundaries, but within an order of discourse rather than a wider field of discursivity. Order of discourse simply refers to this set of mutually exclusive discourses, whose relation to each other is one of potential conflict over the fixation of meaning. As such, 'order of discourse' cannot address where we may be able to conceptualize the regularities that I have identified across my case studies, which are not in any obvious sense competing discourses. Put simply, such regularities still occur across orders of discourse themselves.

${ }^{13}$ For example the rules concerning objects are the surfaces or institutional sites of their emergence, the authorities of their delimitation, and the grids of specification used by these authorities to demarcate expertise. (Foucault 1972)

14

Certainly, there are ways in which rules of discursive formation might conceivably be generative, analogous to the way in which an awareness of the 'rules' of genre might organize further productivity within a particular textual environment. In terms of analytic work, the concepts of a discursive formation, and particular rules of formation, can be regarded as sensitizing, in that they may deductively organize further interpretative work in other discursive domains. Having argued this, such an understanding of method may itself be questioned as being informed by a rather empiricist version of realism, which presupposes the separation of the world and the knowledge that arises from its investigation. I have suggested, in my analysis of Castells' work, that such an understanding fails to consider how the findings of social scientific analysis enter reflexively into the social formations they purport to describe. Similarly, recent discussions of 'the performativity of method' (Law and Urry, 2003), stress the ways in which social realities are enacted or performed into being in social investigation (e.g. Osborne and Rose, 1999, on the creation of the phenomena of 'public opinion'), a position more in line with discourse theory's emphasis on the discursive production of all meaningful realities. 


\section{$\square \square$ Chapter 9.}

\section{Conclusion}

\section{$\underline{9.1 \text { Introduction }}$}

This thesis offers a contribution towards the empirical and theoretical analysis of a number of accounts of technology and inequality, in particular those focused upon 'the digital divide', that have been articulated within various discursive domains over the past five years.

In this concluding chapter, I initially summarize the findings and arguments that I developed in the previous six chapters. Following this, I explicitly consider the implications of certain key findings for the wider analysis of government in the 'Information Age'. The intention of this work is to suggest working hypotheses and sensitizing concepts for analysis and elaboration in further research.

\subsection{Summary of Findings}

In Chapter 3, I provided a detailed textual analysis of a report produced by the Social Exclusion Unit, 'Closing the Digital Divide: information and communication technologies in deprived areas' (PAT 15, 2000), as a case study in the understanding of technology and inequality within UK government discourse. I argued that the report marks the convergence of two prominent discourses within contemporary politics, that of the 'Information Age' and the 'Inclusive Society'.

CtDD presents a passive technologically determinist understanding of radical utopian change in social and economic organization, with an associated policy rationale of helping British society keep up with the emergence of this inevitable, if ill-defined, 'Information Age'. The responsibilities of government 
are thus understood as inexorably framed by technologically determined ground rules. In particular, the narrative structure of CtDD acts as a vehicle for presenting a case for specific action, to identify and overcome the social 'barriers' that might prevent the utopian promise of the Information Age from being realised. At the same time, the direction and shaping of more particular goals beyond this vague freeing of technological potential is largely absent.

Drawing upon Levitas' (1998) analysis of the principal discourses of social exclusion embedded in contemporary British politics and social policy, I additionally argued that the dominant understanding of social exclusion in $C t D D$ is one which directs moral attention onto the distinctiveness of the 'deprived neighbourhood', and sees the individual attainment of job security as central to the achievement of social inclusion. Any broader understandings of social exclusion in terms of wider processes of social polarization, domains of social activity beyond work, structural inequalities throughout society, and redistributive solutions are conspicuously absent and delegitimated.

This 'responsibilization' of the individual is further emphasized in CtDD in that the individual in the Information Age is primarily understood as someone with the potential for personal transformation, particularly once certain attitudinal 'barriers' have been overcome, all of which may be realised through connection with ICTs. The concomitant limits of governmental responsibility are primarily constructed in terms of promoting awareness of, and access to, this potential of ICTS.

These findings extend detailed empirical support to the broad conclusions offered in those traditions of critical scholarship which stress the performative dimensions of Information Society discourse (e.g. May 2002, Preston 2001) and that contemporary discourses of 'social exclusion' offer a means through which issues of poverty, social deprivation, and employment conditions may be depoliticised and individual responsibility emphasized (Byrne 1999, Levitas 1998, Lister 1998). 
I further pointed to a chain of discursive equivalences established in CtDD, for example between societal and individual transformation. In particular, I highlighted the continual discursive equivalence constructed in CtDD between the measures understood as necessary to strengthen national economic competitiveness in the Information Age and those for achieving social inclusion. As such, I argued that CtDD embodies the overall vision and discursive logic of New Labour's 'Third Way', a political programme which has attempted to reconcile themes previously seen as antagonistic in centre-left political discourse. I concluded that the construction of the CtDD text could be understood as a process in which particular political work is done, drawing upon but also, crucially, renewing the wider discourses of the 'Information Age', the 'Inclusive Society' and ultimately the 'Third Way' itself.

In Chapter 4, 1 examined the work of the Social Policy Unit of the telecommunications corporation BT on the issue of the digital divide. I argued that addressing the digital divide is discursively understood in terms of an alignment between the visions and projects of 'Corporate Social Responsibility' and 'the New Economy'. As such, it can be considered as both drawing upon and renewing a wider logic of contemporary corporate discourse that emphasizes the equivalence of social and economic concerns through discursive constructions such as 'triple bottom line accounting', and, in the specific political context of the Company Law Review, 'Enlightened Shareholder Value'.

Further, I argued that the 'issue' of 'the Digital Divide' is both meaningful in terms of the management of internal organizational identity and is constructed as a particular object of external accountability. I agued that one ongoing concern for contemporary corporate discourse is that the presentation of the organization as more widely accountable is seen as increasingly necessary but still a rather unknown proposition. My analysis of the particular performance of accountability in this case study pointed to a situation in flux, where this process of demonstration is being continually worked through. 
I pointed to the contingent discursive practices that configure the parameters of the public in stakeholder subjectivity, construct an object of accountability, and uphold a programmatic self-understanding of engagement via new media as live, interactive and transparent. Discursive resources such as the stakeholder, the Digital Divide, interactivity, transparency and commitment were thus constructed and enlisted to partially stabilize this particular performance of accountability, as an interactive stakeholder consultation on an objective issue. I finally highlighted points of undecideability in this particular case study, and suggested that it may be important to pay further attention to such discursive moments in the contemporary phenomenology of accountability.

In Chapter 5, I examined the work of the G8 Digital Opportunity Task Force (DOT Force) initiative as a case study in the understanding of technology and inequality within supranational discourse. I argued that, as a necessary condition of its credibility and moral authority, the DOT Force presents itself as exemplifying the global through inclusive and innovative organizing principles of multiple representation, networking, and 'electronic outreach'.

However, a detailed analysis of the DOT Force process reveals numerous antagonisms whose resolution in the final report reflects the field of power in which the DOT Force operates. I argued that the Digital Divide can be best understood in this particular engagement as an issue through which the various political interests represented in the DOT Force process can normatively reconfigure the conceptual and ethical possibilities it signifies to ultimately renew a dominant, singular 'secular salvation story' of economically and technologically driven globalization.

The temporality that structures this narrative is one of technologically determined inevitability and irreversibility. Furthermore, an organized discursive positivism regarding the promise of ICT for development saturates the final report. Barely secularized discursive motifs are sutured into the tissue of the account to buttress its resonance and plausibility. I argued that this specific articulation of the digital divide instantiates a transformed and 
action-oriented moral agenda. A broad concern with global inequality is replaced by a pressing imperative to connect with the promise of technology and development, in particular via the adoption of National eStrategies which nonetheless commit to a neoliberal regulatory and policy environment, and the assessment of eReadiness to demonstrate this commitment.

In Chapter 6, I concentrated on the work of Manuel Castells as a key theorist of the 'network society', a context that is often invoked, but rarely explicitly theorized, in discussions of the digital divide. I critically examined the methodological, epistemological and theoretical underpinnings of Castells' Information Age thesis, as well as his specific articulation of the digital divide.

In my reading of his Information Age thesis, I argued that Castells' concept of the network society, and its axiomatic principle of the pre-eminence of morphology over action, 'the power of flows over the flows of power', is troubled by a fundamental issue of causality. Castells attempts to resolve this problem by proposing an 'implicit logic of the network' as central to the causal chain of determination. The seductive idea of 'networking logic' is thus the theoretical kernel of his Information Age thesis.

I suggested that there are three ways that Castells attempts to outline the contours of networking logic. The predominant view reduces this logic to a form of technological determinism. Alternative conceptualizations of networking logic stress the determinacy of economic complexity, and the ethical determinism of a 'spirit of informationalism'. The concept of networking logic is thus not clearly developed or consistently deployed. Further, I argued against Castells' general understanding of networking logic as an abstract determining force and rather emphasized an alternative reading in which networking logic is a social activity, the particular material instantiation of the concept of the network.

I argued that Castells' specific discussion of the digital divide is dependent upon this problematic master concept of networking logic at the same time as discursively renewing its core theoretical underpinnings. I showed how, in the 
structure of Castells' discussion of the digital divide, there is a slippage between two understandings of the digital divide, one strictly morphological, the other more consequential and active.

Overall, I argued that the key closure in Castells' work is the a priori preeminence of morphology over social action. I suggested that this is why his discourse is troubled by causality and dependent for its telos upon seductive, normative ontology, particularly the master concept of an abstract, determinant and inevitable networking logic. I argued that Castells' understanding of inside/outside stratification in the network society, and in particular his articulation of the dichotomous digital divide, fundamentally relies upon this problematic master concept whilst simultaneously renewing its core theoretical underpinnings.

In Chapter 7, I analyzed a series of focus group discussions with a group of participants who are already recognized in a particular institutional discourse of social exclusion. I argued that the participants' discussions presented a highly nuanced, heterogeneous and, at times, contradictory series of understandings of technology and inequality. While there was some broad discursive recognition that technological change was a salient theme in the participants' lives that had to be negotiated, such change was rarely articulated in terms of epochal shifts in their sociocultural environment, nor in the utopian terms of the potential of technology to widely propagate social, political and civic empowerment.

Rather the participants articulated an understanding of technology as radically double-edged, organized in particular around the motif of the double-bind of technological dependence, and the concomitant threat to a coherent sense of self-reliance. In addition, there was some discursive appropriation of the more promissory narratives of technological futures through which the participants sought recognition of their desires without necessarily endorsing the terms of these utopian visions. 
The discussions further stressed the values, interests and purposive action of particular social groups and institutions in the production of technology and the promotion of socio-technical imperatives. Individuals attempted to discursively position themselves, to construct contingent and credible narratives of status and personal identity, through the acceptance, rejection and appropriation of such perceived logics. In particular, the consumption and display of technology was understood as an important symbolic resource for processes of social classification and meaningful identity construction.

While the participants strongly endorsed the view that the educational attainment of computer literacy might enable them to secure paid work, such a belief was articulated within a more complex narrative in which the enduring experience of constraints upon voluntarism in this particular domain of their lives was salient.

I argued that the emphasis upon social determinism in these discussions offered little support to the claim that technological determinism is the dominant form of explanation for making sense of everyday experiences of technology. Further, while there were radically heterogeneous views expressed as to whether technology might facilitate individual empowerment, I argued that ultimately there was a discursive emphasis on self-determination over and beyond any deterministic adaptation to either social or technological imperatives.

In Chapter 8, drawing on the work of Foucault and Zizek, I paid particular analytic attention to some of the regularities across my case studies, specifically in UK government, corporate and supranational discourse. I argued that in each of these case studies 'the digital divide' effectively functions as a pure signifier through which various local articulations occur. Named and denounced as a 'real' problem to be tackled or 'addressed', it is nonetheless never clear what 'the digital divide' is, beyond the nominal reification of a mode of problematization that conjoins the techno-economic (digital) with the social (divide). 
In 'addressing the digital divide', I argued that each case study constructs relations of equivalence between the social and the techno-economic, specifically the mutual reciprocity of a concern with the social and the promotion of the techno-economic. The dominant discursive ethos in all these case studies is that of the equivalence of these two values. I additionally pointed to a dystopian lack as the underlying dislocatory anxiety that is never manifestly represented in these case studies but provokes discursive management via this mode of problematization.

In addition, I highlighted the discursive organization of causal ontology in my case studies. In addressing the digital divide, various processes buttress their legitimacy through discursive enfolding with separate utopian states. I used the term implosion to describe this discursive enfolding of utopian state and process, which instantiates and privileges a specific discursive teleology and mitigates against alternative causal ontologies.

I identified technosocial implosion as the concomitant discursive organization of ethos and teleology. I argued that this occurs where teleological performativity, the discursive enfolding of utopian state and process, is discursively concurrent with a problematization of the social with the technoeconomic. In technosocial implosion, a utopian social state functions as the telos which legitimates the inevitability of a particular techno-economic process.

Finally, following Foucault, I argued that these discursive processes that I identified as regularities across my case studies can be conceptualized as wider rules of discursive formation.

\subsection{The Discursive Formation of The Information Age}

What follows in this conclusion is a discussion of the implications of these rules of discursive formation. I consider 'addressing the digital divide' to be a particular instance in the wider governance of that which is understood to be a specifically technological, networked or information society. ${ }^{1}$ As such, I will 
discuss the implications of these rules of discursive formation in these terms, as elements in the wider governance of what, for clarity, I will term the discursive formation of the Information Age. Accordingly, my mode of address in these discussions will be more provisional than in previous chapters. As Cronbach (1975: 125) notes, 'any generalization is a working hypothesis, not a conclusion'. I will consider each of my key rules of discursive formation in turn, beginning with the discursive construction of ethos through the problematization of the social with the techno-economic.

\subsection{The Ethos of The Information Age}

I have argued that the rule of formation of discursive ethos is that two values are equivalent, a concerm with the social and the promotion of the technoeconomic. The suggestion of potential conflict between these two values is an ethical position against which this equivalence is discursively differentiated.

Let me expand on this. Crucially, $I$ argue that this is not a simple case of proposing technology as the solution to social problems. Even if ultimately the outcome is similar, this is a more subtle ethical position than the straightforward endorsement of a technological fix. This subtlety is necessary in part because the association between technological and social progress has become increasingly open to question in late modern societies. For example, Tester (1993:101) argues that:

Technology, the great product of modernity, is then the site and occasion of utterly contradictory relationships and interpretations .. technology is simply unsayable; it continues but without any discursive legitimacy .. the technology which played such a crucial role in the fabrication of modern human dwelling has become the second natural artifice. It has become a reification in its own right and consequently, a major obstacle to the social and cultural re-definition which it was meant to enhance. In other words, technology has become something in need of transcendence and deconstruction. 
Such ambivalence towards the idea of a technologically guaranteed progress is not just a longstanding intimation from within sociological narratives of modernity and the sine qua non of science and technology studies, but extends in contemporary society beyond the academy. As I detailed in my analysis of focus group discussions in Chapter 7, the claim that technological determinism is the dominant interpretative repertoire for the routine understanding of technology is not supported by the complex and heterogeneous understandings expressed, which emphasize the promotion of particular social interests through technology and the double-bind of technological dependence. Indeed, I argued that Woolgar's (2004) assertion of a growing scepticism towards new technologies is not limited to observers and analysts, but extends to other constituencies of the 'network society'.

This scepticism cannot be completely ignored and hence $I$ argue that it is occasionally discursively acknowledged in terms of a preliminary note of caution about the dangers of a simple technological 'fix':

Activities should not be focused on technology but be supported by it. (CtDD: 20)

Digitally enhanced access to health care information does not automatically translate into better access to health care. (BT 2001: 4)

ICT can thus help to ignite a virtuous circle of sustainable development. But misapplied, they can result in marginalisation of the poor and the unconnected. In order for their development potential to be realised, all stakeholders need to work together towards achieving real change. (DOT Force 2001: p4 my italics)

Here there is some discursive acknowledgement of such ambivalence, that the lesson of the past is that stakeholders need to direct technological development in order to avoid 'misapplication'. Such a position functions as a form of discursive inoculation against accusations of blatant technoboosterism. It is worth reiterating that any detailed consideration of the potential downsides of technological development is essentially non-existent in all of the discursive events cited above, or indeed ignored in the case of 
critical submissions to the DOT Force - such views are those of 'skeptics' who need their 'e-awareness' raised.

However, the dominant understanding in all of these discursive events is that misapplication is not so much a lesson of the past as a thing of the past. Any relative autonomy of the social from the techno-economic ultimately marks the discursive exterior which lies in contrast to, and hence discursively constitutes, the revolutionary equivalence of the social and the technoeconomic in the Information Age:

The social arguments for an inclusive information society reinforce the economic ones and vice versa. (CtDD: Foreword)

New technologies will dramatically change the way the economy and society is organised, allowing traditionally excluded groups to prosper and countries to skip stages in development .. [this] scenario is the concrete utopia that the 'first great philosopher of cyberspace', Manuel Castells, spells out. (BT 2001: 12-13)

This "digital revolution" has been made possible by the potent combination of dramatic increases in the power and versatility of technologies, at significantly lower costs with enormous creativity in the applications of these tools and networks in all aspects of the economy and society. (DOT Force 2001: 6)

Ultimately then technology will not, indeed cannot, be 'misapplied' this time. Misapplication implies separate domains which potentially may not align. The problematization of the social and the techno-economic, the discursive ethos of the Information Age, removes the possibility of this lack of harmonization. The promotion of technology is not one of multiple potential solutions to social problems, not even really the 'solution'. It is simply discursively equivalent to a concern with the social. Indeed, concerned stakeholders cannot but endorse technological progress given this understanding.

I wish to emphasize one further point. I termed the underlying dislocatory anxieties in all of these case studies dystopian states, the lack of a utopian 
social state: a lack of social inclusion in UK government discourse, a lack of social responsibility in corporate discourse, a lack of global equality in supranational discourse. These dystopian states are potentially dislocatory because they all trouble the Durkheimian idea that we can imagine ourselves to be united as members of a wider society. They suggest that the material basis of shared experience is becoming precarious, that society may be a field of conflict rather than a cohesive whole, and hence question the very existence, the very idea, of 'the social'.

As I have already argued, the ethos of this discursive formation does not simply propose technology as a solution to discursively separate social problems. Rather, it suggests a more fundamental contemporary ethical position, that a concern with the social is equivalent to an endorsement of the techno-economic. In other words, the moral horizon of the Information Age is that society is bound together through a shared relation to technology.

\subsubsection{Government}

How then might we think the relation between this discursive ethos and an analytics of power? Foucault's (1978) shift from an analysis of power in terms of processes of discipline to the analysis of government provides my point of entry here. In order to address this question, I need to briefly outline his understanding of government.

For Foucault, the concept of government is broader than a colloquial understanding in terms of direct intervention by specific state apparatuses. It can be most generally defined as the 'conduct of conduct' (Foucault 1978), the art of guiding people, and thus 'government refers to a continuum, which extends from political government right through to forms of self-regulation' (Lemke, 2000: 12). Foucault argues that:

If one wants to analyze the genealogy of the subject in Western civilization, he has to take into account not only techniques of domination but also techniques of the self .. The contact point, where the way individuals are driven by others is 
tied to the way they conduct themselves, is what we can call, 1 think, government. (Foucault 1993: 203)

The concept of government thus continues Foucault's (1979) earlier concern with processes of disciplinary subjectification, but exceeds this analysis of the direct exercise of power to additionally pay particular attention to forms of selfgovernment and their regulation through the structuring and shaping of the field of possible action of subjects. According to Lemke (2000: 4-5):

governmentality is introduced by Foucault to study the "autonomous" individual's capacity for self-control and how this is linked to forms of political rule and economic exploitation .. power relations do not always result in a removal of liberty or options available to individuals. On the contrary power in the sense Foucault gives to the term, could result in an 'empowerment' or 'responsibilization' of subjects, forcing them to 'free' decision-making in fields of action.

The notion of government thus includes the ways in which an individual questions, problematizes and regulates his or her own conduct, and provides a bridge to Foucault's later work on ethics as the arena of self-government and $a$ form of action of 'self on self' (Dean 1999: 11-13).

Government thus operates through the elicitation, promotion, facilitation, attribution and internalization of various capacities, qualities and statuses to and by particular agents that structure their possible ways of self-governance (Dean 1999: 32). For Allen (2003: 82), 'the art of government rests upon the continuous and relatively stable presence of a series of ideals, expectations, received 'truths', standards and frameworks which provoke individuals to govern their lives in particular ways'. Central to the idea of government is that power is at least in part an immanent affair, it is capable of organizing people's lives to the extent that they bring themselves to order.

Foucault's work on government has been particularly developed in the analysis of advanced or neo-liberalism (Barry et al. (eds) 1996, Dean 1999, Lemke 2000). For Dean (1999: 15) 'liberal modes of government are 
distinguished by trying to work through the freedoms or capacities of the governed ..[they] conceive the freedom of the governed as a technical means of securing the ends of government'. Lemke (2000:12) further argues that:

one key feature of the neo-liberal rationality is the congruence it endeavours to achieve between a responsible and moral individual and an economic-rational individual. It aspires to construct responsible subjects whose moral quality is based on the fact that they rationally assess the costs and benefits of a certain act as opposed to other alternative acts .. the consequences of the action are borne by the subject alone, who is also solely responsible for them.

Cruickshank (1999) offers a related analysis, arguing that the problematization of conduct as 'disempowered' or 'dependent' is intimately bound up with practices of government which frame the subject's ability to act predominantly in terms of self-monitoring and measurement. In this reading, the language and techniques of 'self-esteem' and 'empowerment' ultimately have more to do with continual self-assessment than self-respect. Similarly, recent work has pointed to the concept and techniques of 'active citizenship' as central to neo-liberal problematizations of the political present and contemporary forms of government (e.g. Barry 2000, Marinetto 2003, McGhee 2003).

\subsubsection{Agency}

Let me return then to the question of power in terms of a consideration of agency and subjectivity. What forms of agency and what kinds of moral subjectivity are sanctioned in the discursive formation of the Information Age? At this point, I need to briefly reiterate some of my findings from earlier chapters.

In Chapter 3, I argued that the dominant conception of the individual in UK government discourse, particularly the excluded individual, is somebody with the potential for transformation. Transformation is to be achieved in particular through connection with technology and the development of 'ICT literacy' in 
order to individually achieve job security. This is exemplified in the diagram of power (CtDD: 46, reprinted in Chapter 3, p73) centred on the 'Individual', a nebulous figure suspended in a bare web of proliferating choices and potential connections that can be made with the 'Learning Technology Infrastructure'. The dominant narrative is one of self-discovery and self-sufficiency through such connection, embodied in the figure of the 'ICT champion'. Furthermore, I pointed to elements of a moral underclass discourse of social exclusion in which attitudinal resistance to the use of ICTs is understood as a particular obstacle to be overcome if the social is not to place limits on the potential of the technological.

In Chapter 4 on corporate discourse, I argued that individual agency was similarly understood in terms of connection and interactivity. In particular, the figure of the 'stakeholder' was configured as someone who was able to utilize the 'power of the internet'. Stakeholder status was not only understood but, in the relations of readership, normatively conferred upon those on 'the right side of the digital divide', materially and morally. Furthermore, I argued that the concern with the digital divide, and the commitment to an interactive consultation process in particular, could be understood as a performance through which the corporation constitutes itself as an ethical and accountable subject, a 'responsible corporate citizen'.

In Chapter 5 on supranational discourse, I argued that agency, particularly that of the nation state, is understood in terms of a secular salvation story of technological globalization. There is a moral imperative for the 'unconnected' to become eAware and take advantage of the promise of the historic 'Digital Opportunity'. The proposed Plan of Action is centered upon the assessment of eReadiness and the development of national eStrategies which 'should commit, in particular, to the establishment of a pro-competitive regulatory and policy framework as well as the associated institutional policy-making and regulatory capacity, including self-regulating mechanisms' (DOT Force 2001: 14). 
Clearly all of these case studies describe different agents. Nonetheless, I argue that there are certain consistent motifs across all these diverse narratives. Firstly, the expression of agency is predominantly understood as (re)action that enables the agent to not be 'left behind' by the inevitable, technologically determined but otherwise agentless, transformations of the Information Age. Secondly, agency is liminal. Certain socio-technical configurations are associated with a lack of status and opportunity, at best unactualized potential. Other, distinct socio-technical configurations are associated with self-discovery, virtue and empowerment (although the details of such empowerment are often relatively formless beyond the individual power to choose and consume). ${ }^{2}$

However, the key expression of agency in the Information Age is understood to lie in crossing this boundary, moving from the wrong to 'the right side of the digital divide', from unconnected to connected. This dominates the discursive formation's sense of agency and political possibility, rather than any clear inherent quality of such connectedness beyond this threshold. Agency is discursively understood then through the category of connection. Connection underpins the possibility and structuring of further government and selfregulation.

Dean (1996:220-226, 1999) argues that the analysis of the ethical government of the self involves four aspects:

First, it involves ontology, concerned with what we seek to act upon, the governed or ethical substance. This may be the flesh in Christianity .. or the 'soul' of the criminal in modern penology .. Second, it involves ascetics, concerned with how we govern this substance, the governing or ethical work. This may include .. spiritual exercises .. or the procedures of surveillance, management and normalization applied to deviant individuals. Third, it involves deontology, concerned with the who we are when we are governed in such a manner, our 'mode of subjectification', or the governable or ethical subject (as one prey to the weakness of the flesh in Christianity, or an active jobseeker in social programmes). Fourth, it entails a teleology, concerned with why we 
govern or are governed, the ends or goals sought, what we hope to become or the world we hope to create, that which might be called the telos of governmental or ethical practices .. whether other-worldly salvation, the sculpting of a beautiful and noble life and memory, an enterprise culture or an active citizenry and society. (Dean 1999:17)

In the discursive formation of the Information Age, that which is acted upon, the 'ethical substance' or the site for self-regulation, government and transformation is, at a broad level, that which is problematized as unconnected. Lemke (2000:13) argues that 'we can decipher a neo-liberal governmentality in which not only the individual body, but also collective bodies and institutions .. corporations and states have to be "lean", "fit", "flexible" and "autonomous". I concur with his suggestion of a congruence in required qualities across the different agents described in my diverse case studies. However, I argue that the autonomous subject of neo-liberal political rationality is not a discursively privileged endpoint in the Information Age, it does not lie beyond ethical problematization.

Rather the unconnected and the individual are themselves understood as resources to be enrolled in further networks of value, knowledge and government. In terms of deontology then, the 'ethical subject' is the stakeholder or networker, the connected subject. In the Information Age, the 'enfolding of authority' (Dean 1996: 221) that is established between a subject that is knowable and governable in so far as it can know and govern itself, is best encapsulated in the notion of connection.

Moreover, the discursive strength of the category of connection is that it is a metaphor that simultaneously addresses both the technological and the social. $^{3}$ Connection connotes the 'purely technological' relationship (e.g. between two computers), the relationship of the technological and the social (e.g. dialling in or going online), as well as the 'purely social' relationship (e.g. somatic or oral communication). ${ }^{4}$ 
The category of connection then naturalizes the discursive ethos of the Information Age, that a concern with the social is equivalent to an endorsement of the techno-economic.

The development of ICTs provide a vehicle for people living in deprived neighbourhoods to reconnect with society in a variety of productive and positive ways. (CtDD: 59, my italics)

Connectivity - basic access to ICT in its various forms. Without being able to get online, people are effectively cut off from the information revolution. (BT 2001: 8)

The Digital Opportunity Task Force .. calls for an enhanced and coordinated global effort to build digital opportunity for all, to extend the power and promise of the digital revolution to all parts of the globe and all segments of society, to help the poorest help themselves to create richer and fuller lives that express and affirm their own distinctiveness in an increasingly interconnected global village. (DOT Force 2001: 12, my italics)

Barry (2001: 31) argues that 'technology itself, in the form of interactive and networked devices, is thought to provide a significant part of the solution to the problem of forming the kind of person who can .. make choices in a technological society'. Here I suggest that it is the idea of connection that both underpins the dominant understanding of agency, that is the precondition for active citizenship, and legitimates the discursive ethos of the Information Age.

Moreover, the diverse discursive instantiations of this will to connect, the multitude of eAwareness initiatives and eReadiness assessments, access targets and action plans, recommendations and best practices to bridge the Digital Divide, can additionally be understood as citational or ritual edicts, that draw attention to the specific ethical claim that society is bound together through a shared relation to technology, that technology stands in for society's centre ${ }^{5}$. 
Of course, this is not to say that there will necessarily be any direct correspondence between such discursive edicts and the action of subjects. As Dean notes, regimes of government do not determine forms of moral subjectivity: 'they are successful to the extent that these agents come to experience themselves through such capacities (e.g. of rational decisionmaking), qualities (e.g. as having a sexuality) and statuses (e.g. as being an active citizen)' (1999: 32). The 'ascetics' of connection, in the general sense of 'governing or ethical work' (Dean 1999:17), are similarly dependent on such experience and identification.

To this end, it is worth noting that some of the understandings expressed in the focus groups discussions that I analyzed in Chapter 7, particularly those which stressed the necessity of computer literacy for securing paid work in contemporary society, are highly resonant of the understandings of individual agency in the discursive formation of the Information Age. However, as detailed, the narratives articulated were far from straightforward or homogenous. Understandings of agency ranged from the ability of the individual to keep up with inevitable change right through to the ability to avoid deterministic adaptation. In particular, the risks discussed were more heterogeneous than simply 'being left behind'. The salience of the motif of technological dependence and the associated threat to individual values of self-reliance and self determination in these discussions point to a more ambivalent identification with the connected subject. ${ }^{6}$

\subsection{The Teleology of The Information Age}

I now turn to the second key rule of discursive formation, the organization of causal ontology in the Information Age. In my case studies, I argued that, in addressing the digital divide, various processes (e.g. globalization) buttress their legitimacy through discursive enfolding with separate states (e.g. global equality). I termed these utopian states as they suture a potentially dislocatory lack (e.g. a lack of global equality) that is invoked but never directly represented. In Dean's terms, such utopian states are 'the ends or goals sought, what we hope to become or the world we hope to create, that 
which might be called the telos of govermmental or ethical practices' (1999:17).

I used the term implosion to describe this discursive enfolding of utopian state and process, which instantiates a specific discursive teleology. Additionally, I used the term technosocial implosion when a utopian social state is the telos which legitimates the inevitability of a particular techno-economic process. I will discuss some political implications of implosion here. Initially, it is worth emphasizing that government in the Information Age does not begin from the 'ontology of circumstances of being' (Carter and Grieco, 2000: 1739), from the routine conditions of existence. Rather, I have argued that potentially dislocatory lacks are discursively managed such that the suturing of this lack, the imagineering of a utopian state, serves as the promissory telos of practices of government.

Several authors (e.g. Beck 1992, Giddens 1994, Luhmann 1998, Michael 2000a) have described how, under conditions of modernity, 'the future' assumes increasing salience as something to be known and articulated in the present: 'a modern expectation is that one is increasingly capable of historicizing the future in the present .. the future is made manageable by being continuously drawn into the present through the reflexive organization of knowledge environments' (Mason 2006: 2). I argue here that there is a particular discursive closure of 'contested futures' (Brown et al. 2000) through implosion. The discursive enfolding of state and process brackets alternative causal ontologies. Any other narrative of causality, such as a potentially less sanguine consideration of the way in which a particular process might conceivably hinder the emergence of a utopian state (e.g. globalization's potential role in restricting global equality) is discursively ruled out by the contours of this ontological collapse. Rather, the narrative of implosion is such that a particular process is discursively seen as ineluctable, legitimated with reference to the latent utopian state or telos to which it is inevitably drawn. The only permissible political narrative is ultimately that of the futurepresent success story. 
As I have already argued, the assumptions about agency that are embedded in the discursive formation of the Information Age are that the expression of agency is understood as action that enables the agent to avoid the deferral of this success, to not 'be left behind' by inevitable processes of technoeconomic change. In terms of Barry's argument that 'an action is political .. to the extent that it opens up the possibility for disagreement' (2002:270), I argue that implosion places limits on the political by discursively restricting alternative understandings of causal ontology and agency. ${ }^{7}$

\subsubsection{Neoliberal Vocabulary}

In discussing recent transformations in the political language of modernity numerous commentators have alluded to the performative status of the analytic and political vocabulary of neo-liberalism. For example, Lemke argues that, from a governmentality perspective, we can construe neoliberalism 'not just as ideological rhetoric, as a political-economic reality or as a practical anti-humanism, but above all as a political project that endeavours to create a social reality that it suggests already exists' (2000: 13). Bourdieu and Wacquant (2001: 2) similarly describe 'neoliberal newspeak' as follows:

Its vocabulary, which seems to have sprung out of nowhere, is now on everyone's lips: 'globalization' and 'flexibility', 'governance' and 'employability', 'underclass' and 'exclusion', 'new economy' and 'zero tolerance' .. The diffusion of this new planetary vulgate - from which the terms 'capitalism', 'class', 'exploitation', 'domination', and 'inequality' are conspicuous by their absence .. is a form of symbolic violence that relies on a relationship of constrained communication to extort submission.

Furthermore, Bourdieu and Wacquant (2001: 4) suggest that this vocabulary 'is endowed with the performative power to bring into being the very realities it claims to describe, according to the principle of the self fulfilling prophecy'. However, as Fairclough notes in a call for renewed critical discourse analytic work, Bourdieu and Wacquant's characterization of neoliberal newspeak sheds little light on how such performativity operates: 'It is not enough to 
characterize the 'new planetary vulgate' as a list of words, a vocabulary. We need to analyze texts and interactions to show how some of the effects which Bourdieu and Wacquant identify are brought off' (2001: 6).

In the discursive formation of the Information Age, I have identified implosion, the enfolding of state and process, as a particular example of discursive performativity. However, unlike Bourdieu and Wacquant, I have not understood this as an attempt to bring into being certain social realties or states that it is suggested already exist. Rather, I suggest that it best conceptualized as an attempt to govern according to a specific teleology whereby it is particular techno-economic processes (of globalization, of enterprise, of 'leveraging the new economy') that are understood as the ultimate inevitability, rather than the telos of certain utopian states. It is the discursive inevitability of these processes that structures the initiatives and imperatives of government and the contours of agency in the discursive formation of the Information Age. In this particular analysis then, I suggest that Bourdieu and Wacquant's 'principle of the self-fulfilling prophecy' may be more accurately described in terms of the discursive implosion of the selfjustifying process. The extent to which the idea of implosion may illuminate the wider functioning of the contemporary neoliberal episteme is an empirical question that I cannot address here, but one worthy of further research.

\subsection{The Digital Divide}

In this section, I wish to return to specifically discuss 'the digital divide'. How best can we conceptualize its status in the discursive formation of the Information Age? This is not the same as asking 'What is it?' (BT 2001: 4). Indeed, the very asking of this particular question and the discursive organization of the response is central to the phenomenology of the digital divide. To date, I have argued that the digital divide can be conceptualized as an empty term, a pure signifier, that discursive articulation works through. To recap, Butler summarizes the efficacy of the pure signifier (or in her terms, political signifier) as follows: 
The political signifier becomes politically efficacious by instituting and sustaining a set of connections as a political reality. In this sense, the political signifier in Zizek's view operates as a performative rather than a representational term. Paradoxically, the political efficacy of the signifier does not consist in its representational capacity; the term neither represents nor expresses some already existing subjects or their interests. The signifier's efficacy is confirmed by its capacity to structure and constitute the political field, to create new subject-positions and new interests. (Butler 1993: 210, italics in original)

I have argued that, within specific discursive events, 'the digital divide' functions in these terms, as a vehicle through which various local problematizations and implosions that 'address' it can occur. While it certainly becomes relatively clear in each case study what 'addressing the digital divide' involves, 'the digital divide' itself remains indeterminate beyond its naming as something to be addressed.

Here I wish to extend this discussion to consider the status of 'the digital divide' beyond the particular discursive event. I will argue that, in the wider discursive formation of the Information Age, the digital divide can be best conceptualized as a brand, an object of government that organizes relations across a transdiscursive policy space. Before I develop this particular argument, I need to consider some other contemporary discussions of interdiscursivity that suggest possible ways to theorize the status of terms that travel across different discursive domains and communities of practice, such as policymaking and scientific research.

\subsubsection{Boundary Concepts and Transdiscursive Terms}

The idea of the 'boundary object' was developed by Star (Star 1989, Star and Griesemer 1989) to talk about how scientific work, composed of members of different communities of practice, can proceed without necessarily having agreement about its categories of classification. According to Bowker and Star (1999: 297): 
Boundary objects are those objects that both inhabit several communities of practice and satisfy the informational requirements of each of them .. Such objects have different meanings in different social worlds but their structure is common enough to more than one world to make them recognizable, a means of translation .. Boundary objects arise over time from durable cooperation among communities of practice. They are working arrangements that resolve anomalies of naturalization without imposing a naturalization of categories from one community or from an outside source of standardization.

For Bowker and Star (1999), objects exist, with respect to a particular community, along a 'trajectory of naturalization'. Objects become naturalized when the contingencies of their emergence and development disappear and they become regarded as given or self-evident: 'a naturalized object has lost its anthropological strangeness' (p299). Further, Bowker and Star argue that, 'when an object becomes naturalized in more than one community of practice, its naturalization gains enormous power .. because we are always looking to other communities of practice as sources of validity' (p312).

In a study of the history of immunology, Lowy (1992) develops Star's work to propose the idea of the 'boundary concept'. Lowy argues that while welldefined scientific concepts oriented the work of coherent scientific groups, fuzzy, imprecise terms or 'loose concepts' were central to innovative interdisciplinary work between scientists and physicians. It was the very imprecision of such terms that functioned to organize interdiscursive communication, allowing members of different communities of practice to articulate a roughly shared direction of interests and moral commitments whilst maintaining their original professional cultures and identities. For Lowy, boundary concepts are loosely defined concepts which, precisely because of their vagueness, are adaptable to local sites and may facilitate communication and cooperation' (1992: 374), and they hence play an important heuristic role in the construction of new knowledge.

While Lowy stresses the permanent viability of loose, organizing boundary concepts for interdisciplinary scientific work, Lynch's (1998) analysis of the 
developmental trajectory of the concept of 'constructivism' emphasizes how the initial organizing capacity of a loose concept may be gradually lost to be replaced by detailed epistemic debates and more fragmented conceptual elaboration:

It is productive because it provides an initial hook that captivates adherents, encouraging them to invest their theoretical, methodological and political hopes in an academic approach or movement. But it can be confusing when adherents want to replace the surface affinity, which fostered the success of constructivism in the first place, with something deeper and more coherent (1998: 29)

Similarly, Canguilhelm (1988) emphasizes a developmental trajectory in which loose concepts are progressively replaced by more rigorous conceptions through research within a bounded scientific community of practice. Additionally, he develops the idea of 'scientific ideology' to describe how ideas that originate in scientific research are taken up in policymaking (e.g. Spencer's law of evolutionism). In Canguilhelm's view, such political discourses use the conceptual resources of science beyond the acceptable limits of the traditional epistemic criteria and institutional practices of the scientific community, such as peer review, and thus conflict with rigorous research-based elaboration:

By scientific ideology, I mean a discourse that parallels the development of science and that, under the pressure of pragmatic needs, makes statements that go beyond what has actually been proved by research. In relation to science itself, it is both presumptuous and misplaced. Presumptuous because it believes that the end has been reached when research in fact stands at the beginning. Misplaced because when the achievements of science actually do come, they are not in the areas where the ideology thought they would be, nor are they achieved in the manner predicted by the ideology (1988: 57-58)

In contrast, drawing on Knorr-Cetina's (1982) idea of 'transepistemic arenas', where knowledge is constructed through the collaboration of scientific researchers with various other social actors (clients, users, policymakers, funding agencies), Gibbons et al. (1994) and Nowotny et al. (2001) propose a 
rather different understanding of the potential for, and emergence of, the 'new production of knowledge' in contemporary societies than the paradigm of autonomous scientific discovery and conceptual elaboration undertaken in the traditional disciplinary departments of universities (termed 'Mode 1').

The thesis of 'Mode 2' knowledge production is an attempt to describe the transformation of the contemporary research process through emerging trends such as the steering of research priorities, the commercialization of research, and changes in the accountabilities of science (Nowotny et al. 2003 :7-11). 'Mode 2' knowledge production is characterized as being socially distributed, problem-centred, application-oriented, transdisciplinary, heterogeneous, highly reflexive, and associated with novel forms of quality control as the limits of the traditional peer review system become more pronounced (Nowotny et al. 2003: 3-5). The thesis stresses the blurring of the performative and the constative status of concepts, of the organizational and the epistemic functions of 'Mode 2 objects'.

However, the thesis provides little empirical detail from actual case studies of the dynamics of such knowledge production or the trajectories of new conceptual development (Shinn 1999, Weingart 1997). Indeed, as Nowotny et al. (2003:3) state, 'both The New Production of Knowledge and ReThinking Science were written as reflective essays rather than empirical studies .. [whose] purpose was as much to address the need to invent a new language of research as to offer a detailed analysis of the trends.'

Nonetheless, of interest for the present discussion is the developmental trajectory of the thesis itself. Nowotny et al. (2003: 1) themselves note that, 'like all theses that gain a certain popularity (and notoriety), it was radically simplified, collapsed into a single phrase, almost a slogan - Mode 2'. They further assert that the reception and evaluation of the thesis took place in terms of its capacity to confer legitimacy upon research practice: 'Those with most to gain from such a thesis espoused it most warmly .. Those with most to lose were most sceptical' (p1-2). ${ }^{8}$ As such, they argue that: 
Our critics may have even regarded us as hoist by our own petard, because inherent in the very notion of 'Mode 2', or socially distributed knowledge, is the idea that it cannot be authoritatively encoded in traditional forms of scholarly publication. If nurse researchers pounced on 'Mode 2' to reduce their subordination to medical research, or if global accountancy companies placed 'Mode 2' at the heart of newly established 'Centres for Business Knowledge', both of which are actual examples, who were we - the authors - to complain? (2003:

2)

Such a 'collapse into relativism and over-simplification of the argument' (2003: 2) reveals one potential outcome of the blurring of the social and the epistemic that was inherent in the thesis of 'Mode 2', given that it was explicitly conceived of as 'not only a concept, inherently open to manipulation and exploitation by others .. it is also a project, an example of the social distribution of knowledge which it seeks to describe' (p3).

Miettineen's (2002) study of the concept of National Innovation System (NIS) in Finnish research and policymaking is a more detailed empirical study of the emergence of what he calls a 'transdiscursive term'. He argues that the development of transdiscursive terms takes place in part within discrete research and policymaking communities, but is also dependent on interaction between such communities, that 'takes place in more or less stable, intermediary hybrid social arenas with representation from research, policymaking and public administration' (2002: 133). ${ }^{9}$

Through his analysis of NIS, Miettineen argues that it is important to emphasize that such loose concepts not only constitute a means of communication across boundaries' (2002: 133). Rather he stresses that, 'there seems to be a major tension between the epistemic and realityrepresenting functions of such terms, on one hand, and their future-orienting and discourse-organizing functions, on the other .. [which] is most visible within the scientific communities in which they are used' (2002:142). ${ }^{10}$ As such, Miettineen (2002: 135) suggests that the typical trajectory of the transdiscursive term is as follows: 
First, they become fashionable within scientific communities and the titles of many papers and sessions contain them. They arouse the interest of many researchers who connect their research problems to them to find publicity and a favourable context for their work. Second, they also arouse a lot of public attention and soon enter the vocabulary of specialists in administration and policy because of their novelty, their visibility, their apparent comprehensiveness and because of their communicative simplicity. Third, they are criticized by scientific communities on account of being conceptually loose and lacking adequate empirical foundation.

Miettineen concludes that while 'policymaking can certainly not wait for definitive factual knowledge or well-defined concepts in orienting itself to the future .. there is a need for constant critical dialogue while these terms are introduced, used and modified' (2002: 150).

\subsubsection{The Digital Divide as Brand}

I now return to discuss the status of 'the digital divide'. The digital divide has become an object of widespread concern in recent years, and in this thesis I have analyzed particular case studies of this within UK government, corporate, supranational and academic discourse. Furthermore, I highlighted in the previous chapter how specific relations of production and readership (citational networks, the structuring of consultation, 'interactivity', the representation of consensus) that traverse the individual discursive events in the state, corporate and supranational domains point to this wider field of discursivity.

Indeed, I argued that, whatever the reality, the invocation of broad input into the processes of production and authorship, into 'addressing the digital divide', implies that these discursive events are not to be read exclusively as the products or confines of one particular discursive domain with a specific mode of understanding. Rather, it privileges their reception as part of a contemporary discourse of policymaking, a hybrid arena or transdiscursive 
space of government where reality is represented as governable according to the success of understanding and mobilizing connections between various communities of practice, and where a concern such as the digital divide itself can only be properly understood, addressed, and ultimately bridged through such transdiscursive practice.

In this discursive formation then, it is not so much that the digital divide should be understood as a 'loosely defined concept which, precisely because of [its] vagueness .. may facilitate communication and cooperation' (Lowy 1992: 374) or as arising 'over time from durable cooperation among communities of practice' (Bowker and Star 1999: 297). Rather, the digital divide is explicitly represented as a programmatic boundary concept insofar as it is understood to require citation, consultation and consensus to be successfully addressed.

In the specific review of academic scholarship that I undertook in Chapter 2, the understanding of the digital divide could be said to broadly follow the trajectory that Miettineen describes for NIS. After the U.S. Dept of Commerce Falling Through The Net studies, the digital divide became an extremely prominent focus for discussion in the academic community in the 1990s. However, there followed a good deal of differentiation, elaboration and pluralization of the digital divide from this initially hegemonic conceptualization in terms of the issue of access. ${ }^{11}$ I argued that in the 2000s, the digital divide became the starting point for the reframing of a wider analytic agenda beyond access and oriented around the cultural-political concepts of participation, recognition, communicative entitlements, citizenship and inclusion. Tension between the social and epistemic functions of the term is certainly acknowledged most explicitly within academic discourse. For example, Van Dijk (2005: 3) states that:

In the past 5 years, I have often considered dropping the concept of the digital divide altogether and replacing it with the general concept of information inequality and a number of more specific terms. It has caused so many misunderstandings. Particularly, it has led to the misconception of the digital divide as a primarily technological problem. It spurred the narrow interpretation 
of the digital divide as a physical access problem: of having computers and networks and being able to handle them.. Nevertheless, I have chosen to maintain the concept of the digital divide for strategic reasons. It has managed to be put on the public and political agenda. It should not be moved from the table and smashed to pieces by scientific hair-splitting and political opportunism.

The general ideas of the boundary concept and the transdiscursive term clearly have some explanatory value for discussing the status of the digital divide in the wider discursive formation of the Information Age. However, I have already argued that the digital divide is best conceptualized within specific discursive events in terms of the pure signifier, as radically empty.

Now, one clear line of argumentation is that the status of 'the digital divide' as a pure signifier within a specific discursive event is further buttressed because of all the heterogeneous articulations that occur under its sign in other domains - in effect the further sliding of its signified across domains. The event of naming 'the digital divide' can never occur completely ex nihilo, it always to a certain extent connotes other instances of its naming and the diverse articulations that traverse them. ${ }^{12}$

However, rejecting the 'dubious distinction that has plagued much social theory .. between objects and signs' (Slater 2003: 95), I wish to argue here that 'the digital divide' may be usefully conceptualized in the wider discursive formation of the Information Age not just in terms of the pure signifier, but by additionally acknowledging its transdiscursive status, as a particular type of object of government.

I will draw here on Lury's (2004) discussion of the brand as an object. The brand is commonly understood as a sign, something intangible and associated with a range of heterogeneous objects or products, and hence typically theorized in terms of semiotics (e.g. Danesi 2004). ${ }^{13}$ However, Lury argues that the brand itself may be understood as an object in that 'it is something to which some feeling or action is directed; it is an object-ive in that it is 
the object of some purpose or intention, or even a whole series of purposes' (2004: 1).

Lury (2004: 128-131) draws on Knorr-Cetina's (2000) argument that contemporary objects can increasingly be characterized, and are progressively recognized, in terms of their 'indefiniteness of being':

The definition I want to offer of large classes of objects in contemporary life breaks away from received concepts of objects as fixed things of a material nature .. they are characteristically open, question-generating, and in the process of being materially defined .. the central characteristic of these kinds of objects .. is their changing, unfolding character - in the present terminology, their lack of 'object-ivity' and completeness of being, and their non-identity with themselves .. objects of knowledge in many fields have material instantiations, but they must simultaneously be conceived as unfolding structures of absence' $(2000: 528)^{14}$

Lury suggests that the brand 'is not a construction invented in an effort to describe reality' (2004: 151), but that 'the nature of the objectivity of the brand is that it is not and can never be completed .. this is both the source of the value of the brand as an object of contemporary capitalism (it is a thing into which possibility has been introduced) and what makes it open to other concerns' (p165). She highlights the temporality and relationality of the brand:

'The brand is an example of an (abstract) object that calls upon us to relate to it; to interact with it .. It compulsively includes or implicates us in ways that are not always straightforward and are deliberately designed to be open-ended.' (2004: 131)

For Lury then, the brand is an 'object of information' (2004: 150), a 'mode of organizing [information] activities in time and space .. not a closed object, but rather, open, extending into - or better, implicating - social relations' ( $p 1$ ).

Now I am not arguing here that it is useful to consider the digital divide as a brand specifically in the sense of being a 'market cultural form .. [that] mediates the supply and demand of products through the organization, co- 
ordination and integration of the use of information' (Lury 2004: 4), a mode of capital accumulation that operates via re-introducing 'qualitative intensivity into the extensive but limited rationality of a conventional market economy of price' (2004: 6), although I have argued in Chapter 4 that one may consider BT's promotion of the digital divide as operating within such a logic of the qualitative differentiation of 'cause branding'. ${ }^{15}$

However $I$ argue that the general conception of the objectivity of the brand as open and indeterminate, distributed and in process, as a 'happening fact' (Whitehead 1970, cited in Lury 2004: 16) that is never identical to itself, most adequately describes the unfolding status of 'the digital divide' in the wider discursive formation of the Information Age. 'The digital divide' can be considered as a brand of inequality, or in the terms I developed earlier, the branding of various potentially dislocatory dystopian states. It is to be addressed and requires completion across domains including UK government, corporate, supranational and academic discourse. It functions as an object through which the diverse problematizations and implosions that 'address' it can occur in an ongoing manner. Additionally it implicates and organizes social relations of knowledge (citation, consultation and consensus) across transdiscursive space and time.

Furthermore, I argue that considering 'the digital divide' as a brand illuminates its particular functioning as an object of government, one that is variously and continually open to completion across domains. The 'value' of the brand here is that it facilitates, objectifies, an understanding of such domains, and their associated problematizations and implosions, as addressing an object of common concern, as offering a shared moral commitment, despite any potential tension or incommensurability in the manner of this or indeed, in the wider ethoi of such domains. As such, it supports the ontological and ethical underpinnings of the projects and alignments of 'joined-up' government. Indeed, I suggest that it is not problem-centeredness but 'brand awareness' that becomes the responsibility of the ethical social scientist, funding agency, corporation, policymaker, stakeholder and ultimately active citizen in the discursive formation of the Information Age. ${ }^{16}$ 


\section{$\underline{9.7 \text { Conclusion }}$}

In this chapter, I have drawn on the multiple histories of the digital divide that I have detailed in my case studies, but explicitly attempted to look beyond them. I have interpreted certain regularities across these case studies as wider rules of discursive formation, and considered them in terms of their implications for government in the Information Age. Whether the treatment of the digital divide is ultimately paradigmatic of wider government in the Information Age is an empirical question that cannot be conclusively addressed here. My intention in this chapter was to suggest working hypotheses and sensitizing concepts for analysis and elaboration in further research. However, it is my opinion that the arguments summarized below have such resonance with other contemporary practices of government that such a possibility is within the reasonable bounds of interpretation.

Firstly, I argued that the dominant mode of problematization of the Information Age is one that does not simply view technology as a solution to discursively separate social problems. Rather, it asserts the fundamental ethical equivalence of two values, that a concern with the social is equivalent to an endorsement of the techno-economic. I argued then that the moral horizon of the Information Age is that society comes together around a shared relation to technology, that ethically, technology stands in for society's centre. I further proposed that the category of connection naturalizes this discursive ethos and structures the dominant understanding of agency and the government of conduct in the Information Age, such that the ethical subject is the connected subject. Moreover, I argued that the diverse discursive instantiations of this will to connect can hence be understood as citational or ritual edicts that draw attention to the specific ethical claims of the Information Age.

Secondly, I argued that the dominant narrative of causality in the Information Age is that of a specific teleology which emphasizes the inevitability of processes of techno-economic change through their discursive enfolding with utopian social states. I argued that this brackets alternative causal ontologies and narratives, and privileges an understanding of agency such that the 
government of conduct is structured in terms of 'not being left behind' by such techno-economic processes. Further, I suggested that the wider performativity of the contemporary neoliberal episteme may profitably be analyzed in terms of the seductive centrality of an imploded causal ontology.

Finally, I pointed to how individual discursive events may also be considered as reflexively institutionalizing, or at least representing, an embeddedness within a hybrid space of government where reality is understood as governable according to the success of establishing and mobilizing connections across various communities of practice. As such, rather then simply viewing 'the digital divide' as a localized pure signifier, I argued that it can additionally be conceptualized as an incomplete and open-ended object of government, a brand of inequality, through which the various problematizations and implosions that 'address' it can occur, and through which various social relations of knowledge are implicated and joined up across the discursive formation of the Information Age. 


\section{Coda}

In the week that I am writing this conclusion in November 2005, new diagnostic apparatuses, specifically designed to monitor the global digital divide by comparing countries' 'Infostates' (Orbicom 2005), are a focus of discussion at the World Summit on the Information Society in Tunis. In the previous week, the UK government published 'Inclusion Through Innovation: Tackling Social Exclusion Through New Technologies' (Social Exclusion Unit 2005), a complement to 'Connecting the UK: the Digital Strategy' (DTI 2005) which 'sets out the overall Government strategy to make the UK a world leader in digital technology and bridge the digital divide' (Social Exclusion Unit 2005:13). In November 2004, BT delivered a stark future vision of 'The Digital Divide in 2025 (BT, 2004). Commenting on the forecast, Adrian Horsford, Director of the BT Social Policy Unit, concluded that 'Britain could be facing grave consequences if the digital divide is not taken seriously. There is a hard rump of have-nots who are not engaging with the net. They don't have the motivation or skills to perceive the benefits' (quoted in 'Millions to miss out on the net', BBC News Online, 8 December 2004).

In this thesis, I have examined the specific ontological claim of the digital divide and detailed the discursive articulation and legitimation of various strategies, agendas and imperatives to address, bridge and close it, through which it has been, and continues to be, made to matter. I have analyzed the digital divide as a continually unfolding object of government through which a particular understanding of technosocial formation, exemplified in the idea of exclusion or disconnection from an autonomous and inevitable networking logic, comes to dominate a sense of contemporary ethical possibility and political imagination. I argue in this thesis that a discursive approach provides one way of demonstrating the assumptions, seductions and closures of this understanding, of recovering a sense of its historical specificity and purposeful construction, and of opening up the digital divide to close critical scrutiny. 


\section{Notes}

1 Various terms are used throughout the case studies. For example, the 'e-nation' (CtDD: 2), 'information society' (CtDD: 6) and 'Our Information Age' (CtDD: 10) in UK government discourse; the 'digital age' (BT 2001: 23) in corporate discourse; the 'Global Information Society' (DOT Force 2001: 4) in supranational discourse; the 'network society' and 'Information Age' in Castells' work.

2 Similarly, in Castells' analysis of the Information Age, I pointed to the intimation of moral distinctiveness between those included and excluded by the pervasive networking logic. While the network and the figure of the individual 'networker' are the carriers of a distinctive ethical 'spirit of informationalism', a common cultural code of flexible connection and creative destruction, those who are not 'able to operate within the global networks of value' (Castells 2001: 271) are forced to 'reconstruct meaning on the basis of an entirely distinct set of beliefs and values' (Castells 2000a: 382).

${ }^{3}$ Arguing that connection can be understood as a metaphor does not assume that there is a primary sense of connection, social or technological, to which other connections bear a metaphorical relation: 'Synonymy, metonymy and metaphor are not forms of thought that add a second sense to a primary, constitutive literality of social relations; instead, they are part of the primary terrain itself in which the social is constituted' (Laclau and Mouffe 1985: 110).

${ }^{4}$ For Latour (1996) and Serres (1995), it does not make sense to talk of the 'purely social' relationship in human sociality. Rather, it is the use of material objects that defines and maintains human sociality, that makes 'the social' stable. It is only in the social life of primates, a 'paradise of interactionism' (Latour 1996: 229) that the volatile 'purely social' relationship may be found:

Our relationships, social bonds, would be airy as clouds were there only contracts between subjects. In fact, the object .. stabilizes our relationships .. For an unstable bond of baboons, social changes are flaring up every minute. One could characterize their history as unbound, insanely so .. The social bond would only be fuzzy and unstable if it were not objectified. (Serres 1995: 87-8) 
5 This argument draws on Couldry's (2002b) interpretation of 'media rituals', organized around the categories of 'reality' and 'liveness', as pointing to the presumed ability of the media to represent the social whole. Such an analysis is beyond my remit here, but I suggest that aspects of contemporary sociotechnical activity (e.g. checking e-mail) are often structured, embodied and coded in habitual dispositions or ritual forms that are organized around the category of 'connection', which itself points to wider ethical claims about the nature of the social.

6 Barry (2001: 6) notes that, "resistance" has sometimes been equated with the inevitable failures of government to forge a correspondence between the idealised objects of political and economic thought ... and the knowledge that is generated about such objects by experts, administrators and individual citizens'. As such, it is important to clarify that I am not making such an assertion here, simply highlighting a particular difference between the narratives of policy and citizens in this domain.

${ }^{7}$ Barry (2002: 270) argues that 'it is useful to make a distinction between politics - as a set of technical practices, forms of knowledge and institutions - and the political as an index of disagreement'.

${ }^{8}$ Shinn (1999: 172), for example, argues that:

Careful examination of the new production of knowledge hypothesis and the triple helix model suggests that the discontinuist message more often reflects a partisan political agenda and ideology than it does serious-minded history and sociology. Several of the most vituperative radical discontinuity advocates are themselves government and industry actors or consultants. Other closer to academia, have hitched their career to radical discontinuity studies - financing their research work via industry and government coffers.

${ }^{9}$ Miettineen (2002: 141-42) argues that the concept of national innovation system:

emerged as an attempt to explain national differences in the economic growth rates between nations. Policy relevance was built into it from the beginning. Its development as a term, as a candidate for scientific concept, was dependent on its reception in policy. On the other hand, its strength as a rhetorical device in policy is dependent on its epistemic qualities .. its credibility as an organizing concept depended on its status in scientific communities. An academically marginal concept is not likely to achieve such 
status. On the other hand, political acceptance and success help a research program obtain funding and strengthen its position in academic discourse .. On the other hand, the scientific credibility of a term is also, at least over time, dependent on the constant scrutiny of its epistemological status in the scientific communities where it is used. The epistemic, social and political arenas are interwoven through the interconnections between scientific and political activities.

10 Miettineen suggests six different potential 'social-epistemic functions' that 'might serve as a means of recognizing the complexity and multiple meanings of these terms' (2002:150):

1. They have traditional epistemic functions as representations and as well-founded accounts of reality

2. They function as epistemic organizers: terms and metaphors used as organizing or umbrella terms integrating in themselves various themes formerly regarded as separate

3. They supply a world-view or diagnosis of an era

4. They serve as boundary crossers by engaging various social groups and institutions in shared discussion

5. They serve ideological and consensus-creating functions

6. They mobilize and empower (2002: 137)

11 As Selwyn (2005: 265) notes, 'many academics now couch their discussion of information-age inequalities in pluralistic terms of 'digital divides' and 'digital dynamics' - acknowledging the multi-faceted and ever-shifting nature of the (in)accessibility of new media in everyday life'.

12 In Derrida's (1997a) discussion of signification, naming is never arbitrary or coincidental, nor purely citational or self-identical, but is rather always an alteration it traces a 'graphic of iterability' rather than following a logic of repetition.

13 It is worth noting here that Zizek's exemplars in outlining his formulation of the radically empty pure signifier include the global brands of Marlboro and Coca-Cola ("Coke, this is it!"). Indeed, the description of the pure signifier as the "guaranteeing of the identity of an object in all counterfactual situations - through a change in all of its descriptive features' (Zizek 1989: 94) could effectively describe the contemporary 
corporate logic of establishing a brand identity across a range of vastly heterogeneous products.

${ }^{14}$ For Knorr-Cetina, there is a structural affinity in contemporary society between the unfolding indefiniteness of objects and the institutionalization of opportunities to constitute subjectivity as lack: 'the argument is that the incompleteness of being which I have attributed to contemporary objects uniquely matches the structure of wanting by which I have characterized the self (2000: 530). Furthermore, the knowledge of this unfolding indefiniteness underpins a generative reciprocity:

An individual looping his or her desire through an object and back is not only likely to learn something about the object in the process. He or she is also likely to develop a shared lifeworld with these objects, a larger context of practices and things within which the relationship is enacted. (2000: 532)

${ }^{15}$ As I argued in Chapter 4, the cause branding of issues such as 'the digital divide' serves important internal functions within a complex organization such as BT with personnel in disparate sites and departments. The realignment of already existing projects and inter-departmental communications are driven by such issues, and staff are encouraged to contribute to an identified, worthy and organization-wide initiative. As Lury (2004: 33) notes, 'the brand may thus be seen as one of a growing number of devices to monitor and control the performance of the employee'.

16 I suggest that the development of brand awareness, beyond the ostensibly corporate domain, as a contemporary technology and ascetic of lifestyle government is an area of much potential for further research. 


\section{घu Bibliography.}

Alibhai-Brown, Y. (2000). Review of Young and Byrne. The Political Quarterly, $71(2), 249-250$.

Allen, J. (2003). Lost Geographies of Power. Oxford: Blackwell.

Antaki, C., Billig, M., Edwards, D., \& Potter, J. (2003). Discourse Analysis Means Doing Analysis: A Critique Of Six Analytic Shortcomings, Discourse Analysis Online. 1, 1 http://extra.shu.ac.uk/daol/previous/v1 n1.html

Armitage, J., \& Graham, P. (2001). Project(ile)s of Hypermodern(organ)iaztion. Ephemera, 1(2), 131-148.

Arthur, W. B. (1994). Increasing Returns and Path Dependence in the Economy. Ann Arbor, MI: University of Michigan Press.

Askonas, P., \& Stewart, A. (eds.). (2000). Social Inclusion: Possibilities and Tensions. London: Macmillan.

Atkinson, A. B. (1998). Social Exclusion, Poverty and Unemployment. In J. Hills \& A. B. Atkinson (eds.), CASE Paper 4: Exclusion, Opportunity and Employment. London: Centre for Analysis of Social Exclusion.

Austin, J. L. (1976). How to Do Things with Words. Oxford: Oxford University Press.

Bakardjieva, M., \& Smith, R. (2001). The Internet in Everyday Life: computer networking from the standpoint of the domestic user. New Media And Society, 3(1), 67-83.

Bakhtin, M. (1981). The Dialogical Imagination. Austin: University of Texas Press.

Barbrook, N. (1996). The Californian Ideology. Accessed Jan 2005 at http://www.hrc.wmin.ac.uk/theory-californianideology.html

Barry, A. (2000, 28-30 September). Making the Active Scientific Citizen. Paper presented at the 4s/EASST conference 'Technoscience, Citizenship and Culture', University of Vienna.

Barry, A. (2001). Political Machines: Governing A Technological Society. London: Athlone Press.

Barry, A. (2002). The Anti-Political Economy. Economy and Society, 31(2), 268284. 
Barry, A., Osborne, T., \& Rose, N. (eds.). (1996). Foucault and political reason: liberalism, neo-liberalism and the rationalities of government. London: UCL Press.

Bauchspies, W., Croissant, J., \& Restivo, S. (2006). Science, Technology and Society. Oxford: Blackwell.

Baudrillard, J. (1983). In the Shadow of the Silent Majorities, or, the end of the social and other essays. New York: Semiotext(e).

Baudrillard, J. (1997). Consumer Society: Myths and Structures London: Sage.

Bauman, Z. (1998). Work, Consumerism and the New Poor. Milton Keynes: Open University Press.

Bauman, Z. (2003). Liquid Love Oxford: Polity Press.

BBC News Online. (8 December 2004). Millions Miss Out on Net. Accessed December 2004 at: http://news.bbc.co.uk/1/hi/technology/4076717.stm

Beck, U. (1992). Risk Society: Towards A New Modernity London: Sage

Bellah, R., Madsen, R., Sullivan, W., Swidler, A., \& Tipton, S. (1985). Habits of the Heart: Individualism and Commitment in American Life. Berkeley, CA: University of California Press.

Beninger, J. (1986). The Control Revolution. Cambridge, MA: Harvard University Press.

Bijker, W. (1995). Of Bicycles, Bakelites, and Bulbs: Toward and Theory of Sociotechnical Change. Cambridge, MA: MIT Press.

Bijker, W., \& Law, J. (eds.). (1994). Shaping technology / building society: studies in sociotechnical change. Cambridge MA: The MIT Press.

Bimber, B. (1994). Three Faces of Technological Determinism. In M. R. Smith \& L. Marx (eds.), Does Technology Drive History? The Dilemmas of Technological Determinism (pp. 79-100). Cambridge, MA: MIT Press.

Bishop, J. (2000). Ethics and Capitalism. Toronto: University of Toronto Press.

Blair, A. (1997, 23 November). Opinion. The Observer.

Blair, A. (1998). The Third Way: New Politics for the New Century. London: Fabian Society.

Blair, A. (2000, 7 March 2000). Speech at the Knowledge 2000 Conference. Available at: http://www.number-10.gov.uk/output/Page1521.asp. 
Bolt, D., \& Crawford, R. (2000). Digital Divide: Computers and Our Children's Future. New York: TV Books.

Bond, M. (2004). The Backlash Against NGOs. In F. Lechner \& J. Boli (eds.), The Globalization Reader. Oxford: Blackwell Publishing.

Booz, Allen, \& Hamilton. (2000). Achieving Universal Access. London: Booz, Allen \& Hamilton.

Bourdieu, P. (1999). The Weight of the World. Cambridge: Polity Press.

Bourdieu, P., \& Wacquant, L. (2001). Neo-Liberal Newspeak: Notes on the new planetary vulgate. Radical Philosophy, 105(1), 2-5.

Bowker, G., \& Star, S. L. (1999). Sorting Things Out: Classification and its Consequences. Cambridge, MA: The MIT Press.

Braverman, H. (1974). Labour and Monopoly Capital: The Degradation of Work in the Twentieth Century. New York: Monthly Review Press.

Brazil. (2001). Submission to the DOT Force. Accessed January 2002 at: http://www.dotforce.org

Bridges.org. (2002). E-readiness assessment: Who is Doing What and Where. Accessed June 2004 at: http://wnw.bridges.org/

Bromley, S. (2004). The Space of Flows and Timeless Time. In F. Webster \& B. Dimitriou (eds.), Manuel Castells: Sage Masters of Modern Social Thought Vol 3 (pp. 102-120). London: Sage.

Brown, N., \& Michael, M. (2002). From Authority to Authenticity: The Changing Governance of Biotechnology. Paper presented at European Association of Studies of Science and Technology Annual Conference, York, UK. $\left(31^{\text {st }}\right.$ July -3rd Aug 2002)

Brown, N., Rappert, B., \& Webster, A. (eds.). (2000). Contested Futures: $A$ sociology of prospective techno-science. Aldershot: Ashgate.

BT. (1998). A Question of Balance. London: BT.

BT. (2001). The Digital Divide - Better World Our Commitment to Society. London: BT.

BT. (2001a). Better World Social and Environmental Report. London: BT.

BT. (2003). The Operating and Financial Review Working Group on Materiality: A Consultation Document. Accessed Feb 2004 at: http://www.dti.gov.uk/cld/financialreview/pdfs/response-18-btgroup.pdf. 
BT. (2004). The Digital Divide in 2025. London: BT.

BT. (2005). Better World Social and Environmental Report 2005. London: BT.

Bucchi, M. (2004). Science in Society. London: Routledge.

Burchardt, T. (2001). Social Exclusion: concepts and evidence. In D. Gordon \& P. Townsend (eds.), Breadline Europe: the measurement of poverty. Bristol: The Policy Press.

Burchardt, T., Le Grand, J., \& Piachaud, D. (1999). Social Exclusion in Britain 1991-1995. Social Policy and Administration, 33(3), 227-244.

Butler, J. (1990). Gender Trouble: feminism and the subversion of identity. London: Routledge.

Butler, J. (1993). Critically Queer, Bodies that Matter. London: Routledge.

Butler, J. (1994). Gender as Performance: An Interview. Radical Philosophy, 67 (Summer), p33-41

Butler, J. (2000). Restaging the Universal: Hegemony and the Limits of Formalism. In J. Butler \& E. Laclau \& S. Zizek (eds.), Contingency, Hegemony, Universality. London: Verso.

Butler, J., Laclau, E., \& Zizek, S. (2000). Contingency, Hegemony, Universality. London: Verso.

Byrne, D. (1997). Social exclusion and capitalism: the reserve army across time and space. Critical Social Policy, 17(1), 27-51.

Byrne, D. (1999). Social Exclusion. Buckingham: Open University Press.

Calhoun, C. (2000). Resisting Globalization or Shaping It? Prometheus, 3, 29-47.

Callinicos, A. (2004). Myths of the 'New Economy'. In F. Webster \& B. Dimitriou (eds.), Manuel Castells: Sage Masters of Modern Social Thought Vol 3. London: Sage.

Callon, M. (1987). Society in the Making; the study of technology as a tool for sociological analysis. In W. Bijker \& T. Hughes \& T. Pinch (eds.), The Social Construction of Technical Systems: New Directions in the Sociology and History of Technology. Cambridge, MA: MIT Press.

Callon, M. (1991). Techno-economic networks and irreversibility. In J. Law (ed.), A sociology of monsters: essays on power, technology and domination (pp. 132-161). London: Routledge. 
Callon, M. (1999). Actor-Network Theory - the market test. In J. Law \& J. Hassard (eds.), Actor Network Theory and After (pp. 181-195). Oxford: Blackwell Publishers / The Sociological Review.

Callon, M., \& Latour, B. (1992). Don't Throw the Baby Out With the Bath School! A Reply to Collins and Yearley. In A. Pickering (ed.), Science as Practice and Culture. Chicago: University of Chicago Press.

Callon, M., Law, J., \& Rip, A. (1986). Mapping the Dynamics of Science and Technology. London: Macmillan.

Cameron, D. (2000). Good to Talk? London: Sage.

Campbell, D. (1999). National Deconstruction: Violence, Identity and Justice in Bosnia. Minneapolis: University of Minnesota Press.

Canguilhem, G. (1988). Ideology and rationality in the history of science. Cambridge, MA: The MIT Press.

Carter, C., \& Grieco, M. (2000). New Deals, No Wheels; Social Exclusion, TeleOptions and Electronic Ontology. Urban Studies, 37(10), 1735-1748.

Carvin, A. (2000, May 19, 2000). Beyond Access: Understanding the Digital Divide. Paper presented at the NYU Third Act Conference, New York.

Castells, M. (1997). An Introduction to the Information Age. City, 7, 6-16.

Castells, M. (2000). The Rise of the Network Society: The Information Age Volume I (2nd ed.). Oxford: Blackwell.

Castells, M. (2000a). End of Millennium: The Information Age Volume III (2nd ed.). Oxford: Blackwell.

Castells, M. (2000b). Materials for an exploratory theory of the network society. British Journal of Sociology, 51(1), 5-24.

Castells, M. (2001). The Intemet Galaxy. Oxford: Oxford University Press.

Castells, M. (2001b). The Information City, The New Economy, and the Network Society. In A. Kasvio (ed.), People, Cities and the New Information Economy. Helsinki: Palmenia.

Castells, M. (2004). The Power of Identity: The Information Age Volume II (2nd ed.). Oxford: Blackwell.

Castells, M. (2004a). Informationalism, Networks, and the Network Society: A Theoretical Blueprint. In M. Castells (ed.), The Network Society: A crosscultural perspective. Cheltenham: Edward Elgar. 
Caulkin. (2001, October 5th). Can Business Save The World? The Observer.

Central Office of Information. (1998). Our Information Age: the Government's Vision. London: HMSO.

Ceruzzi, P. (1996). From scientific instrument to everyday appliance; the emergence of personal computers, 1970-77. History and Technology, 13, $1-31$.

Chilton, P., \& Schaffner, C. (1997). Discourse and Politics. In D. Van, T. (ed.), Discourse as Social Interaction (pp. 206-230). London: Sage.

Chouliaraki, L., \& Fairclough, N. (1999). Discourse in Late Modernity: Rethinking Critical Discourse Analysis. Edinburgh: Edinburgh University Press.

CIDMEF. (2002). The Global Information Technology Report 2001-2002: Readiness for the Networked World'. Harvard: Harvard University Press.

Cockburn, C., \& Ormrod, S. (1993). Gender and Technology in the Making. London: Sage.

Colby, D. (2001). Conceptualizing the 'Digital Divide': Closing the 'Gap' by creating a postmodern network that distributes the productive power of speech. Communication Law and Policy, 6(1), 123-173.

Compaine, B. (2001). The Digital Divide: facing a crisis or creating a myth? Cambridge, MA: MIT Press.

Cone, C. (2001). Cause Branding in the 21st Century. In S. Zadek \& N. Hojenssgard (eds.), Perspectives on the New Economy of Corporate Citizenship. Copenhagen: The Copenhagen Centre.

Cooper, R. (1990). Organization/disorganization. In J. Hasard \& D. Pym (eds.), The Theory and Philosophy of Organizations. London: Routledge.

Couldry, N. (2000). Inside Culture: Re-imagining the Method of Cultural Studies. London: Sage.

Couldry, N. (2002a, May 10-12, 2002). The Forgotten Digital Divide; Researching Social Exclusion in the Age of Personalised Media. Paper presented at the Media in Transition: Globalization and Convergence, MIT.

Couldry, N. (2002b). Media Rituals: A critical approach. London: Sage.

Cronbach, L. J. (1975). Beyond the two disciplines of scientific psychology. American Psychologist, 30, 116-127. 
Crowther, D. (2000). Corporate Reporting, Stakeholders and the Internet: Mapping the New Corporate Landscape. Urban Studies, 37(10), 18371848.

Cruickshank, B. (1999). The Will to Empower: democratic citizens and other subjects. New York: Cornell University Press.

Danesi, M. (2004). Brands. London: Taylor \& Francis Ltd.

Day, P., \& Klein, R. (1987). Accountabilities. Five Public Services. London: Tavistock.

Dean, M. (1991). The Constitution of Poverty. London: Routledge.

Dean, M. (1996). Foucault, government and the enfolding of authority. In A. Barry \& T. Osborne \& N. Rose (eds.), Foucault and political reason: liberalism, neo-liberalism and the rationalities of government. London: UCL Press.

Dean, M. (1999). Governmentality: Power and Rule in Modern Society. London: Sage.

Deleuze, G. (1985). Nomad Thought. In D. Allison (ed.), The New Nietzsche: Contemporary Styles of Interaction. Cambridge MA: The MIT Press.

Department for Education and Employment. (1999). Skills for the Information Age. London: HMSO.

Department of Commerce. (1995). Falling through the Net: A Survey of the 'Have Nots' in Rural and Urban America. Washington DC: U.S. Department of Commerce.

Department of Commerce. (1998). Falling through the Net II: More Data on the Digital Divide. Washington D.C.: U.S. Department of Commerce.

Department of Commerce. (1999). Falling through the Net III: Defining the Digital Divide. Washington D.C.: U.S. Department of Commerce.

Department of Commerce. (2000). Falling through the Net IV: Towards Digital Inclusion. Washington D.C.: U.S. Department of Commerce.

Department of Commerce. (2002). A Nation Online. Washington D.C.: U.S. Department of Commerce.

Department of Social Security. (1999). Indicators of Success: definitions, data and baseline information. London: HMSO. 
Department of Trade and Industry. (2001). Modern Company Law For A Competitive Economy: The Strategic Framework. HMSO. Accessed Jan 2004 at: http://www.dti.gov.uk/cld/final report/index.htm.

Department of Trade and Industry. (2004). Corporate Social Responsibility: A Government Update: Department of Trade and Industry.

Department of Trade and Industry. (2005a). Company Law Reform White Paper. HMSO. Accessed June 2005 at: http://www.dti.gov.uk/cld/WhitePaper.htm.

Department of Trade and Industry. (2005b). Connecting the UK: Britain's Digital Strategy. London: HMSO.

Derrida, J. (1976). Of Grammatology (G. C. Spivak, Trans.). Baltimore, MD: John Hopkins University Press.

Derrida, J. (1981). Positions. Chicago: University of Chicago Press.

Derrida, J. (1996). Remarks on deconstruction and pragmatism. In C. Mouffe (ed.), Deconstruction and Pragmatism (pp. 445-463). London and New York: Routledge.

Derrida, J. (1997a). Signature Event Context. In J. Derrida (ed.), Limited Inc. Evanston, IL: Northwestern University Press.

Derrida, J. (1997b). Limited Inc. abc. In J. Derrida (ed.), Limited Inc. Evanston, IL: Northwestern University Press.

Derrida, J. (1997c). Afterword: toward an ethic of discussion, Limited Inc. Evanston, IL: Northwestern University Press.

Digital Opportunity Initiative. (2001). Creating A Development Dynamic: From Digital Divide to Digital Opportunities for Development. New York: DOI.

DiMaggio, P., Hargittai, E., Neuman, W. R., \& Robinson, J. (2001). Social Implications of the Internet. Annual Review of Sociology, 27, 307-336.

Donzelot, J., \& Roman, J. (1991). Le deplacement de la question sociale. In J. Donzelot (ed.), Face a l'exclusion: Le modele francais. Paris: Editions Espirit.

DOT Force. (2001). Digital Opportunities For All: Meeting the Challenge. DOT Force. Accessed Jan 2002 at: http://www. dotforce.org/.

DOT Force Secretariat. (2000a). Consultation Matrix. Accessed Jan 2002 at: http://www.dotforce.org/ 
DOT Force Secretariat. (2000b). Consultation Strategy Note. Accessed Jan 2002 at: http://www.dotforce.org/

Douglas, M. (1998). Knowing The Code, Demos Collection 12. London: Demos.

Driver, S., \& Martell, L. (1998). New Labour, Politics after Thatcherism. London: Longmans.

Drucker, P. (1993). Post-Capitalist Society. New York: Harper Collins.

Dutton, W. (1999). Society on the Line: Information Politics in the Digital Age. Oxford: Oxford University Press.

EC. (2001). European Commission Submission to the DOT Force. Accessed January 2002 at: http://www.dotforce.org I

ECD. (2001). Enhanced Consultation Among DOT Force Developing Countries. Accessed January 2002 at: http://www. dotforce.org/

Economist Intelligence Unit. (2005). The 2005 e-readiness rankings. London: The Economist Intelligence Unit.

Egypt. (2001). Submission to the DOT Force. Accessed January 2002 at: http://www.dotforce.org/

Eliasoph, N. (1998). Avoiding Politics. Cambridge: Cambridge University Press.

Elliot, A., \& Lemert, C. (2006). The New Individualism: The Emotional Costs of Globalization. Abingdon: Routledge.

Ellis, V. (2001). Remarks on Behalf of the Private Sector. Accessed January 2002 at: http://www.dotforce.org/

Fairclough, N. (2000). New Labour, New Language. London: Routledge.

Fairclough, N. (2001). The dialectics of discourse. Textus, XIV(2), 3-10.

Fallis, D. (2004). Social Epistemology and the Digital Divide. Paper presented at the Computing and Philosophy Conference, Canberra.

Fleck, J. (1999). Learning by Trying: the implementation of configural technology. In D. Mackenzie \& J. Wajcman (eds.), The Social Shaping of Technology (2nd ed.). Milton Keynes: Open University Press.

Foucault, M. (1969). The Order of Things; An Archaeology of the Human Sciences. London: Tavistock. 
Foucault, M. (1972). The Archaeology of Knowledge. London: Tavistock.

Foucault, M. (1973). The Birth of the Clinic; An Archaeology of Medical Perception. London: Tavistock.

Foucault, M. (1977). What is an Author? In D. Bouchard (ed.), Language, Counter-Memory, Practice (pp. 124-127). New York: Cornell University Press.

Foucault, M. (1978). Governmentality (lecture at the College de France, 1 February). In G. Burchell \& C. Gordon \& P. Miller (eds.), The Foucault Effect: Studies in Governmentality 1991 (pp. 87-104). Hemel Hempstead: Harvester Wheatsheaf.

Foucault, M. (1979). Discipline and Punish: the birth of the prison. London: Penguin.

Foucault, M. (1981). The Order of Discourse. In R. Young (ed.), Untying the Text: A Post-Structuralist Reader. London: Routledge.

Foucault, M. (1984). The History of Sexuality Vol II: The Use of Pleasure. New York: Pantheon.

Foucault, M. (1984a). Polemics, Politics and Problematizations. In P. Rabinow (ed.), The Foucault Reader. London: Penguin.

Foucault, M. (1984b). What is Enlightenment? In P. Rabinow (ed.), The Foucault Reader. London: Penguin.

Foucault, M. (1988). The History of Sexuality Vol III: The Care of the Self. London: Allen Lane.

Foucault, M. (1993). About the Beginning of the Hermeneutics of the Self (transcription of two lectures in Darthmouth on Nov 17 and 24, 1980, ed. by Mark Blasius). Political Theory, 21(2), 198-227.

Foucault, M. (2001). Fearless Speech. New York: Semiotext(e).

Frank, T. (2002). One Market Under God. London: Vintage.

Friends of the Earth. (2006). Press Release: Friends of the Earth Take Chancellor to Court. London: FoE.

Fuller, S. (1999). Review Essay. Science, Technology and Human Values, 24(1), 159-166.

Gandy, O. (2002). The Real Digital Divide. In L. Lievrouw \& S. Livingstone (eds.), The Handbook of New Media. London: Sage. 
Garfinkel, H. (1967). Studies in Ethnomethodology. Englewood Cliffs: Prentice Hall.

Garnham, N. (2004). Information Society Theory as Ideology. In F. Webster (ed.), The Information Society Reader. London: Routledge.

Gee, J. (2005). An Introduction to Discourse Analysis: theory and method. London: Routledge.

Genosko, G. (1999). McLuhan and Baudrillard: The Masters of Implosion. London: Routledge.

Gibbons, M., Nowotny, H., Limoges, C., Trow, M., Schwartmann, S., \& Scott, P. (1994). The New Production of Knowledge; the dynamics of science and research in contemporary societies. London: Sage.

Giddens, A. (1994). Living in Post-Traditional Society. In U. Beck \& A. Giddens \& S. Lash (eds.), Reflexive Modernisation. Cambridge: Polity Press.

Giddens, A. $\left(1996,13^{\text {th }}\right.$ Dec). Out of Place. Times Higher Educational Supplement

Giddens, A. (1998). The Third Way: the renewal of social democracy. Cambridge: Polity Press.

Giddens, A. (1999). Runaway World: how globalization is shaping our lives. London: Profile.

Giddens, A. (2000). The Third Way and Its Critics. Cambridge: Polity Press.

Giddens, A. (ed.). (2001). The Global Third Way Debate Cambridge: Polity Press.

Gilliom, J. (2001). Overseers of the Poor. Chicago: University of Chicago Press.

Gilmore, C., \& Wilmott, H. (1992). Company law and financial reporting: a sociological history of the UK experience. In M. Bromwich \& A. Hopwood (eds.), Accounting and the Law (pp. 159-191). Hemel Hempstead: Prentice Books.

Gittell, R., \& Vidal, A. (1998). Community Organising: Building Social Capital as a Development Strategy. Newbury Park, CA: Sage.

Goldman, M. (2001). The Birth of a Discipline: Producing authoritative green knowledge, World-bank style. Ethnography, 2(2), 191-217.

Goodwin, I., \& Spittle, S. (2002). The European Union and the information society. New Media and Society, 4(2), 225-249. 
Goodwin, M. (1995). Poverty in the city. In D. Philo (ed.), Off the map; the Social Geography of Poverty in the UK. London: Child Poverty Action Group.

Gordon, D., Adelman, L., Ashworth, K., Bradshaw, J., Levitas, R., Middleton, S., Pantazis, C., Patsios, D., Payne, S., Townsend, P., \& Williams, J. (2000). Poverty and Social Exclusion in Britain. York: Joseph Rowntree Foundation.

Gordon, D., \& Pantazis, P. (eds.). (1997). Breadline Britain in the 1990s. Aldershot: Ashgate.

Gouldner, A. (1976). The dialectic of ideology and technology. London: Macmillan.

Graham, P. (2000). Hypercapitalism: a political economy of informational idealism. New Media and Society, 2(4), 387-406.

Granovetter, M. (1974). Getting A Job. Cambridge: Harvard University Press.

Granovetter, M. (1985). Economic Action and Social Structure: The Problem of Embeddedness. AJS, 91/3, 481-510.

Gray, R. (1995). Briefing: Social and Environmental Accounting Research. Swindon: ESRC.

Gray, R., Owen, D., \& Adams, C. (1996). Accounting and Accountability: Changes and Challenges in corporate social and environmental reporting. London: Prentice-Hall Europe.

Griggs, S., \& Howarth, D. (2000). New environmental movements and direct action protest. In D. Howarth, A. Norval \& Y. Stavrakakis (eds.), Discourse Theory and Political Analysis: Identities, Hegemonies and Social Change. Manchester: Manchester University Press.

Grint, K., \& Woolgar, S. (1997). The Machine at Work: Technology, Work and Organisation. Cambridge: Polity Press.

Gunkel, D. (2003). Second Thoughts: Toward a critique of the digital divide. New Media and Society, 5(4), 499-522.

Hague, B., \& Loader, B. (1999). Digital Democracy: Discourse and Decision Making in the Information Age. London: Routledge.

Hajnal, P. (1999). The G7/G8 System. Aldershot: Ashgate.

Hakken, D. (1999). Cyborgs@Cyberspace. London: Routledge. 
Halcli, A., \& Webster, F. (2000). Inequality and Mobilization in The Information Age. European Journal of Social Theory, 3(1), 67-81.

Haraway, D. (1997).Modest_Witness@Second_Millenium:

Femaleman_Meets_OncomouseTM. London: Routledge.

Hargittai, E. (2002). The Second Level Digital Divide. First Monday, 7(4).

Heap, N., Einon, G., Mason, R., \& Thomas, R. (1995). Information, Technology and Society. London: Sage.

Heilbroner, R. (1974). An Inquiry into the Human Prospect. New York: Newton.

Held, D., Barnett, A., \& Henderson, C. (2005). Debating Globalization. Cambridge: Polity Press.

Hellawell, S. (2001). Beyond Access: ICT and Social Inclusion. London: Fabian Society.

Henderson, D. (2001). Misguided Virtue: False Notions of Corporate Social Responsibility. New Zealand Business Roundtable and Institute of Economic Affairs, 2001.

Henderson, D. (2004). The Case Against 'Corporate Social Responsibility". In F. Lechner \& J. Boli (eds.), The Globalization Reader. Oxford: Blackwell Publishing.

Henwood, F., Wyatt, S., Miller, N., \& Senker, P. (2000). Critical Perspectives on Technologies, In/Equalities and the Information Society. In S. Wyatt \& F. Henwood \& N. Miller \& P. Senker (eds.), Technology and In/equality. London: Routledge.

Hills, J., LeGrand, J., \& Piachaud, D. (2002). Understanding Social Exclusion. Oxford: Oxford University Press.

Himanen, P. (2001). The Hacker Ethic and The Spirit of the Information Age. New York: Random House.

Himmelfarb, G. (1984). The idea of poverty: England in the early Industrial age. New York: Alfred P. Knopf.

Hine, C. (2000). Virtual Ethnography. London: Sage.

Hochschild, A. (2003). The Commercialisation of Intimate Life. Berkeley: University of California Press.

Holden, C. (1999). Globalisation, social exclusion and labour's new work ethic. Critical Social Policy, 19(4), 529-538. 
Howarth, D. (2000). Discourse. Milton Keynes: Open University Press.

Howarth, D., \& Stavrakakis, Y. (2000). Introducing Discourse Theory and Political Analysis. In D. Howarth, A. Norval \& Y. Stavrakakis (eds.), Discourse Theory and Political Analysis: Identities, Hegemonies and Social Change. Manchester: Manchester University Press.

Hudson, J. (2003). E-galitarianism? The information society and New Labour's repositioning of welfare. Critical Social Policy, 23(2), 268-290.

Hutchby, I. (1999). Power in Discourse: The Case of Arguments on a British Talk Radio Show. In A. Jaworski \& N. Coupland (eds.), The Discourse Reader. London: Routledge.

Hutchby, I. (2001). Conversation and Technology. Cambridge: Polity Press.

Innes, M. (2001). Investigating the Investigators. In N. Gilbert (ed.), Researching Social Life (2nd ed., pp. 211-223). London: Sage.

IPT. (2001). The Digital Divide - A Research Perspective. Accessed Jan 2002 at: http://www.dotforce.org/reports/documents/35/.

ITU. (1999). Challenges to the Network: Internet for Development. Geneva: ITU. Jasanoff, S., Petersen, J., Pinch, T., \& Markle, G. (eds.). (1995). Handbook of Science and Technology Studies. Thousand Oaks, CA.: Sage.

Jordan, T. (1999). Cyberpower. London: Routledge.

Jordan, T. (2002). Technopower and Its Cyberfutures. In J. Armitage \& J. Roberts (eds.), Living With Cyberspace. New York: Continuum.

Kelly, K. (1995). Out of Control: the rise of neo-biological civilization. Menlo Park, CA: Addison-Wesley.

Kelly, K. (1998). New Rules for the New Economy: Ten Ways the Network Economy is Changing Everything. London: Fourth Estate.

Kittler, F. (1999). Gramophone, Film, Typewriter. Stanford, CA: Stanford University Press.

Klein, N. (2000). The Tyranny of the Brands. New Statesman, 24 January, pp2528.

Kline, R., \& Pinch, T. (1999). The social construction of technology. In D. Mackenzie \& J. Wajcman (eds.), The Social Shaping of Technology (2nd ed.). Milton Keynes: Open University Press. 
Kling, R. (1994). Reading 'all about' computerization: how genre conventions shape non-fiction social analysis. The Information Society, 10(3), 147-172.

KMPG. (2002). International Survey of Corporate Sustainability Reporting. London: KMPG.

Knights, D., Noble, F., Vurdubakis, T., \& Wilmott, H. (2002). Allegories of Creative Destruction: Technology and Organization in Narratives of the eEconomy. In S. Woolgar (ed.), Virtual Society? Technology, Cyberbole, Reality (pp. 99-114). Oxford: Oxford University Press.

Knorr-Cetina, K. (1982). Scientific communities or transepistemic arenas of research? Social Studies of Science, 12, 101-130.

Knorr-Cetina, K. (2000). Post-social theory. In G. Ritzer \& B. Smart (eds.), The Handbook of Social Theory (pp. 520-537). London: Sage.

Kranakis, E. (1997). Constructing A Bridge: An Exploration of Engineering Culture, Design and Research in Nineteenth-Century France and America. Cambridge, Ma: MIT Press.

Laclau, E. (1990). New Reflections on the Revolutions of Our Time. London: Verso.

Laclau, E. (1996). Emancipations. London: Verso.

Laclau, E. (2000). Foreword. In D. Howarth \& A. Norval \& Y. Stavrakakis (eds.), Discourse theory and political analysis; identities, hegemonies and social change. Manchester: Manchester University Press.

Laclau, E., \& Mouffe, C. (1985). Hegemony and Socialist Strategy. London: Verso.

Lasch, C. (2004). The Degradation of the Practical Arts. In F. Webster (ed.), The Information Society Reader. London: Routledge.

Latour, B. (1993). We have never been modern. Hemel Hempstead: Harvester Wheatsheaf.

Latour, B. (1996). On interobjectivity. Mind, Culture and Activity, 3(4).

Latour, B. (2005). Reassembling the Social. Oxford: Oxford University Press.

Latour, B., \& Woolgar, S. (1979). Laboratory Life: the construction of scientific facts. Princeton, N.J.: Princeton University Press. 
Law, J. (1999). After ANT: complexity, naming and topology. In J. Law \& J. Hassard (eds.), Actor Network Theory and After (pp. 1-14). Oxford: Blackwell Publishers / The Sociological Review.

Law, J., \& Hassard, J. (1999). Actor Network Theory and After. Oxford: Blackwell Publishers.

Law, J., \& Urry, J. (2003). Enacting the Social. Department of Sociology Lancaster University. Accessed Jan 2004 at: http://www.comp.lancs.ac.Uk/sociology/papers/Law-Urry-Enacting-theSocial.pdf.

Lemke, J. (1995). Textual Politics: discourse and social dynamics. London: Taylor and Francis.

Lemke, T. (2000, September 21-24). Foucault, Governmentality and Critique. Paper presented at the Rethinking Marxism Conference, University of Amherst.

Lemke, T. (2001). Participation. Accessed March 2005 at: http://www.thomaslemkeweb.de/publications-engl.htm.

Lenoir, R. (1974). Les Exclus: un Français sur dix. Paris: Seuil.

Lessig, L. (1999). Code - and Other Laws of Cyberspace. U.S.: Basic Books Inc.

Levitas, R. (1996). The Concept of Social Exclusion and the New Durkheimian Hegemony. Critical Social Policy, 16(46), 5-20.

Levitas, R. (1998). The Inclusive Society? Social Exclusion and New Labour. London: Macmillan.

Levitas, R. (2000). What is Social Exclusion? In D. Gordon \& P. Townsend (eds.), Breadline Europe: the measurement of poverty. Bristol: The Policy Press.

Levitas, R. (2005). The Inclusive Society? Social Exclusion and New Labour (2nd ed.). London: Macmillan.

Lie, M., \& Sorenson, K. (eds.). (1996). Making Technology Our Own, Domesticating Technology Into Everyday Life. Oslo: Scandanavian University Press.

Lister, R. (1998). From Equality to Social Inclusion. Critical Social Policy, 18(2), 215-225.

Loader, B. (1998). Cyberspace Divide; equality, agency and policy in the information society. London: Routledge. 
Lomborg, B. (ed.). (2004). Global Crises, Global Solutions. Cambridge:

Cambridge University Press.

Lopez, J. (2003). Society and its Metaphors. London: Continuum.

Lowy, L. (1992). The strength of loose concepts: boundary concepts, federative experimental strategies and disciplinary growth -- the case of immunology. History of Science, 30, 371-396.

Luhmann, N. (1998). Observations on Modernity. Stanford: Stanford University Press.

Lury, C. (2004). Brands: The Logos of the Global Economy. London: Routledge.

Lynch, M. (1998). Towards a constructivist genealogy of social constructivism. In I. Velody \& R. Williams (eds.), The politics of constructivism (pp. 1-29). London: Sage.

Lyon, D. (1999). The world wide of surveillance: the internet and off-world power flows. In H. Mackay \& T. O'Sullivan (eds.), The Media Reader: Continuity and Transformation. London: Sage.

Lyon, D. (2000). The Net, the Self and the Future. Prometheus, 3, 58-68.

Mackenzie, D., \& Wajcman, J. (eds.). (1999). The Social Shaping of Technology (2nd ed.). Milton Keynes: Open University Press.

Mandelson, P. (1997). Labour's Next Steps. Paper presented at the Fabian Society Summer Lecture 14 August.

Manovich, L. (2001). The Language of New Media. Cambridge, MA: MIT Press.

Manovich, L. (2001b). New Media: A User's Guide. In R. M. Collective \& G. Lovink (eds.), The Sarai Reader 2001: The Public Domain. Delhi: Sarai.

Mansell, R. (2002). From Digital Divides to Digital Entitlements in Knowledge Societies. Current Sociology, 50(3), 407-426.

Mansell, R., \& Silverstone, R. (1996). Communication by Design: The Politics of Information and Communication Technologies. Oxford: Oxford University Pres.

Marinetto, M. (2003). Who Wants to be an Active citizen? The Politics and Practice of Community Involvement. Sociology, 37(1), 103-120.

Martin, C. (1996). Review Article: The debate in France over "Social Exclusion". Social Policy and Administration, 30(4), 382-392. 
Marx, K. (1847). The Poverty of Philosophy, In Collected Works Vol 6 (pp. 105212). London: Lawrence \& Wishart.

Marx, K., \& Engels, F. (1968). The Communist Manifesto. Harmondsworth: Penguin Books.

Mason, A. (2006). Forecasting Histories of the Future of Liberalized Natural Gas Markets. Forthcoming Public Culture (18)(3).

Mason, J. (1996). Qualitative Researching. London: Sage.

Matthews, J. (2004). Power Shift. In F. Lechner \& J. Boli (eds.), The Globalization Reader. Oxford: Blackwell Publishing.

May, C. (2002). The Information Society: A Sceptical View. Cambridge: Polity.

McConnell International. (2000). Risk E-Business: Seizing the Opportunity of Global E-Readiness. McConnell International. Accessed Jan 2005 at: http://www.mcconnellinternational.com/ereadiness/EReadinessReport.htm

McGhee, D. (2003). Joined-up government, community safety and lesbian, gay, bisexual and transgender 'active citizens'. Critical Social Policy, 23(3), 345-374.

McGrail, B. (2002). Confronting Electronic Surveillance: Desiring and Resisting New Technologies. In S. Woolgar (ed.), Virtual Society? Technology, Cyberbole, Reality (pp. 115-136). Oxford: Oxford University Press.

McGuigan, J. (1999). Modernity and Postmodern Culture. Buckingham: Open University Press.

McLuhan, M. (1964). Understanding Media: The Extensions of Man. New York: McGraw-Hill.

Melucci, A. (1996). Challenging Codes: Collective action in the information age. Cambridge: Cambridge University Press.

Merton, R. (1968). The Matthew effect in science. Science, 159, 56-63.

Michael, M. (2000). Reconnecting Culture, Technology and Nature. London: Routledge.

Michael, M. (2000a). Futures of the present: From Performativity to Prehension. In N. Brown \& B. Rappert \& A. Webster (eds.), Contested Futures: A sociology of prospective techno-science. Aldershot: Ashgate.

Miettinen, R. (2002). National Innovation System: scientific concept or political rhetoric. Helsinki: Sitra Publications. 
Miller, D., \& Slater, D. (2000). The Internet: An Ethnographic Approach. Oxford: Berg.

Mills, S. (2005). Discourse, The Literary Encyclopedia: The Literary Dictionary Company.

Moore, K. (2002, 18 November). Versions of the Future in Young People's Talk about Mobile Devices. Paper presented at the BSA Youth Group Conference on 'Young People and New Technology', Roehampton, Surrey.

MORI. (1999). The British and Technology. Basingstoke: Motorola.

Mueller, M. (2001). Universal service policies as wealth redistribution. In B. Compaine (ed.), The Digital Divide: facing a crisis or creating a myth? (pp. 179-187). Cambridge, MA: MIT Press.

Mulgan. (2000). Accountability: An ever-expanding concept. Public Administration, 78(3), 555-573.

Mulgan, G. (1997). Connexity: How to Live in a Connected World. London: Chatto and Windus.

Mumford, L. (1967). The Myth of the Machine: Technics and Human Development. London: Secker and Warburg.

Munro, R. (1996). Alignment and Identity Work: the study of accounts and accountability. In R. Munro \& j. Mouritsen (eds.), Accountability: power, ethos and the technologies of managing (pp. 1-19). Boston: International Thomson Business Press.

Munro, R., \& Mouritsen, J. (eds.). (1996). Accountability: power, ethos and the technologies of managing. Boston: International Thomson Business Press.

Murdock, G. (2002). Rethinking Communication Exclusion: Tackling the Digital Divide. Coventry: British Educational Communications and Technology Agency (BECTa).

National Statistics. (2000). Internet Access: First Quarter 2000. London: National Statistics.

Negroponte, N. (1995). Being Digital: The Road Map for Survival on the Information Superhighway. London: Hodder \& Staughton.

Noble, D. (1979). Social Choice in machine design: the case of the automatically controlled machine tools. In Zimbalist (ed.), Case Studies in the Labour Process (pp. 18-50). New York: Monthly Review Press. 
Noble, D. (1984). Forces of Production: A Social History of Industrial Automation. New York: Oxford University Press.

Norris, P. (2000). A Virtuous Circle. Cambridge: Cambridge University Press.

Norris, P. (2001). Digital Divide: Civic Engagement, Information Poverty, and the Internet Worldwide. Cambridge MA: Cambridge University Press.

Norval, A. J. (1996). Deconstructing Apartheid Discourse. London: Verso.

Nowotny, H., Scott, P., \& Gibbons, N. (2001). Re-thinking Science: knowledge and the public in an age of uncertainty. Oxford: Polity Press.

Nowotny, H., Scott, P., \& Gibbons, N. (2003). Re-thinking Science: Mode 2 in Societal Context. Accessed June 2005 at: http://www.nowotny.ethz.ch/pdf/Nowotny Gibbons Scott Mode2.pdf.

O Baoill, A. (2000). Slashdot and the Public Sphere. First Monday, 5(9).

OECD. (2001). Understanding the Digital Divide. Paris: Organisation for Economic Co-operation and Development.

OECD Trade Union Advisory Committee. (2001). Submission to the DOT Force. Accessed January 2002 at: http://www.dotforce.org

Orbicom. (2005). From the Digital Divide to Digital Opportunities: Measuring Infostates for Development. Montreal: NRC Press.

Osborne, T. (2004). Capitalism Accountability and Ethical Discourse. http://www.sbs.ox.ac.uk/news/archives/Main/Science+and+Technology+Vi siting+Speakers.htm. (Accessed Sept 2005)

Osborne, T., \& Rose, N. (1999). Do the Social Sciences Create Phenomena? the Example of Public Opinion Research. British Journal of Sociology, 50, 367-396.

Packard, H. (2004). e-inclusion strategy. Accessed June 2005 at: http://www.hp.com/e-inclusion/en/vision/strategy.html

Pantazis, C., Gordon, D., \& Levitas, R. (eds.). (2004). Poverty and Social Exclusion in Britain: The Millennium Survey. Bristol.

Paugam, S. (1993). La societe francaise et ses pauvres. Paris: Presses Universitaires de France.

Percy-Smith, J. (ed.). (2000). Policy Responses to Social Exclusion: towards inclusion? Milton Keynes: Open University Press. 
Performance and Innovation Unit. (1999). e-commerce@its best.uk. London: HMSO.

Perkin, H. (1989). The Rise of Professional Society: Britain since 1880. London: Routledge.

Perlas, N. (2000). Shaping Globalization: Civil Society, Cultural Power and Threefolding. Quezon City, Philippines: Centre for Alternative Development Initiatives.

Perri 6. (2002). The governance of friends and acquaintances? public policy and social networks. In V. Nash (ed.), Reclaiming Community. London: Institute of Public Policy Research.

Phillips, L., \& Jorgensen, M. (2002). Discourse Analysis as Theory and Method. London: Sage.

Phipps, L. (2000). New Communication Technologies: A Conduit for Social Inclusion. Information, Communication and Society, 3(1).

Pinch, T., \& Bijker, W. (1989). The Social Construction of Facts and Artifacts. In W. Bijker \& T. Hughes \& T. Pinch (eds.), The Social Construction of Technical Systems. Massachusetts: M.I.T. Press.

Policy Action Team 15. (2000). Closing the Digital Divide: information and communication technologies in deprived areas. London: HMSO.

Potter, J. (1996). Representing Reality. London: Sage.

Preston, P. (2001). Reshaping Communications. London: Sage.

Rawls, J. (1971). A Theory of Justice. Cambridge, MA: Harvard University Press.

Reich, R. (1991). The Work of Nations: Preparing Ourselves for 21st Century Capitalism. New York: Vintage.

Rhinegold, H. (1993). The Virtual Community: Finding Connection in a Computerised World. London: Secker and Warburg.

Richter, J. (2001). Holding Corporations Accountable: corporate conduct, international codes, and citizen action. London: Zed Books.

Rifkin, J. (2000). The Age of Access: The New Culture of Hypercapitalism. London: Penguin.

Robins, K., \& Webster, F. (1999). Times of the Technoculture. London: Routledge. 
Robinson, M. (2004). Beyond Good Intentions: Corporate Citizenship for a New Century. In F. Lechner \& J. Boli (eds.), The Globalization Reader. Oxford: Blackwell Publishing.

Rose, N. (1996). Governing "advanced" liberal democracies. In A. Barry \& T. Osborne \& N. Rose (eds.), Foucault and Political Reason. London: UCL Press.

Sanderson, I. (2000). Access to Services. In J. Percy-Smith (ed.), Policy Responses to Social Exclusion; towards inclusion? Milton Keynes: Open University Press.

Sardar, Z. (1999). 'The Future is Ours to Change'. New Statesman, 19 Mar(25-7).

Sassen, S. (1991). The Global City. Princeton, NJ.: Princeton University Press.

Sassen, S. (2001). A New Geography of Power? Accessed April 2003 at: http://www.globalpolicy.org/nations/sassen.htm.

Schegloff, E., \& Sacks, H. (1973). Opening up Closings. Semiotica, 8, 289-327.

Schiller, R. (2000). Irrational Exuberance. Melbourne: Scribe Publications.

Schofield-Clark, L., Demont-Heinrich, C., \& Webber, S. (2004). Ethnographic Interviews on the Digital Divide. New Media and Society, 6(4), 529-547.

Schon, D. (1979). Generative metaphor: A perspective on problem-setting in social policy. In A. Ortony (ed.), Metaphor and Thought (pp. 254-283). Cambridge: Cambridge University Press.

Scott, A. (1997). The Limits of Globalization. London: Routledge.

Searle, J. (1977). Reiterating the Differences: A Reply to Derrida. Glyph, 1, 198 210.

Selwyn, N. (2002). E-stablishing an inclusive society? Technology, exclusion and UK government policy-making. Journal of Social Policy, 31(1), 1-20.

Selwyn, N. (2002a). Defining the 'Digital Divide': Developing a Theoretical Understanding of Inequalities in the Information Age. Occasional Paper 49: Cardiff University School of Social Sciences.

Selwyn, N. (2005). Review Article: The digital divide is dead: long live the digital divides. Information Communication and Society, 8(2), 265-269.

Selwyn, N., \& Gorard, S. (2002). The Information Age. Cardiff: University of Wales Press. 
Selwyn, N., Gorard, S., \& Furlong, J. (2005). Whose Internet is it Anyway? Exploring Adults (Non) Use of the Internet in Everyday Life. European Journal of Communication, 20(1), 5-26.

Sen, A. (1999). Development as Freedom. Oxford: Oxford University Press.

Sennett, R. (1998). The Corrosion of Character: The Personal Consequences of Work in The New Capitalism. New York: Norton.

Serres, M. (1995). Genesis. Michigan: Michigan University Press.

Servon, L. (2002). Bridging the Digital Divide. Oxford: Blackwell Publishing.

Shields, R. (1996). Introduction: Virtual Spaces, Real Histories, Living Bodies. In R. Shields (ed.), Cultures of Internet. London: Sage.

Shinn, T. (1999). Change or Mutation? reflections on the foundations of contemporary science. Social Science Information, 38(1), 149-176.

Silver, H. (1994). Social exclusion and social solidarity: three paradigms. International Labour Review, 133(5-6), 531-578.

Silver, $H$. (1995). Reconceptualizing social disadvantage: three paradigms of social exclusion. In G. Rodgers \& C. Gore \& J. Figueiredo (eds.), Social Exclusion: Rhetoric, Reality, Responses. Geneva: ILO.

Silverstone, R., \& Hirsch, E. (1992). Consuming Technologies: Media and Information in Domestic Spaces. London: Routledge.

Sklair, L. (1990). Sociology of the Global System. Oxford: Blackwell.

Slater, D. (2003). Markets, materiality and the 'new economy'. In J. Metcalfe (ed.), Market Relations and the Competitive Process. Manchester: Manchester University Press.

Smart, B. (2000). A Political Economy of New Times? Critical Reflections on the Network Society and the Ethos of Informational Capitalism. European Journal of Social Theory, 3(1), 51-65.

Smith, M. R., \& Marx, L. (1994). Does Technology Drive History? The Dilemmas of Technological Determinism. Cambridge, MA: MIT Press.

Social Exclusion Unit. (1998). Bringing Britain Together, a national strategy for neighbourhood renewal. London: HMSO.

Social Exclusion Unit. (2000). National Strategy for Neighbourhood Renewal; framework for consultation'. London: HMSO. 
Social Exclusion Unit. (2000a). What is Social Exclusion? Accessed Oct 2002 at: http://www.cabinet-office.gov.uk/seu/.

Social Exclusion Unit. (2005). Inclusion Through Innovation: Tackling Social Exclusion Through New Technologies. London: HMSO.

Soros, G. (1998). The Crisis of Global Capitalism. London: Little, Brown.

Spivak, G. (1996). Revolutions that as yet have no model. In D. Landry \& G. Maclean (eds.), The Spivak Reader. London Routledge.

Stake, R. (1994). Case Studies. In N. Denzin \& Y. Lincoln (eds.), Handbook of Qualitative Research (pp. 236-247). London: Sage.

Star, S. L. (1989). The Structure of III-Structured Solutions: Heterogeneous Problem Solving, Boundary Objects and Distributed Artificial Intelligence. In M. Huhns \& L. Gasser (eds.), Distributed Artificial Intelligence 2 (pp. 3754). Menlo Park, CA.: Morgan Kauffmann.

Star, S. L., \& Griesemer, J. (1989). Institutional Ecology, 'Translations' and Boundary Objects. Social Studies of Science, 19, 387-420.

Stewart, J. (2000). The Digital Divide in the UK: A Review of Quantitative Indicators and Public Policies. Paper presented at the The Digital Divide, Bremen, Germany.

Strathern, M. (2002). Abstraction and Decontextualisation: an anthropological comment. In S. Woolgar (ed.), Virtual Society? Oxford: Oxford University Press.

Suchman, L. (1994). Do Categories Have Politics? the language/action perspective reconsidered. Computer-Supported Cooperative Work, 2(1), 177-190.

Suchman, L. (2000). Human/Machine Reconsidered. Department of Sociology, Lancaster University. Accessed June 2003 at: http://www.comp.lancaster.ac.uk/sociology/040ls. html.

Taylor, M. (2001, 15 March 2001). Ideas of Community. Paper presented at the Public Policy and Social Networks; Promoting Social Inclusion, Institute of Materials, London.

Tester, K. (1993). The Life and Times of Post-modernity. London: Routledge.

The White House Office of the Press Secretary. (April 17 2000). Remarks By The President in Digital Divide Discussion with the East Palo Alto Community. Accessed Feb 2002 at: http://clinton4.nara.govMHH/New/New Markets0004/20000417-4.html. 
Thompson, J. (2001). The Media and Modernity. Cambridge: Polity Press.

Tichenor, P., Donohue, G., \& Olien, C. (1970). Mass media flow and differential growth in knowledge. Public Opinion Quarterly, 34, 159-170.

Tilly, C. (1999). Durable inequality. Berkeley, CA: University of California Press.

Toffler, A. (1970). Future Shock. London: Bodley Head.

Toffler, A. (1980). The Third Wave. New York: Bantam.

Toffler, A. (1990). Power Shift: Knowledge, Wealth, and Violence at the Edge of the 21st Century. New York: Bantam.

Toffler, A., \& Toffler, H. (1988). The Discontinuous Future. Foreign Affairs, 77(2), 170.

Torfing, J. (1999). New Theories of Discourse: Laclau, Mouffe and Zizek. London: Blackwell.

U.S. Government. (2001). U.S. Government Submission to the DOT Force. Accessed January 2002 at: http://www.dotforce.org

UNESCO. (1998). World Communication Report: The Media Challenges of the New Technologies. Paris: UNESCO.

UNICT. (2001). Press Release: Launch of the UN Information and Communication Technology Task Force.

United Nations Information Service. (May 17 2001). World Telecommunications Day Statement. Accessed Aug 2002 at: http://www.unis. unvienna.org/unis/pressrels/2001/sgsm7791.html.

Van Dijk, J. (1999a). The one-dimensional network society of Manuel Castells. New Media and Society, 1(1), 127-138.

Van Dijk, J. (2002). A Framework for Digital Divide Research. Electronic Journal of Communication, 12(1\&2).

Van Dijk, J. (2002b). Editors Introduction. Electronic Journal of Communication, $12(1 \& 2)$.

Van Dijk, J. (2005). The Deepening Divide. London: Sage.

Van Dijk, J., \& Hacker, K. (2003). The Digital Divide as a Complex and Dynamic Phenomenon. The Information Society, 19, 315-326. 
Van Lente, H. (2000). Forceful Futures: From Promise to Requirement. In N. Brown \& B. Rappert \& A. Webster (eds.), Contested Futures: a sociology of prospective techno-science (pp. 43-64). Gateshead: Athenaeum Press.

Virilio, P. (1986). Speed and Politics: An Essay on Dromology. New York: Autonomedia.

Virilio, P. (1989). The Last Vehicle. In Baudrillard, J. (ed.), Looking Back on the End of the World. New York: Semiotext(e).

Visvanathan, S. (2004). The Grand Sociology of Manuel Castells. In F. Webster \& B. Dimitriou (eds.), Manuel Castells: Sage Masters of Modern Social Thought, Vol 3. London: Sage.

Waldrop, M. (1992). Complexity: The Emerging Science at the Edge of Order and Chaos. New York: Touchstone.

Walker, G. (2000). Defining the Digital Divide. Accessed Feb 2002 at: http://www. citizensonline.org.uk/presentation/movie4.htm.

Warschauer, M. (2004). Technology and Social Inclusion: Rethinking the Digital Divide. Cambridge, MA: MIT Press.

Watt, P., \& Jacobs, K. (2000). Discourses of Social Exclusion. Housing, Theory \& Society, 17, 14-26.

Weber, M. (1958 [1904-5]). The Protestant Ethic and the Spirit of Capitalism. New York: Charles Scribner.

Weber, M. (1978). Anticritical Last Word on the Spirit of Capitalism. American Journal of Sociology, 83(5), 1105-1131.

Webster, F. (1995). Theories of the Information Society. London: Routledge.

Webster, F. (1997). Is This the Information Age? Towards a Critique of Manuel Castells. City, 8, 71-84.

Webster, F. (2002). Theories of the Information Society (2nd ed.). London: Routledge.

Webster, F. (2004a). Manuel Castells: Analyst of the Information Age. In F. Webster \& B. Dimitriou (eds.), Manuel Castells: Sage Masters of Modern Social Thought (Vol. 3, pp. 81-102). London: Sage.

Webster, F. (ed.). (2004). The Information Society Reader. London: Routledge.

Webster, F., \& Dimitriou, B. (2004). Manuel Castells: Sage Masters of Modern Social Thought, Vol 1 - 3. London: Sage. 
WEF. (2001). From the Global Digital Divide to the Global Digital Opportunity. New York: World Economic Forum.

Weick, K. (1995). Sensemaking in Organizations. Thousand Oaks, CA: Sage.

Weinberg, A., \& Ruano-Borbalan, J.-C. (1993). Understanding Exclusion.

Sciences Humaines, 28(5), 12-15.

Weingert, P. (1997). From 'finalization' to 'Mode 2': old wine in new bottles. Social Science Information, 36(4), 591-613.

White, L. (1962). Medieval Technology and Social Change. New York: Oxford University Press.

Williams, C., \& Conley, J. (2004). An Emerging Third Way? The Erosion of the Anglo-American Shareholder Value Construct. UNC Legal Studies Research Paper No. 04-09. Accessed Sept 2005 at: http://ssrn.com/abstract $=632347$.

Williams, R. (1974). Television: Technology and Cultural Form. London: Fontana.

Williams, R. (1983). Towards 2000. London: Chatto \& Windus.

Wills, M. (2000). Defining the Digital Divide. Accessed Feb 2002 at: http://www.citizensonline.org.uk/presentation/movie13.htm.

Winner, L. (1977). Autonomous Technology: Technics-out-of-Controls a Theme in Political Thought. London: MIT Press.

Winner, L. (1980). Do artifacts have politics. Daedalus, 109, 121-136.

Woolgar, S. (1991). Configuring the User: the case of usability trials. In J. Law (ed.), A Sociology of Monsters (pp. 58-99). London: Routledge.

Woolgar, S. (2000). Virtual Technologies and Social Theory. In R. Rogers (ed.), Preferred Placement: knowledge politics on the web. Maastrict: Jan Van Eyck Academie.

Woolgar, S. (2000b). Towards the Global Information Society? Paper presented at the E-Business 2000 conference, St Catharine's College Oxford, March 30th-31st

Woolgar, S. (2002). Five Rules of Virtuality. In S. Woolgar (ed.), Virtual Society? Technology, Cyberbole, Reality (pp. 1-22). Oxford: Oxford University Press. 
Woolgar, S. (2004). Reflexive Internet? The British Experience of New Electronic Technologies. In M. Castells (ed.), The Network Society: A Cross-cultural Perspective. Cheltenham: Edward Elgar Publishing.

Woolgar, S. (ed.). (2002). Virtual Society? Technology, Cyberbole, Reality. Oxford: Oxford University Press.

Wyatt, S., Henwood, F., Miller, N., \& Senker, P. (2000). Technology and In/equality: Questioning the Information Society. London: Routledge.

Wyatt, S., Thomas, G., \& Terranova, T. (2002). They Came, They Surfed, They Went Back to the Beach. In S. Woolgar (ed.) Virtual Society? Technology, Cyberbole, Reality. Oxford: Oxford University Press.

Young, J. (1999). The Exclusive Society: Social Exclusion, Crime and Difference in Late Modernity. London: Sage.

Zizek, S. (1989). The Sublime Object of Ideology. London: Verso.

Zizek, S. (1997). The Plague of Fantasies. London: Verso.

Zizek, S. (1998). A Leftist Plea for 'Eurocentrism'. Critical Inquiry, 24(4), 992. 